\title{
Design of Oxy-Coal Reactors for Calcium Carbide Production Using CFD
}

Albio Gutierrez

Follow this and additional works at: https://researchrepository.wvu.edu/etd

\section{Recommended Citation}

Gutierrez, Albio, "Design of Oxy-Coal Reactors for Calcium Carbide Production Using CFD" (2015).

Graduate Theses, Dissertations, and Problem Reports. 5725.

https://researchrepository.wvu.edu/etd/5725

This Dissertation is protected by copyright and/or related rights. It has been brought to you by the The Research Repository @ WVU with permission from the rights-holder(s). You are free to use this Dissertation in any way that is permitted by the copyright and related rights legislation that applies to your use. For other uses you must obtain permission from the rights-holder(s) directly, unless additional rights are indicated by a Creative Commons license in the record and/ or on the work itself. This Dissertation has been accepted for inclusion in WVU Graduate Theses, Dissertations, and Problem Reports collection by an authorized administrator of The Research Repository @ WVU.

For more information, please contact researchrepository@mail.wvu.edu. 
Design of Oxy-Coal Reactors for Calcium Carbide Production Using CFD

\author{
Albio Gutierrez \\ Dissertation submitted \\ to the Benjamin M. Statler College of Engineering and Mineral Resources \\ at West Virginia University
}

in partial fulfillment of the requirements for the degree of

Doctor of Philosophy in

Mechanical Engineering

Ismail Celik, PhD., Chair

John Kuhlman, PhD.

Hailin Li, PhD.

John Zondlo, PhD.

Matthew Targett, PhD.

Department of Mechanical and Aerospace Engineering

Morgantown, West Virginia

2015

Keywords: Oxy-Coal Combustion, Calcium Carbide Production, Slag Flow Modeling, Computational Fluid Dynamics.

Copyright 2015 Albio Gutierrez 


\section{ABSTRACT \\ Design of Oxy-Coal Reactors for Calcium Carbide Production Using CFD}

\section{Albio Gutierrez}

Oxy-coal combustion with recirculating flue gas is a promising technology in $\mathrm{CO}_{2}$ capture. This technology is intended to reduce emissions of $\mathrm{CO}_{2}$ and other pollutants, such as NOx and $\mathrm{SO}_{2}$. Since the $\mathrm{CO}_{2}$ concentration in flue gas is higher than in conventional air operation, $\mathrm{CO}_{2}$ capture is easier. Other unique applications of oxy-coal combustion are now possible due to the very high temperatures (circa $2000-2500^{\circ} \mathrm{C}$ ) that can be generated with char/ $\mathrm{O}_{2} / \mathrm{CO}_{2}$ mixtures which in turn can be used to activate chemical reactions which can lead to high valued chemical products. This for example can be an economical alternative to the energy intensive electric arc furnace process for calcium carbide $\left(\mathrm{CaC}_{2}\right)$ production. At present, research towards developing an oxy-coal combustion process for production of $\mathrm{CaC}_{2}$ from char and calcium oxide $(\mathrm{CaO})$ is being conducted by the U.S.-China Clean Energy Research Center (CERC). In this process, $\mathrm{CaC}_{2}$ is produced in the molten slag layer flowing along the walls of an oxy-coal combustion reactor. A model capable of predicting the performance of oxy-coal reactors for $\mathrm{CaC}_{2}$ production will be a useful tool to support this effort. Nonetheless, previous work in the field of slag modeling in coal-fired systems has been focused on analyzing its effect on the wall heat transfer and the combustion process. This alone is not sufficient to support the design of a carbide producing reactor.

In the present work, a physics-based computational model has been developed to predict the performance of oxy-coal combustion reactors for $\mathrm{CaC}_{2}$ production. The approach is based on a computational framework that utilizes the computational fluid dynamics (CFD) method to model both the oxy-coal combustion process and the slag flow. The slag flow model (SFM) describes the slag behavior including the chemical reactions occurring during the synthesis of $\mathrm{CaC}_{2}$, as well as the liquid and solid layer thickness, average velocity and bulk temperature of the slag layer.

The model developed was applied to the design of two different types of reactors, namely, a vertical down-fired reactor, known as very high temperature entrained flow reactor (VHTER) and a horizontal reactor referred to as CTC reactor. It was found that the minimum temperatures required to activate the $\mathrm{CaC}_{2}$ formation in the VHTER were obtained for oxy-coal combustion cases with $35 \%$ molar oxygen concentrations; $\mathrm{CO}_{2}$ the balance gas. The results for the slag flow model showed that although the VHTER reactor is able to attain the high temperatures required for the production of $\mathrm{CaC}_{2}$, the viscosities obtained can be so small that the residence time of the slag is insufficient to attain a considerable formation of $\mathrm{CaC}_{2}$ in the slag.

The simulation results for the CTC reactor indicated that the operation conditions evaluated in current tests were not suitable for $\mathrm{CaC}_{2}$ production. Nonetheless, it was possible to obtain suitable temperatures for production of $\mathrm{CaC}_{2}$ in the $\mathrm{CTC}$ reactor by modifying the operation conditions. The modifications included increasing the amount of natural gas, as well as replacing a portion of the air entering the reactor with pure $\mathrm{O}_{2}$. 


\section{ACKNOWLEDGEMENTS}

First of all, I am grateful to God for the good health and well-being I have been able to enjoy and which have been so necessary to complete this project.

I wish to express my sincere gratitude to my advisor Dr. Ismail Celik for giving me the opportunity and the trust to work on this project for the last four years of my life. I thank him for his time, patience and guidance. I thank him also for providing me with all the necessary financial support, training opportunities and work materials, and, finally, for teaching me a work methodology I am convinced will bring success to my future career.

I would like to express my special gratitude to my committee members: Dr. John Kuhlman, Dr. Hailin Li, Dr. John Zondlo and Dr. Matthew Targett for their time, cooperation and advice. I would also like to thank Dr. Victor Mucino for his guidance and trust through the completion of my doctoral studies. Thanks to Dr. Steve Rowan for his leading and patience. Thanks also to the Mechanical and Engineering Department of West Virginia University for their acceptance to the $\mathrm{PhD}$ program and for giving me the chance of being a Mountaineer.

A remarkable mention is deserved by Dr. Jose Escobar and Dr. Sergio Escobar, first for their friendship and, secondly, for providing me with their support in the areas of combustion, CFD and the use of ANSYS Fluent. Thanks also to Dr. Hayri Sezer for his unconditional friendship and moral support.

I want to thank also to Dr. Alejandro Posada and wife and Andres Garcia and wife for their

friendship and their support upon my arrival to the US. Finally, I would like to thank Alejandro 
Posada for introducing me to Dr. Ismail Celik and the members of the CFD lab team, as well as for his technical advice during the first stage of my $\mathrm{PhD}$.

\section{FUNDING AGENCIES}

A remarkable mention is deserved by LP Amina and the US-China Clean Energy Research Center-Advanced Coal Technology Consortium (CERC-ACTC)'s ongoing research on coal utilization, under the United States Department of Energy (DOE) contract DE-PI0000017. 
Dedicated to

Elena 


\section{Table of Content}

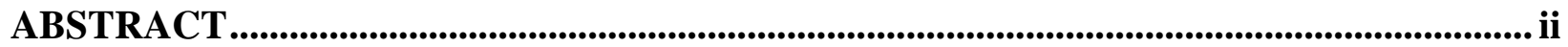

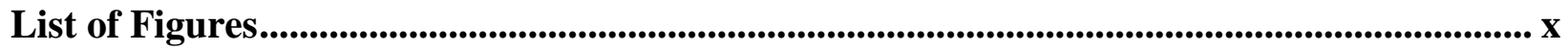

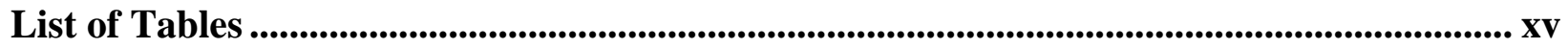

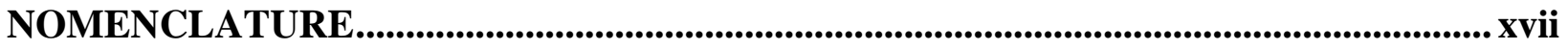

Chapter 1 - Introduction ......................................................................................................................... 1

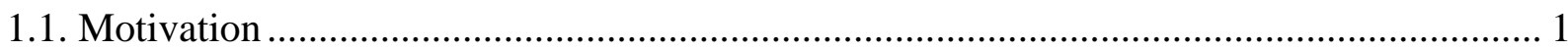

1.2. General Objective................................................................................................. 4

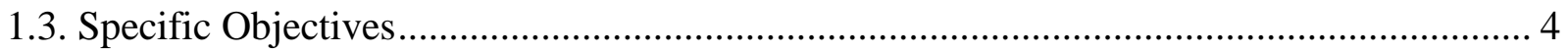

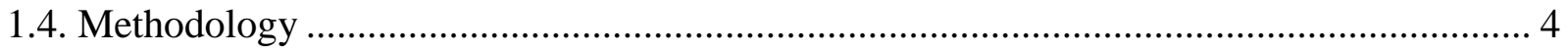

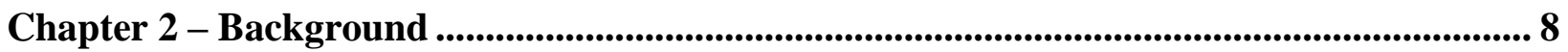

2.1. Coal Technologies as an Strategic Issue for the U.S. and China ................................. 8

2.2. U.S.-China Cooperation Agreement on Advanced Coal Technologies .......................... 11

2.3. Oxy-Combustion: Low Emissions Technology ................................................... 12

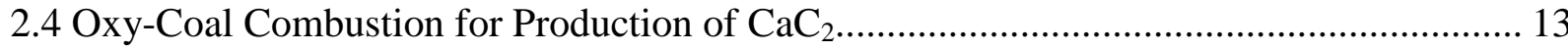

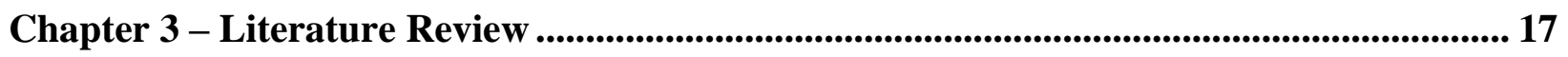

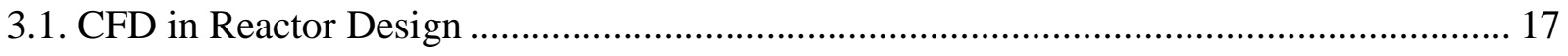

3.2. Turbulence Modeling ............................................................................................. 18

3.3. Main Differences between Oxy-Coal and Air-Coal Combustion ................................. 20

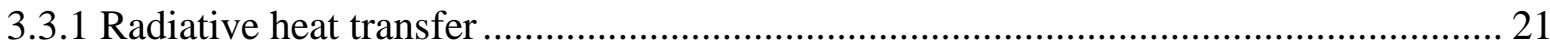


3.4. CFD Modeling in Oxy-Coal Combustion .............................................................. 27

3.5. Slagging Modeling in Coal Fired Combustors ......................................................... 31

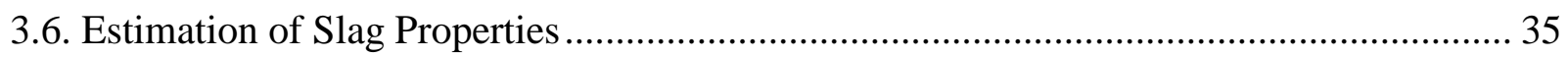

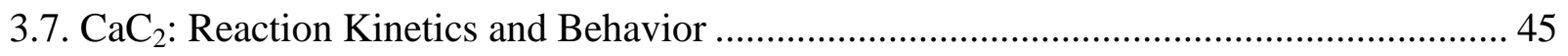

3.8. $\mathrm{CaC}_{2}$ : Kinetic Reaction Rate Models ............................................................... 48

Chapter 4 - Description of the System............................................................................ 53

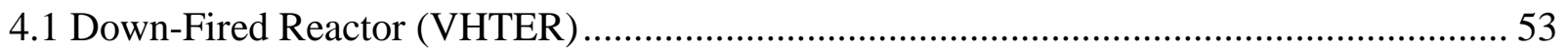

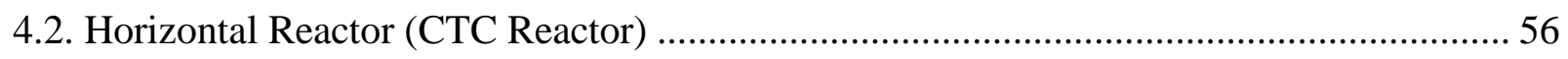

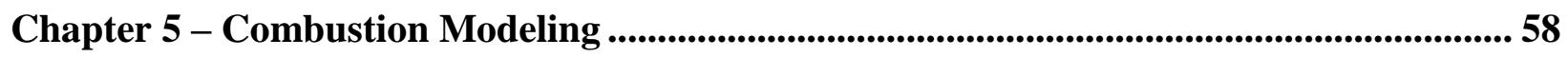

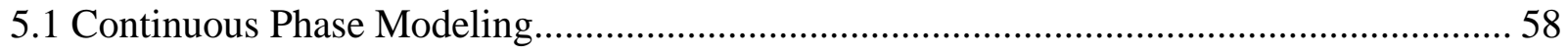

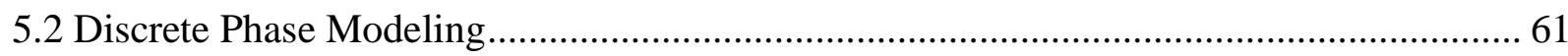

5.3 Domain Discretization and Boundary Conditions ................................................... 66

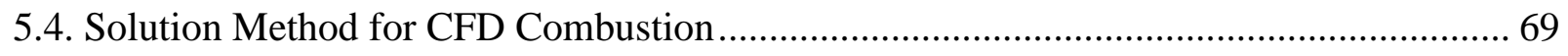

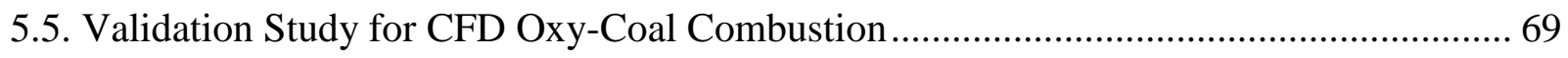

Chapter 6 - Slag Flow Modeling ................................................................................................ 76

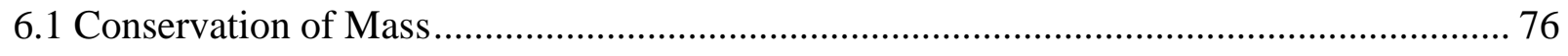

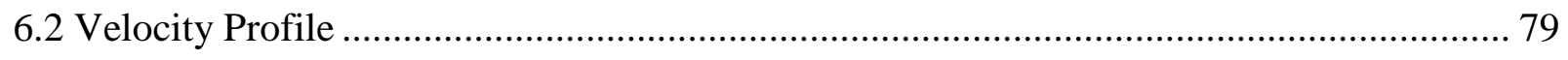

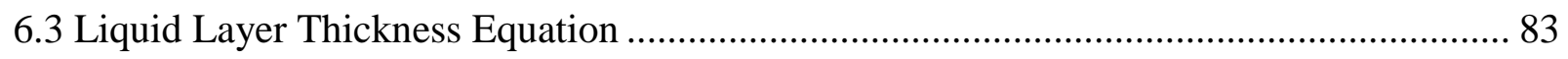




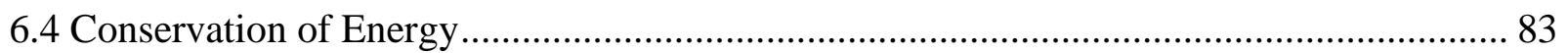

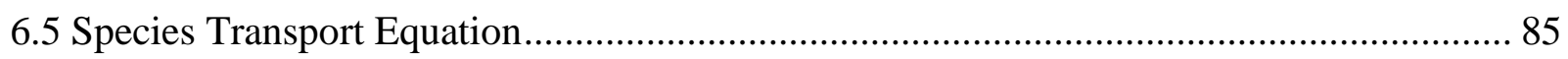

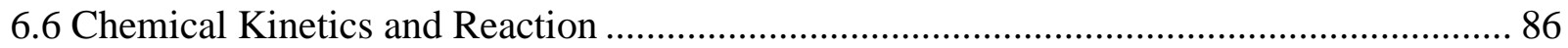

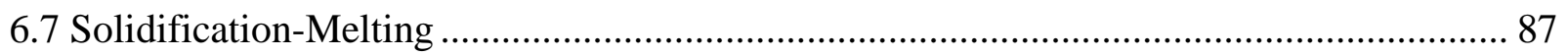

6.7.1 Solidification sub-model for $\mathrm{CaO}$ and $\mathrm{CaC}_{2}$ transported in the slag ........................... 87

6.7.2 Solidification sub-model for the solidified slag layer .............................................. 90

6.8 Release Model for Carbon Monoxide from the Slag ........................................................ 91

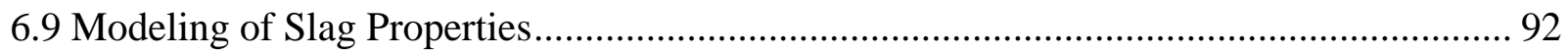

6.10 Solution Method for the Slag Model................................................................................. 94

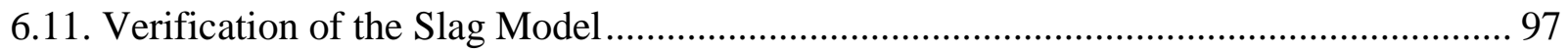

Chapter 7 - VHTER: Results and Discussion .................................................................................. 100

7.1 VHTER: Exploratory Study …………………………............................................. 100

7.2 VHTER: Design for $\mathrm{CaC}_{2}$ Production .................................................................. 112

7.3 VHTER: Slag Model Results .................................................................................. 124

Chapter 8 - Horizontal Reactor: Results and Discussion ............................................................... 131

8.1 CTC Reactor: Combustion Results for the Experimental Conditions at WRI.................. 131

8.2 CTC Reactor: Design for $\mathrm{CaC}_{2}$ Production ………....................................................... 136

8.3 CTC Reactor: Slag Model Results …………………............................................... 137

Chapter 9 - Conclusions and Future Work ..................................................................................... 141 


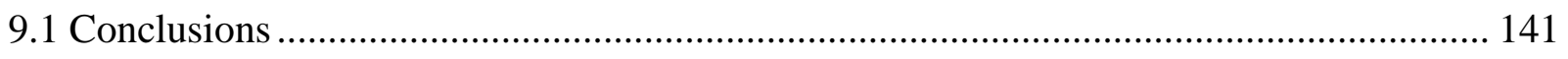

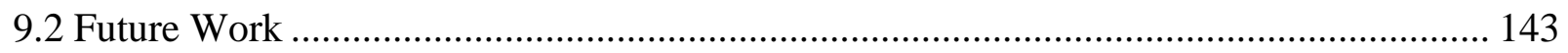

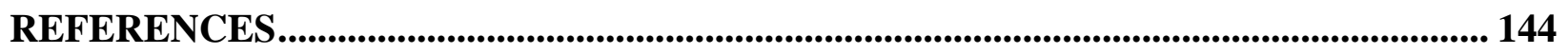

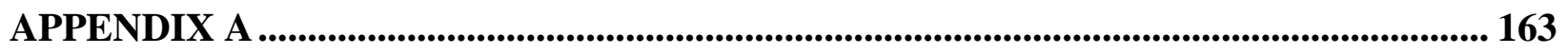

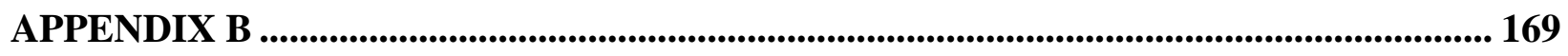

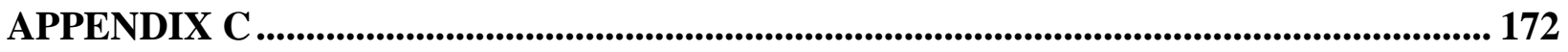




\section{List of Figures}

Figure 1-1. Computational framework for the proposed methodology ................................... 7

Figure 2-1. a) World total energy consumption by source type, 1990-2040 (Quadrillions BTU) b) World coal consumption by leading consuming countries, 2010-2024 (Quadrillion BTU)

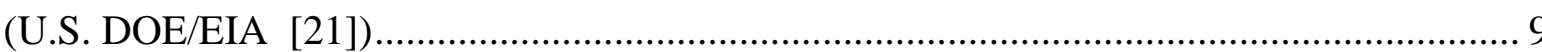

Figure 2-2. a) Primary energy use by source in US (Quadrillion Btu and \% of total) b) Primary energy use by source in China (Quadrillion Btu and \% of total) (U.S. EIA) ..................... 10

Figure 2-3. Global share of recoverable coal reserves (U.S. EIA) ..................................... 10

Figure 2-4. Diagram of an oxy-coal combustion power plant (Alstom Group, [24])................ 12

Figure 2-5. Production/consumption of $\mathrm{CaC}_{2}$ and its link to acetylene consumption in 2007 (IHS [26]) 14

Figure 2-6. Example of an EAF used in the production of $\mathrm{CaC}_{2}$ (SMS Group [32])................ 16

Figure 3-1. Spectral absorptivity as a function of wavenumber for water vapor, carbon dioxide and methane (Edwards [44])

23

Figure 3-2. Comparison of total intensity measurements (symbols) and gas radiation modeling (lines) at $384 \mathrm{~mm}$ away from the burner inlet (Andersson et al. [51]) 24

Figure 3-3. Char oxidation/gasification experiments in oxy-fuel conditions (Chen et al. [42])... 26

Figure 3-4. (a) Mass and heat transfer to reactor wall. (b) Illustration of particle capture/rebound by the slag layer and wall consumption of trapped particles (Yong et al. [16])................. 32

Figure 3-5. Slag model in CFD framework (Yong et al. [69])............................................ 33

Figure 4-1. Detailed view of the sections and components of the VHTER.............................. 55

Figure 4-2. VHTER: (a) Combustion chamber and (b) Burner region................................... 55 
Figure 4-3. Diagram of the CTC system including the methane-oxidant premixer and exhaust gas cooling pipe 57

Figure 5-1. Example of the computational domains utilized in the modeling of the VHTER. .... 68 Figure 5-2. Example of the computational domains utilized for the horizontal reactor modeling.

Figure 5-3. Chalmers $100 \mathrm{~kW}$ Combustor Unit. (Andersson [128]) .................................... 71

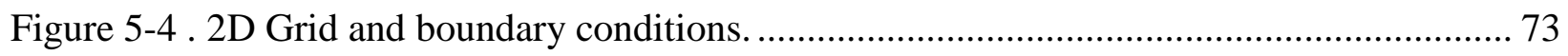

Figure 5-5. (a) 3D grid (b) Closer view at the inlet region............................................. 73

Figure 5-6. Contours and Iso-lines of temperature for (a) experiments performed by Andersson [128] and (b) CFD simulations performed by Gutierrez et al. [111].............................. 74

Figure 5-7. Comparison of temperature profiles against experiments and previous published results. (a) port $1(x=0.215 \mathrm{~m})$, (b) port $2(\mathrm{x}=0.384 \mathrm{~m})$, (c) port $3(\mathrm{x}=0.553 \mathrm{~m}) \ldots \ldots \ldots \ldots . . .75$

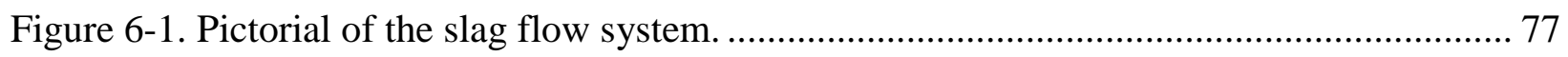

Figure 6-2. Solid-liquid equilibrium phase diagram for $\mathrm{CaO}-\mathrm{CaC}$. Taken from [130]............. 88

Figure 6-3. Heat transfer at the solid/liquid interface ................................................. 90

Figure 6-4. a) Predicted viscosity by the models of Urbain, BCURA $S^{2}$ and modified Urbain inside their experimental temperature range. b) Extrapolation to the temperature range of

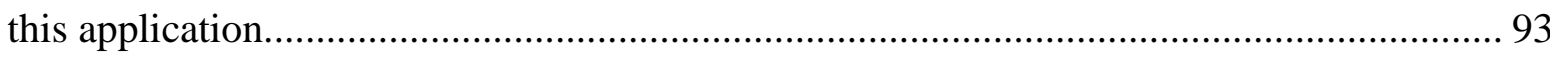

Figure 6-5. Courant number profile along the domain for a typical solution of the SFM (case OF35-02-B). 94

Figure 6-6. Computational framework of the slag model................................................. 96 
Figure 6-7. (a) Comparison of the liquid boundary layer thickness given by the SFM against the analytical solution. (b) Comparison of the solidified layer thickness given by the SFM against the analytical solution.

Figure 7-1. Velocity recirculation pattern and temperature contours in the BRZ for the OF25-E and OF50-E cases 101

Figure 7-2. Contours of (a) Temperature (K), (b) Mass fraction of volatiles and (c) Char burnout $(\mathrm{kg} / \mathrm{s})$ for the OF25 case. 103

Figure 7-3. Contours of (a) Temperature (K), (b) Mass fraction of volatiles and (c) Char burnout $(\mathrm{kg} / \mathrm{s})$ for the OF50 case. 104

Figure 7-4. Discrete phase particle (DPM) report for OF50 case (Conversion of coal is 97 percent, approximately) 105

Figure 7-5.Temperature contours and profiles for the OF50E-02 case. 108

Figure 7-6. Particle deposition and temperature along the wall of coal injected through the primary port for the down-fired reactor (OF50-E-02 case). 109

Figure 7-7. Particle deposition and temperature along the wall of tangentially injected coal for the down-fired reactor (OF50 case). 109

Figure 7-8. Particle deposition and particle temperature along the wall of down-fired reactor for tangentially injected $\mathrm{CaO}$ (OF50-E-02 case). 110

Figure 7-9. a) Ash collector temperature contours at planes xy and zx b) Particle flow pattern inside the ash collector c) Ash collector: temperature patter in the middle section of the cooling jacket.

Figure 7-10. Gas temperature profiles near the wall for the VHTER cases in Table 7-6. 117 
Figure 7-11. Effect of particle injection on the gas temperature near the wall for the OF50-01 cases.

Figure 7-12. Effect of preheating on the temperature profiles near the wall for the VHTER... 121 Figure 7-13. Velocity recirculation pattern and temperature contours in the BRZ for the cases in Table 7-8. 122

Figure 7-14. a) Deposition distribution and b) Temperature for char particles (OF50-02-B case)

Figure 7-15. a) Deposition distribution and b) Temperature for $\mathrm{CaO}$ particles (OF50-02-B case). 123

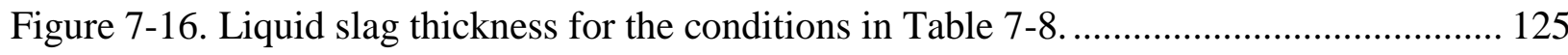

Figure 7-17. Thickness of the solidified slag layer for the conditions in Table 7-8................ 126

Figure 7-18. Average velocity of the liquid slag for the conditions in Table 7-8................... 127

Figure 7-19. Bulk slag temperature for the conditions in Table 7-8.................................. 127

Figure 7-20. Mass fraction of $\mathrm{CaC}_{2}$ in the slag for the conditions in Table 7-8.................... 128

Figure 7-21. Energy consumed by the $\mathrm{CaC}_{2}$ reaction for the conditions in Table 7-8............. 129

Figure 7-22. Slag viscosity profiles along the wall of the VHTER for the conditions in Table 7-8.

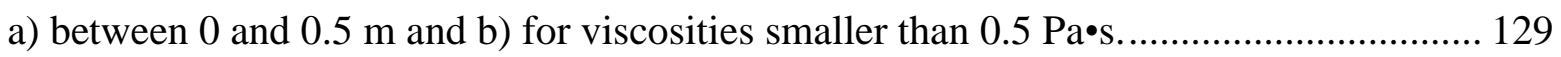

Figure 8-1. Example of the registered inlet conditions for the CTC reactor .......................... 132

Figure 8-2. Comparison of simulation results and experimental results for WRI-01-23-15 case.

Figure 8-3. Comparison of simulation results and experimental results for WRI-02-03-15 case. 
Figure 8-4. Comparison of simulation results and experimental results for WRI-03-31-15 case.

Figure 8-5. CTC Reactor bottom wall temperature profiles (cases in Table 8-1)................... 135

Figure 8-6. Bottom wall temperature profiles for simulations detailed in Table 8-2............... 137

Figure 8-7. Particle deposition of carbon and $\mathrm{CaO}$ as a function of (a) distance along the longitudinal axis, and (b) reactor circumference angle for the CTC-Reactor-52 case....... 138

Figure 8-8. Reference for definition of angular deposition coordinates............................... 138

Figure 8-9. Slag model results at steady state for the CTC-Reactor-52 case. (top left) slag pool depth (top right) average slag velocity (bottom left) bulk temperature of slag (bottom right)

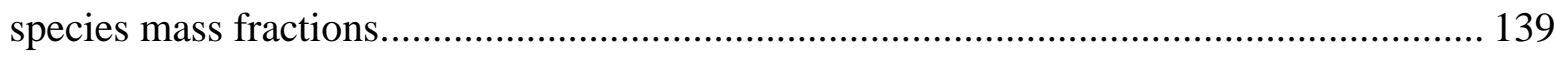

Figure 8-10. Accumulation of mass predicted by the SFM for the OF50-02-B case............... 140 


\section{List of Tables}

Table 5-1. Summary of the models utilized in the oxy-coal combustion simulations................ 65

Table 5-2. Flow inlet conditions for utilized in the validation study for oxy-coal combustion. .. 71

Table 5-3. German lignite properties. .......................................................................... 71

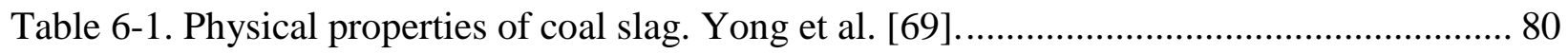

Table 6-2. Order of magnitude of the terms in the momentum equation. ................................. 80

Table 6-3. Order of magnitude of the terms in the temperature energy equation....................... 84

Table 6-4. Relevant properties for the natural convection boundary layer problem with solidification

Table 7-1. Oxidant gas inlet conditions for the exploratory study. 101

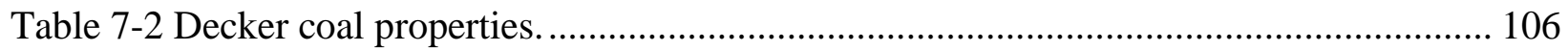

Table 7-3 Inlet mass flow rates of every reactant in $\mathrm{kg} / \mathrm{s}$ through every injection port for the OF50-E-02 case. 106

Table 7-4 Particle wall deposition for each of the injections for the OF50-E-02 case. 110

Table 7-5. Example of the combustion stability study for the OF50 case. 115

Table 7-6. Inlet conditions for the VHTER simulations 116

Table 7-7. Deposition of mass on the wall in $\mathrm{kg} / \mathrm{h}$ for the VHTER cases in Table 7-6 suitable for $\mathrm{CaC}_{2}$ production. 118

Table 7-8. Inlet conditions for the VHTER cases with preheating and balanced amount of chemical reactants. 121

Table 7-9. Particle deposition on the wall on the wall the cases in Table 7-8. 124

Table 7-10. Relevant information to $\mathrm{CaC}_{2}$ production in the VHTER 130 
Table 8-1. CTC Reactor Operation conditions: WRI tests, 2015's tests. Mass flow rates in $\mathrm{kg} / \mathrm{h}$,

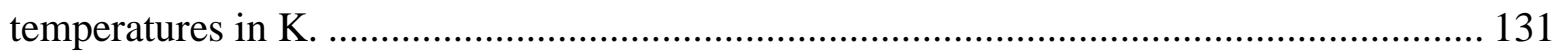

Table 8-2. Reactor operating conditions for simulations to enhance $\mathrm{CaC}_{2}$ production............. 136 


\section{NOMENCLATURE}

A

$a_{l s} \quad$ relaxation parameter in the solidification sub-model for $\mathrm{CaO}$ and

$\mathrm{CaC}_{2}$ transported in the slag

$C_{p} \quad$ specific heat under constant pressure

D

$E$

$E_{a}$

$g$

$g_{x}$

$G_{x}$

$G_{\phi}$

$h_{m C O}$

$h_{\text {env }}$

$H_{f} \quad$ heat of fusion of the slag

pre-exponential factor in Arhennius rate expression

mass diffusion coefficient

energy

Activation energy in Arhennius rate expression

gravity

gravity component along the slag flow direction

axial flux of linear momentum at the burner region of the reactor

axial flux of angular momentum at the burner region of the reactor

mass transfer coefficient for carbon monoxide release from the slag

convection heat transfer coefficient from the reactor to the environment

xvii 


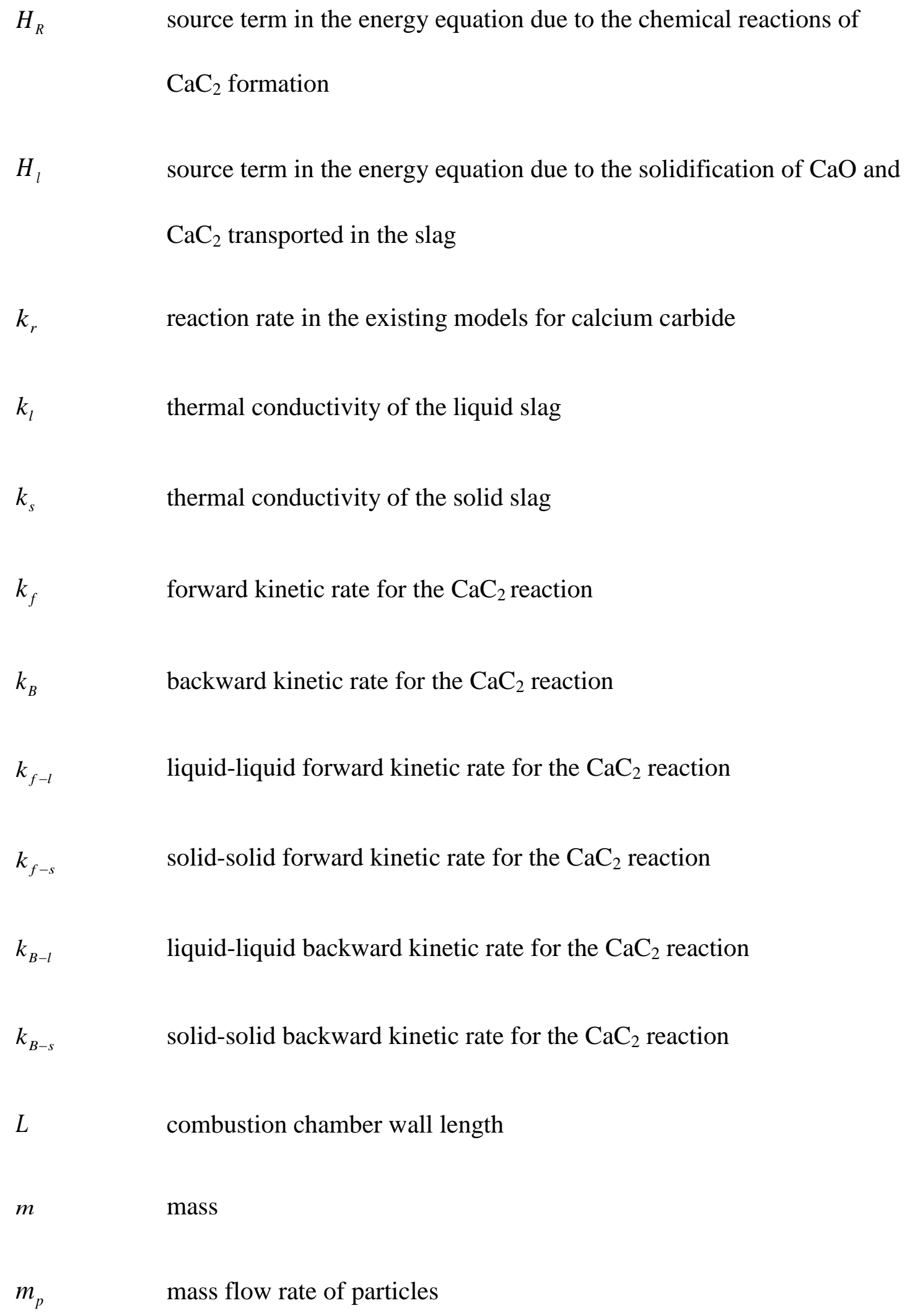




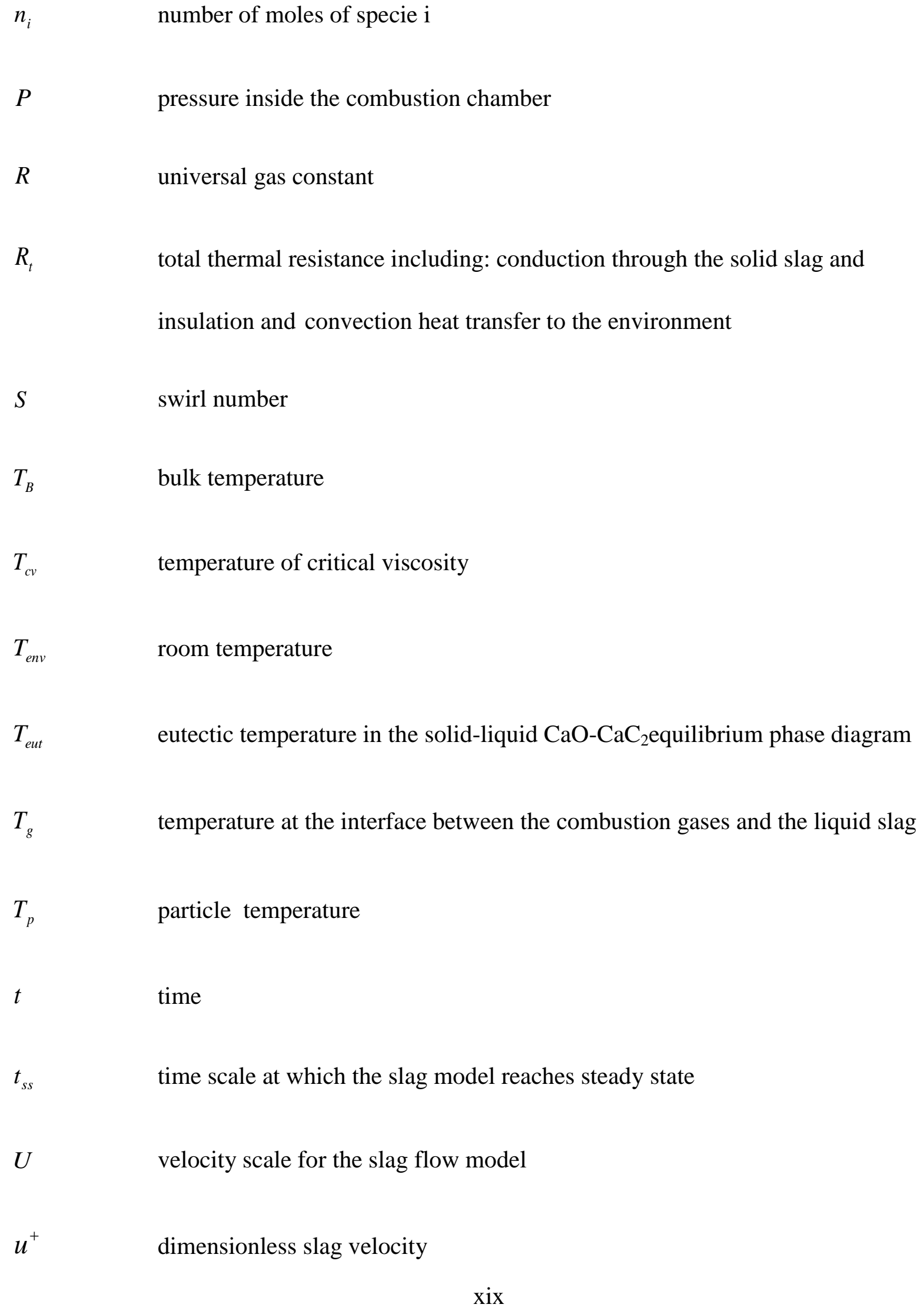




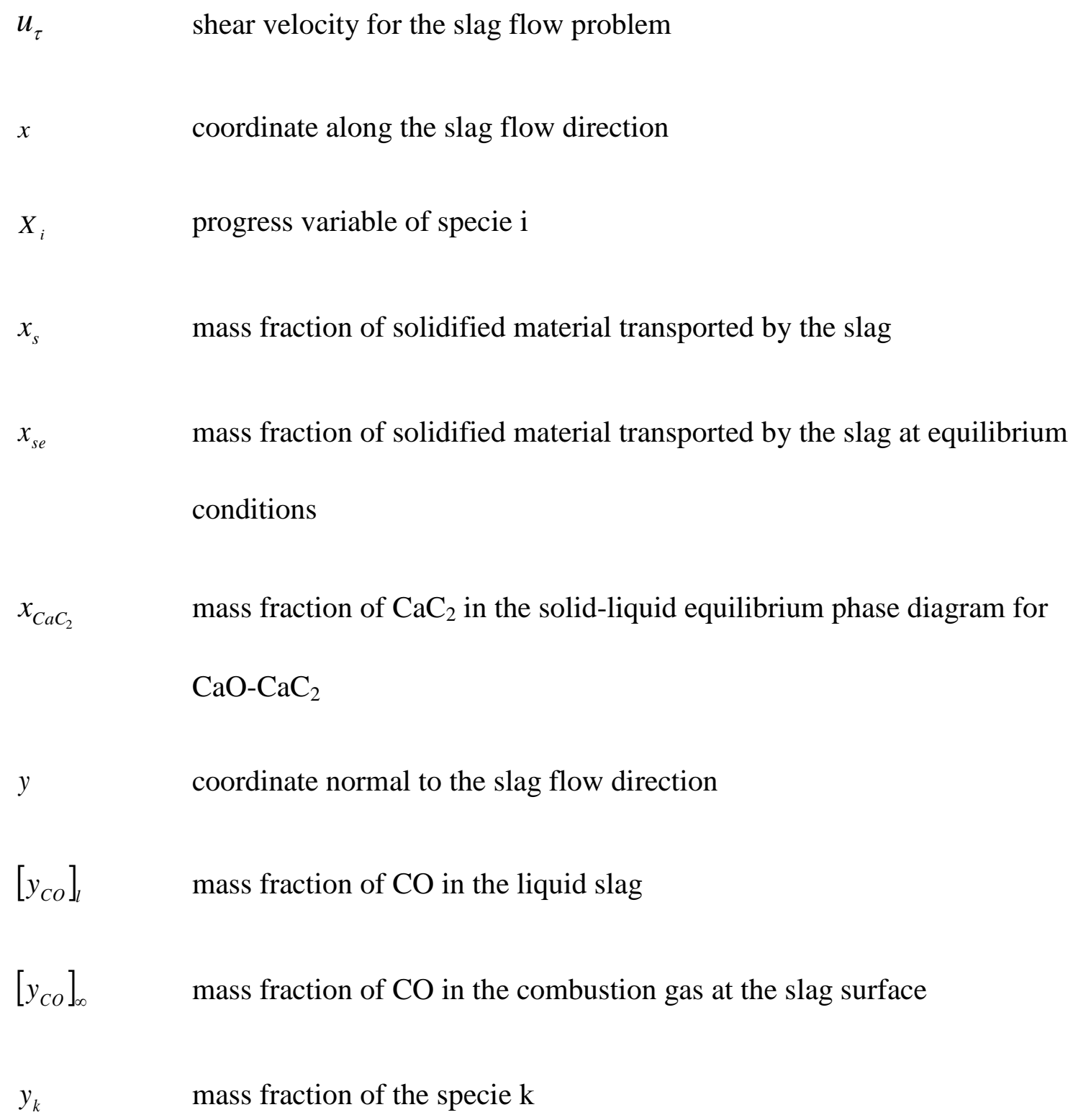

\section{Greek letters}

$\alpha \quad$ dimensionless coefficient in the slag velocity profile

$\alpha_{p} \quad$ thermal diffusivity of paraffin in the verification problem 
$\alpha_{r} \quad$ extent of reaction in the previous models for calcium carbide

$\beta_{p} \quad$ compressibility factor of paraffin in the verification problem

$\lambda_{l s}$

progress variable in the solidification sub-model for $\mathrm{CaO}$ and $\mathrm{CaC}_{2}$

transported in the slag

$\Delta t \quad$ time step in the solution of the slag flow problem

$\Delta x \quad$ dimension of a slag cell in the slag flow direction

$\Delta P \quad$ pressure change along the combustion chamber

$\delta_{l} \quad$ thickness of liquid slag

$\delta_{l s} \quad$ thickness of the liquid-solid interface of the slag

$\delta_{s} \quad$ thickness of the solidified slag

$\varepsilon_{f} \quad$ ratio of the solid amount to the total amount of $\mathrm{CaO}$ in the slag

$\varepsilon_{B} \quad$ ratio of the solid amount to the total amount of $\mathrm{CaC} 2$ in the slag

$\eta \quad$ slag dimensionless coordinate in the normal direction to the slag flow

$\mu \quad$ dynamic viscosity

$\mu \phi \quad$ viscous dissipation term in the slag flow

$v \quad$ kinematic viscosity 

$\tau_{g l} \quad$ shear stress at the interface of the molten slag and the combustion gas
$\tau_{w} \quad$ wall shear stress
$\omega \quad$ source term in the species transport equation
$\rho \quad$ density

\section{Subscripts}

( ) $)_{\text {Ash }} \quad$ ash

( ) ave average

()$_{k} \quad$ specie $\mathrm{k}$

()$_{j} \quad$ particle $\mathbf{j}$

()$_{C} \quad$ carbon

( ) $)_{\mathrm{CaO}} \quad$ calcium oxide

$\left[\begin{array}{ll}]_{c v} & \text { control volume }\end{array}\right.$ 

()$_{e} \quad$ east face
( ) $g$ generation term (source)
()$_{l} \quad$ liquid slag
()$_{n} \quad$ north face
( ) s south face
( ) $\quad$ west face
()$_{P} \quad$ cell center

\section{Superscripts}

( ) time rate

[]$^{o} \quad$ previous time step 


\section{Chapter 1 - Introduction}

\subsection{Motivation}

Oxy-coal combustion with recirculating flue gas is a promising technology in the $\mathrm{CO}_{2}$ capture and storage process. This technology is being implemented in existing air based equipment for power generation in order to reduce anthropogenic emissions of $\mathrm{CO}_{2}$ and other pollutants such as $\mathrm{NOx}$ and $\mathrm{SO}_{2}$ into the atmosphere. Oxy-coal combustion has been recently proposed for the activation of chemical reactions due to the very high temperatures that can be obtained. (i.e., temperature gases at circa $2000-2500{ }^{\circ} \mathrm{C}$ ) from char $/ \mathrm{O}_{2} / \mathrm{CO}_{2}$ mixtures. This application entails an economical alternative to the traditional electric arc furnace process for production of $\mathrm{CaC}_{2}{ }^{1}$.

Calcium carbide $\left(\mathrm{CaC}_{2}\right)$ is a highly valued chemical utilized mainly for acetylene generation. In the traditional electric arc furnace process $\mathrm{CaC}_{2}$ is obtained from the chemical reaction of coke and calcium oxide $(\mathrm{CaO})$ within temperatures ranging from 1800 to $2000{ }^{\circ} \mathrm{C}$.

The traditional process is highly energy intensive and consumes a disproportionate amount of coal in order to supply the required electrical power for the heating process. Additionally, the traditional process may also generate a significant harmful effect in the environment. This fact represents a significant limitation to his industrial expansion, consequently, affecting the availability of carbide and acetylene.

\footnotetext{
${ }^{1}$ See section 2.4 for a discussion on the traditional process for production of $\mathrm{CaC}_{2}$.
} 
These facts have motivated the pursuit of technologies intended to produce $\mathrm{CaC}_{2}$ in a more efficient and environmentally friendly manner. An additional consideration in this pursuit is the motivation to rely on available coal reserves, especially in locations where oil resources are scarce and coal reserves plentiful.

During the 1950's, two European companies explored alternatives for an oxy-thermal process and published different number of patents. Stamicarbon $[1,2,3,4,5]$ in Holland, and BASF in Germany $[6,7,8]$. Again in the 1980 's, Hoechst filed additional new patents $[9,10,11]$. Despite all the efforts and attempts to develop an oxy-thermal process, none of these processes were ever successfully commercialized.

In 2009, Bayer Technology Services and LP Amina collaborated to develop a new and improved oxy-thermal process, and collectively filed two patents $[12,13]$

The uniqueness of the Bayer-LP Amina process lies in its direct coupling of an oxy-thermal carbide making process with conventional power generation. The new invention utilizes an oxyfired cyclone burner and is highly energy efficient due to the direct coupling. This results in a step change energy efficiency gain that holds the promise of a new low-cost, low-emission supply of carbide and acetylene. A further advantage of the Bayer-LP Amina process is modularization and ease of retrofits. An individual cyclone burner can be replaced on a coalfired power plant in way that "numbers-up" capacity without the need for all new large-scale capital investments. It is expected that this breakthrough will create new markets and open up a new industrial segment for this process and other related coal-to-liquids processes. 
Research efforts intended to develop the oxy-coal combustion process for the production of $\mathrm{CaC}_{2}$ from char and calcium oxide ${ }^{2}(\mathrm{CaO})$ are being conducted by the U.S.-China Clean Energy Research Center (CERC). In this process, the $\mathrm{CaC}_{2}$ will be produced in the molten slag layer flowing along the walls of an oxy-coal combustion reactor; consequently, this is a slagging reactor. In this type of reactor, the temperature is so high that coal ash will be melted down and the molten slag layer will then capture the reactants more easily. For this application, the reactants consist of char/coal and $\mathrm{CaO}$ particles. A model capable of predicting the performance of oxy-coal reactors for $\mathrm{CaC}_{2}$ production will be an advantageous tool to develop this technology.

Previous work conducted in the field has been aimed at predicting the behavior of slagging in coal fired systems, mainly with the intention of analyzing its effect on the wall heat transfer and on the combustion process. Previous contributions include the work of Seggiani [14], who developed a simplified slag model coupled with a computational fluid dynamics (CFD) gasifier model. This model studied the slag accumulation and flow on the walls. The CFD model provided the inputs for the simplified slag model. In the work of Seggiani [14], the effects of changes in the gasifier operating conditions over the slag behavior were analyzed. For instance, similar effects on the slag thickness were obtained either by increasing the oxygen or by increasing the limestone amount. The transient response in the slag and gas, due to the change in operation conditions, was also assessed. The model provided solid and liquid slag thicknesses, temperature across the slag, and heat flux to the wall.

${ }^{2}$ Commonly known as quicklime or burnt lime. 
Wang et al. [15] used the same approach that Seggiani used [14], i.e., the combination of the CFD combustion model with a slag model. Wang et al. [15] took into account that particles trapped in the slag can contain combustible matter that will continue burning. For this reason, the authors introduced a wall burning model. Most recently, Yong et al. [16] presented a slag model based on the work of Seggiani [14] and Wang et al. [15]. Coupled calculations between the slag model and the CFD reactor model were performed too by Yong et al. [16].

\subsection{General Objective}

Partially due to the more narrow focus of the production of $\mathrm{CaC}_{2}$ in the molten slag of oxy-coal reactors, and despite of all efforts, none of the models discussed above are suitable to describe it. Therefore, the development of such a model is the purpose of this work. The proposed model will work as a tool intended to aid the design process of oxy-coal reactors for $\mathrm{CaC}_{2}$ production.

\subsection{Specific Objectives}

The model developed in the present work will:

- To set the reactor operating conditions required for production of $\mathrm{CaC}_{2}$.

- To predict the slag behavior; including the chemical reactions within the slag, the liquid and solid thickness, average velocity and bulk temperature.

- $\quad$ To predict the rate of production of $\mathrm{CaC}_{2}$.

\subsection{Methodology}

The methodology consists of a CFD model for oxy-combustion combined with a slag flow model. The CFD model for oxy-combustion uses the Reynolds-Averaged Navier-Stokes (RANS) 
approach for fluid flow, heat transfer, and turbulent-chemistry interactions. The multiphase character of the flow in the combustion chamber is considered using the Eulerian- Lagrangian treatment for the continuous gas phase and the particle discrete phase, respectively. The interaction between continuous and discrete phases is taken into account by using source terms in the coupling equations for mass, momentum and energy transport.

The slag model is based on an integral approach similar to the one utilized in the solution of boundary layer problems. The slag model is coupled with a chemical kinetics model for $\mathrm{CaC}_{2}$ production. The CFD model for turbulent combustion provides the inputs for the slagging model, such as boundary conditions and source terms. This methodology was tested in the ongoing design of pilot scale reactors conducted by CERC-ACTC.

The aforementioned strategy was divided into the four following parts:

1. Application of a CFD oxy-coal combustion model suitable for the conditions required for $\mathrm{CaC}_{2}$ production, such as high temperatures, high oxygen and $\mathrm{CO}_{2}$ concentrations, and the presence of $\mathrm{CaO}$ particles. This task was done in a commercial code. This model includes a wall particle capture sub-model via a user-defined function (UDF). The CFD oxy-coal combustion model was supported by a Reduce Order Model (ROM) for chemical equilibrium calculations developed by Rowan et al. [17]. The ROM uses the NASA equilibrium 
software $^{3}$ along with a pre-existing coal devolatilization model, the chemical percolation and devolatilization model (CPD) HEAT developed by Grant et al. [18] and Fletcher et al. $[19,20]$. The ROM was used to calculate the equilibrium flame temperature under the flow conditions of interest prior to CFD modeling, thus reducing the computational time.

2. Development of a slag flow model capable of describing the conversion process of char and $\mathrm{CaO}$ into $\mathrm{CaC}_{2}$ in the molten slag.

3. Integration of models and sub-models in a computational framework. The diagram depicted in Figure 1-1 illustrates the proposed computational framework.

4. Evaluation of the model in the design process of pilot scale reactors being developed by CERC-ACTC.

\footnotetext{
${ }^{3}$ The NASA Chemical Equilibrium with Applications (CEA) code is a free web-based application (the FORTRAN source code is also available for download) available in http://www.grc.nasa.gov/WWW/CEAWeb/.
} 


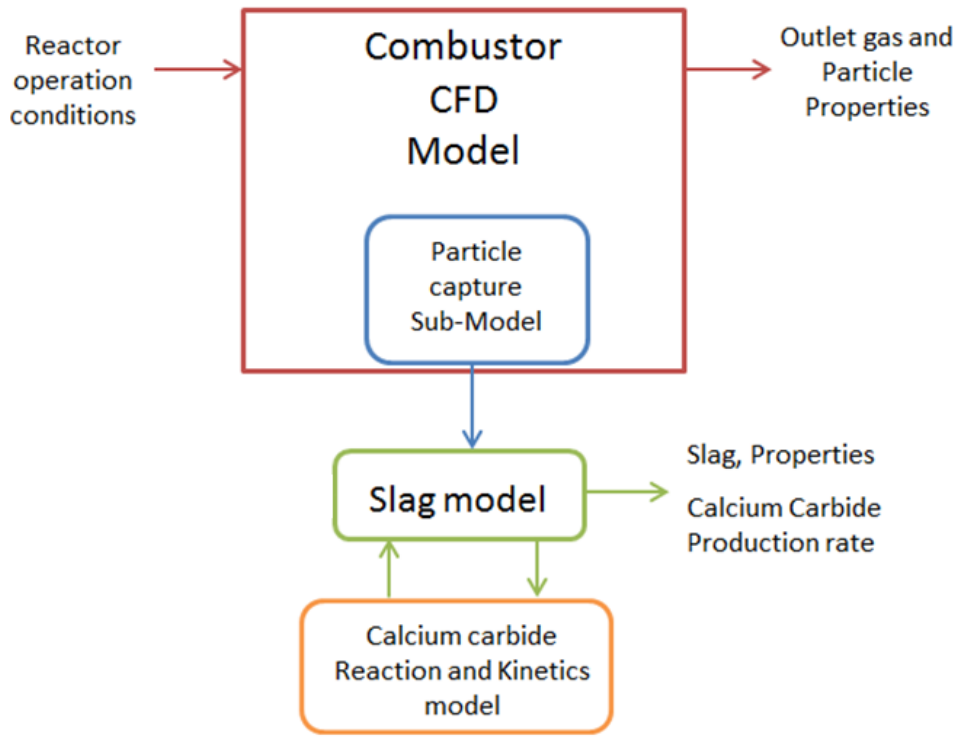

Figure 1-1. Computational framework for the proposed methodology 


\section{Chapter 2 - Background}

\subsection{Coal Technologies as an Strategic Issue for the U.S. and China}

According to the U.S. Energy Information Administration (EIA) [21], world coal consumption grew by 59 percent from 2000 to 2010 , due, in large extent, to China's rapidly growing energy demand. In China alone, coal consumption tripled during 2000-2010. Coal accounted for 23 percent of world energy consumption in 2000, compared to a 38 percent share for liquids. In 2010, the gap narrowed substantially, with a 28 percent for the coal share and a 34 percent for the liquids share.

According to the U.S. EIA, it is foreseen that world coal consumption will increase by an average of 1.3 percent per year from 147 Quad $^{4}$ in 2010 to 180 Quad in 2020 (Figure 2-1a). The near-term increase reflects significant increases in coal consumption by China, India, and other non-OECD ${ }^{5}$ countries. It is expected that coal use in non-OECD Asia increases by $1.9 \%$ per year (Figure 2-1b).

\footnotetext{
${ }^{4}$ Quadrillion BTU

${ }^{5}$ Organization for Economic Co-operation and Development
} 


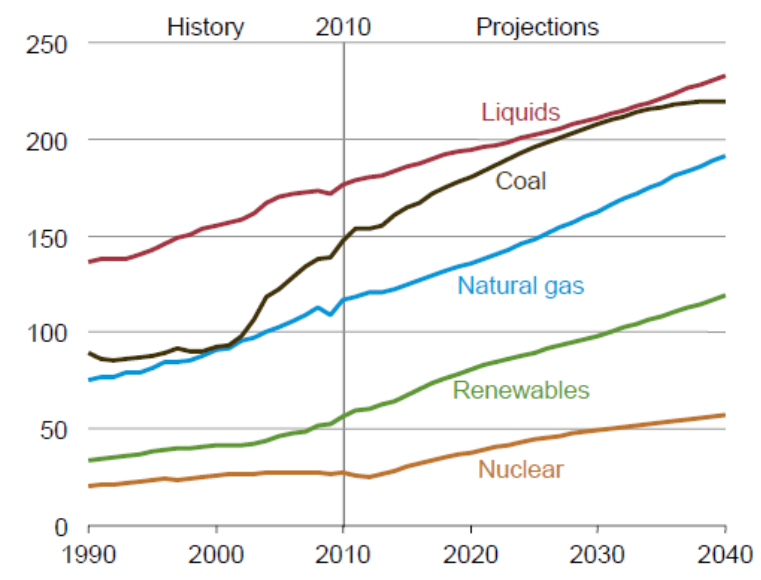

(a)

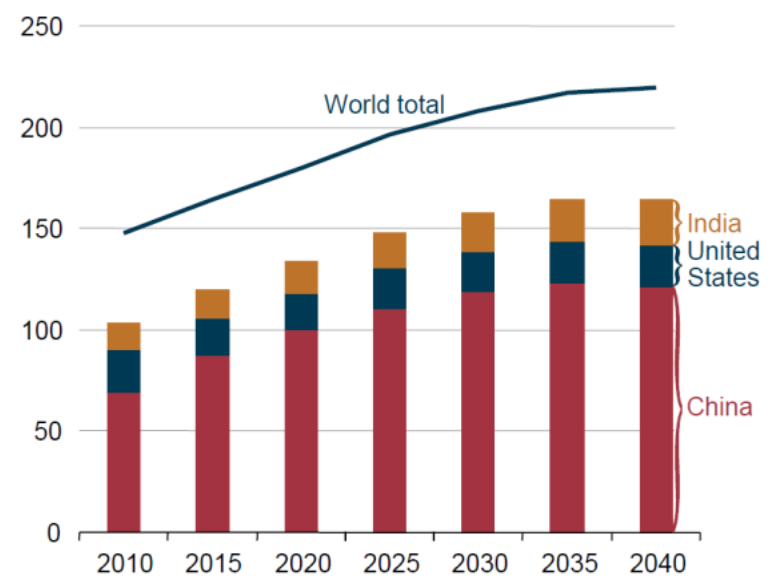

(b)

Figure 2-1. a) World total energy consumption by source type, 1990-2040 (Quadrillions BTU) b) World coal consumption by leading consuming countries, 2010-2024 (Quadrillion BTU) (U.S. DOE/EIA [21])

Currently, fossil fuels make up nearly 80 percent of the total primary energy source in the United States (Figure 2-2a), with coal being about 18 percent of the total. Approximately 91 percent of the coal used for electricity generation and the remaining 8 percent used in industrial applications. Fossil fuels account for nearly 91 percent of the total primary energy usage in China (Figure 2-2b), with coal being about 69 percent of the total. Industrial applications make up 77 percent of the coal demand in China with the remainder four percent going to the commercial sector, 11 percent for the residential sector, and eight percent for transportation.

China's continued economic growth, along with the fact that the United States and China account for an important share of the recoverable coal reserves in the world (Figure 2-3), makes the development of advanced coal technologies a strategic priority for both nations. 


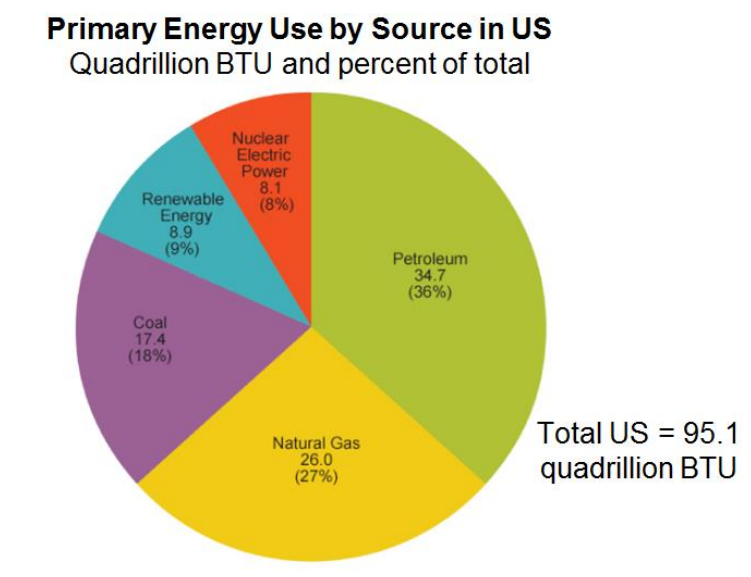

Source: U.S. Energy Information Administration, Monthly Energy Review, Table 1.3 (April 2013), preliminary 2012 data.
Primary Energy Use by Source in China

Quadrillion BTU and percent of total

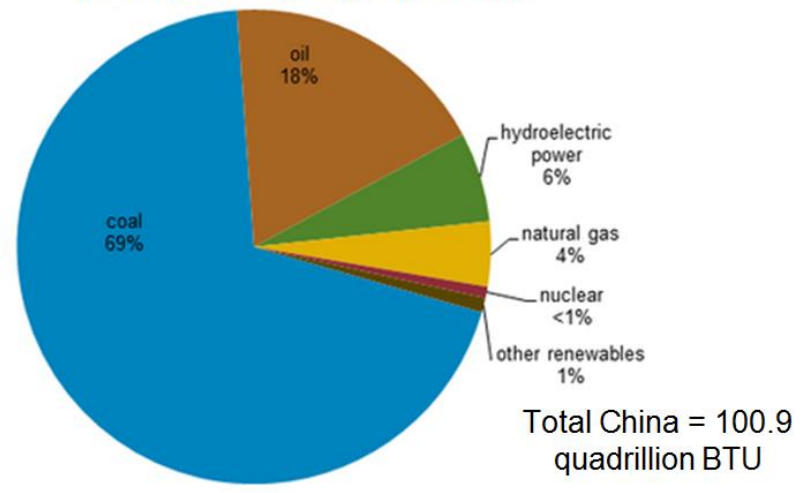

Source: U.S. Energy Information Administration 2011 data.

(a)

(b)

Figure 2-2. a) Primary energy use by source in US (Quadrillion Btu and $\%$ of total) b) Primary energy use by source in China (Quadrillion Btu and \% of total) (U.S. EIA)

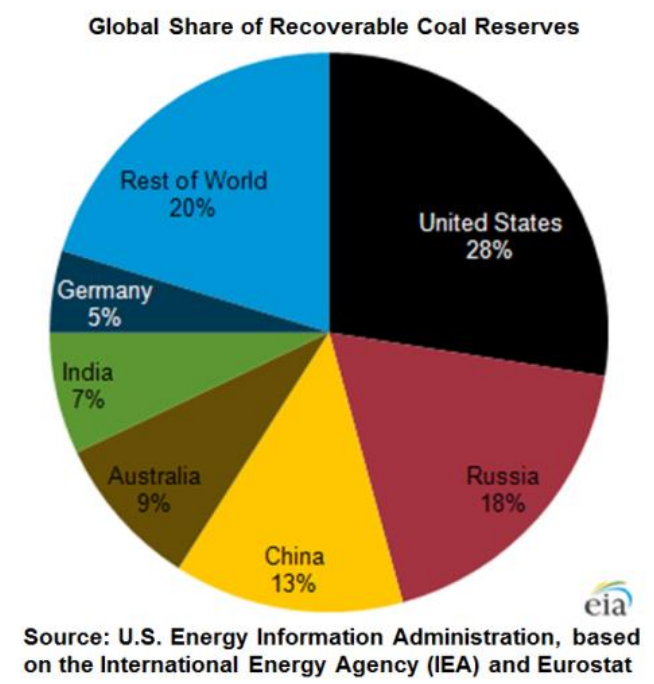

Figure 2-3. Global share of recoverable coal reserves (U.S. EIA)

Although abundant and supply-secure, the future of coal will be likely constrained by greenhouse gas reduction policies. An increase in the use of high-efficiency coal-fired generation 
technologies, as well as carbon capture and storage, is expected to allow a smooth transition to a low carbon power system, while reducing the risk of a shortage in the energy capacity.

\subsection{U.S.-China Cooperation Agreement on Advanced Coal Technologies}

The U.S.-China CERC was established in 2009 by a protocol signed by President Barack Obama and President $\mathrm{Hu}$ Jintao [22]. This protocol expresses the intention of the two nations to keep collaborating under the Science and Technology Cooperation Agreement of 1979 [23]. The United States and China have identified the research on advanced coal technologies as one of their three strategic areas of bilateral cooperation on clean energy innovation ${ }^{6}$. This joint effort is being executed through the establishment of the CERC Advance Coal Technology Consortium, collectively, the CERC-ACTC, which involves academic, governmental and industrial institutions.

In the United States, the consortium is led by West Virginia University Research Corporation, WVU, Morgantown, WV. The research conducted by the CERC-ACTC includes work in the following fields: advanced power generation, clean coal conversion technology, pre-combustion capture, post-combustion capture, oxy-combustion capture, $\mathrm{CO}_{2}$ sequestration, $\mathrm{CO}_{2}$ utilization, simulation and assessment, and communication and integration. This research covers the areas of oxy-combustion, clean coal conversion technology, and simulation and assessment.

\footnotetext{
${ }^{6}$ The other two areas are: Building Energy Efficiency and Clean Vehicles.
} 


\subsection{Oxy-Combustion: Low Emissions Technology}

Oxy-coal combustion with recirculating flue gas is a promising technology in the $\mathrm{CO}_{2}$ capture and storage process. This technology aims at reducing the anthropogenic emissions of $\mathrm{CO}_{2}$ and other pollutants into the atmosphere. In this process, the recycled $\mathrm{CO}_{2}$ from the flue gases is mixed with pure oxygen to be injected later as the oxidant instead of air (Figure 2-4). As the $\mathrm{CO}_{2}$ concentration in flue gases is higher than in the conventional air operation, the $\mathrm{CO}_{2}$ capture is enhanced and brings about the additional advantage of a reduction in the emissions of NOx.

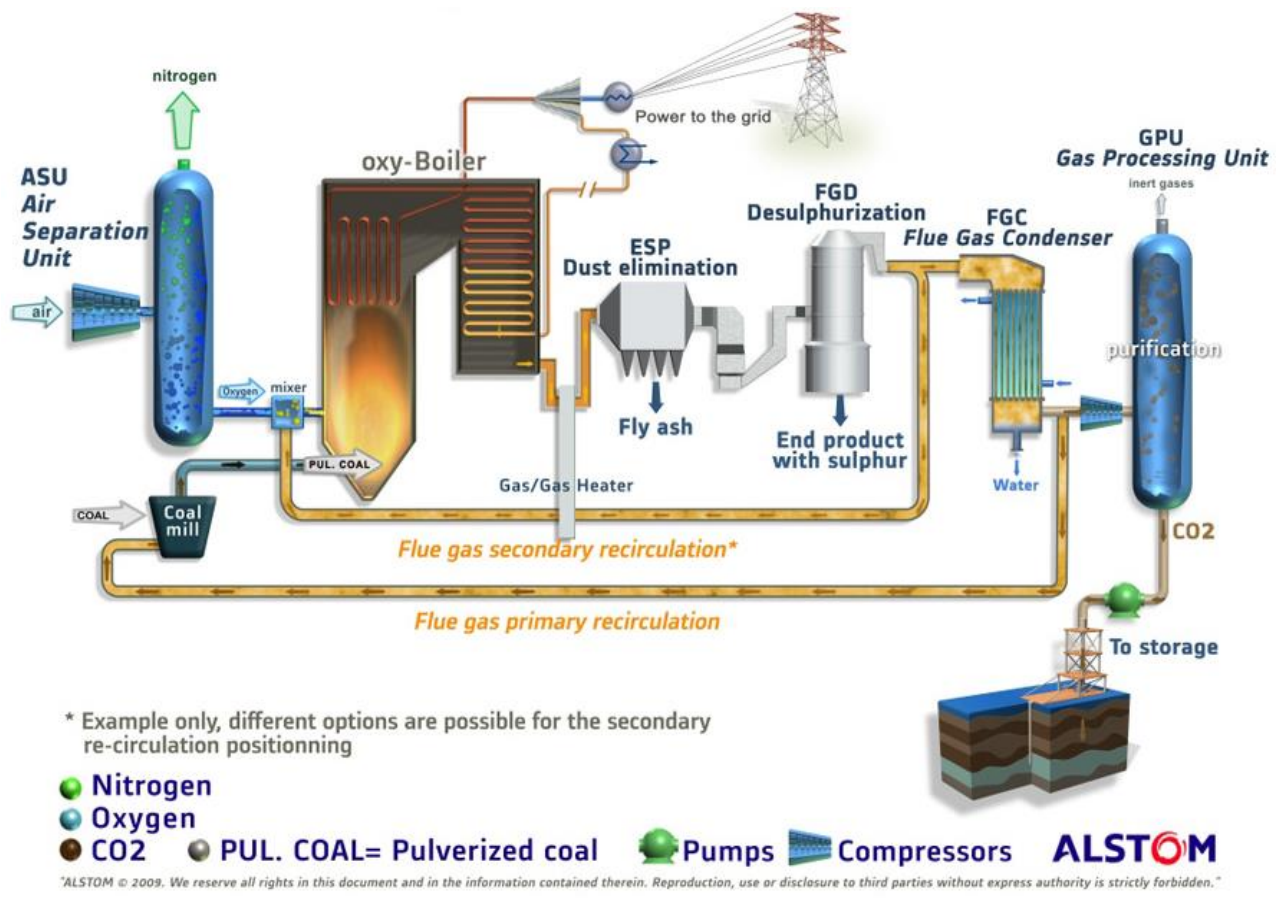

Figure 2-4. Diagram of an oxy-coal combustion power plant (Alstom Group, [24])

Oxy-coal combustion with recirculating flue gas is being implemented in existing air-based equipment, such as boilers and furnaces. Nonetheless, the main drawback is the oxygen separation process, which requires a substantial amount of energy, reducing its overall efficiency. In order to overcome this issue, some technologies, such as oxygen and ion transport 
membranes or chemical looping, are being developed. A review of the state of the art of oxy-coal combustion is presented in $[25]^{7}$.

\subsection{Oxy-Coal Combustion for Production of $\mathrm{CaC}_{2}$}

$\mathrm{CaC}_{2}$ is an inorganic compound used mainly in the generation of acetylene (90-95 percent of total consumption). Other applications include production of calcium cyanamide, a nitrogen fertilizer; desulfurization reagent in the iron (foundry) and steel industries, and a slag modifier/conditioner (reducer) in the production of ductile iron and steel.

China accounts for 95 percent of the total world production and consumption of $\mathrm{CaC}_{2}$ (Figure 2-5). This market is linked to the country's strong economic growth, large coal reserves and everincreasing acetylene demand for the production of PVC. The $\mathrm{CaC}_{2}-$ to-PVC process, considered as an antiquated process in developed parts of the world, accounts for 94 to 97 percent of China's total PVC production. [26]. The annual production of $\mathrm{CaC}_{2}$ has been increasing in the past decade and has reached about 17 million tons in 2011 in China alone [27].

7 See also: "Innovations for existing plants-Advanced Combustion," NETL, accessed Jan 20, 2015, http://www.netl.doe.gov/technologies/coalpower/ewr/co2/OxyCombustion.html\# 
Production of Calcium Carbide by Major Region -2007

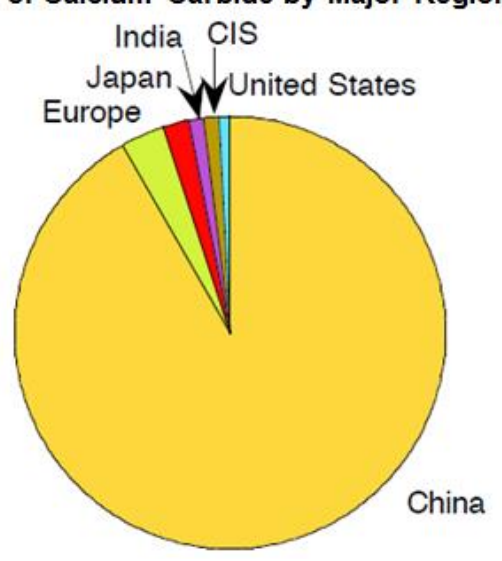

Consumption of Acetylene by Major Region -2007

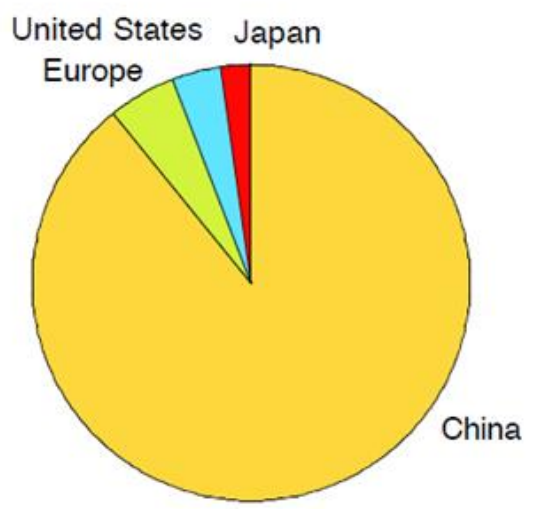

Figure 2-5. Production/consumption of $\mathrm{CaC}_{2}$ and its link to acetylene consumption in 2007 (IHS [26])

Despite of the size of the market, traditional $\mathrm{CaC}_{2}$ production technique has remained almost virtually the same for more than a century $[28,29]$.

In the traditional process, a coke drier is used to remove the moisture content of coke, whereas a lime kiln is used to produce quicklime through the calcination of limestone. The fines resulting from the coke drying and the calcination of limestone may be recycled. A ground mixture of coke and quicklime is then fed into a moving-bed electric arc furnace (EAF) that uses a consumable electrode (see Figure 2-6). The electrode consists of a paste composed of coal tar pitch binder and anthracite coal fed into a steel casing that is baked by heat from the EAF before being placed into the furnace. The baked electrode exits the steel casing inside the furnace cover and is consumed in the $\mathrm{CaC}_{2}$ production process.

There are three basic types of electric arc furnaces for $\mathrm{CaC}_{2}$ production [30]: the open furnace, in which the $\mathrm{CO}$ burns to carbon dioxide $\left(\mathrm{CO}_{2}\right)$ when it contacts the air above the charge; the closed furnace, in which the gas is collected from the furnace and either used as fuel for other 
processes or flared; and the semi-covered furnace, in which the mixture is fed around the openings for the electrodes in the primary furnace cover, resulting in mix seals. The molten product of the EAF is tapped, cooled, cast, and then crushed and ground to the size required for marketing.

The purity of commercial $\mathrm{CaC}_{2}$ is measured by the percentage content of pure $\mathrm{CaC}_{2}$, which typically ranges between 75 to 90 percent $\mathrm{CaC}_{2}$. The main balance elements are lime, alumina, silica, and free carbon [31]. The percentage of $\mathrm{CaC}_{2}$ is assessed by measuring the volume of acetylene produced when the commercial $\mathrm{CaC}_{2}$ reacts with water, e.g., 314 liters of acetylene per kilogram of commercial $\mathrm{CaC}_{2}$ corresponds to $90 \% \mathrm{CaC}_{2}$ purity [29].

One of the main drawbacks of the traditional EAF process is that coke and $\mathrm{CaO}$ particle sizes are typically in the range of 5 to $30 \mathrm{~mm}$. in order to favor the release of the by-product carbon monoxide $(\mathrm{CO})$. This does not allow for good surface contact of the reactants, which is large obstacle for mass and heat transfer, as well as, reaction rates. For this reason, it is necessary to obtain high reaction temperatures $\left(\sim 2200^{\circ} \mathrm{C}\right)^{8}$ and long reaction times $(1-2 \mathrm{~h})$, resulting in high electric energy consumption $\left(\sim 4000 \mathrm{~kW} \cdot \mathrm{h}\right.$ per ton of pure $\left.\mathrm{CaC}_{2}\right)$ [27].

\footnotetext{
${ }^{8}$ Not practically achievable with traditional combustion processes.
} 


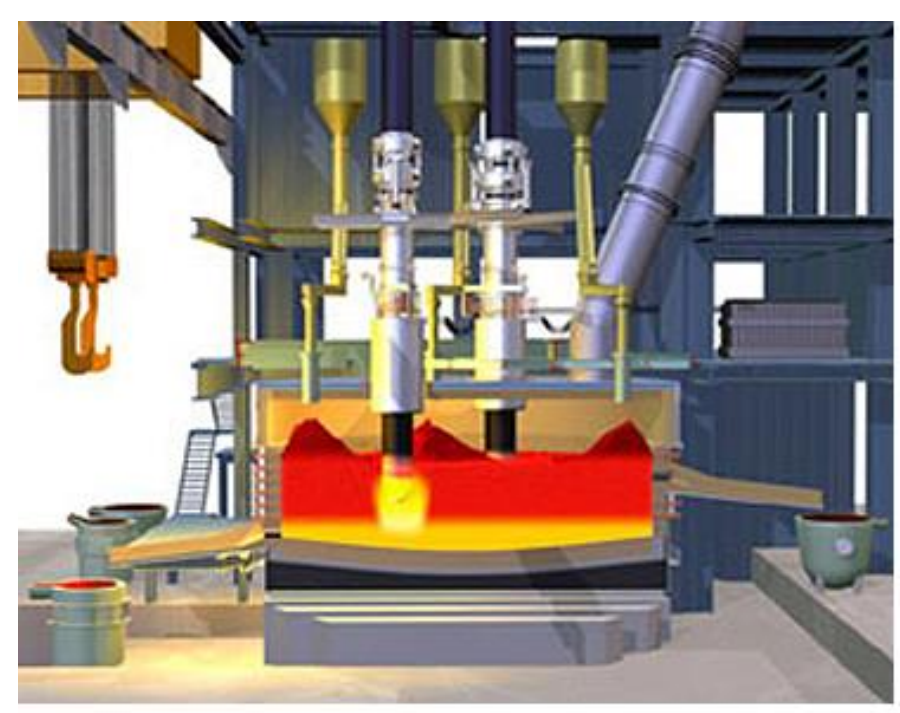

Figure 2-6. Example of an EAF used in the production of $\mathrm{CaC}_{2}$ (SMS Group [32])

Due to the elevated electric energy consumption, different options for an economical production of $\mathrm{CaC}_{2}$ have been suggested, some including autothermal heating processes via oxycombustion, e.g., plasma spout-fluid bed [33], rotary kiln with partial oxygen-fuel heating [34], and auto thermal processes with full oxygen-fuel heating $[4,35]$. These processes, however, have used ground materials with the particle size ranges as those processes, thus including the same limitations discussed above.

A work presented recently by Li et al. [36] addressed that issue and showed that it is possible to activate the $\mathrm{CaC}_{2}$ reaction at temperatures lower than $1750{ }^{\circ} \mathrm{C}$ if fine particles (i.e., with sizes smaller than $0.1 \mathrm{~mm}$ ) are used. The work of $\mathrm{Li}$ et al. [36] is performed at these lower temperatures to understand the reaction behavior and develop a kinetic model to be applied in the scale-up of the reactor design process. A review of the state of the art of the reaction and kinetics modeling for $\mathrm{CaC}_{2}$ is discussed in section 3.7. 


\section{Chapter 3 - Literature Review}

\subsection{CFD in Reactor Design}

CFD has evolved as a technique that was initially used primarily for aerospace applications. However, it has been recently applied to many industrial flow problems [37]. CFD is a useful tool for designing complex flow processes and equipment. Its implementation in the power generation industry helps engineers improve equipment design, which can result in increased thermal efficiency and reduction of environmental emissions. Improvements in design can lead to lower product costs and higher product quality in the chemical industry. Current societal concerns that need to be addressed, such as environmental issues, depletion of traditionally used fossil fuels, and a competitive marketplace, require engineers to look for the aforementioned improvements constantly.

Some advantages brought about by the implementation of CFD in the reactor design process are the following [38]: i) it allows for a detailed understanding of flow distribution, weight losses, mass and heat transfer, and particulate separation; ii) it makes it possible to evaluate the effect of geometric changes in much less time and with lower costs compared to laboratory testing; iii) it answers many 'what if' questions in a fast manner; iv) it reduces scale-up problems because the models are based on fundamental physics and are scale independent; v) it can simulate conditions where it is not possible to take detailed measurements, such as high temperatures or dangerous environments; iv) since the implementation of the CFD in the reactor design process is a pro-active analysis and design tool, it can highlight the root cause and not just the effect when evaluating plant problems. An additional advantage of the CFD simulations over 
experimental methods is that the diagnosis does not disturb the flow and normal equipment operation.

In spite of all the aforementioned advantages, the implementation of CFD in the reactor design process is a difficult task when compared to non-reacting flow applications. That is due to the additional flow complexities involved in a typical reactor design problem. Thus, turbulence as well as many different effects such as heat transfer, compressibility, multiphase flow, phase changes, combustion and other chemical reactions, and the non-linear interactions between these effects, are present. In turbulent combustion, for instance, the modeling of turbulence is one of the most critical processes because of its role in establishing the flow, mixing, and combustion processes [39]. Even though models to account for additional effects have been continuously developed and incorporated into many commercial codes, research in this area is still incomplete [40].

\subsection{Turbulence Modeling}

The solution of the turbulent flow field is a challenging task because flow properties change significantly in a random and chaotic fashion in space and time, even when constant boundary conditions are imposed. Similarly, flow properties reveal the existence of eddies in a wide range of different space and time scales. The presence of eddies increases the transportation of flow properties by mixing, e.g., mass, momentum, energy, entropy. Therefore, the solution methods must include the effects of the fluctuations in the flow. 
Turbulent flow calculations are done using different methods: Direct Numerical Simulation (DNS), Large Eddy Simulation (LES), and RANS. In the DNS method, the Navier-Stokes equations are solved for all space scales. For this reason, spatial grids should be sufficiently fine ${ }^{9}$ so that the Kolmogorov length scales at which energy dissipation takes place can be resolved. Spatial grid should also allow resolving the period of the fastest fluctuations in sufficiently small time steps. DNS is then highly computationally expensive and not practical for industrial applications where the computational resources required would exceed the computer power currently available. Nonetheless, DNS is a highly valuable tool for fundamental research and model validation ${ }^{10}$

In the LES method, the Navier-Stokes equations are solved after application of a filter process in space. The filtering process rejects the smaller eddies that should then be modeled using a subgrid scale model. The LES solution includes the mean flow plus the effects of large eddies. LES is less computational expensive than DNS but still requires high computationally resources.

Finally, the RANS method focuses on the mean flow and the effects of turbulence on the mean properties by accounting for the turbulence interaction via additional terms in the time-averaged (Reynolds Averaged) equations; therefore, no scales are solved but their effect is modeled. These additional terms are modeled with classical turbulent models, e.g., mixing length, k- $\epsilon$, k- $\omega$,

\footnotetext{
${ }^{9}$ Proportional to the cubic power of the Reynolds number $\left(\operatorname{Re}^{3}\right)$

${ }^{10}$ See, for instance, "Direct Numerical Simulation”, Combustion Research Facility, Sandia National Laboratories, accessed May 25, 2013, http://crf.sandia.gov/index.php/combustion-research-facility/reactingflow/modeling/dns/\#. UaE9Dpz194M
} 
Spalart-Allmaras. RANS-based CFD represents a reasonable compromise between accuracy and expenses, so that it is preferred in industrial applications. In fact, it has been the mainstay of flow calculations over the past three decades [41].

\subsection{Main Differences between Oxy-Coal and Air-Coal Combustion}

Different aspects need to be considered when moving from air to oxy-coal combustion modeling. Chen et al. [42] provide references to the experiments and numerical studies performed in the

field. The authors also present a comprehensive review to the thermodynamics, transport and chemistry processes in oxy-coal combustion. The processes and aspects to be considered in oxycoal combustion vs. air-coal combustion are:

1. Heat Transfer
a. Radiative heat transfer
b. Convective heat transfer
c. Combustion temperature

2. Fuel delivery and injection

3. Heating and moisture evaporation of coal particles

4. Ignition of coal particles
a. Ignition delay
b. Burning of volatiles

5. Oxy-char combustion
a. Kinetics of char oxidation in oxy-fuel combustion
b. Effect of diffusivity 

c. Effect of gasification reactions
d. Effect of heat capacity
e. Effect of pressure

This section presents a discussion about the most relevant aspects to be considered in the present application. These are: radiative heat transfer and char combustion. The reader is referred to Chen et al. [42] for a more detailed discussion.

\subsubsection{Radiative heat transfer}

During oxy-coal combustion with flue gas recirculation, the partial pressures of $\mathrm{CO}_{2}$ and $\mathrm{H}_{2} \mathrm{O}$ in the burning gases are considerable higher than in normal air-fuel combustion. Gases with symmetric diatomic molecules, such as $\mathrm{N}_{2}$, are transparent to infrared radiation and do not emit significantly. On the other hand, heteropolar gases that absorb and emit significantly, such as $\mathrm{CO}_{2}$ and $\mathrm{H}_{2} \mathrm{O}$, are not transparent to infrared radiation. Therefore, absorption and radiation are considerably higher in oxy-coal combustion environment when compared with air-fuel combustion.

When a radiation beam of wavelength $\lambda$ travels an infinitesimal length, ds, through a gas, a fraction of its radiation intensity, $\alpha_{\lambda}$, is absorbed by the gas. In this process, the change in the spectral radiation intensity, $d I_{\lambda}$ of the radiation beam is given by the expression [43]:

$$
d I_{\lambda}=-k_{\lambda} I_{\lambda} d s
$$


In this expression, $k_{\lambda}$ is the spectral absorption coefficient, which is a function of the wavelength, gas composition, gas temperature and pressure. If equation (1) is integrated over the length, $\mathrm{s}$, the spectral absorptivity and emissivity of the gas can be obtained as:

$$
\alpha_{\lambda}=\varepsilon_{\lambda}=1-\exp \left[-k_{\lambda} s\right]
$$

The effective absorptivity and emissivity of a gas mixture can be obtained by integrating equation (2) over the full spectrum. However, direct computation of the gas absorptivity is difficult. Figure 3-1 shows the spectral absorptivity, $\alpha_{\lambda}$, as a function of wavenumber for water vapor, carbon dioxide and methane during a combustion process [44]. It can be observed that absorption is not continuous over the entire spectrum; instead it is concentrated in a number of moderately wide spectral bands. To overcome this difficulty more practical approaches, such as the weighted sum of grey gas model (WSGG), are used in the CFD modeling. For instance, the WSGG model has been used in the works performed by Khare et al. [45], Toporov et al. [46], Chen et al. [47], and Nikolopoulos et al [48]. This same approach has been used in the present work. 


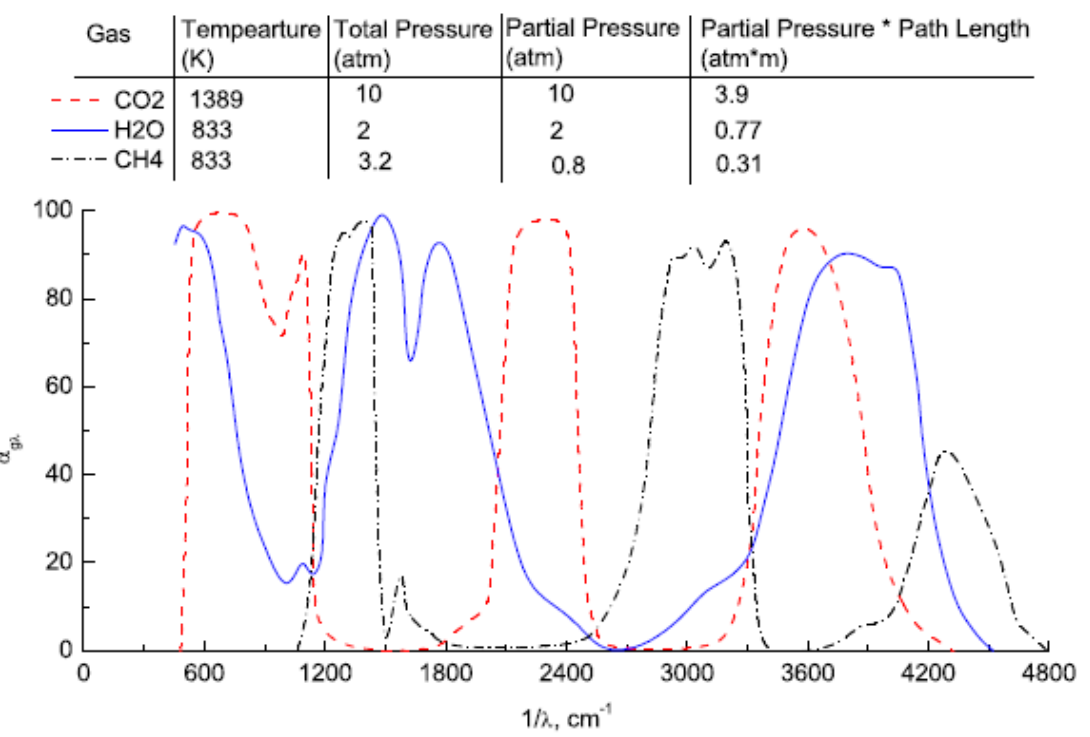

Figure 3-1. Spectral absorptivity as a function of wavenumber for water vapor, carbon dioxide and methane (Edwards [44]).

Despite of the effect of the enhanced gas radiation during oxy-fuel combustion, it has been shown by Andersson and coworkers [49,50,51] that gas radiation during oxy-fuel combustion becomes less important when compared to the particle radiation. The authors investigated the radiation intensity of lignite coal-fired oxy-fuel flames in the $100 \mathrm{~kW}$ test facility at Chalmers University of Technology ${ }^{11}$. The authors showed that particle radiation contributes about 60 to $70 \%$ of the total radiation in both air-fired and oxy-fired cases.

This can be observed in Fig. 8 where the authors show the radiation intensity of the gas and the total radiation intensity (gas and particles) at the flame zone. The data correspond to the port located at $384 \mathrm{~mm}$ away from the burner inlet. It can be also observed that in lignite oxy-fuel

\footnotetext{
${ }^{11}$ This unit is described in section 5.5.
} 
combustion with an oxygen molar fraction of 0.25 (OF25) the total radiation intensity is similar to the conventional air operation although gas radiation is enhanced. Again, the larger amount of radiation is emitted by particles, which have similar contribution in both combustion environments.

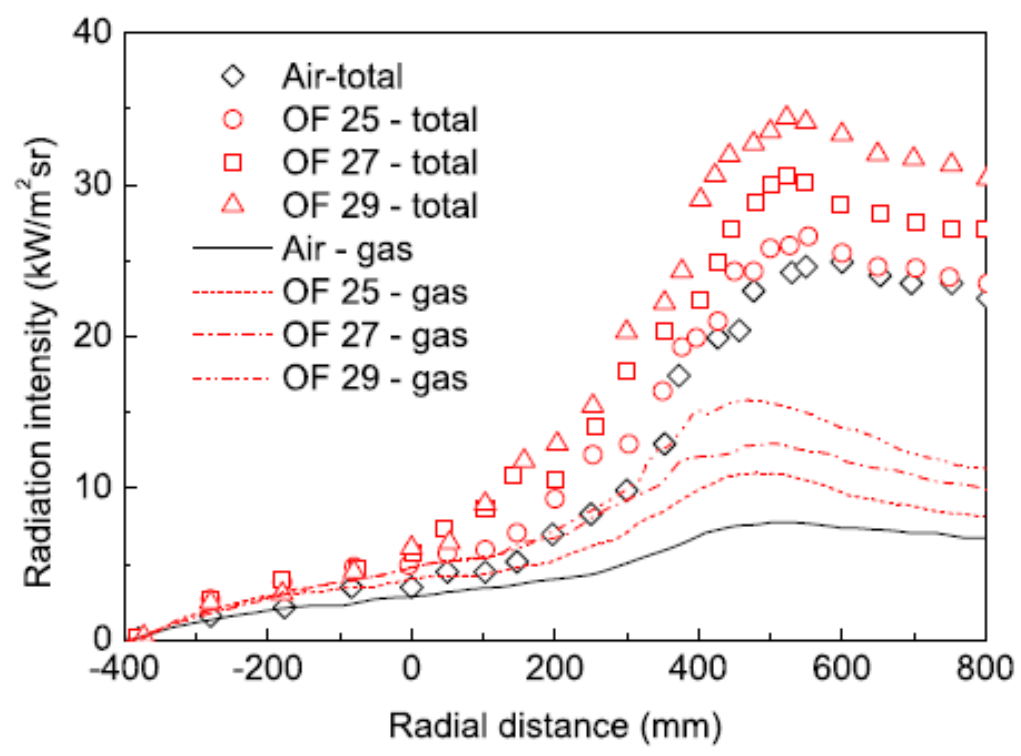

Figure 3-2. Comparison of total intensity measurements (symbols) and gas radiation modeling (lines) at $384 \mathrm{~mm}$ away from the burner inlet (Andersson et al. [51])

\subsubsection{Char Conversion}

Different works have been conducted to evaluate the differences in char conversion under oxyfuel conditions, examples can be found in the references $[52,53,54,55]$. Regarding the presence of $\mathrm{CO}_{2}$ vs $\mathrm{N}_{2}$, Chen et al. [42], indicate that $\mathrm{CO}_{2}$ may affect char combustion under different mechanisms: i) the reduced oxygen mass transfer in $\mathrm{CO}_{2}$; ii) the lower combustion temperature due to the higher heat capacity of $\mathrm{CO}_{2}$; and iii) the char- $\mathrm{CO}_{2}$ gasification reaction. The authors 
also indicate that char oxidation may take place in three different regimes: kinetic-controlled, diffusion-controlled, or kinetics and diffusion controlled.

Based on the oxygen concentrations and nominal temperatures in char oxidation/gasification experiments conducted under air and oxy-fuel conditions, Chen et al. [42] classify the results of different investigations. Figure 3-3 shows this classification and depicts three regions (A, B, and C). Region A is characterized by low temperatures. In region A, the reactions rates are the same in both $\mathrm{O}_{2} / \mathrm{N}_{2}$ and $\mathrm{O}_{2} / \mathrm{CO}_{2}$ conditions. Region $\mathrm{B}$ is characterized by high oxygen levels and high temperatures. In region $\mathrm{B}$, the reaction rates are lower in oxy-fuel conditions. Region $\mathrm{C}$ is characterized by low oxygen level and high temperatures. In region $\mathrm{C}$, reaction rates are higher in oxy-fuel conditions. In Figure 3-3, the error bars are color coded to represent the change in the char consumption rate. The black color represents an unchanged char consumption rate, whereas the blue color represents a decrease, and the red color an increase in the char consumption rate.

Another important effect on char consumption is the influence of gasification reactions on char consumption. Different from char oxidation reactions, char gasification are highly endothermic, thus requiring heat transfer to the particle. An example of a gasification reaction scheme is the one utilized in the multi-surface reaction model of Smith [56]:

$$
\begin{aligned}
& 2 \mathrm{C}(\mathrm{s})+\mathrm{O}_{2} \rightarrow 2 \mathrm{CO} \\
& \mathrm{C}(\mathrm{s})+\mathrm{H}_{2} \mathrm{O} \rightarrow 2 \mathrm{CO} \\
& \mathrm{C}(\mathrm{s})+\mathrm{CO}_{2} \rightarrow 2 \mathrm{CO}
\end{aligned}
$$

Gasification reactions have also much higher apparent activation energies. While the char- $\mathrm{O}_{2}$ reaction activation energy is about $160 \mathrm{~kJ} / \mathrm{mol}$, the activation energies of the char- $\mathrm{CO}_{2}$ are in the 
range of $230-270 \mathrm{~kJ} / \mathrm{mol}$, and for char- $\mathrm{H}_{2} \mathrm{O}$, the activation energies are in the range of 190 to 270 $\mathrm{kJ} / \mathrm{mol}$, [149]. Therefore, gasification reactions only occur at high temperatures.

Based on the experimental work of Kajitani et al. [57], Chen et al. [42] indicate that gasification reactions can only contribute to a higher char consumption rate at high temperatures with low oxygen concentrations in $\mathrm{CO}_{2}$-rich environments (Region $\mathrm{C}$ in Figure 3-3). This means that, as long as the oxygen concentration is high, the contribution of gasification reactions is relatively smaller than that of oxidation reactions ${ }^{12}$.

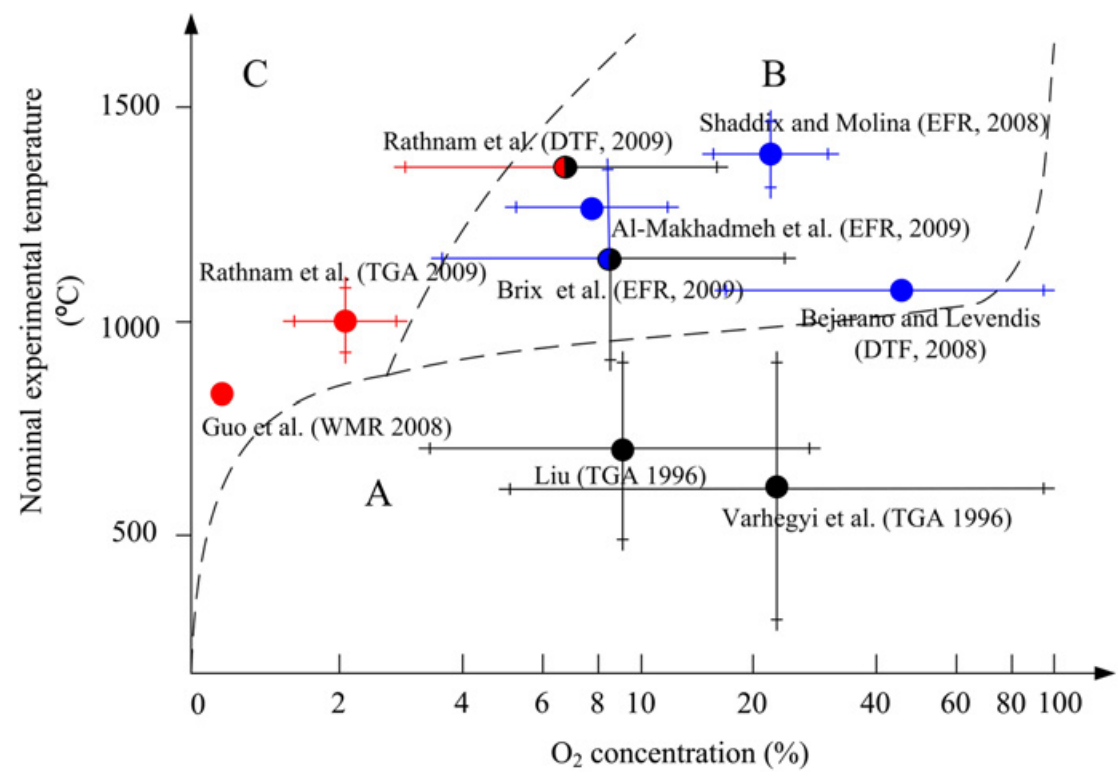

Figure 3-3. Char oxidation/gasification experiments in oxy-fuel conditions (Chen et al. [42])

\footnotetext{
${ }^{12}$ For this reason, gasification reactions are not considered in the char combustion reaction model utilized in this work.
} 


\subsection{CFD Modeling in Oxy-Coal Combustion}

When sub-models are used in connection with Reynolds-Averaged Navier-Stokes (RANS), CFD provides a relatively inexpensive and indispensable tool to perform comprehensive studies on fluid flow, heat transfer, and chemical reactions in combustion [42]. Currently, CFD modeling of oxy-coal combustion is based on approaches and sub-models that are similar to those developed under air-fired conditions.

On the other hand, significant efforts are being made in order to develop and validate new combustion sub-models that consider the differences between oxy-coal and air-coal combustion in the combustion environment. The effects of high temperatures and $\mathrm{CO}_{2}$ concentrations in the particle combustion behavior are particularly important. For instance, it is known that high temperatures can lead to char thermal deactivation during oxy-coal combustion [58]. Furthermore, elevated levels of $\mathrm{CO}_{2}$ may influence char consumption via the reduced diffusivity of oxygen in $\mathrm{CO}_{2}[54,59,60]$.

Previous development of new combustion sub-models is based on those created for the air-fired conditions. Chen et al. [42] offer a review of sub-models implemented for turbulence, radiation heat transfer, char combustion and homogeneous reactions. The authors also include a selection of distinct CFD simulation studies on oxy-coal combustion where different sub-models are applied. Some of those studies are discussed next.

For instance, experiments and CFD simulations were conducted by Chui et al. [61] in the vertical combustor research facility at the Canada Centre for Mineral and Energy Technology (CANMET). The objective of that work was to improve the burner and combustor design in 
order to reduce NOx emissions. CFD proved to be an efficient and cost effective tool for this application. The new burner design showed better flame characteristics and lower NOx and CO emissions. Moreover, the effect of the furnace size in the burner performance could be quantified, and, consequently, it was noted that enlarging the combustor to an inner diameter minimized wall effects. That becomes important when attempting to expand the flame volume so as to improve oxygen management within the flame.

Another example of a CFD application in oxy-coal combustion is presented by Toporov et al. [46]. The work was performed in a $100 \mathrm{~kW}$ pilot-scale furnace at the Institute of Heat and Mass Transfer, RWTH, at Aachen University. In this application, the swirl burner design and operation conditions were established in order to promote flame stabilization through $\mathrm{CO}$ formation, by using $\mathrm{O}_{2} / \mathrm{CO}_{2}$ mixtures with oxygen content similar to that of the air, i.e., $21 \mathrm{vol} \% \mathrm{O}_{2}$. Numerical model results for gas velocities, gas and particle temperatures, and gas compositions showed a good match with experiments.

Al-Abbas et al. [62] used CFD to model the combustion of pulverized dry lignite coal in air and different $\mathrm{O}_{2} / \mathrm{CO}_{2}$ atmospheres. This work was based on the experiments conducted by Hjärtstam et al. [63] at Chalmers University of Technology in a 100kWth down-fired furnace. Three different $\mathrm{O}_{2} / \mathrm{CO}_{2}$ atmospheres were evaluated: 25, 27 and 29 vol\% $\mathrm{O}_{2}$. Temperatures and species concentration profiles showed a good match with the experiments. Results for 25 percent oxygen were closer to air in terms of flame temperature distribution. On the other hand, in the 27 and 29 percent oxygen cases, the flame temperature was higher and more confined in the closest region of the burner exit plane. 
Álvarez et al. [64] performed CFD based simulations of an entrained flow reactor (EFR) under oxy-coal combustion conditions. These simulations were made for different $\mathrm{O}_{2} / \mathrm{CO}_{2}$ atmospheres i.e., 21-35 vol\% $\mathrm{O}_{2}$. The authors used three coals of different volatile matter content. These simulations were validated with experimental results in the EFR, showing a good match. The predictions of the CFD model for temperature profiles, burning rates, burnout and concentration of major species were compared with an air reference case. Their CFD model results showed that lower gas temperatures and burning rate levels observed for the $21 \mathrm{vol} \% \mathrm{O}_{2}$ case were lower than in the air reference case. Their results also showed a decrease in coal burnout when $\mathrm{N}_{2}$ was replaced by $\mathrm{CO}_{2}$ keeping the same oxygen concentration, i.e., 21 vol\% $\mathrm{O}_{2}$, but there was an improvement when the oxygen concentration was higher than $30 \mathrm{vol} \% \mathrm{O}_{2}$.

Chen and Ghoniem [39] conducted a numerical study on oxy-fuel combustion of lignite coal in a $100 \mathrm{~kW}$ test facility, using LES and RANS approaches. The authors evaluated the performance of different turbulence models by comparing their predictions with experimental measurements.

An example of the CFD application to the study of the particle combustion behavior under oxycoal conditions is the work of Singer et al. [58]. CFD simulations were performed to analyze the influence of gasification reactions on char consumption of lignite coal in a pilot-scale oxy-fuel test facility with 29 percent oxygen feed. The authors considered that combusting particles experience time-dependent boundary conditions along their trajectories through different regions of the combustion chamber, i.e., through the pre-flame, flame, and post-flame regions. The 
regions were obtained from CFD simulations and were used to establish representative timedependent boundary conditions, to be applied to single particle sub-models.

Particle trajectories were divided into two different modes according to the regions where char combustion took place. Particles in mode 1 (PM1) combusted in the pre-flame and post-flame regions exposed to relatively high oxygen concentrations and lower temperatures, while particles in mode 2 (PM2) combusted in the flame and post-flame regions exposed to low oxygen concentrations and high temperatures. Singer et al. [58] concluded that the effect of gasification reactions on char conversion for PM1 particles was not significant. However, according to the authors, it can be significant for PM2 particles, depending on the particular char physical and kinetic properties.

The effect of high temperature (up to $1800 \mathrm{~K}$ ) and $\mathrm{CO}_{2}$ dilution (up to 36 percent $\mathrm{O}_{2}$ ) have been analyzed and implemented by Chen and Ghoniem [39] in their simulations It is also known that modifications of the char combustion behavior at high temperatures can influence the prediction of the reactor operation via loss of char reactivity. Moreover, change in the heterogeneous rate of reactions at high temperatures can be significant.

That phenomenon seems to be strongly related to thermally induced modifications of the carbon structure. Different models have been considered to account for that effect and to be implemented into CFD simulations in a practical way. Examples of those models are the CBK model by Hurt et al. [65] and in its subsequent implementations: the CBK-E model by Niksa et al. [66], the CBK-G model by Liu \& Niksa [67] and the model of Senneca \& Salatino [68]. This last model includes the thermal annealing effect, that is, loss of char combustion reactivity and burn off, for temperatures up to $2500 \mathrm{~K}$. 


\subsection{Slagging Modeling in Coal Fired Combustors}

Different CFD models have been used in different works with slagging models in a computational framework; their goal has been to model the slagging process in coal-fired combustors. Most of those works have studied the effect of the slag in the combustor. Particle deposition and the slag characteristics may affect the combustor conditions through modifications of the wall boundary conditions, Wang et al. [15], by changing the transfer through the wall, for instance.

The aforementioned models include sub-models for slag particle capture/rebound and for slag properties. As an example, Seggiani [14] developed a simplified slag model coupled with a CFD gasifier model. This model studied the slag accumulation and flow on the walls. The CFD model provided the inputs for the simplified slag model. The effects of changes in the gasifier operating conditions over the slag behavior were analyzed. For instance, similar effects on the slag thickness were obtained either by increasing the oxygen or by increasing the limestone amount. The transient response in the slag and gas, due to the change in operation conditions, was assessed as well. The model provided solid and liquid slag thicknesses, temperature change across the slag, and heat flux to the wall.

Wang et al. [15] used the same approach as Seggiani, [14], i.e., the combination of the CFD combustion model with a slag model. Wang et al. [15] took into account that particles trapped in the slag possibly contain combustible matter that will continue burning. For this reason, the authors introduced a wall burning model. They indicated that burning particles in the slag increase the deposition rate and, therefore, the slag thickness. Most recently, Yong et al. [16] presented a slag model based on the work of Seggiani [14] and Wang et al. [15]. Coupled 
calculations between the slag model and the CFD reactor model were performed too by Yong et al. [69].

Figure 3-4 depicts the mass and heat transfer to the reactor wall and the particle/slag interaction which is typically assumed in slagging models. Figure 3-5 shows the interaction between the CFD combustor model and the slag model in the computational framework. The CFD combustor model provides the slag model inputs, i.e., particle mass flux, particle temperature, particle velocity. The slag model provides values such as average slag velocity, slag temperature profiles, slag thickness and heat transfer to the coolant. Then, the slag temperature calculated from the slag model is fed back as the boundary condition in the CFD combustor simulation.
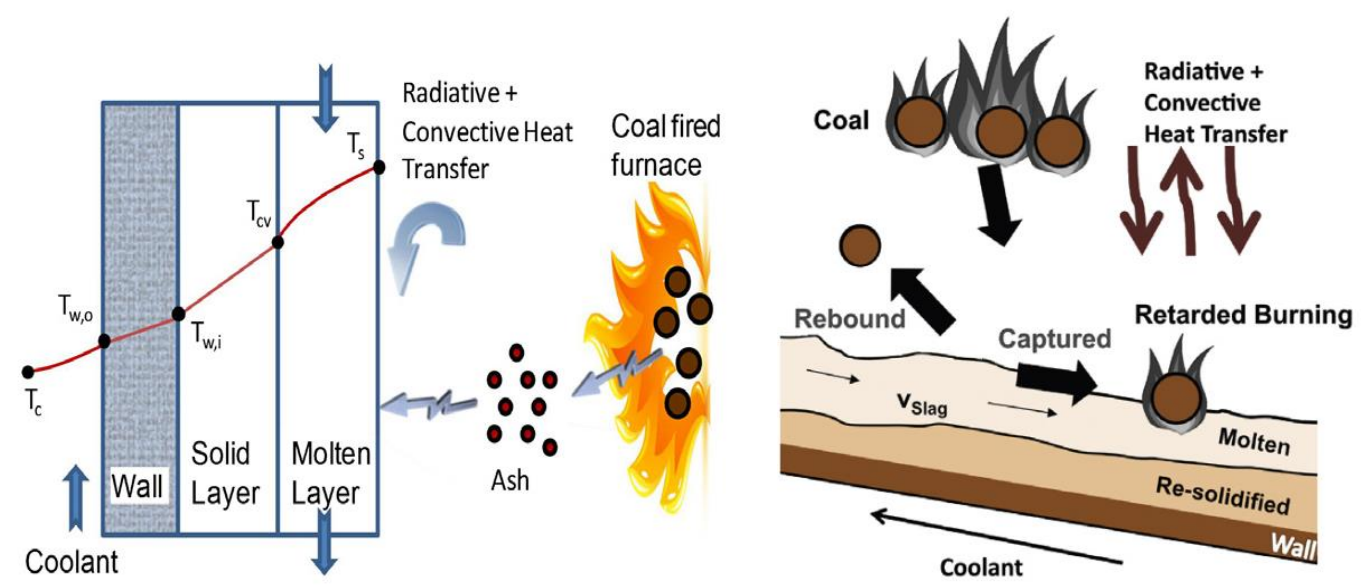

Figure 3-4. (a) Mass and heat transfer to reactor wall. (b) Illustration of particle capture/rebound by the slag layer and wall consumption of trapped particles (Yong et al. [16]). 


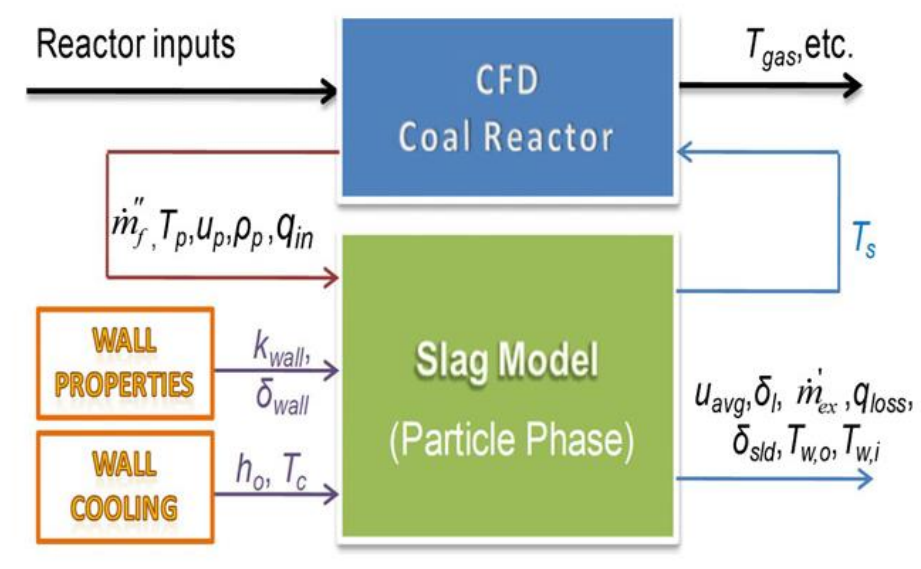

Figure 3-5. Slag model in CFD framework (Yong et al. [69]).

As mentioned before, particle capture/rebound and slag properties modeling are key components in the development of slagging models. Efforts oriented towards the validation and comparison of some of the models previously mentioned have been performed by Ai and Kuhlman [70]. The authors modeled ash deposition experiments conducted by Ichikawa et al. [71]. The experimental setup consisted of a $1 \mathrm{~m}$ height and $60 \mathrm{~mm}$ inner diameter ash-heating tube with a cooled temperature controlled surface for impinging particles. The heating tube was used for simulating a gasifier temperature history with operating temperatures between 1873 and $1573 \mathrm{~K}$.

$\mathrm{Ai}$ and Kuhlman used a commercial CFD code and implemented a user-defined function (UDF) based on the JKR theory [72], the work of Brach and Dunn [73], and Soltani and Ahmadi [74]; their goal was to describe particle sticking/rebounding and particle detachment on the impinged wall surface. This particle sticking/rebounding model is based on a critical particle velocity. Their results for adhesion and rebound of particles showed good agreement with the experiments. Their work was the initial stage of the development and evaluation of a computer 
model to be implemented in a CFD framework to study the effect of slagging and fly ash formation in the coal gasification process.

Additional work of Kuhlman and Ai [75] modeling the same experimental set up as Ichikawa et al. [71] was done to compare two models for prediction of coal ash particle deposition, i.e., the aforementioned model based on a critical velocity and the model of Walsh et al. [76], based on a critical viscosity criteria. When implementing the model of Walsh et al. [76], the model of Browning et al. [77] was used to describe the slag viscosity dependence on temperature and ash composition. The results indicated a better prediction of the experimental results of the model of Brach and Dunn [78], based on a critical velocity criteria, than the prediction of the model of Walsh et al. [76], based on critical viscosity criteria.

Krishnaswamy et al. [79] presented two analytical formulations intended to describe the fluid interactions of slag with the porous refractory linings of gasification reactors. Their first formulation considers the infiltration velocity of slag into the porous of the refractory wall. In this formulation, the capillary pressure was assumed to be the main mechanism driving the infiltration process. Their second formulation describes the thickness of the slag that flows down along the wall. In their second formulation, the slag thickness was approximated by equating the rate of slag production of the gasifier to the integration of the velocity profile with respect to the cross-sectional area of the film. The two aforementioned formulations permitted to visualize that the infiltration velocity and the slag thickness are sensitive to the slag viscosity. The authors applied their slag thickness model to predict the film thickness in a generic slagging gasifier under two different conditions. The first condition considered a constant slag volumetric flow 
rate down the gasifier wall. The second condition considered a constant fly ash flux distributed uniformly along the wall of the gasifier.

\subsection{Estimation of Slag Properties}

Different models are described in the literature for predicting the properties of slags. Mills [80] presents a detailed review of these models. These models can be classified into the following groups: i) numerical fits, ii) neural network models, iii) partial molar models, iv) models based on structural parameters, v) thermodynamic models and vi) molecular dynamics models. Mills [80] also provides a summary of each of these models as well as references to their development and application.

One of the reasons behind such a variety of models is the difficulty to find a single model suitable for many different types of slags. This is due mainly to the great variety of slag compositions that can be found in different applications. For instance, metallurgical slags are mainly based on the $\mathrm{CaO}-\mathrm{Al}_{2} \mathrm{O}_{3}-\mathrm{SiO}_{2}$ system; non-ferrous slags are frequently based on fayalite $\left(\mathrm{Fe}_{2} \mathrm{SiO}_{4}\right)$; coal slags are mainly composed of $\mathrm{CaO}+\mathrm{Al}_{2} \mathrm{O}_{3}+\mathrm{SiO}_{2}{ }^{13} ; \mathrm{ESR}^{14}$-slags are made of oxides and significant amounts of fluorides e.g., $\mathrm{CaF}_{2}+\mathrm{CaO}+\mathrm{Al}_{2} \mathrm{O} 3$; glasses tend to have high $\mathrm{SiO}_{2}$ contents; enamels contain significant amounts of $\mathrm{B}_{2} \mathrm{O}_{3}$ [80]. For the particular case of coal slags, it is well known that their chemical composition varies greatly between mining regions and, consequently, the properties of the slags also vary to a large extent.

\footnotetext{
${ }^{13}$ In addition to the main components, elements such as: $\mathrm{Fe}_{2} \mathrm{O}_{3}, \mathrm{TiO}_{2}, \mathrm{P}_{2} \mathrm{O}_{5}, \mathrm{MgO}, \mathrm{Na}_{2} \mathrm{O}, \mathrm{K}_{2} \mathrm{O}$ and $\mathrm{SO}_{3}$ are also part of the coal slag composition.

${ }^{14}$ Electro-Slag Re-Melting
} 
Another complication is the fact that these models rely on experimental measurements which are difficult to collect in most of the cases, mainly due to the high temperatures involved. Furthermore, predictive equations are based on ash analysis, but significant losses of some elements may occur as the ash is heated to the melting temperature. For example, tests results reported by Streeter et al. [81] for 18 out of 24 viscosity tests for low-rank coal showed that 80 to 100 percent of the $\mathrm{SO}_{3}$, if present, and all the $\mathrm{P}_{2} \mathrm{O}_{5}$, were volatilized during melting of the ash. Although these are minor slag components, the amount of some other components such as $\mathrm{Na}_{2} \mathrm{O}$ can be significant in some coal ashes.

Streeter et al. [81] also reported that $\mathrm{Na}_{2} \mathrm{O}$ was devolatilized in amounts ranging from 10 to 50 percent in 11 out of 15 instances in which $\mathrm{Na}_{2} \mathrm{O}$ was present. Additionally, reactions with the sample crucible may result in depletion or enrichment of some components; for instance, $\mathrm{Fe}_{2} \mathrm{O}_{3}$ resulted in depletion for carbon-crucible tests and depletion or enrichment for alumina crucible tests in the experiments performed by Streeter et al. [81].

Beyond all these complications, most of the models aimed at predicting the properties of slags have shown to provide satisfactory results, particularly for slag coal related processes $[14,15,69,75]$. In order to obtain valid predictions from the slag flow model developed in this study, it is necessary to estimate the fluid flow and thermal properties of the slag, e.g., viscosity, temperature of critical viscosity, density, heat capacity, thermal conductivity, and emissivity of the slag.

From all the fluid flow and thermal properties of the slag, viscosity is perhaps the property most related to the control and design of the process. For a Newtonian fluid, the viscosity dependence on temperature is exponential, or equivalently, the logarithm of viscosity shows linear 
temperature dependence. Slag cooling experiments ${ }^{15}$ have shown that the logarithm of viscosity vs. temperature curve exhibits a linear dependence down to some point, which is designated as the temperature of critical viscosity. At this point, the viscosity starts to increase abruptly as the temperature decreases. This effect is suspected to be related to the start of precipitation of solid crystalline phases in the slag [81].

Traditionally, the straight-line portion of the logarithm of viscosity vs. temperature curve in a slag system is designated 'Newtonian region' of slag behavior, whereas the region below the temperature of critical viscosity is designated 'plastic region'. Nonetheless, the slag can retain Newtonian properties below the temperature of critical viscosity [81]. It is also possible to find non-Newtonian behavior below the temperature of critical viscosity; thus, pseudoplastic and thixotropic behavior was found at the higher viscosities in almost all the slags studied by Streeter et al. [81].

Different authors have performed experimental measurements of the temperature of critical viscosity and have developed models to predict its value. Most of the models are based on empirical correlations that relate the temperature of critical viscosity to composition or, in the case of coal, on characteristic temperature values of the ASTM ash fusion test ${ }^{16}$. A detailed review of different models for prediction of the critical viscosity temperature can be found in Vargas et al. [82].

\footnotetext{
${ }^{15}$ For instance, those performed by Streeter et al. [81]

${ }^{16}$ ASTM standard D 1857-87.
} 
In molten slag, viscosity is influenced primarily by temperature, composition and the structure of the slag, i.e., the degree of polymerization or de-polymerization of slag. In a simplified manner, it can be stated that elements such as $\mathrm{SiO}_{2}$ and $\mathrm{Al}_{2} \mathrm{O}_{3}$, known as network-formers, increase the polymerization degree which brings about and increase in viscosity. On the other hand, elements such as $\mathrm{Na}_{2} \mathrm{O}, \mathrm{Li}_{2} \mathrm{O}, \mathrm{CaO}, \mathrm{MgO}, \mathrm{K}_{2} \mathrm{O}, \mathrm{SrO}$ and $\mathrm{BaO}$, known as network - breakers, decrease the degree of polymerization ${ }^{17}$, which brings about a decrease in viscosity.

All the models that have been proposed to estimate the viscosity of the slags account for the structure in some manner. Mills [80] includes a summary and classification of these models, also pointing out their uncertainties in predicting the viscosity of different slag systems. Most of the popular viscosity models are expressed in terms of Arrhenius-type or Weymann-type equations that take into account the effects of temperature, composition and structure. The parameters in these models are calculated by curve fitting experimental viscosity measurements. These models provide predictions within a 30 percent error, similarly than in experimental uncertainties in the measurements of slag viscosities $[83,80]$. Some selected models will be discussed below due to their applicability in coal slag systems as well as their convenience regarding their application to the development of CFD based slag flow models.

A popular viscosity model is, for instance, the model of Urbain et al. [84], which was developed for metallurgical slags by fitting experimental data from the $\mathrm{SiO}_{2}-\mathrm{Al}_{2} \mathrm{O}_{3}-\mathrm{CaO}-\mathrm{MgO}$ system. Although, the Urbain model was developed for metallurgical slags, it has been commonly

\footnotetext{
${ }^{17}$ The reader is referred to Mills [80] and Senior and Srinivasachar [139] for a complete discussion on the slag structure and its effect on the slag properties.
} 
employed to estimate the viscosity of lignite slags, since the main constituents for metallurgical and lignite slags are the same.

Further modifications to the Urbain model have been developed to account for the effect of composition on the viscosity of the slag. For instance, Schobert [85] applied the Urbain model to lignite ash and derived different formulas according to the relative amount of silica in the slag, i.e., the slag was classified as high, medium or low silica. He included the effect of what Urbain categorized as the constituents of silicate melts, i.e., glass-formers $\left(\mathrm{SiO}_{2}\right.$ and $\left.\mathrm{P}_{2} \mathrm{O}_{5}\right)$, modifiers $\left(\mathrm{CaO}, \mathrm{MgO}, \mathrm{Na}_{2} \mathrm{O}\right.$, and $\left.\mathrm{K}_{2} \mathrm{O}\right)$ and amphoterics $\left(\mathrm{Al}_{2} \mathrm{O}_{3}\right.$ and $\mathrm{Fe}_{2} \mathrm{O}_{3}$ ), which can act as glassformers or modifiers. The effect of these elements was included by developing correlations; specifically, concluding that for high-silica slags the silica content of the slags is the dominating factor, whereas for low-silica slags the correlation term is the ratio of $\mathrm{CaO}$ to modifiers ${ }^{18}$.

Kalmanovitch and Frank [86] modified the model of Urbain to extend the range of composition. Unlike Schobert [85], they developed a single correlation that includes most of the major components of the slag, with exception of $\mathrm{SO}_{3}$. Another characteristic of this model is that all the forms of iron oxide are treated as FeO.

Browning et al. [77] developed a viscosity model by following a different procedure than the one used in the Urbain family models. Based on the observation of Nicholls and Reid [87], they assumed that the viscosity-temperature gradient profile for all coal ash slags within the Newtonian region must be consistent. Therefore, all the viscosity-temperature curves should

\footnotetext{
${ }^{18}$ In a simplified manner, viscosity increases with the amount of $\mathrm{SiO}_{2}$ (glass former) and tends to decrease with the amount of $\mathrm{CaO}$ (modifier) present in the slag.
} 
overlay if they are shifted along the temperature axis by some quantity. By selecting a standard curve and using least squares regression, they developed a single expression that relates the temperature shift with a parameter based on the molar ratio of network-formers and networkmodifiers. More particularly, the parameter is based on the ratio of former and fluxing ions. The model provided satisfactory results for British coal ash slags.

Two useful empirical models were developed during the 1960s at the British Coal Utilization Research Association (BCURA), namely, the $\mathrm{S}^{2}$ model ${ }^{19}$ [88] and the Watt-Fereday model [89]. These models are based on regression analysis of viscosity-temperature curves for British bituminous coals. The BCURA $S^{2}$ model utilizes an Arrhenius-type equation that relates the viscosity to temperature and to a single parameter called the silica ratio. The silica ratio is defined as the relation between the mass fraction of $\mathrm{SiO}_{2}$ to the total mass fraction of $\mathrm{SiO}_{2}$, $\mathrm{Fe}_{2} \mathrm{O}_{3}, \mathrm{CaO}$ and $\mathrm{MgO}$. The Watt-Fereday model is based on a linear equation that relates the logarithm of the viscosity to a single function of temperature. In this equation, the values of the slope and intercept are calculated based on the normalized weight percentages of $\mathrm{SiO}_{2}, \mathrm{Fe}_{2} \mathrm{O}_{3}$, $\mathrm{CaO}$ and $\mathrm{MgO}$.

Different researchers have completed studies to compare the predictions of the aforementioned viscosity models. As an example, Streeter et al. [81] conducted experimental viscosity tests and compared the predictions of different slag models. They selected 17 low-rank coal samples, ranging from lignite to bituminous, from different locations in the U.S., mostly in the western U.S., namely, North Dakota, Montana, Wyoming, Texas and Alabama. Some of the tested

\footnotetext{
${ }^{19}$ Commonly known as the BCURA $S^{2}$ model.
} 
models were: the aforementioned model of Urbain [84], the model of Schobert [85], the BCURA $S^{2}$ [88], and the Watt-Fereday model [89]. Their results indicate that, although the predictions for these models are satisfactory in most cases, different models perform better than others for certain types of coal slags. For instance, it was reported that the conventional Urbain model [84] provided a reasonable good fit for two thirds of the viscosity tests.

Laumb [90] compared the predictions of seven viscosity models against measured viscosities for slag produced from 19 ash samples of lignite and one cyclone slag. The author concluded that, although the broad range of composition found in lignite coals makes the prediction of slag a challenging task, many of the models provide satisfactory results for specific compositions. For instance, Laumb reported that the model of Kalmanovitch and Frank [86] worked the best for lignite slags containing high mounts of $\mathrm{SiO}_{2}$ and lower amounts of $\mathrm{Fe}$.

The work of Fernades et al. [91] is another good and comprehensive example of evaluation of different slag viscosity models. The authors tested the model of Urbain [84], the model of Kalmanovitch and Frank [86], the aforementioned model of Browning et al. [77], and the BCURA $S^{2}$ model [81]. These models were tested in a Pittsburgh No. 8 coal for different densities and particle sizes. Results indicated a high potential for the BCURA $S^{2}$ as a prediction tool.

Concerning the estimation of density, several models aimed at predicting its value for molten slags have been developed. Mills and Keene [92] proposed which is probably the most practical approach. In this model, the density of the molten slag is calculated according to an empirical expression that considers a correction from a constant value. The correction is expressed in terms of the weight percentages of $\mathrm{FeO}, \mathrm{Fe}_{2} \mathrm{O}_{3}$, and $\mathrm{MnO}$. According to Mills and Rhine [93], this 
model allows estimating density values of slag systems with a relative small error, e.g., within a five percent error for slag temperatures close to $1673 \mathrm{~K}$ [92].

Mills [80], points out that, since the density of liquid slags do not depend significantly on the structure, it is possible to obtain reasonably accurate density values using simple expressions; specifically, expressions involving molar weighted averages of the molar volume for every particular constituent present in the slag, even if the molar volume of every constituent in the solution is assumed to be the molar volume of the pure component. Examples of these type of density models were developed by Bottinga and Weill [94], Nelson and Carmichael [95] and Mo et al. [96]. More refined models that include the effect of the structure of the slag on the density can be found, for instance, in the works of Bottinga et al. [97] and Mills [83].

Mills [93] shows that the structure of the solid formed during the solidification of the slag depends on the cooling rate, which means that a very small cooling rate will result in the formation of a crystalline slag, whereas a rapid quench will produce a glass. Mills shows the relationship between the enthalpy change and temperature for these two conditions. The curve for the glassy phase of the slag is made of the glass phase, for temperatures between the ambient temperature and the glass-transition temperature, which is around $900 \mathrm{~K}$; the supercooled liquid, for temperatures between the glass-transition temperature ${ }^{20}$ and the liquid temperature, close to $1600 \mathrm{~K}$; the liquid phase, for temperatures above the liquid temperature. The curve for the crystalline phase ranges from the standard temperature up to the liquid temperature.

\footnotetext{
${ }^{20}$ At this temperature, the curve of heat capacity vs. temperature for the glassy slag shows a sharp increase, similar to a step.
} 
Both the curve for the enthalpy and the curve for the temperature of the glassy and crystalline slags show an approximately linear relation with similar slopes. The linear relation is stronger in the liquid region, which results in the usual assumption that the heat capacity is completely independent from temperature. The similarity of the slopes suggests that the heat capacity does not strongly depend on the structure of the slag, as indicated by Mills [80]. It also indicates that the value of the heat capacity for a sample in a laboratory or industrial process depends on the amount of crystallization, and thus lies between the values provided by the two curves.

Mills [93] also provides a method to estimate the constant value of the heat capacity as a function of temperature and the composition of the slag. He points out that the heat capacity can be estimated by using the partial molar heat capacities of the slag constituents. In the liquid region, the heat capacities of the slag constituents are considered independent from temperature, whereas for the crystal and glass phases, the temperature dependence of the slag constituents is taken into account by a second order polynomial relation. This method provided heat capacity values within two percent of the experimental measurements.

The work by Mills and Rhine [98] supported the observations made by Mills [93] for the heat capacity of the slags. They conducted measurements of the thermal properties of coal slags formed in a British gasifier. Slags of crystalline and glassy structures were obtained and the curves for enthalpy vs. temperature and heat capacity vs. temperature were obtained. Results for the heat capacities of the glassy and liquid slag samples were also reported.

Much work has been done in the area of thermal conductivity. Mills [80] offers a review of that previous work and includes several references. For instance, in the study conducted by Nishioka et al. [99], the thermal conductivity of $\mathrm{CaO}-\mathrm{SiO}_{2}-\mathrm{Al}_{2} \mathrm{O}_{3}$ slags in the glassy and crystalline states 
is measured. In this work, it was found that the thermal conductivity of the crystalline state is about 1.5 to 2.5 times larger than the thermal conductivity of the glassy state. According to the authors, this can be explained by the higher packing density of the crystalline state.

Mills and Rhine [98] also measured the thermal conductivity. The authors point out that the thermal conduction of a semi-transparent media such as slags is made of the contributions of the thermal conductivity ${ }^{21}$, the radiation conductivity, and the electronic conductivity. They also discuss experimental difficulties associated with separating each contribution, being more convenient to combine all of them in terms of an effective conductivity. Another important observation made by the authors is the convenience of obtaining the thermal conductivity using measurements of the effective thermal diffusivity.

Perhaps the most important fact about the thermal conductivity of the slag is that it strongly depends on structure. For instance, as is shown by Mills [80], it has been observed that the thermal conductivity of the slags increases with an increase in the $\mathrm{SiO}_{2}$ content or, equivalently, with the degree of polymerization. Mills [80] considers that this is due to the fact that the resistance to phonon transportation is much smaller when passing along the chain than the resistance of moving phonons from chain to chain. He also explains that, since the thermal conductivity increases with the polymerization degree, it can be expressed as a function of the viscosity $^{22}$. Mills additionally mentions that the variation of the thermal conductivity with temperature can be well represented with similar functions as those for viscosity. Examples of these relations are found in Mills [80] and Hayashi et al. [100].

\footnotetext{
${ }^{21}$ Which involves the movement of phonons and it is usually referred to as 'phonon conduction'.

${ }^{22}$ See also Hayashi et al. [100]
} 
Discussion and references to additional slag properties such as surface tension, electrical conductivity, absorption coefficient, and emissivity of the slag are thoroughly described in Mills [80,83], and Mills and Rhine [98].

\section{7. $\mathrm{CaC}_{2}$ : Reaction Kinetics and Behavior}

The reaction stoichiometry for the formation of $\mathrm{CaC}_{2}$ from carbon and $\mathrm{CaO}$ is governed by the following global reaction $(3 / 1 \mathrm{C}$ to $\mathrm{CaO})$ :

$$
3 \mathrm{C}_{(\mathrm{s})}+\mathrm{CaO}_{(\mathrm{s})} \rightarrow \mathrm{CaC}_{2(\mathrm{~s})}+\mathrm{CO}_{(\mathrm{g})}
$$

The complete mechanism is still being researched but several authors have attempted to develop different reaction mechanisms and descriptions of the kinetic behavior. For instance, Tagawa and Sugawara [101] conducted experiments using thermo-gravimetric analysis to study the carbonization process of $\mathrm{CaO}$ in a solid-solid reaction, at temperatures between 1600 and 1800 ${ }^{\circ} \mathrm{C}$. The kinetics of the $\mathrm{CaC}_{2}$ formation was examined using a thermobalance at various carbon monoxide pressures, specifically, 50, 100 and $200 \mathrm{mmHg}$. The authors reported that the reaction rate curves show a parabolic behavior and that the process may be governed by the diffusion of carbon into $\mathrm{CaO}$ and vice versa, as well as by the diffusion of carbon monoxide through the product layer.

Brookes et al. [102] developed a model for the formation of $\mathrm{CaC}_{2}$ in solid pellets of $2.22 \mathrm{~cm}$ diameter, using 3/1 mixtures of carbon and $\mathrm{CaO}$ between 1650 and $1720{ }^{\circ} \mathrm{C}$ and $50 \mathrm{mmHg}$. They 
assumed that the heat transfer across a growing product layer controls the rate of movement of a reaction front through the solid pellet.

Müller completed a detailed study of the properties and reactions of $\mathrm{CaO}$ in burnt lime, including the diffusion of carbon into solid lime, as well as he included composite reactions of $\mathrm{CaO}$ and $\mathrm{C}$ in solid and liquid states [103,104,105].

El-Naas studied the kinetics using fine graphite and $\mathrm{CaO}$ powder $(<170 \mu \mathrm{m})$ in a semi-batch spout-fluid bed reactor with a DC plasma torch. The author suggested that chemical reaction is the controlling step with an apparent activation energy of $377 \mathrm{~kJ}$ mol-1. $[33,106]$.

Experiments conducted by $\mathrm{Li}$ et al. [107] using thermal gravimetric analysis (TGA) and mass spectrometry (MS) techniques addressed the reaction mechanisms of coke and $\mathrm{CaO}$ for $\mathrm{CaC}_{2}$ production. Their results indicated that reaction of carbon with $\mathrm{CaO}$ has three stages. The first stage is the direct reaction of coke and lime to form $\mathrm{CaC}_{2}$, reaction (6), starting at $1460{ }^{\circ} \mathrm{C}$. The second stage is the reaction of $\mathrm{CaC}_{2}$ with $\mathrm{CaO}$, reaction (7), starting at $1520^{\circ} \mathrm{C}$, observable only at the complete consumption of carbon. The third stage is the decomposition of $\mathrm{CaC}_{2}$ into calcium and carbon, reaction (8), controlled by surface evaporation of Ca. The authors also propose a reaction behavior in the surface of coke and $\mathrm{CaO}$ particles which includes the three stages and the formation of the eutectic $\mathrm{CaC}_{2}-\mathrm{CaO}$. Finally, $\mathrm{Li}$ et al. [107] discuss the effect of different $\mathrm{C} / \mathrm{CaO}$ feed ratios in the reaction behavior. They point out that, for instance, for a ratio of 3.6, the second stage disappears. 


$$
\begin{aligned}
& \mathrm{CaC}_{2(\mathrm{~s})}+2 \mathrm{CaO}_{(\mathrm{s})} \rightarrow 3 \mathrm{Ca}_{(\mathrm{g})}+2 \mathrm{CO}_{(\mathrm{s})} \\
& \mathrm{CaC}_{2(\mathrm{~s})} \rightarrow \mathrm{Ca}_{(\mathrm{g})}+2 \mathrm{C}_{(\mathrm{s})}
\end{aligned}
$$

Additional work presented by $\mathrm{Li}$ et al. [27] focuses on the kinetic behavior of $\mathrm{CaC}_{2}$ production derived from coke and $\mathrm{CaO}$, including the effect of coke properties, such as crystalline structure and specific surface area, on the initial reaction temperature for $\mathrm{CaC}_{2}$ production. The authors report a linear decrease in the dependence of the initial temperature with an increasing number of contact points between coke and $\mathrm{CaO}$ particles until the particle size is $0.06 \mathrm{~mm}$, which corresponds to an initial temperature of $1440{ }^{\circ} \mathrm{C}$. Furthermore, that mass transfer direction is mainly from $\mathrm{CaO}$ to coke, which suggests that a reduction in the coke particle size is more effective than a reduction in the $\mathrm{CaO}$ particle size when looking for a reduction of the initial reaction temperature.

Li et al. also suggest that the reaction proceeds in different ways for two different temperature ranges, i.e., $\left[1550\right.$ to $\left.1700{ }^{\circ} \mathrm{C}\right]$ and $\left[1700\right.$ to $\left.1750{ }^{\circ} \mathrm{C}\right]$, where the mass transfer of solid $\mathrm{CaO}$ toward solid coke is the rate-limiting step. There is an apparent activation energy of $456 \mathrm{~kJ} / \mathrm{mole}$ in the first range and mass transfer of liquid $\mathrm{CaO}$ in the form of $\mathrm{CaC}_{2}-\mathrm{CaO}$ eutectics toward the solid coke in the second range, with a reduced apparent activation energy of $256 \mathrm{~kJ} / \mathrm{mole}$. The presence of the eutectic $\mathrm{CaC}_{2}-\mathrm{CaO}$ at $1700{ }^{\circ} \mathrm{C}$ was not proved but is supported by comparing the effect of a reduced activation energy found in similar systems and performing experiments where the reaction of large granular reactants was promoted by doping of fine reactants. These results 
provide useful information for reactor design, especially concerning particle size and temperature ranges.

\section{8. $\mathrm{CaC}_{2}$ : Kinetic Reaction Rate Models}

A complete review of the kinetic reaction rate models is presented by Rowan et al. [108]. In their review, four previous reaction rate models for calcium carbide formation are explained. They also present an evaluation of these previous models and compare them with their proposed models, namely, their progress variable model (PVM) and their multistep reaction model (MRM).

From the four existing kinetic rate models for the formation of calcium carbide, the first three were predicted by considering the idea of a contracting reaction front that travels through the reacting solid whereas the fourth model was that of two reacting solids. This fourth model is based on three-dimensional diffusion of the solids. All these models are described in this section. They are also presented in greater detail by House [109]. Rowan et al. [108] also presents the comparison of these models with experimental data presented by Mu and Hard [34].

The first kinetic model for the formation of calcium carbide is based on a spherical geometry. In this model, the reaction front progresses from the surface to the center of the sphere and only along the radial direction. This model is known as the 1-D contraction model and is given by the expression:

$$
1-\left(1-\alpha_{r}\right)^{2 / 3}=k_{r} t
$$

in this expression, $k_{r}$ is the reaction rate, $\mathrm{t}$ is time and $\alpha_{r}$ is the extent of reaction. In the case of $\mathrm{CaC}_{2}$ formation the extent of reaction represents the fraction of $\mathrm{CaO}$ that is converted into $\mathrm{CaC}_{2}$. 
The second model is based on a long cylindrical solid geometry. In this model, it is assumed that the reaction does not take place on the small end surfaces but only on the long curved surfaces. Additionally, it is assumed that the reaction front progresses uniformly along the radial coordinate towards the axis of the cylinder. This model is also known as the contracting area model and is given by the following expression:

$$
1-\left(1-\alpha_{r}\right)^{1 / 2}=k_{r} t
$$

The third model is known as the contracting volume model. This model considers a more general case of a noncylindrical, nonspherical solid in which the reaction begins at each face of the solid surface and proceeds inward. This model is given by

$$
1-\left(1-\alpha_{r}\right)^{1 / 3}=k_{r} t
$$

The fourth and final existing reaction rate model is known as the two reacting solids model. This model is based upon the three-dimensional diffusion rate law. This model is typically used in cases where different solid particles are brought into contact with one another and heated in order to bring about a chemical reaction. This model is given by:

$$
1-\left(1-\alpha_{r}\right)^{1 / 3}=k_{r} t
$$


The two reacting solids model has been the typical approach to describe the kinetics of calcium carbide formation. In this model, Tagawa and Sugawara [101] assumed that $k_{r}$ can be expressed as an Arhennius rate expression having the following equation:

$$
k_{r}=A \cdot \exp \left(-E_{a} / R T\right)
$$

where $\mathrm{A}$ is a pre-exponential factor, $\mathrm{Ea}$ is the activation energy of the reaction, $\mathrm{R}$ is the universal gas constant, and $\mathrm{T}$ is the temperature at which the reaction is taking place. The values for the pre-exponential factor and the activation energy are provided by Rowan et al. [108]. However, it is important to mention that the Arhennius rate expression is not commonly used to describe solid-solid reactions. Therefore, the value of $k_{r}$ should be interpreted carefully.

From the previous four models, the two reacting solids model is the one that most accurately predicts the time-based reduction of $\mathrm{CaO}$ into $\mathrm{CaC}_{2}$. Nonetheless, as pointed out by Rowan et al. [108], all the previous four models suffer from the same limitation in that they only allow for the reaction to proceed in a single direction, thus not allowing for reverse reactions to occur.

Rowan et al. [108] developed two new models for the reaction kinetics of $\mathrm{CaC}_{2}$ from coalderived coke and $\mathrm{CaO}$ that overcome the limitation of not allowing for reverse reactions to occur. The first of these new models is referred to as the progress variable model (PVM). The PVM utilizes equilibrium mass fraction data to determine the direction in which the reaction must proceed in order to reach a state of chemical equilibrium. The second model, known as the 
multistep reaction model (MRM), entails modeling the kinetic rates of the $\mathrm{CaC}_{2}$ formation and disassociation reactions.

In the progress variable model a progress variable is introduced for each of the chemical species included in the reaction. Each progress variable is defined as the ratio of the current specie mass fraction over the specie mass fraction in equilibrium conditions. Rowan et al. [108] developed this model based on the global reaction for calcium carbide, i.e., equation 6 . In this formulation, the four progress variables can be expressed as:

$$
\begin{aligned}
& X_{C(s)}=\frac{m_{C(s)}}{m^{i n i} C(s)}, \quad X_{C a O(s)}=\frac{m_{C a O(s)}}{m^{i n i} C a O(s)} \\
& X_{\mathrm{CaC}_{2}(s)}=\frac{m_{\mathrm{CaC}_{2}(s)}}{m^{\text {theor }} \mathrm{CaC}_{2}(s)}, \quad X_{C O(g)}=\frac{m_{\mathrm{CO}(g)}}{m^{\text {theor }} \mathrm{CO}(\mathrm{g})}
\end{aligned}
$$

where $m_{i}$ and $m_{i}^{i n i}$ are the current and initial mass fractions of the $i^{\text {th }}$ chemical species; and $m_{i}^{\text {theor }}$ is the theoretical production or consumption of the species $i$, as determined from the chemical equilibrium conditions for a given reaction temperature. The progress variables lead to a system of equations that, for example, for $\mathrm{CaO}$ have the following form:

$$
\frac{d X_{C a O(s)}}{d t}=-k_{f, 1}^{e f f} X_{C(s)} X_{C a O(s)}+k_{r, 1}^{e f f} X_{C a C 2(s)} X_{C O(g)}
$$


where $k_{f, 1}^{e f f}$ and $k_{r, 1}^{e f f}$ are the effective chemical reaction rates in the forward and reverse directions. Rowan et al. [108] solved this system of equations by utilizing a second order Runge-Kutta Method. In this model, the condition of chemical equilibrium is attained when the values of these progress variables approach a value of 1.0. This allows the reaction to proceed toward equilibrium in either the forward or reverse directions.

In the MRM model, the formation of calcium carbide and its subsequent disassociation into solid carbon and gaseous calcium (equations 6 and 7) are combined into a single differential equation of the form:

$$
\frac{d n_{i}}{d t}=v(i, 1)\left(k_{f 1} n_{C} n_{C a O}-k_{r 1} n_{C a C 2} n_{C O}\right)+v(i, 2)\left(k_{f 2} n_{C a C 2}-k_{r 2} n_{C} n_{C a}\right)
$$

In this expression $n$ denotes the number of moles of the $i^{\text {th }}$ species, the forward and reverse reaction rates are $\mathrm{k}_{\mathrm{f} 1}, \mathrm{k}_{\mathrm{r} 1}, \mathrm{k}_{\mathrm{f} 2}$ and $\mathrm{k}_{\mathrm{r} 2}$, and $\mathrm{v}(\mathrm{i})$ 's are the stoichiometric coefficients. Rowan et al. [108] also solved this equation by using a second order Runge-Kutta method. In their solution process the number of moles of each species present is updated at each time step. This allows the prediction of the instantaneous number of moles of each species present as a function of time. They also assumed that weight loss is caused by the release of gaseous calcium and carbon monoxide. This fact enables the prediction of weight loss as a function of time. 


\section{Chapter 4 - Description of the System}

Different designs of oxy-coal reactor are being developed by CERC-ACTC in the U.S. and China. Those designs can be divided into two main categories according to their configuration: down-fired and horizontal.

The down-fired design is being developed at West Virginia University. This design has being named 'very high temperature entrained flow reactor' (VHTER). The horizontal design is being developed by LP Amina. Due to the disclosure agreement between LP Amina and West Virginia University, the results for the horizontal reactor will not be included in this document, although general description of the reactor is provided in section 4.2.

\subsection{Down-Fired Reactor (VHTER)}

The main design characteristics of this type of reactor are shown in Figure 4-1. The reactor is divided into several sections, each of which has several insulation layers and ports. The modular design allows the replacement of reactor lining section with significant erosion and/or thermal damage. The combustion chamber diameter is $150 \mathrm{~mm}$, and the burner is composed of two concentric ports. The first port is for injection of pulverized coal by means of oxidant gas as carrier. The main amount of oxidant is injected through a second port, which is swirled with a fin angle of $45^{\circ}$ in order to provide a swirling flame stabilization mechanism. The burner is designed 
with a divergent zone and a step at the entrance of the combustion chamber diameter in order to enhance the recirculation of hot gases and further increase the flame stabilization ${ }^{23}$ (Figure 4-2).

For injection of the chemical reactants, i.e., $\mathrm{CaO}$ and char, two tangential ports are provided. The tangential oxidant injection improves the flame stability via an increased swirl flow condition; it also increases the particle residence time, as well as forces the reactants to reach the wall, increasing their deposition rate in the initial section of the combustion chamber, which is desirable for slag formation.

The collection of the molten slag containing chemical products, i.e., $\mathrm{CaC}_{2}$ and unreacted lime and char, is achieved by means of an ash collection system located at the bottom of the combustion chamber. Currently, this design has been created to be used in a batch reactor mode, and requires periodic changes of ash collector systems. The ash collector stores the liquid slag, where some chemical reactions for $\mathrm{CaC}_{2}$ formation may be still taking place. Furthermore, the ash collector has a flue gas cleaning role, since it traps most of the fly ash. The refractory wall of the ash collector is cooled down by a water jacket. This reactor design is intended to be a simple alternative regarding maintenance and operation.

23 The design of the combustion chamber is based on the furnace described in Nikzat et al. [136] for the reactor of the Aichi Science and Technology Foundation, Cooperation Research Center for Advanced Technology, Nagoya, Japan. The burner design is based on the one described in Costa et al. [138] for the reactor facility at the Imperial College, London. 

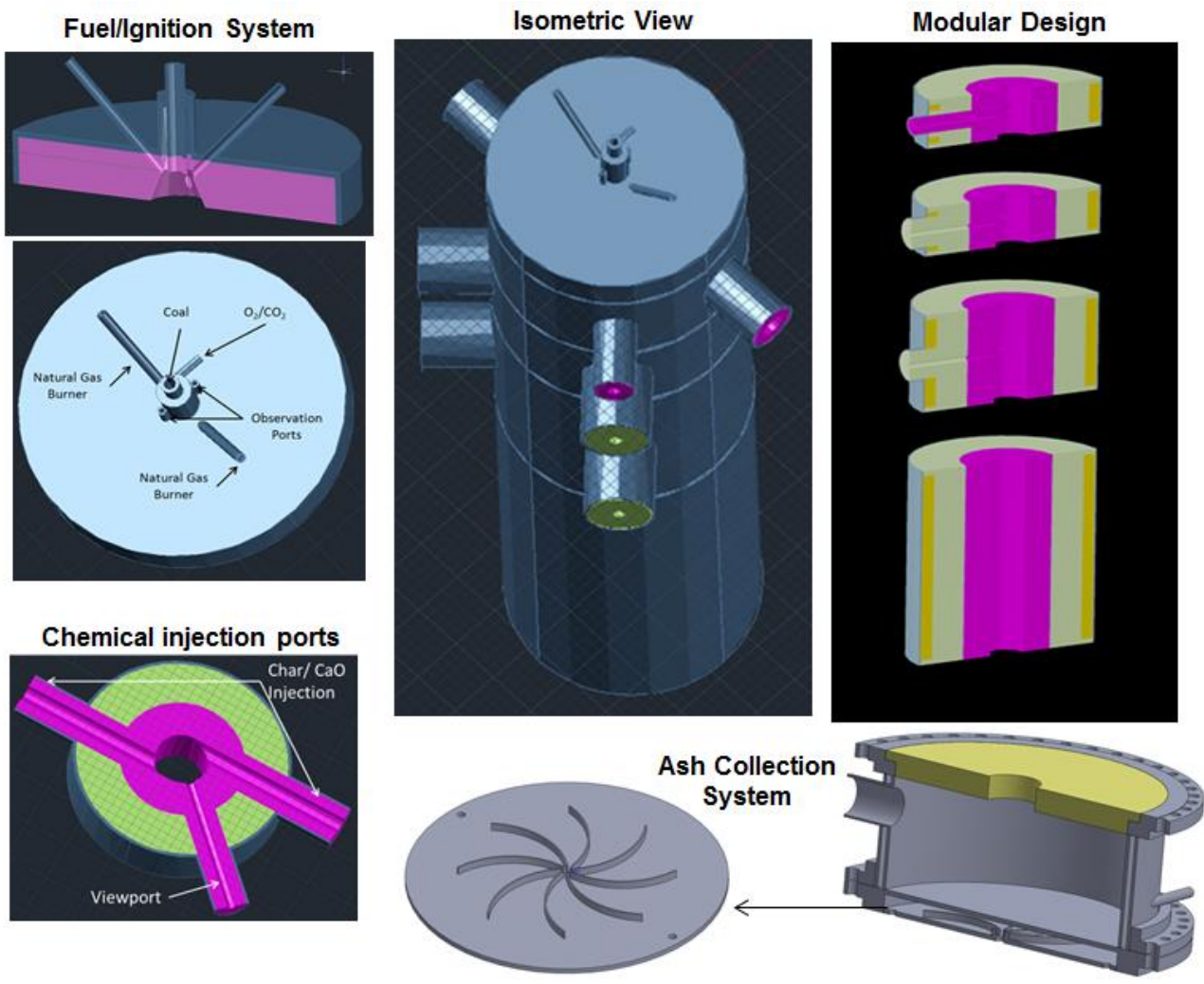

Figure 4-1. Detailed view of the sections and components of the VHTER

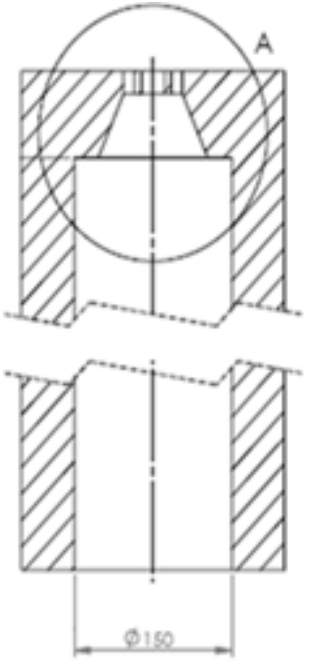

(a)

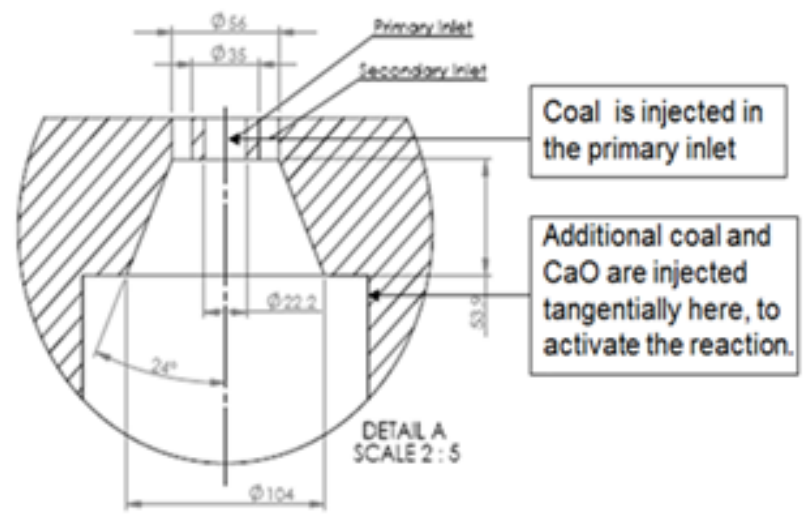

(b)

Figure 4-2. VHTER: (a) Combustion chamber and (b) Burner region. 


\subsection{Horizontal Reactor (CTC Reactor)}

The main characteristic of this reactor is its horizontal design, which enhances the release of byproduct $_{\text {gases }}{ }^{24}$ produced in the slag by means of buoyancy effects. The cyclonic effect is obtained by the tangential injection of a combustible gas mixture through the port SA. This flow provides the swirling flame stabilization mechanism, convects the hot gases towards the wall and provides the centrifugal effect that forces the reactants to reach the wall, thus enhancing the particle wall deposition.

A significant difference of the horizontal reactor with respect to the down-fired design is that the slag is forced to flow predominantly along the bottom wall. Additionally, the residence time of the slag is higher, since the gravitational component along the slag flow direction is much smaller. Another difference is that this design is intended to work in a continuous flow operation mode. This makes this configuration more attractive for industrial production, in exchange of additional operation and maintenance complexities.

A typical cyclone reactor for coal combustion is presented in Baumestier, T. [110]. Figure 4-3 shows the reactor inside a red box as well as their injection ports. A premixer for oxidant and natural gas can be observed in the SA port. The cooling pipe is used for exhaust gas treatment.

\footnotetext{
${ }^{24} \mathrm{By}$ product gases in the calcium carbide $\left(\mathrm{CaC}_{2}\right)$ reaction are carbon monoxide $(\mathrm{CO})$ and calcium gas $\left(\mathrm{Ca}_{\mathrm{g}}\right)$.
} 


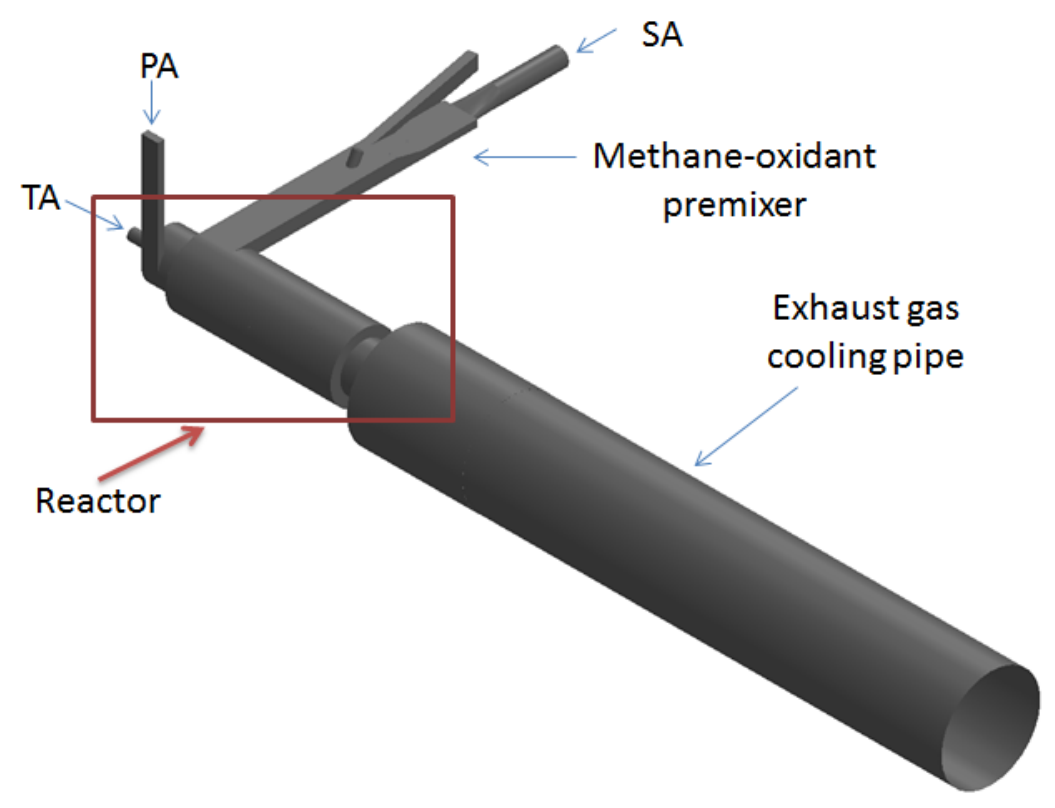

Figure 4-3. Diagram of the CTC system including the methane-oxidant premixer and exhaust gas cooling pipe.

The disposition of the PA and SA ports provide the cyclonic effect. The TA port is used for injection of oxygen; the PA port is used for injection of coal and chemical reactants. The oxidant injected through the SA port consists of air plus oxygen premixed with natural gas. 


\section{Chapter 5 - Combustion Modeling}

The initial stage of the combustion modeling process involved a validation study, which was presented at the 2012 International Pittsburgh Coal Conference [111]. The validation study permitted to select the most suitable combination of models and sub-models to conduct oxy-coal combustion simulations. Selected results are presented in section 5.5.

All the simulations were performed in ANSYS Fluent. In general, the combustion process was modeled using the Eulerian-Lagrangian approach for the continuous and discrete phases, respectively. This approach includes models for turbulence, multiphase flow of gas and particles, combustion reactions of coal volatiles and char, radiation heat $\operatorname{transfer}^{25}$, particle motion and dispersion, heat and mass exchange between the continuous and disperse phase, and particle wall interaction, among others. A more detailed description is provided below. A summary of the models utilized is presented in Table 5-1.

\subsection{Continuous Phase Modeling}

The Aerodynamics of the continuous media is determined by solving the Navier-Stokes equations using the RANS Approach. In the RANS approach, the Reynolds stresses are modeled by utilizing the standard k- $\varepsilon$ model of Launder and Spalding [112]. This model is used for turbulence due to its robustness, economy and reasonable accuracy for a wide range of industrial

\footnotetext{
${ }^{25}$ Due to his complexity, the radiation heat transfer equation is solved separately from the energy equation but its effect is coupled as a source term.
} 
applications. The modeling of turbulence close to the wall region is performed by using standard wall functions developed by Launder and Spalding [113] for near-wall treatment.

Combustion and species transport for the gas phase was modeled using the species transport model, where the mixing and transport of chemical species in the continuous phase is determined from the solution of transport equations by considering convection, diffusion and reaction sources. This equation is solved for the N-1 species fractions considered in the volumetric reactions. In this model, the net rate of production of all chemical species by chemical reactions as well as additional sources ${ }^{26}$ are used. The diffusion flux of species due to gradients of temperature and concentration, as well as its improved mixing effect by turbulence is taken into account too. The thermal diffusion effect, i.e., Soret Effect, is neglected, since it is just relevant for light species such as $\mathrm{H}, \mathrm{H}_{2}$ or $\mathrm{He}$ at low temperatures [114].The turbulent Schmidt number is calculated from the turbulent viscosity and the turbulent binary diffusivity.

In ANSYS Fluent, the transport energy equation is formulated in terms of the specific energy; it includes the contribution of conduction, convection and viscous dissipation, with effective thermal and diffusive properties modified by turbulent effects. The effects of combustion, radiation heat transfer, and additional sources are also included. The enthalpy is estimated from the summation of all species mass fractions. Values for thermochemical properties are taken from the NIST-JANAF Thermochemical Tables [115].

\footnotetext{
${ }^{26}$ Additional sources can be found in domain regions of combustion systems with sinks/ sources of species, such as in the selective catalytic reaction (SCR) process for NOx control.
} 
Fourth order temperature dependence in combustion makes the heat transfer a dominant mode due to thermal radiation. Therefore, it is highly important to calculate the radiant heat flux inside the combustion chamber accurately. This is achieved by solving the Radiative Transfer Equation (RTE) for a participating media in which the effect of absorption, emission and scattering is considered. This equation was solved using the P-1 radiation model and the discrete ordinates (OD) radiation model (Howell, Siegel, \& Pinar [43]), which can account for the effect of radiation exchange between the gas and particle phases as well as for scattering ${ }^{27}$. Both models were tested for oxy coal combustion in the exploratory study completed for this project [111].

In the simulations conducted in this study, both models provided similar predictions. Although the P-1 radiation model showed more stability, it was found that the Discrete Ordinates (OD) radiation model converged for a significantly smaller amount of iterations. Therefore, further simulations were developed using the $\mathrm{P}-1$ radiation model at the initial stage of the solution process of the RTE due to its stability, followed by the DO model.

For turbulent-chemistry interaction, the net reaction rate is taken as the minimum of two limits. The first limit is reached when turbulent fluctuations can be ignored, and the reaction rates are determined by Arrhenius kinetic expressions. This limit is known as the laminar finite-rate model and is true for laminar flames but it is also applied to combustion with relatively slow chemistry and small turbulence-chemistry interaction.

In the laminar finite-rate model, the source term providing each of the species in the species transport equation is determined by the sum of the generation/consumption rate over all the

\footnotetext{
${ }^{27}$ Mie Scattering is especially significant in spray and pulverized coal combustion.
} 
reactions in which such species participates. The reaction mechanism selected provides the number of chemical species in the system and the stoichiometric coefficients for reactants and products in each reaction. The molar rate of generation/consumption of species in each of the reaction is estimated from the molar concentration of each species and the forward and backward reaction rates for such a reaction. The forward rate constant for each reaction is obtained from the Arrhenius expression formulated in terms of the pre-exponential factor, the temperature exponent, and the activation energy. The backward rate constant is obtained from equilibrium considerations, with the equilibrium constant being computed from the Gibbs free energy, which is estimated from the standard-state entropy and the heat of formation for each of the species present in the reaction.

The second limit considers that most fuels are fast burning. i.e., the chemical time scale is much shorter than the turbulent mixing time scale. Therefore, the overall rate of the reaction is controlled by turbulent mixing. This limit is known as Eddy-dissipation model. In this model, the limiting process is the rate at which turbulence transports/mixes cold reactants and hot products, as in premixed flames or fuel and oxidizer, as in non-premixed flames. In this case, the turbulentchemistry model of Magnussen \& Hjertager [116] is utilized, and the chemical reaction rate is dominated by the large eddy mixing time scale.

\subsection{Discrete Phase Modeling}

The evolution of a coal particle in the combustion environment is described as follows: in the initial stage, a typical particle experiences the interchange of energy with the continuous phase without change of phase or interchange of mass. In this initial stage, the particle is heated until it 
reaches the point at which any existing moisture starts to evaporate. This process continues as long as the particle temperature is lower than the evaporation temperature for the liquid phases contained in the particle. In this case, the energy balance for the particle is modeled as only accounting for convection and radiation interchange with the particle environment. Once the moisture evaporation stage starts, i.e., when the particle temperature surpasses the evaporation temperature, the latent heat energy is included in the particle energy balance. After all the moisture content is consumed, the particle temperature continues increasing until the devolatilization temperature is reached.

During the devolatilization stage, a typical coal particle releases its volatiles into the continuous phase. This process continues until all the volatiles are consumed. In this work, coal devolatilization is modeled using the single kinetic rate devolatilization model of Badzioch and Hawksley [117]. This model assumes that the rate of devolatilization is first-order dependent on the amount of volatiles remaining in the particle; it also assumes that the kinetic rate is defined by empirical Arrhenius type expressions requiring the specification of the pre-exponential factor and the activation energy for the coal being modeled.

The composition of volatiles depends on the composition and properties of the coal but also on the particle evolution during the combustion process, which means that it depends on the particle temperature history, heating rate, and combusting atmosphere. Different empirical models have been developed to tackle this problem, but their generalization entails practical limitations due to the diversity in composition found in coal from one area to another. Some examples are found in Matthesiu, et al. [118], and Suuberg, et al. [119]. 
Unlike a more empirical approach, the Chemical Percolation and Devolatilization model (CPD) $[18,19,20]$ characterizes the devolatilization behavior of rapidly heated coal based on the physical and chemical transformations of the coal structure. Nonetheless, the CPD model is computational expensive and it relies on coal structure parameters that must be determined experimentally.

Therefore, a more practical approach is considered, where the volatiles are defined by the following two steps reaction mechanism. In this mechanism, the specie "volatiles" is a generic hydrocarbon obtained from the proximate and ultimate analysis of coal:

$$
\begin{aligned}
& \text { volatiles }+v_{1} \mathrm{O}_{2} \rightarrow v_{2} \mathrm{CO}+v_{3} \mathrm{H}_{2} \mathrm{O}+v_{4} \mathrm{~N}_{2}+v_{5} \mathrm{SO}_{2} \\
& \mathrm{CO}+\frac{1}{2} \mathrm{O}_{2} \rightarrow \mathrm{CO}_{2}
\end{aligned}
$$

The particle diameter during devolatilization is tracked by solving the equation of its evolution, whose behavior is characterized by the swelling coefficient. The effect of particle swelling is reflected in the particle trajectory via the modification in the drag coefficient and, additionally, in the oxidation rate that follows the devolatilization process, where the particle diameter has a quadratic effect.

After devolatilization, the particle is assumed to be composed of carbon in the graphite phase and ash, i.e., char. Oxidation of char is specified in terms of the stoichiometric requirement of the surface "burnout" reaction, which is defined in terms of mass of oxidant per mass of char. The oxidant and product species for char oxidation were defined with the following simple approach: 


$$
\mathrm{C}(s)+\frac{1}{2} \mathrm{O}_{2} \rightarrow \mathrm{CO}_{2}
$$

Fluid-solid reaction models are related to the particle size and the ability of the fluid to diffuse into the solid particle. Regarding the particle size, it can be assumed that particle may either change in size or remain the same with a fixed diameter during the oxidation process. Furthermore, according to the mechanism that controls the reaction, it can be considered that: (i) oxidant diffusion through a gas film controls the reaction; (ii) diffusion through the ash formed controls the reaction; (iii) chemical kinetics controls the reaction.

A detailed review can be found in Levenspiel, O. [120]. In this research, the kinetics/diffusionlimited surface reaction model of Baum and Street [78] and Field [121] was selected to model the char oxidation process. Both effects are considered in this model, which means that the reaction rate is determined either by the diffusion rate of oxygen through the particle external surface, or by the effective char reactivity.

Regarding the devolatilization process, the kinetic rate during char oxidation is given by empirical Arrhenius type expressions requiring the specification of the pre-exponential factor and the activation energy. The energy balance accounts for the rate of heat release, which is estimated from the enthalpy of reaction, from the particle mass rate of change, and from a fraction of the energy released consumed by the particle itself. This fraction is 0.3 when the char burnout product is considered to be $\mathrm{CO}_{2}$ [122]. After the carbon in the char is consumed by combustion, the particle is composed of ash. The ash particles continue the exchange of heat with its environment without any chemical reactions taking place. 
During the particle evolution through the combustion process, the trajectory of particles is calculated by integrating the momentum balance equation for the particle. This equation accounts for the effect of the drag force. The drag force is calculated from the fluid flow velocity, the particle velocity, the molecular viscosity of the fluid, the fluid density, the particle density, the particle diameter, and the relative Reynolds number. The drag coefficient is calculated assuming the spherical drag law [123]. Additional forces arising from pressure or temperature gradients such as thermophoretic forces are taken into account as well.

The turbulent dispersion of particles was modeled using the Discrete Random Walk (DRW) model [124]. Initially, the particle-wall interaction was modeled as a non-elastic spherical collision with a restitution coefficient of 0.9 ; once the solution showed convergence, the condition was changed to particle trap via an UDF, in order to obtain the information required for the slag model. $\mathrm{CaO}$ particles are treated as non-reactive particles capable of absorbing energy without change of phase.

Table 5-1. Summary of the models utilized in the oxy-coal combustion simulations.

\begin{tabular}{|l|l|}
\hline Gas Phase & Eulerian \\
\hline Particle Phase & Lagrangian \\
\hline Turbulence & Standard k- $\varepsilon$ model with standard wall functions \\
\hline Mixing and transport of chemical species & Species transport model \\
\hline Species considered & Coal Volatiles, $\mathrm{O}_{2}, \mathrm{~N}_{2}, \mathrm{CO}_{2}, \mathrm{H}_{2} \mathrm{O}, \mathrm{CO}, \mathrm{SO}_{2}$ \\
\hline Turbulence-chemistry interaction & Eddy break-up model \\
\hline Volumetric reactions & Two-step reaction mechanism \\
\hline Particle combustion & Global reaction \\
\hline Particle size distribution & $\begin{array}{l}\text { Constant diameter 50 microns for the VHTER } \\
\text { and the 200 Reactor; Rosin Rammler } \\
\text { distribution for the CTC Reactor. }\end{array}$ \\
\hline Turbulent dispersion of particles & Random walk model \\
\hline
\end{tabular}




\begin{tabular}{|l|l|}
\hline Coal devolatilization & Single kinetic rate devolatilization model \\
\hline Char oxidation & kinetics/diffusion-limited surface reaction model \\
\hline $\mathrm{CaO}$ particles & $\begin{array}{l}\text { Treated as non-reactive particles with a constant } \\
\text { diameter 50 microns }\end{array}$ \\
\hline Particle-wall interaction & $\begin{array}{l}\text { Non-elastic spherical collision (Initially) } \\
\text { UDF (for wall deposition) }\end{array}$ \\
\hline Radiation heat transfer & Discrete Ordinates \\
\hline
\end{tabular}

\subsection{Domain Discretization and Boundary Conditions}

Governing equations for turbulent flow, combustion, heat and mass transfer for the continuous and discrete phase were solved using the finite volume method in structure grid systems. Although most of the simulations for the VHTER were conducted in 2D axisymmetric domains due to its symmetry, some were conducted in 3D domains. All the simulations for the horizontal reactor were done in 3D domains, due to the asymmetry brought about by the disposition of the injection ports. Grids were refined towards the center, inlet ports, and walls. Some examples are shown in Figure 5-1 and Figure 5-2. The premixer section in the horizontal reactor is not included in the model, but the assumption of a completely premixed combustion mixture was considered instead.

Regarding the down-fired design, the boundary conditions for the primary and secondary ports were set as inlet flow conditions. For the secondary port, a swirling flow component was given in order to model the $45^{\circ}$ fins swirler. Furthermore, a tangential velocity component is set in order to model the flow conditions imposed by the tangential injection ports for chemical reactants. For the horizontal design, internal burner details are included to model the flame stabilization mechanism by swirling flow motion. 
In the preliminary study, the walls were modeled assuming a constant heat transfer loss. The heat loss was considered to be 25 percent of the power plus an additional estimation for the chemical reaction of $\mathrm{CaC}_{2}$. This strategy was refined in the final stage, where the thin shell model available in ANSYS Fluent was utilized, along with the energy consumption from the $\mathrm{CaC}_{2}$ reaction $^{28}$ estimated from the SFM. A constant emissivity of 0.8 was used to account for the presence of $\operatorname{slag}^{29}$.

At the beginning of the simulation process, the particle-wall interaction was modeled as a nonelastic spherical collision with a restitution coefficient of 0.9 , as recommended by Abbas et al. [62]. Once a stable combustion was attained, the particle-wall interaction was modeled as a trap condition, which is a good assumption for walls covered by molten ash [16]. The outlet condition is set as pressure outlet with standard pressure and back flow temperature close to the average outlet temperature.

The domain for the ash collector along with its cooling system is shown in Figure 5-1c. The inlet flow conditions were taken from the 2D axisymmetric model, i.e., the velocities and gas composition of the continuous phase, and the amount of particles, which are mainly fly ash and some small percentage of unburnt carbon. The top wall is set as adiabatic, and the vertical and bottom wall are considered to be at $773 \mathrm{~K}$. This constant temperature condition was also utilized

28 The strategy to model the heat transfer through the wall is broader explained in chapter 7.

29 As pointed out by Mills [83], and Mills and Rhine [98], an emissivity value of $0.8+-0.1$ can be adopted for coal and metallurgical slags in the range (1100 to $1900 \mathrm{~K}$ ). 
for the inner wall of the cooling jacket. Apart from the constant temperature condition, a constant heat transfer rate was set for the cooling modeling.

Regarding the particles, coal and $\mathrm{CaO}$ particles were modeled with a constant 50 microns diameter for the VHTER, since no information about the particle size distribution was available. For the horizontal reactor, the Rosin-Rammler distribution method for pulverized coal particles [125] was utilized, since the particle size distribution was provided by LP Amina. A 50 microns diameter was also used for $\mathrm{CaO}$ particles in the horizontal reactor.

a)

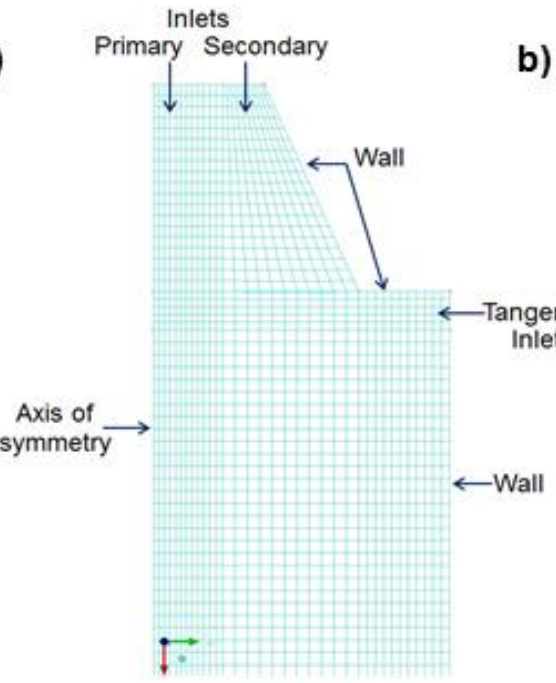

b)

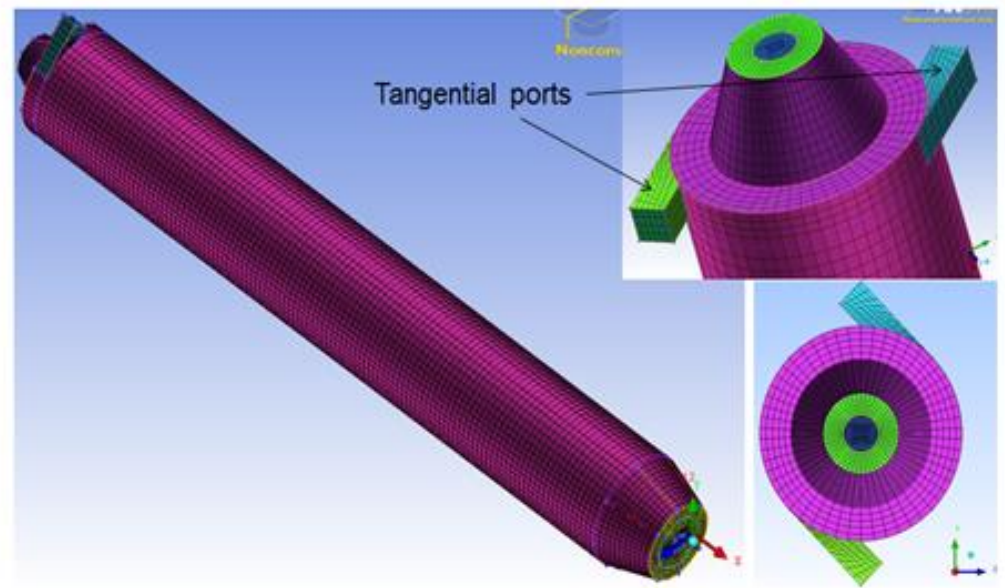

c)
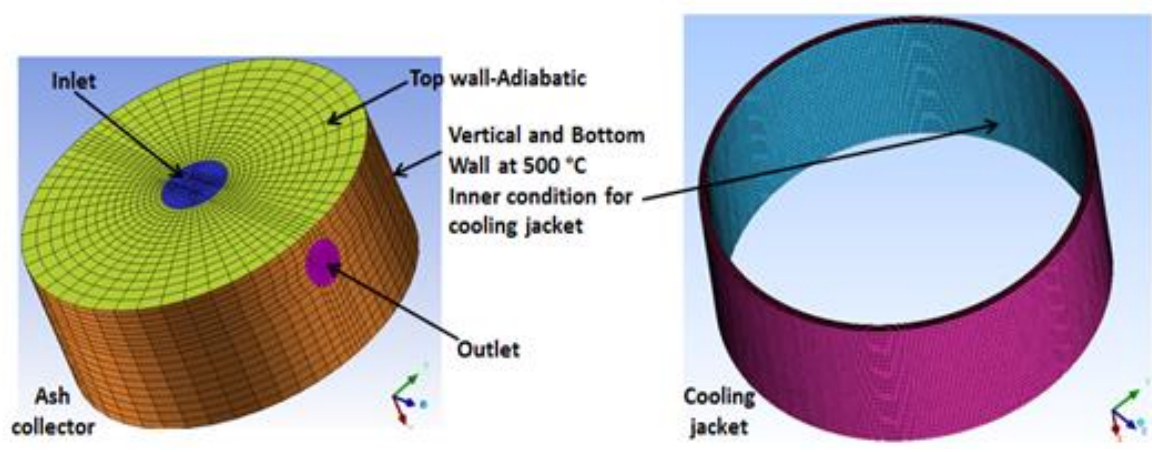

Figure 5-1. Example of the computational domains utilized in the modeling of the VHTER. 


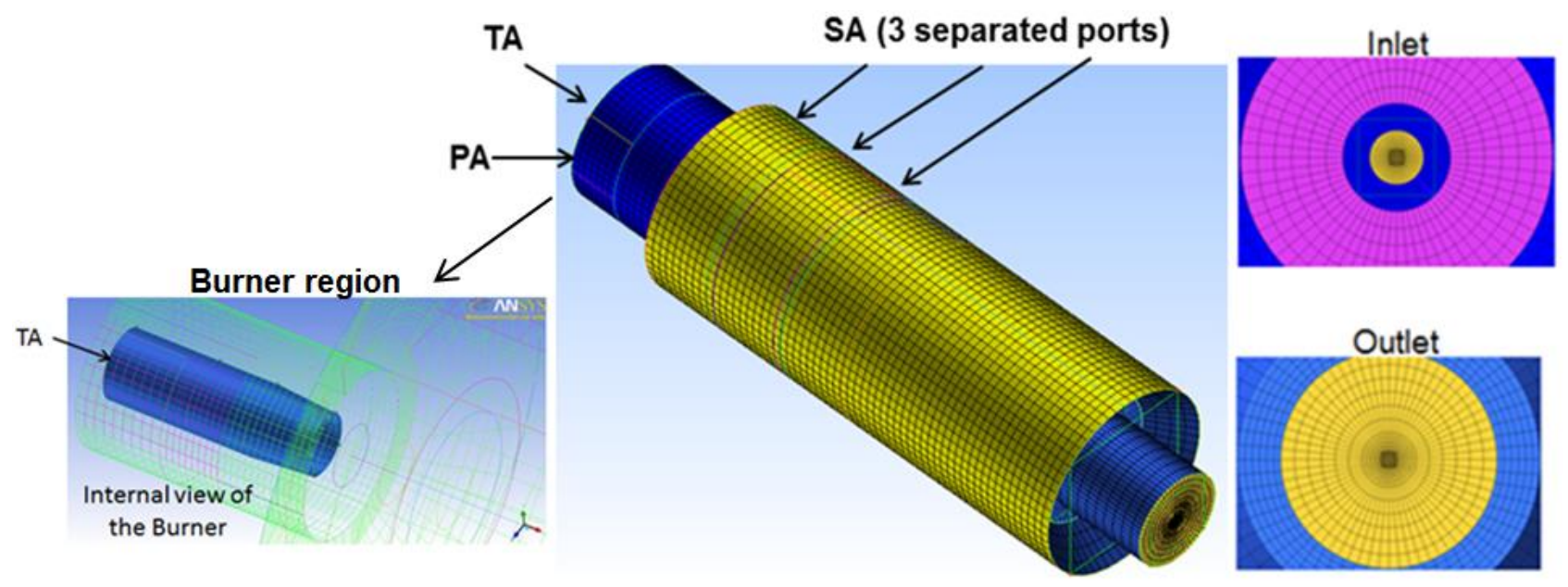

Figure 5-2. Example of the computational domains utilized for the horizontal reactor modeling.

\subsection{Solution Method for CFD Combustion}

The SIMPLE scheme [41] was used for pressure-velocity coupling in conjunction with the PRESTO scheme [126] for pressure interpolation, as is recommended for strong swirling flows [127]. Turbulent flow, transport of species, and radiative heat transfer equations were solved using the first order upwind scheme [41]. Normalized residuals were set to values smaller than 1e-06, and the energy balance was checked as recommended by ANSYS Fluent [127].

\subsection{Validation Study for CFD Oxy-Coal Combustion}

The validation of the CFD oxy-coal combustion models involved the study of an oxy-coal combustion process for pulverized lignite coal under an $\mathrm{O}_{2} / \mathrm{CO}_{2}$ oxidizing atmosphere, with an 
oxygen molar fraction of 0.25 . The simulations were based on the experimental work performed by Andersson [128] and Hjärtstam et al. [63].

The furnace modeled in this study was a $100 \mathrm{~kW}$ test unit located at Chalmers University of Technology. This combustor is a down-fired unit and has a cylindrical refractory-lined furnace with a height of $2.4 \mathrm{~m}$ and an inner diameter of $0.8 \mathrm{~m}$ (Figure 5-3). The combustion chamber is cooled by four water cooled tubes. The burner configuration has three concentrically separate lances. The central one ( $34 \mathrm{~mm}$ dia.) is used to feed the fuel, which is a mixture of carrier gas (air or $\mathrm{O}_{2} / \mathrm{CO}_{2}$ ) and pulverized coal. The primary (52 $\mathrm{mm}$ dia.) and secondary (92 $\mathrm{mm} \mathrm{dia.)}$ registers are used to inject the oxidizer (air or $\mathrm{O}_{2} / \mathrm{CO}_{2}$ ). The primary and secondary registers have swirling fins oriented $45^{\circ}$ and $15^{\circ}$ respectively. The gas flow inlet conditions are shown in Table 5-2. The pulverized coal was injected at a mass flow rate of $3.64 \mathrm{e}-03 \mathrm{~kg} / \mathrm{s}$. The coal utilized was German lignite. Table 5-3 shows the properties of this type of coal. 


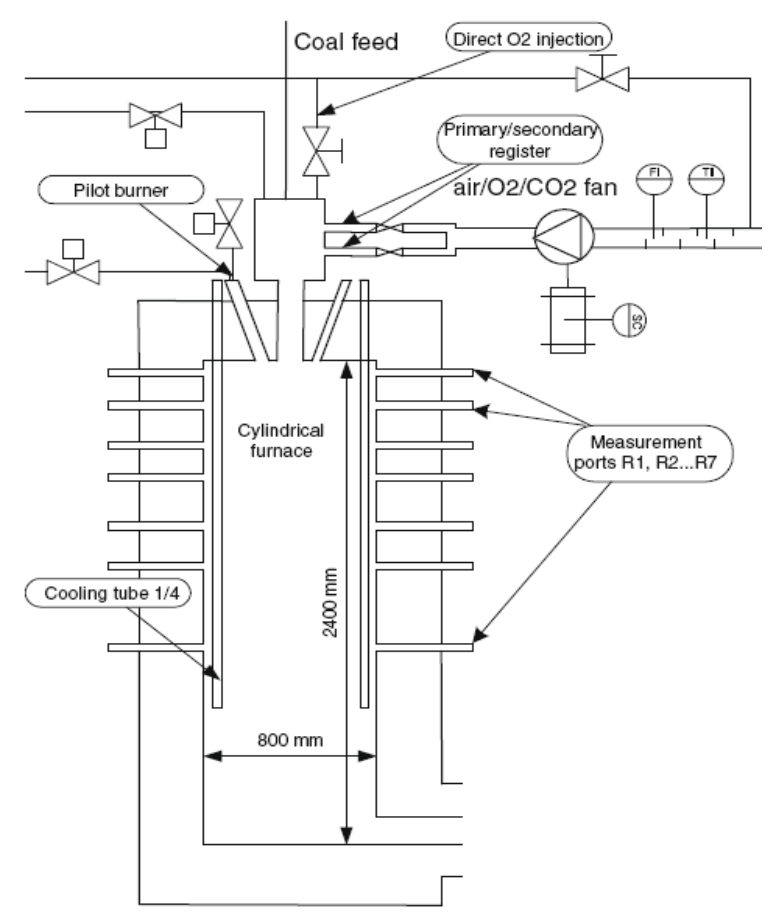

Figure 5-3. Chalmers $100 \mathrm{~kW}$ Combustor Unit. (Andersson [128])

Table 5-2. Flow inlet conditions for utilized in the validation study for oxy-coal combustion.

\begin{tabular}{|l|c|c|c|}
\hline Streams & Fuel carrier gas & Primary inlet & Secondary inlet \\
\hline Mass flow rate $(\mathrm{kg} / \mathrm{s})$ & $1.09 \mathrm{e}-03$ & $1.33 \mathrm{e}-02$ & $3.1 \mathrm{e}-02$ \\
\hline $\mathrm{O}_{2}$ molar fraction & 0.3 & 0.25 & 0.25 \\
\hline $\mathrm{CO}_{2}$ molar fraction & 0.68 & 0.72 & 0.72 \\
\hline Temperature $(\mathrm{K})$ & 298 & 298 & 298 \\
\hline
\end{tabular}

Table 5-3. German lignite properties.

\begin{tabular}{|c|c|c|c|c|c|c|c|c|c|}
\hline \multicolumn{2}{|c|}{$\begin{array}{c}\text { Proximate analysis } \\
\text { (wt\% as received) }\end{array}$} & \multicolumn{3}{|c|}{$\begin{array}{c}\text { VM } \\
\text { (\%d.a.f) }\end{array}$} & \multicolumn{4}{|c|}{ Ultimate analysis (wt\% d.a.f.) } & LHV \\
\cline { 1 - 5 } Moisture & Ash & combustibles & \multirow{2}{*}{59.4} & $\mathrm{C}$ & $\mathrm{H}$ & $\mathrm{N}$ & $\mathrm{S}$ & $\mathrm{O}$ & $(\mathrm{MJ} / \mathrm{kg})$ \\
\hline 10.2 & 5.0 & 84.8 & & 69.9 & 5.4 & 0.6 & 1.0 & 23.1 & 20.9 \\
\hline
\end{tabular}


The simulations were performed using the models described in section 5.1 and 5.2. The physical parameters, such as coal size, emissivity and reaction rates, were taken from Al-Abbas et al. $[62]^{30}$.

Regarding the boundary conditions, different approaches were used to model the swirling fins in the primary and the secondary registers by, for instance, prescribing velocity profiles for the axial and tangential (swirl) velocity components, or by providing a solid body rotation boundary condition to describe the swirl profiles. Nonetheless, good agreement was obtained by simply prescribing constant velocity profiles with the fin angle directions. For the outlet, the usual outlet pressure boundary condition was used. The walls were modeled as constant temperature boundaries, and the emissivity values for the particles and the furnace walls were taken as 0.7 and 0.52 , respectively, as suggested by Al-Abbas et al. (2011).

The simulations were performed in $2 \mathrm{D}$ and $3 \mathrm{D}$ computational domains. All the meshes were built with the furnace length, i.e., $2.4 \mathrm{~m}$, and the diameter, i.e., $0.8 \mathrm{~m}$. A symmetry condition was assumed in the 2D models. Examples of these domains can be observed in Figures 5-4 and 5-5.

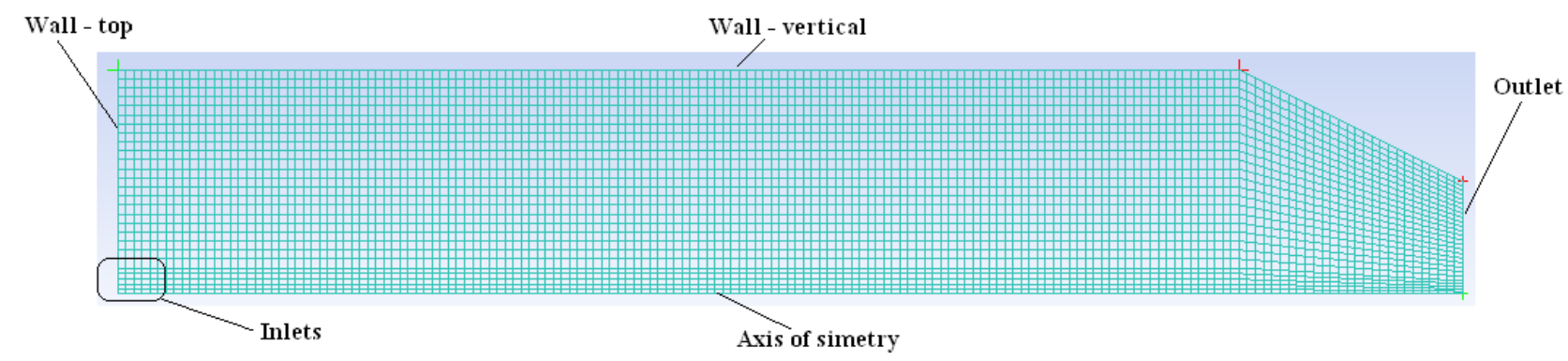

${ }^{30}$ Al-Abbas et al. [62] also performed CFD simulations of the experimental work performed by Andersson [128] and Hjärtstam et al. [63]. 
Figure 5-4 . 2D Grid and boundary conditions.

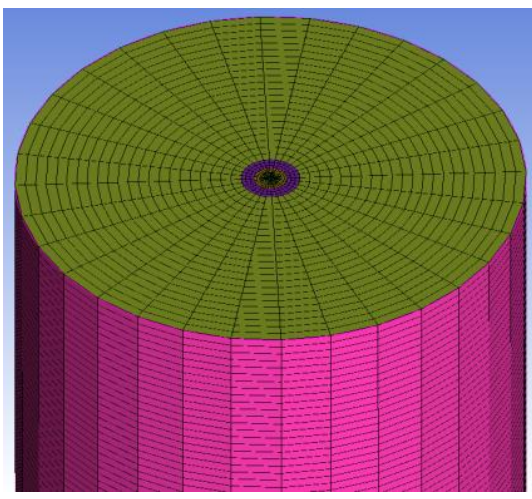

(a)

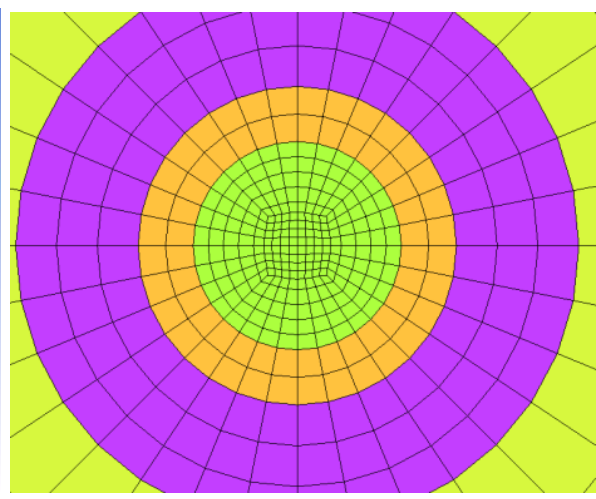

(b)

Figure 5-5. (a) 3D grid (b) Closer view at the inlet region.

The results of the validation study showed that it is possible to obtain good predictions by utilizing 2D domains. Figure 5-6 shows the comparison between the experiments performed by Andersson [128], and CFD oxy-coal combustion simulations performed by the Gutierrez et al. [111] in a 2D axisymmetric domain. It can be observed that the temperatures seem to be in reasonable agreement with the experiments. 


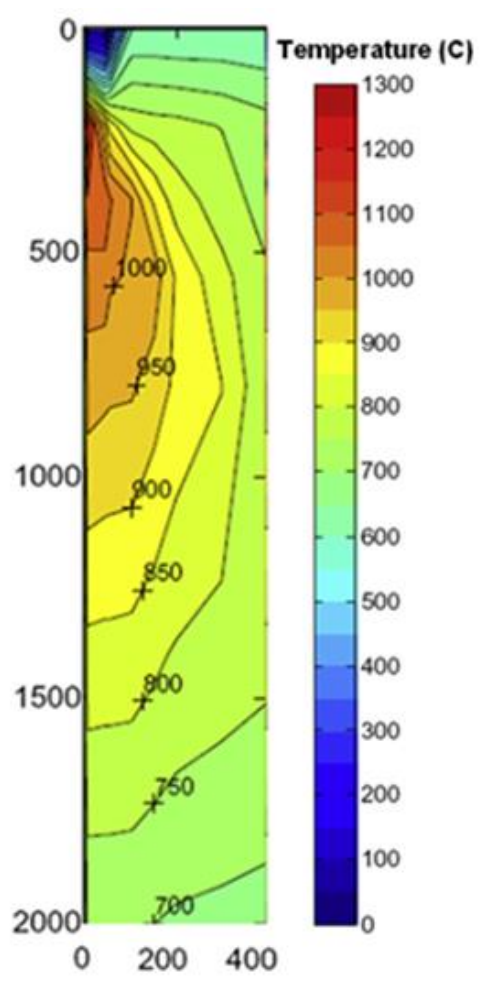

(a)

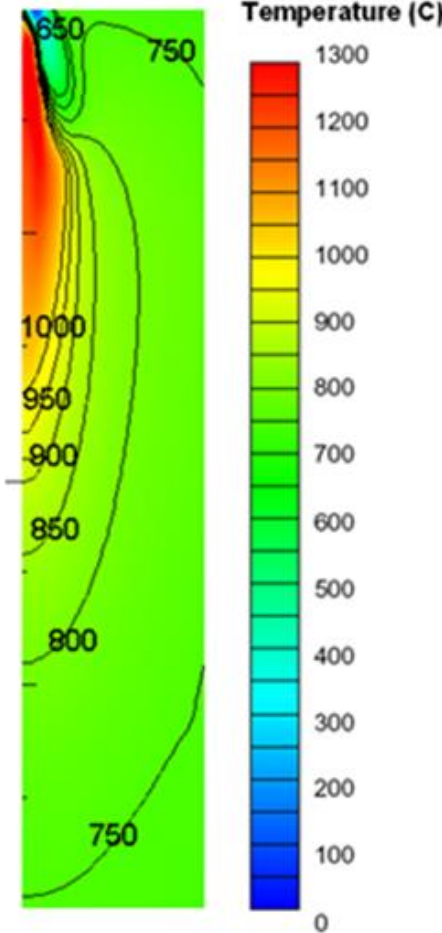

(b)

Figure 5-6. Contours and Iso-lines of temperature for (a) experiments performed by Andersson [128] and (b) CFD simulations performed by Gutierrez et al. [111].

Another comparison is shown in Figure 5-7, specifically, the comparison of CFD simulation results for the radial temperature profiles at three different port locations. The radial temperature profiles are reported in the experiments of Andersson [128]. The ports are located in the early development region of the flame. The first port is located at an axial distance of $0.215 \mathrm{~m}$ from the top ceiling; the second port is at a distance of $0.384 \mathrm{~m}$; and the third port is located at a distance of $0.553 \mathrm{~m}$. The comparison also includes the CFD simulation results reported by AlAbbas et al. [62]. It is shown that the temperature profiles over all conform to measurements, albeit a closure look indicates differences among various investigations, as should be expected. 


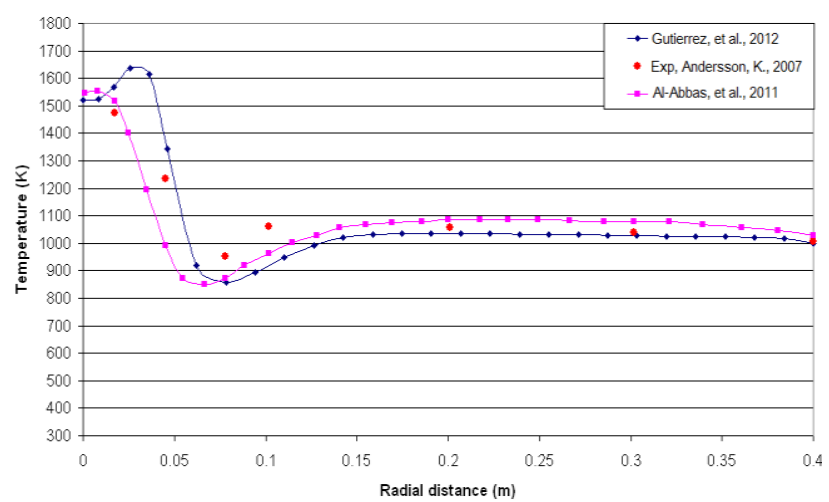

(a)

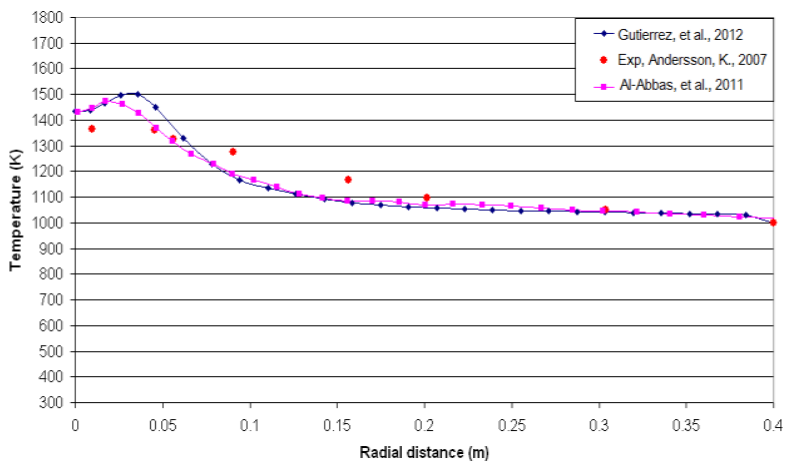

(b)

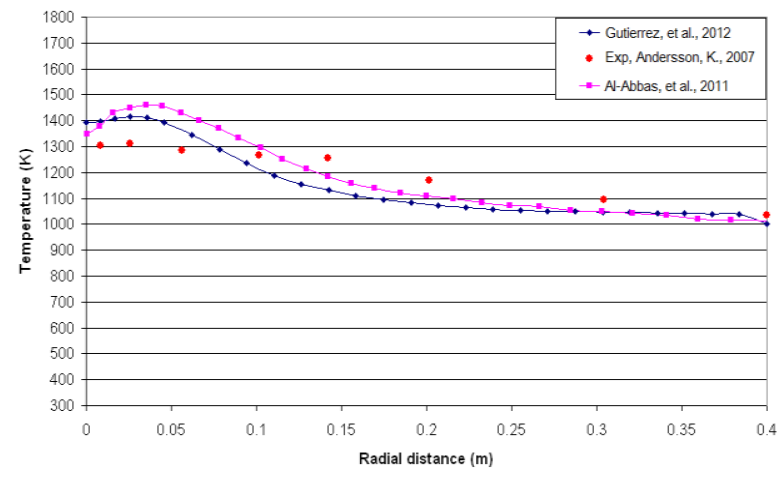

(c)

Figure 5-7. Comparison of temperature profiles against experiments and previous published results. (a) port $1(x=0.215 \mathrm{~m}),(\mathrm{b})$ port $2(\mathrm{x}=0.384 \mathrm{~m}),(\mathrm{c})$ port $3(\mathrm{x}=0.553 \mathrm{~m})$. 


\section{Chapter 6 - Slag Flow Modeling}

In the model presented in this work, unsteady-state transport equations for mass, energy and species concentration were formulated in a one dimensional control volume. This was done following an integral approach, similar to that used in the boundary layer theory, where a suitable velocity profile is required. This velocity profile is derived from the solution of the momentum equation in the slag flow direction, after a simplification of such equation by conducting an order of magnitude analysis (OMA).

The boundary conditions and the particle deposition rates at the interface between the molten slag and the gaseous atmosphere of the reactor are provided by CFD results of simulations conducted in the reactor design process. Reactor dimensions and insulation materials are also included in the formulation. The source terms for the species transport equation are provided by the $\mathrm{CaC}_{2}$ reaction and kinetics model described in Rowan et al. [108]. The formulation process leads to a set of unsteady state partial differential equations that are solved by numerical techniques. The slag model formulation and the sub-models utilized in its development are explained below in greater detail.

\subsection{Conservation of Mass}

Figure 6-1 shows a pictorial representation of the system. The control volume enclosed by dashed lines represents a one dimensional cell of the liquid slag layer. The size of the liquid cell 
is considered to be time dependent. It is assumed that the mass flux into the slag flow direction, i.e., through the west and east faces, is due to convection only ${ }^{31}$.

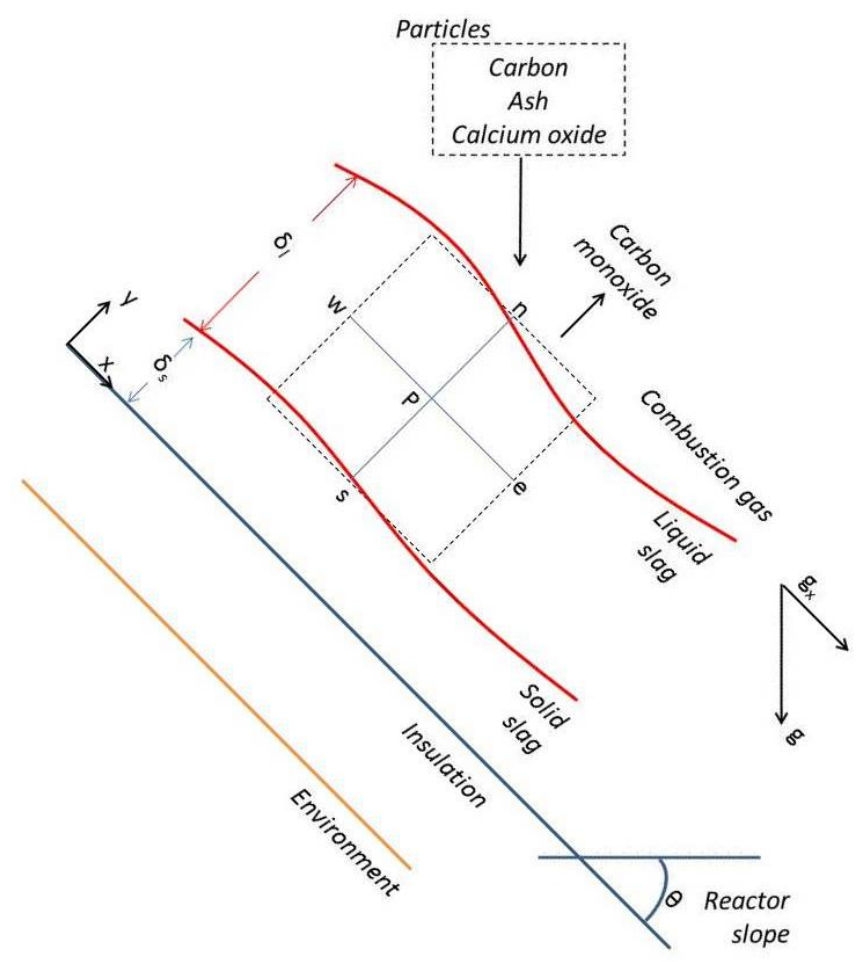

Figure 6-1. Pictorial of the slag flow system.

${ }^{31}$ The mass diffusivity of various cations and anionic species in typical silicate melts is in the order of $10^{-12} \mathrm{~m}^{2} / \mathrm{s}$ [141]. Therefore, the calculated Peclet number for mass diffusivity of these species in the slag flow direction was estimated to be in the order of $10^{7}$ for this application. Furthermore, the Peclet number for thermal diffusivity was estimated to be in the order of $10^{2}$. 
The north face of the cell corresponds to the moving interface between the molten slag and the gaseous atmosphere of the reactor. The south face corresponds to the interface between the liquid and molten slag. It is assumed that this interface is defined by the critical viscosity temperature.

The general expression for the conservation of mass in the control volume of Figure 6-1 can be stated as:

$$
\frac{\partial}{\partial t}[m]_{c v}=\dot{m}_{w}-\dot{m}_{e}+\dot{m}_{n}-\dot{m}_{s}
$$

The first term on the left hand size corresponds to the rate of change of the liquid mass. After special integration in the control volume, the rate of mass change inside the control volume per unit depth can be expressed as:

$$
\frac{\partial}{\partial t}[m]_{c v}=\frac{\partial}{\partial t}\left[\rho_{l} \cdot \delta_{l} \cdot \Delta x\right]
$$

The mass flow rate along the slag flow direction, e.g., for the west face, can be expressed as:

$$
\dot{m}_{w}=\left[\rho_{l} \cdot u_{\text {ave }} \cdot \delta_{l}\right]_{w}
$$

The velocity profile required to obtain the average velocity is obtained from the momentum equation. The total mass flux through the north face is given by the total particle deposition and 
by-product gases of the chemical reaction such as $\mathrm{CO}$ and $\mathrm{Ca}_{(\mathrm{g})}{ }^{32}$, which are released through the surface of the slag. This can be expressed as:

$$
\dot{m}_{n}=\dot{m}_{C}+\dot{m}_{A s h}+\dot{m}_{C a O}-\dot{m}_{C O}
$$

The total mass flux through the south face is given by the rate of solidification or melting at the liquid-solid slag interface. This amount is determined by using the Stefan's model [129].

Under the previous assumptions, the conservation of mass for the control volume can be expressed as:

$$
\frac{\partial}{\partial t}\left[\rho_{l} \cdot \delta_{l} \cdot \Delta x\right]=\left[\rho_{l} \cdot u_{\text {ave }} \cdot \delta_{l}\right]_{w}-\left[\rho_{l} \cdot u_{\text {ave }} \cdot \delta_{l}\right]_{e}+\dot{m}_{n}-\dot{m}_{s}
$$

\subsection{Velocity Profile}

The expression for the velocity profile was developed considering the main forces found in the slag flow. This was accomplished by conducting an OMA for each of the terms in the momentum equation along the slag flow direction. The general expression for the conservation of momentum in the slag flow direction can be written as:

\footnotetext{
${ }^{32}$ However, calcium is not formed as by-product gas under the assumed chemical reaction mechanism.
} 


$$
\frac{\partial u}{\partial t}+u \frac{\partial u}{\partial x}+v \frac{\partial u}{\partial y}=-\frac{1}{\rho} \frac{\partial P}{\partial x}+g_{x}+\frac{\partial}{\partial x}\left(v \frac{\partial u}{\partial x}\right)+\frac{\partial}{\partial y}\left(v \frac{\partial u}{\partial y}\right)
$$

The OMA of each term is estimated according to the order of magnitude of the slag properties, the thicknesses and velocity values common to molten slag flows, and typical reactor dimensions. Table 6-1 depicts typical values for slag properties. Table 6-2 shows the order of magnitude of each term in the momentum equation.

Table 6-1. Physical properties of coal slag. Yong et al. [69].

\begin{tabular}{|l|c|}
\hline \multicolumn{1}{|c|}{ Slag Properties } & Range \\
\hline Temperature of critical viscosity, $\mathrm{T}_{\mathrm{cv}}(\mathrm{K})$ & $1580-1780$ \\
\hline Viscosity, $\mu(\mathrm{Pa} \mathrm{s})$ & $6.2-334.5$ \\
\hline Density, $\rho\left(\mathrm{kg} / \mathrm{m}^{3}\right)$ & $2779.9-2887.9$ \\
\hline Specific heat, $C_{p}(\mathrm{~kJ} / \mathrm{kg} \mathrm{K})$ & 1.3825 \\
\hline Thermal conductivity, $k_{l}(\mathrm{~W} / \mathrm{mK})$ & $1.73-1.80$ \\
\hline
\end{tabular}

Table 6-2. Order of magnitude of the terms in the momentum equation.

\begin{tabular}{|c|c|c|}
\hline Term & Scale as: & $\begin{array}{c}\text { Order of } \\
\text { Magnitude }\end{array}$ \\
\hline$u \frac{\partial u}{\partial x}$ & $\frac{U^{2}}{L}$ & $O\left(10^{-6}\right)$ \\
\hline$v \frac{\partial u}{\partial y}$ & $V \frac{U}{\delta}$ & $O\left(10^{-6}\right)$ \\
\hline$v \frac{\partial^{2} u}{\partial x^{2}}$ & $v \frac{U}{L^{2}}$ & $O\left(10^{-4}\right)$ \\
\hline$v \frac{\partial^{2} u}{\partial y^{2}}$ & $v \frac{U}{\delta^{2}}$ & $O\left(10^{2}\right)$ \\
\hline
\end{tabular}




\begin{tabular}{|c|c|c|}
\hline$\frac{1}{\rho} \frac{\partial P}{\partial x}$ & $\frac{\Delta P}{\rho L}$ & $O\left(10^{-2}\right)$ \\
\hline$\frac{\partial u}{\partial t}$ & $\frac{\Delta U}{t_{s s}}$ & $O\left(10^{-6}\right)$ \\
\hline$g_{x}$ & $g$ & $O(10)$ \\
\hline
\end{tabular}

After the simplification, the following expression for the momentum equation in the slag flow direction $\mathrm{x}$ is stated:

$$
0=g_{x}+v \frac{\partial^{2} u}{\partial y^{2}}
$$

The previous expression is subjected to the non-slip condition at the wall and to the assumption that the shear stress is the same for the gas and the liquid at their interface:

$$
\begin{gathered}
u(0)=0 \\
\tau(\delta)=\tau_{g l}
\end{gathered}
$$

Where $\tau_{g l}(x)$ is modeled as being equal to $\tau_{w}(x)$, which is obtained from the CFD combustion model of the reactor. The velocity profile is given by the solution of this second order ODE and it can be expressed in dimensionless form as:

$$
u^{+}=\alpha\left[2 \eta-\eta^{2}\right]+\beta \eta
$$

Where:

$$
u^{+}=\frac{u}{u_{\tau}}
$$




$$
\begin{aligned}
& u_{\tau}=\left[\frac{\tau_{g l}}{\rho}\right]^{1 / 2} \\
& \alpha=\frac{\rho g_{x}}{2 \mu \cdot u_{\tau}} \delta_{l}^{2} \\
& \beta=\left[\frac{\tau_{g l}}{\mu \cdot u_{\tau}}\right] \delta_{l} \\
& \eta=\frac{y}{\delta_{l}}
\end{aligned}
$$

Utilizing this profile, the mass flow through a particular face normal to the slag flow direction can be expressed as:

$$
\int_{\delta_{s}}^{\delta_{l}} \rho u d y=\rho u_{\tau} \delta_{l} \int_{0}^{1} u^{+} d \eta=\rho u_{\tau} \delta_{l}\left[\frac{2}{3} \alpha+\frac{1}{2} \beta\right]
$$

And the average velocity can be determined from:

$$
u_{\text {ave }}=\frac{1}{\delta_{l}} \int_{\delta_{s}}^{\delta_{l}} u d y=u_{\tau}\left[\frac{2}{3} \alpha+\frac{1}{2} \beta\right]
$$




\subsection{Liquid Layer Thickness Equation}

Using the previous results, and after spatial integration and implicit integration in time, the expression for the conservation of mass can be written as:

$$
\frac{\left[\rho \delta_{l} \Delta x\right]_{P}-\left[\rho \delta_{l} \Delta x\right]_{P}^{o}}{\Delta t}=\left[\rho u_{\text {ave }} \delta_{l}\right]_{w}^{o}-\left[\rho u_{a v e} \delta_{l}\right]_{e}^{o}+\left[\dot{m}_{n}\right]^{o} \Delta x-\left[\dot{m}_{s}\right]^{o} \Delta x
$$

For numerical solution purposes, this expression can be written in terms of the liquid boundary layer thickness as:

$$
\left[\delta_{l}\right]_{p}=a_{w}^{o}\left[\delta_{l}\right]_{w}^{o}-a_{e}^{o}\left[\delta_{l}\right]_{e}^{o}+S_{p}^{o}
$$

Where:

$$
\begin{aligned}
& a_{w}^{o}=\left[u_{\text {ave }}\right]_{w}^{o} \frac{\Delta t}{\Delta x} \\
& a_{e}^{o}=\left[u_{\text {ave }}\right]_{e}^{o} \frac{\Delta t}{\Delta x} \\
& S_{p}^{o}=\left[\delta_{l}\right]_{P}^{o}+\left[\dot{m}_{n}\right]^{o} \frac{\Delta t}{\rho}-\left[\dot{m}_{s}\right]^{o} \frac{\Delta t}{\rho}
\end{aligned}
$$

\subsection{Conservation of Energy}

The energy balance for the control volume of a molten slag cell can be expressed as:

$$
\frac{\partial}{\partial t}[E]_{c v}=\dot{E}_{w}-\dot{E}_{e}+\dot{E}_{n}-\dot{E}_{s}+\left[\dot{E}_{g}\right]_{c v}
$$


In order to determine the contribution of each term on (42), an OAM is conducted in an alternative form of the energy equation, namely, the energy equation for incompressible flow in terms of temperature, i.e., (43). The OMA is summarized in Table 6-3. ${ }^{33}$

$$
\frac{\partial}{\partial t}\left(\rho c_{p} T\right)=-\left[\frac{\partial}{\partial x}\left(\rho c_{p} u T\right)+\frac{\partial}{\partial y}\left(\rho c_{p} v T\right)\right]+\left[\frac{\partial}{\partial x}\left(k \frac{\partial T}{\partial x}\right)+\frac{\partial}{\partial y}\left(k \frac{\partial T}{\partial y}\right)\right]+\mu \phi+\dot{H}_{R}+\dot{H}_{l s}
$$

Table 6-3. Order of magnitude of the terms in the temperature energy equation.

\begin{tabular}{|c|c|c|}
\hline Term & Scale as & Order of Magnitude \\
\hline$\frac{\partial}{\partial x}\left(\rho c_{p} u T\right)$ & $\frac{\rho c_{p} u \Delta T}{L}$ & $O\left(10^{4}\right)$ \\
\hline$\frac{\partial}{\partial y}\left(\rho c_{p} v T\right)$ & $\frac{\rho c_{p} v \Delta T}{\delta}$ & $O\left(10^{4}\right)$ \\
\hline$\frac{\partial}{\partial x}\left(k \frac{\partial T}{\partial x}\right)$ & $\frac{k \Delta T}{L^{2}}$ & $O(1)$ \\
\hline$\frac{\partial}{\partial y}\left(k \frac{\partial T}{\partial y}\right)$ & $\frac{k \Delta T}{\delta^{2}}$ & $O\left(10^{6}\right)$ \\
\hline$\mu \phi=\mu\left[\frac{\partial u}{\partial y}\right]^{2}$ & $\mu\left(\frac{U}{\delta}\right)^{2}$ & $O\left(10^{2}\right)$ \\
\hline
\end{tabular}

Neglecting the contribution of the smallest order terms, the energy equation for the slag flow model can be written as:

$$
\frac{\partial}{\partial t}\left(\rho c_{p} T\right)=-\left[\frac{\partial}{\partial x}\left(\rho c_{p} u T\right)+\frac{\partial}{\partial y}\left(\rho c_{p} v T\right)\right]+\frac{\partial}{\partial y}\left(k \frac{\partial T}{\partial y}\right)+\dot{H}_{R}+\dot{H}_{l s}
$$

\footnotetext{
${ }^{33}$ An alternative procedure to the OMA is show in Appendix C. In this alternative procedure the OMA for the energy equation is expressed in terms of the Peclet and Brinkman numbers.
} 
After spatial integration and implicit integration in time, this expression can be written in terms of the slag bulk temperature $T_{m}$ as:

$$
\begin{aligned}
\frac{\left[\rho c_{p} T_{m} \delta_{l}\right]_{p}-\left[\rho c_{p} T_{m} \delta_{l}\right]_{p}^{o}}{\Delta t} \Delta x=\left[\rho c_{p} u_{a v e} T_{m} \delta_{l}\right]_{w}^{o} & -\left[\rho c_{p} u_{a v e} T_{m} \delta_{l}\right]_{e}^{o}+ \\
& \dot{q}_{n} \Delta x-\dot{q}_{s} \Delta x+\sum_{j}\left(\dot{m}_{p} c_{p} T_{p}\right)_{j}+\dot{H}_{R}+\dot{H}_{l s}
\end{aligned}
$$

For numerical solution purposes, this expression is written in terms of the slag bulk temperature as:

$$
a_{p}\left[T_{m}\right]_{P}=F_{w}^{o}\left[T_{m}\right]_{w}^{o}-F_{e}^{o}\left[T_{m}\right]_{e}^{o}+S^{o}
$$

Where:

$$
\begin{aligned}
& a_{p}=\left\lfloor\rho c_{p} T_{m}\right]_{p} \\
& F_{w}^{o}=\left[\rho c_{p} u_{\text {ave }} \delta_{l}\right]_{w}^{o} \frac{\Delta t}{\Delta x} \\
& F_{e}^{o}=\left[\rho c_{p} u_{a v e} \delta_{l}\right]_{e}^{o} \frac{\Delta t}{\Delta x} \\
& S^{o}=\dot{q}_{n} \Delta x-\dot{q}_{s} \Delta x+\sum_{j}\left(\dot{m}_{p} c_{p} T_{p}\right)_{j}+\dot{H}_{R}+\dot{H}_{l s}
\end{aligned}
$$

\subsection{Species Transport Equation}

The general expression for the species mass transport equation is expressed as: 


$$
\frac{\partial\left(\rho y_{k}\right)}{\partial t}+\frac{\partial\left(\rho u y_{k}\right)}{\partial x}=\frac{\partial}{\partial x}\left(\rho D_{k} \frac{\partial y_{k}}{\partial x}\right)+\dot{m}_{n} y_{k}-\dot{m}_{s} y_{k}+\dot{\omega}_{k}
$$

Following the same integration procedure in the control volume, the species transport equation can be written for solution purposes in terms of the mass fraction of a particular specie as:

$$
\begin{aligned}
{\left[\rho y_{k} \delta_{l}\right]_{p}=\left[y_{k} \delta_{l} u_{\text {ave }}\right]_{w}^{o} \frac{\Delta t}{\Delta x}-\left[y_{k} \delta_{l} u_{\text {ave }}\right]_{l}^{o} } & \frac{\Delta t}{\Delta x}+ \\
& {\left[\dot{m}_{n} y_{k}\right]_{p}^{o} \Delta t-\left[\dot{m}_{s} y_{k}\right]_{p}^{o} \Delta t+\left[\rho y_{k} \delta_{l}\right]_{p}^{o}+\left[\dot{\omega}_{k} \delta_{l}\right]_{p}^{o} \Delta t }
\end{aligned}
$$

Where, taking into consideration the value for the Peclet number of mass diffusivity, the diffusion term in the slag flow direction has been neglected.

The solution of the species transport equation allows estimating the species balance once some properties and variables are known at the previous time step, as, for instance, slag thickness, average velocity, and the source term for the chemical reaction of $\mathrm{CaC}_{2}$.

\subsection{Chemical Kinetics and Reaction}

Rowan et al. [108] conducted comparisons between their model predictions and experimental data found in literature for reactant consumption, $\mathrm{CaC}_{2}$ production and weight loss. The authors showed that the second model that they developed, namely the MRM model, provides accurate predictions. Therefore, the MRM was selected as the chemical kinetics model aimed at estimating the source term in the species transport equation. Nonetheless, a simplification was 
included. The simplification entailed assuming only the first reaction of their proposed mechanism.

\subsection{Solidification-Melting}

Two solidification mechanisms are considered in the slag flow model. The first one is the solidification that takes place inside the control volume, from which solids can be transported by the flow; the second is the solidification/melting at the solid-liquid interface. The models to account for both of these processes are discussed next.

\subsubsection{Solidification sub-model for $\mathrm{CaO}$ and $\mathrm{CaC}_{2}$ transported in the slag}

The amount of solidified material that can be transported by the slag is considered to be a fraction $\lambda_{l s}$ of the value provided by the solid-liquid equilibrium phase diagram for $\mathrm{CaO}-\mathrm{CaC}$.

$$
x_{s}=\lambda_{l s} x_{s e}
$$

$\lambda_{l s}$ can be considered as a progress variable that depends on the sub cooling temperature. This progress variable is modeled as:

$$
\lambda_{l s}=1-\exp \left(-a_{l s} \cdot\left(T_{e u t}-T_{m}\right)\right)
$$

Where $a_{l s}$ is a relaxation parameter.

The equilibrium diagram is shown in Figure 6-2. It can be found in the reference [130]. 


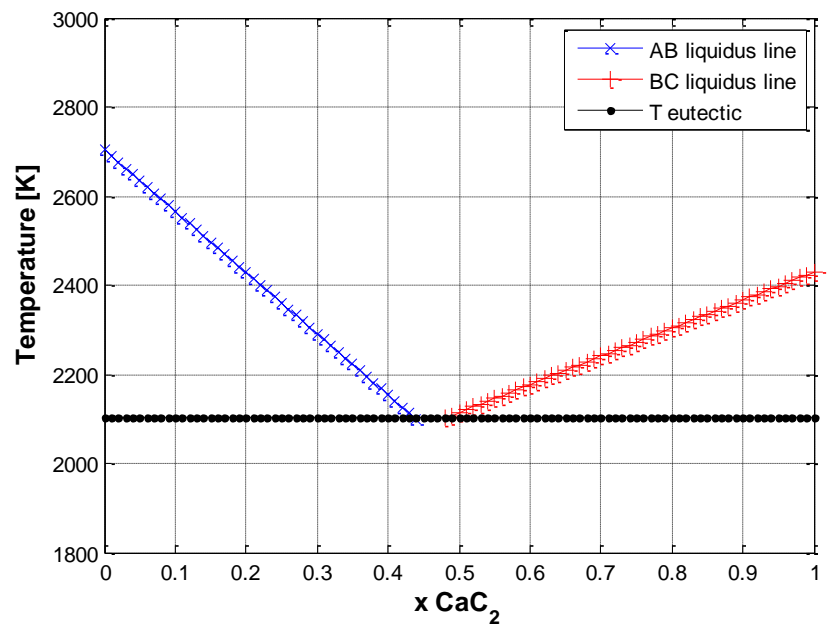

Figure 6-2. Solid-liquid equilibrium phase diagram for $\mathrm{CaO}-\mathrm{CaC} 2$. Taken from [130]

At this point, it should be stated that the MRM for the chemical kinetics of $\mathrm{CaC}_{2}$ has been developed based on solid-solid reactions. Nonetheless, since a higher contact area will be brought about by the liquid, the rate of reaction will be likely to increase. In order to account for this effect, a simple model is proposed in this work. In this model, the forward and backward rate coefficients of the reaction are calculated based on a weighted average of the relative solid and liquid amounts of $\mathrm{CaO}$ and $\mathrm{CaC}_{2}$. This relation can be expressed as:

$$
\begin{aligned}
& k_{f}=\left(1-\varepsilon_{f}\right) k_{f-l}+\varepsilon_{f} k_{f-s} \\
& k_{B}=\left(1-\varepsilon_{B}\right) k_{B-l}+\varepsilon_{B} k_{B-s}
\end{aligned}
$$


Where the relative solid and liquid amounts of $\mathrm{CaO}$ and $\mathrm{CaC}_{2}$ are expressed as:

$$
\begin{aligned}
& \varepsilon_{f}=\frac{x_{\mathrm{CaO}(s)}}{x_{\mathrm{CaO}(s)}+x_{\mathrm{CaO}(l)}} \\
& \varepsilon_{B}=\frac{x_{\mathrm{CaC}_{2}(s)}}{x_{\mathrm{CaC}_{2}(s)}+x_{\mathrm{CaC}_{2}(l)}}
\end{aligned}
$$

And the forward and backward rate coefficients for the liquid are assumed to be multiples of the rate coefficients based on solid-solid reactions:

$$
\begin{aligned}
& k_{f-l}=\lambda_{k-f} \cdot k_{f-s} \\
& k_{B-l}=\lambda_{k-B} \cdot k_{B-s}
\end{aligned}
$$

This simple approach allows estimating the effect a higher contact area on the rate of $\mathrm{CaC}_{2}$ formation in terms of the parameters $\lambda_{k-f}$ and $\lambda_{k-B}$. 


\subsubsection{Solidification sub-model for the solidified slag layer}

The rate of growth or decrease of the solidified slag layer is modeled by applying the Stefan's condition [129]. This condition states that such growth or decrease depends on the difference in the amount of heat transfer to the liquid-solid interface, as shown in Figure 6-3. This condition can be expressed as:

$$
\left.k_{s} \frac{\partial T_{s}}{\partial y}\right|_{y=\delta_{s}}-\left.k_{l} \frac{\partial T_{l}}{\partial y}\right|_{y=\delta_{l s}+\delta_{s}}=\rho H_{f} \frac{d \delta_{l s}}{d t}
$$

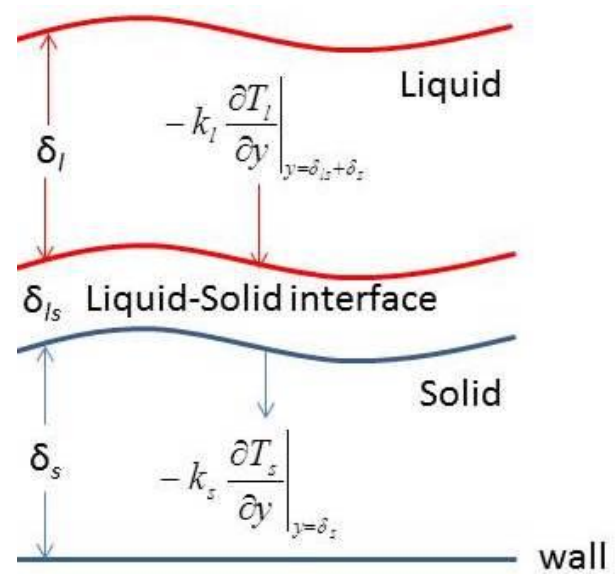

Figure 6-3. Heat transfer at the solid/liquid interface

Where:

$-\left.k_{l} \frac{\partial T_{l}}{\partial y}\right|_{y=\delta_{l s}+\delta_{s}}$ is the heat transfer from the liquid to the solid-liquid interface. 
$-\left.k_{s} \frac{\partial T_{s}}{\partial y}\right|_{y=\delta_{s}}$ is the heat transfer from the solid-liquid interface to the solid.

Assuming a linear temperature profile through the solid, the rate of growth or decrease of the solidified slag layer can be expressed as a function of the total thermal resistance of the solid slag and the furnace insulation materials:

$$
\frac{d \delta_{l s}}{d t}=\frac{1}{\rho H_{f}}\left[-\left.k_{l} \frac{\partial T_{l}}{\partial y}\right|_{y=\delta_{l s}+\delta_{s}}-\frac{\left(T_{c v}-T_{e n v}\right)}{R_{t}}\right]
$$

Where $R_{t}=\frac{\delta_{s}}{k_{s}}+R_{i n s}+\frac{1}{h_{e n v}}$ is the total resistance of the solid slag, insulation and the environment.

\subsection{Release Model for Carbon Monoxide from the Slag}

The gaseous product $\mathrm{CO}$ formed in the reaction is assumed to be released at the surface of the control volume, i.e., through the north face. The rate at which the $\mathrm{CO}$ is released is assumed to be proportional to the difference between the $\mathrm{CO}$ concentration in the slag and the gaseous atmosphere of the reactor in the proximity of the liquid slag layer. This can be expressed as:

$$
\left[\dot{m}_{c o}\right]_{n}=h_{m C O} \cdot \Delta x \cdot\left(\left[y_{C O}\right]_{l}-\left[y_{C O}\right]_{\infty}\right)
$$


Where $h_{m C O}$ is the CO release coefficient. This coefficient should be estimated experimentally for the slag system in this work, where the experimental value provided by Solar and Guthrie [131] in a metallurgical application has been used.

\subsection{Modeling of Slag Properties}

The slag properties were modeled considering the facts included in section 3.6. The models were selected to provide reliable property values at a reasonable computational cost. As was pointed out in section 3.6, viscosity is perhaps the property most related to the control and design of the process. Unfortunately, currently, there is no viscosity model available for the slag system or the temperatures involved in this application.

Figure 6-4 shows the comparison between three of the viscosity models discussed in section 3.6, namely the model of Urbain [84], the BCURA $S^{2}$ model [88], and the model of Kalmanovitch and Frank [86] (modified Urbain model). The predictions for the slag were plotted from the coal used in the design of the oxy-coal reactors developed in this work (Decker coal). Figure 6-4 (a) shows the viscosity predictions inside the temperature range of applicability for the three viscosity models, i.e., for temperatures ranging from the critical viscosity temperature up to temperatures close to $1770 \mathrm{~K}$. Figure 6-4 (b) depicts the predicted viscosity for extrapolation to the temperature range of this application. It can be observed that the Urbain model predicts higher viscosity values. Moreover, the predictions of the BCURA $S^{2}$ model and the modified Urbain are similar. These two models predicted viscosity values between 0.04 and $0.1 \mathrm{~Pa}$ s in the range of extrapolated temperature. In this work, the BCURA $S^{2}$ model [88] was selected to predict the viscosity of the slag. Nonetheless, it is emphasized that experimental measurements 
and development of viscosity models appropriate for the slag system and the temperature range of this application must be developed.

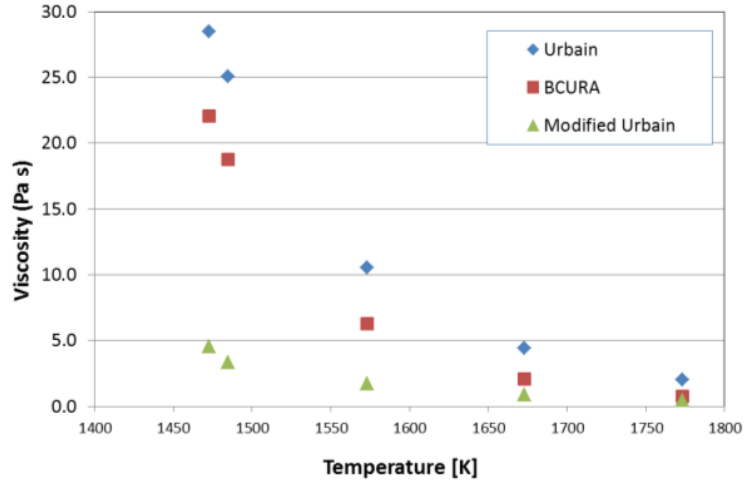

(a)

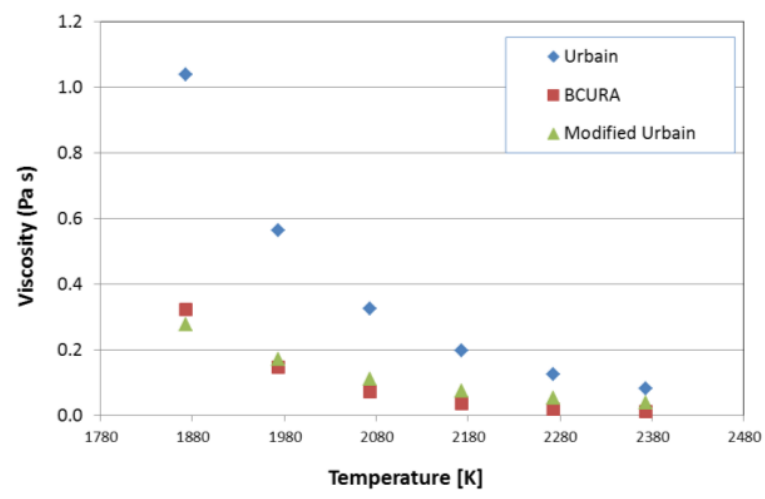

(b)

Figure 6-4. a) Predicted viscosity by the models of Urbain, BCURA $S^{2}$ and modified Urbain inside their experimental temperature range. b) Extrapolation to the temperature range of this application.

Regarding the temperature of critical viscosity, its value was estimated by using the method followed by Seggiani [132]. The estimated value for the critical viscosity temperature is close to $1485 \mathrm{~K}$. The density was estimated as recommended by Mills [80], i.e., from the molar weighted average of the molar volume for every particular constituent present in the slag. As suggested by Mills [93], this same approach was used to model the heat capacity of the slag.

Regarding the thermal conductivity of the slag, it was mentioned in section 3.6 that the thermal conductivity of slag systems does not depend strongly on composition but on the structure of the slag. Nonetheless, the range of variation of the thermal conductivity is narrow, e.g., between 1.73 and $1.8 \mathrm{~kW} / \mathrm{m} \mathrm{K}$, as reported by Yong et al. [69]. The constant value at the middle of this range was selected for the thermal conductivity. 
Regarding the slag composition, only the main species were considered, which are $\mathrm{C}, \mathrm{CaO}$, $\mathrm{CaC}_{2}, \mathrm{CO}, \mathrm{SiO}_{2}, \mathrm{Al}_{2} \mathrm{O}_{3}$ and $\mathrm{Fe}_{2} \mathrm{O}_{3}$. From those, the species contained in the ash were assumed as non-reacting species except for $\mathrm{CaO}$. The information required for the calculations of the SFM, such as the thermo-physical properties of the slag constituents, ash composition, and reactor insulation materials, is reported in appendix B.

\subsection{Solution Method for the Slag Model}

The SFM transport equations were solved by using the upwind scheme for spatial integration and by using explicit integration in time. The domain was divided in 60 cells. This division provided a good compromise between accuracy and the computational time required to obtain a steady state solution. The time step was set to a value of 5 milliseconds. This value produced a conservative Courant number. The value for the courant number for a typical solution is plotted along the domain in Figure 6-5.

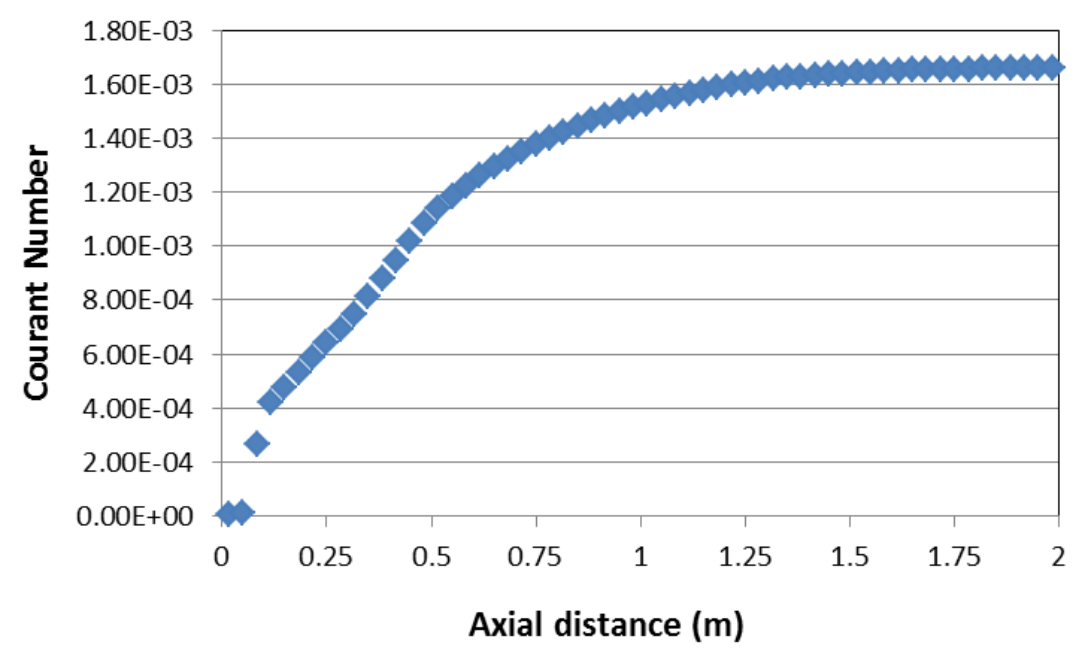

Figure 6-5. Courant number profile along the domain for a typical solution of the SFM (case OF35-02-B). 
The steps of the solution algorithm can be summarized in the following sequence:

1. Specify parameters
a. Reactor dimensions.
b. Insulation materials.
c. Environment conditions.
d. Ash composition.
e. Cell size.
f. Solution time.

2. Specify boundary conditions in every $i$ cell.
a. In the north face: gas temperature, gas velocity, shear stress, particle deposition
b. In the south face: critical viscosity temperature and total insulation resistance

3. Specify initial conditions in every $i$ cell. Assume:
a. Solid and molten slag thicknesses.
b. Slag bulk temperature.
c. Slag average viscosity.
d. Initial composition.

4. Calculate liquid slag thickness in $\mathrm{t}+\mathrm{dt}$.

5. Calculate the velocity profile in the molten slag.

6. Calculate the source terms for the species transport equation from the chemical kinetics.

7. Solve the Species transport equation.

8. Calculate the source terms for the energy equation.

9. Solve the energy equation and calculate the bulk slag temperature. 
10. Calculate the solid slag thickness in $\mathrm{t}+\mathrm{dt}$.

11. Update slag properties.

12. Go to step 4.

13. Finish if steady is reached.

The computational framework of the slag model is shown in Figure 6-6.

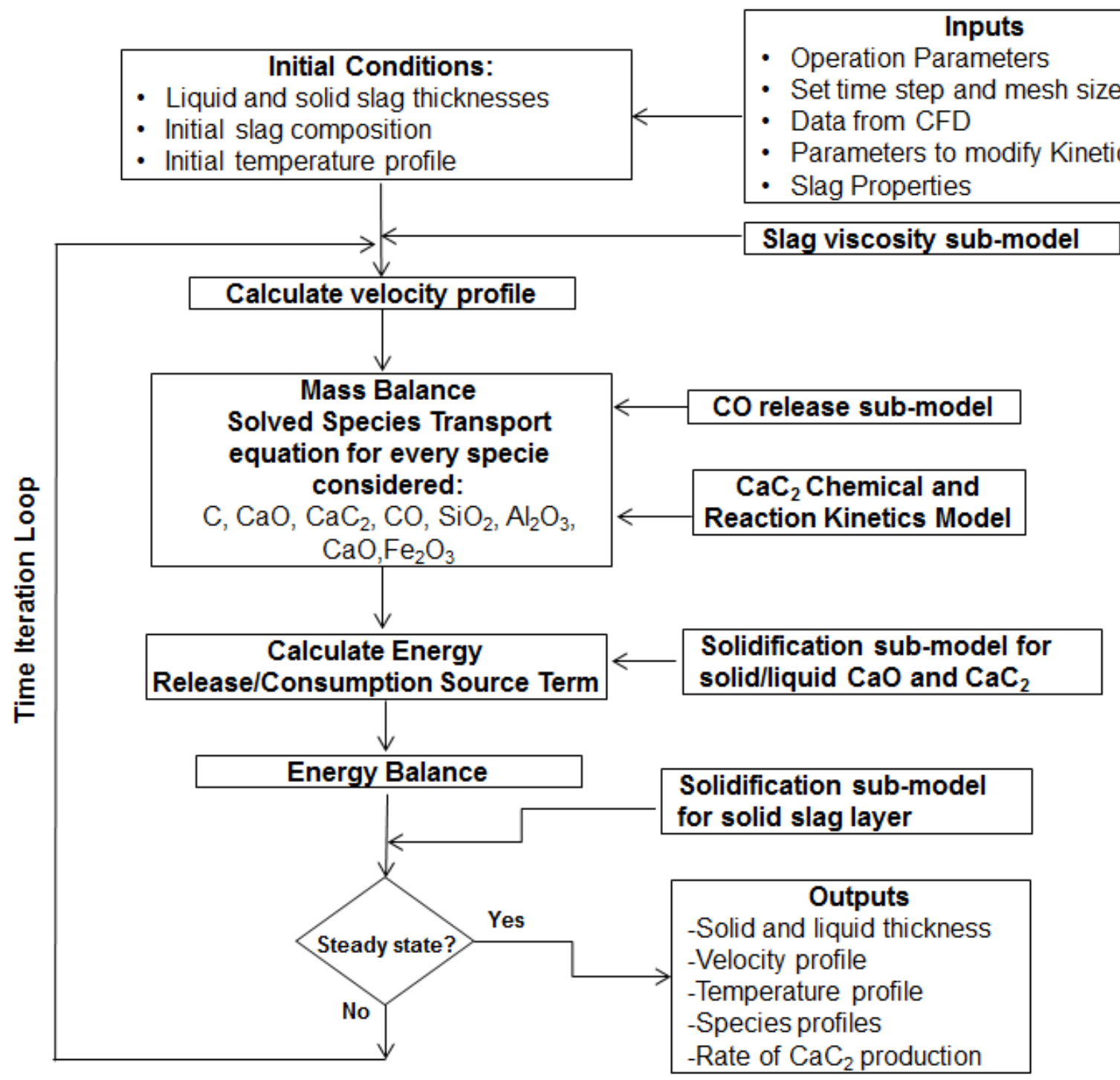

Figure 6-6. Computational framework of the slag model. 


\subsection{Verification of the Slag Model}

Due to the lack of experimental results available for the slag system modeled in this research, a verification procedure was conducted to test the reliability of the SFM. The procedure involved the comparison of the solution provided by the slag flow model against the analytical solution for a natural convection boundary layer problem with solidification.

The problem is proposed by Bejan [133]. The author states that a vertical isothermal wall is put in contact with an isothermal pool of paraffin. Since the solidification point of the paraffin is between the wall temperature and the pool temperature, the wall becomes covered with a thin layer of solidified paraffin. The relevant properties of the paraffin are provided in the Table 6-4.

Table 6-4. Relevant properties for the natural convection boundary layer problem with solidification.

\begin{tabular}{|l|c|}
\hline \multicolumn{1}{|c|}{ Property } & Value \\
\hline Thermal conductivity of the liquid paraffin, $k_{f}$ & $0.15 \mathrm{~W} / \mathrm{mK}$ \\
\hline Thermal conductivity of the solid paraffin, $k_{s}$ & $0.36 \mathrm{~W} / \mathrm{mK}$ \\
\hline Compressibility factor, $\beta$ & $8.5 \mathrm{e}-04 \mathrm{~K}^{-1}$ \\
\hline Thermal diffusivity, $\alpha$ & $9 \mathrm{e}-08 \mathrm{~m}^{2} / \mathrm{s}$ \\
\hline Prandtl number, Pr & 55.9 \\
\hline
\end{tabular}

The solution for the thickness of solidified paraffin is given by Bejan [133]:

$$
\frac{\delta_{s}}{L}=\frac{k_{s}\left(T_{m}-T_{w}\right)}{k_{f}\left(T_{\infty}-T_{m}\right)} \frac{1}{0.487 R a_{L}^{1 / 4}}\left(\frac{x}{L}\right)^{1 / 4}
$$


Whereas the solution for the liquid layer thickness of the boundary layer is obtained from the integral approximate solution given by Burmeister [134]:

$$
\delta_{l}=4\left(\frac{15}{16}\right)^{1 / 4} \frac{(1+20 / 21 \mathrm{Pr})^{1 / 4}}{\left[g \beta\left(T_{w}-T_{g}\right) \operatorname{Pr} / v^{2}\right]^{1 / 4}} x^{1 / 4}
$$

The mass flow rate deposition function along the slag flow direction, needed as an input in the SFM, was provided such that the integral of its distribution is equal to the analytical value of the mass flow rate given at that distance, $x$. This condition can be stated as:

$$
\int_{0}^{x} \dot{m}^{\prime} d x=\left[\rho u_{a v e} \delta_{l}\right]_{x}
$$

Figure 6-7 (a) shows the comparison of the liquid boundary layer thickness given by the SFM against the analytical solution given by Burmeister. It can be observed that the solution provided by the SFM matches the analytical solution.

Figure 6-7 (b) depicts the comparison of the solid layer thickness given by the slag flow model against the analytical solution given by Bejan. The solution provided by the SFM matches the order of magnitude of the analytical solution. This, taking into account that the solidification model utilized in the SFM is different than the one provided by Bejan. 
In the solution provided by Bejan, the latent heat of fusion is not considered. Instead, the solidified thickness is obtained by estimating the heat transfer based on correlations for the Nusselt Number, which is a function of the Rayleigh number and the Prandtl Number.

In the SFM, the solidified slag thickness depends on the latent heat of fusion, which is a key parameter in solidification problems ${ }^{34}$. As can be seen in Figure 6-7 (b), different values of the latent heat of fusion for the slag result in different solution profiles for the solidified thickness. Three different values of the latent heat of fusion were utilized, which correspond to actual values of paraffin waxes reported by Ukrainczyk et al. [135]. The selected values cover the range reported by the authors.

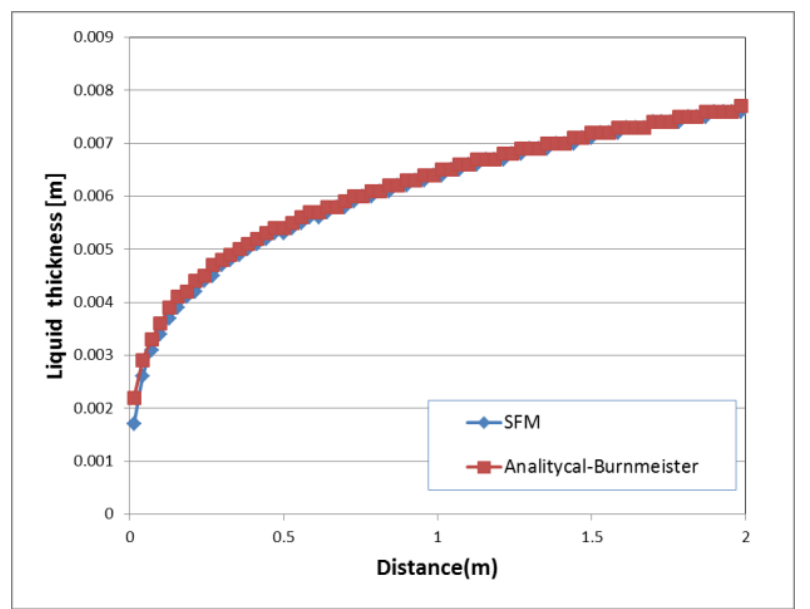

(a)

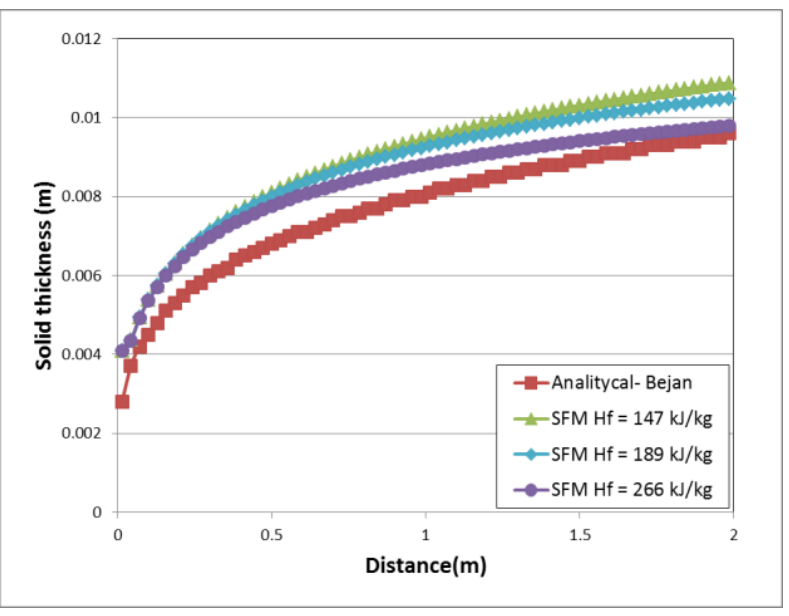

(b)

Figure 6-7. (a) Comparison of the liquid boundary layer thickness given by the SFM against the analytical solution. (b) Comparison of the solidified layer thickness given by the SFM against the analytical solution.

\footnotetext{
${ }^{34}$ See, for instance, the aforementioned problem of Stefan [129] and the problems found in Ozisik [140].
} 


\section{Chapter 7 - VHTER: Results and Discussion}

\subsection{VHTER: Exploratory Study}

In the initial stage, a pilot study with a simplified model was conducted to analyze the down-

fired design under oxy-coal conditions. Only the combustion process was studied with this simplified model. An additional simplification entailed considering only one meter length of the combustion chamber. At that point, no information regarding the type of coal to be used was known, so that the same coal used in the validation study [111], i.e. German lignite, was selected (Table 5-2). All the simulations were based on a power input of $100 \mathrm{~kW}$, which is equivalent to a mass flow rate of $4.78 \mathrm{e}-03 \mathrm{~kg} / \mathrm{s}$ of pulverized coal.

Two different oxidant mixtures were considered initially, including $\mathrm{O}_{2}$ molar fractions of 0.25 and 0.50, with $\mathrm{CO}_{2}$ as the balance gas. These cases were named OF25-E for 0.25 and OF50-E for 0.50. The heat loses through the wall were assumed to be 25 percent of the power input, which is similar to the reactor operation described in Nikzat et al. [136]. The mass flow rate of oxidant was calculated considering a fuel to oxidant stoichiometric ratio of 0.85 . Approximately, 11 percent of the oxidant was injected through the primary port as carrier gas for pulverized coal, while the rest was injected through the secondary port. This value was established after different percentages were assessed in order to find a well-defined burner recirculation zone (BRZ). The oxidant mass flow rates are given in Table 7-1. Standard pressure and temperature conditions were assumed for the inlet gas and coal particles. 
Table 7-1. Oxidant gas inlet conditions for the exploratory study.

\begin{tabular}{|c|c|c|c|c|}
\hline \multirow{2}{*}{ CASE } & \multicolumn{2}{|c|}{ Primary port } & \multicolumn{2}{c|}{ Secondary port } \\
\cline { 2 - 5 } & $\mathrm{kg} / \mathrm{s}$ & $\mathrm{T}, \mathrm{K}$ & $\mathrm{kg} / \mathrm{s}$ & $\mathrm{T}, \mathrm{K}$ \\
\hline OF25-E & 21.71 & 300 & 195.48 & 300 \\
\hline OF50-E & 10.44 & 300 & 90.72 & 300 \\
\hline
\end{tabular}

Figure 7-1shows the flow pattern and temperature contours for the reacting flow of the OF25-E and OF50-E cases. A different location for the BRZ can be observed. As is depicted, the BRZ becomes narrower in the OF50 and is located downstream with respect to the OF25 case.

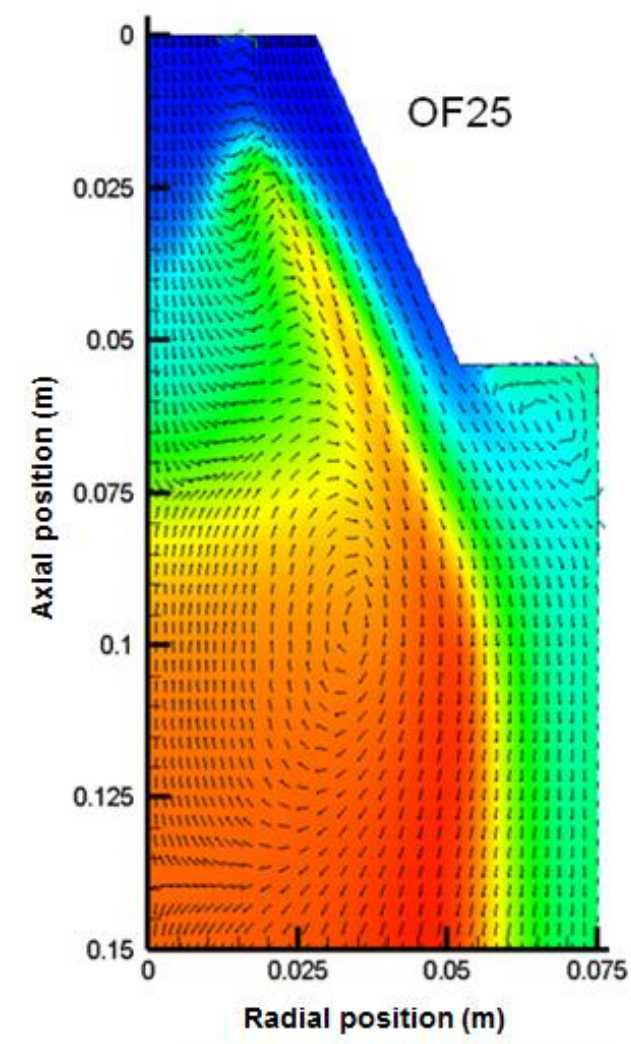

Temperature: 300500700900110013001500170019002100

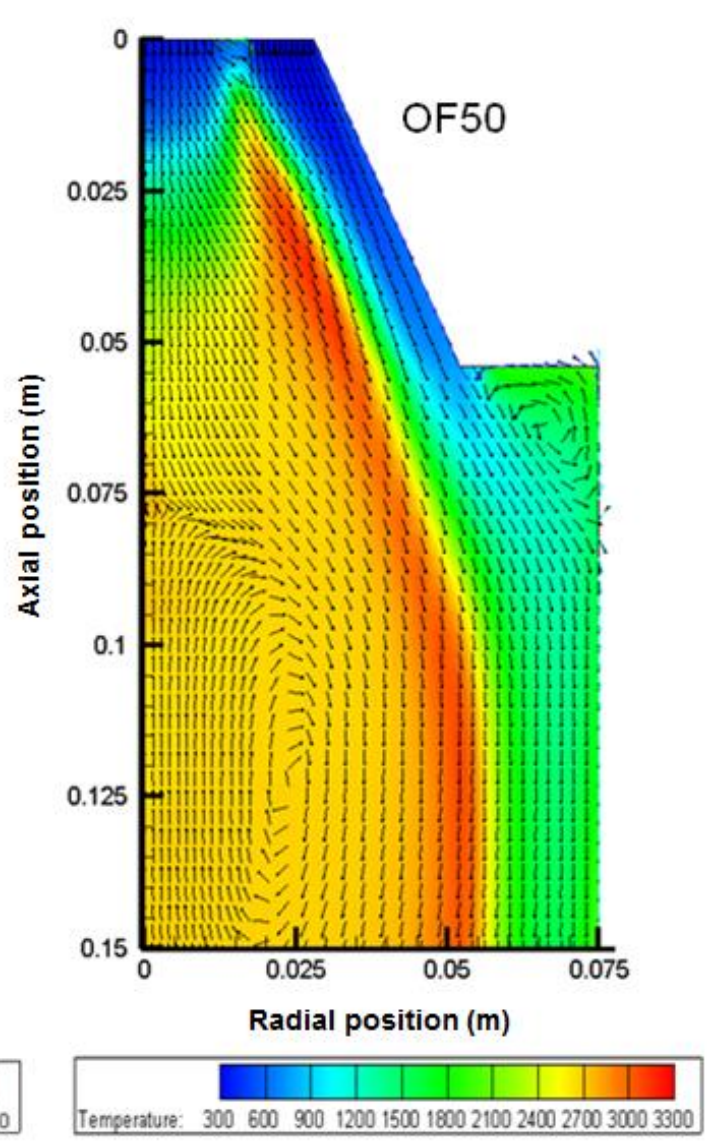

Figure 7-1. Velocity recirculation pattern and temperature contours in the BRZ for the OF25-E and OF50-E cases. 
Figures 7-2 and 7-3 depict the temperature contours, mass fraction of volatiles, and the char burnout for the two cases. The figures show that the reactor temperatures reached values in the range of 1700 to $2000 \mathrm{~K}$ for the OF25 case, and 2400 to $3000 \mathrm{~K}$ for the OF50 case.

These contours indicate that maximum temperatures are obtained in the center of the chamber and become lower towards the wall, especially in the upper part of the chamber. This is convenient for protecting the wall from high temperatures in certain applications. However, it is not convenient for activating the formation of $\mathrm{CaC}_{2}$ in the molten slag. This cold region towards the wall is relieved by the tangential flow injection of oxidant that works as carrier gas for feeding the coal and $\mathrm{CaO}$ particles.

Results for combustion of coal indicated that a complete coal devolatilization is attained for these conditions, as well as a char burnout of approximately 97 percent. An increase of the devolatilization and char burnout regions can be noted with an increase in the oxygen concentration.

Results for combustion of coal, obtained from the discrete phase model report for the OF50 case, are shown in Figure 7-4. The first arrow indicates the time spent in the combustion; the second arrow shows the mass release; the third arrow is related to the energy released by the discrete phase; the fourth arrow depicts the percentage of volatiles and char, highlighted in red, converted in the furnace; zone 20 refers to the outlet. 


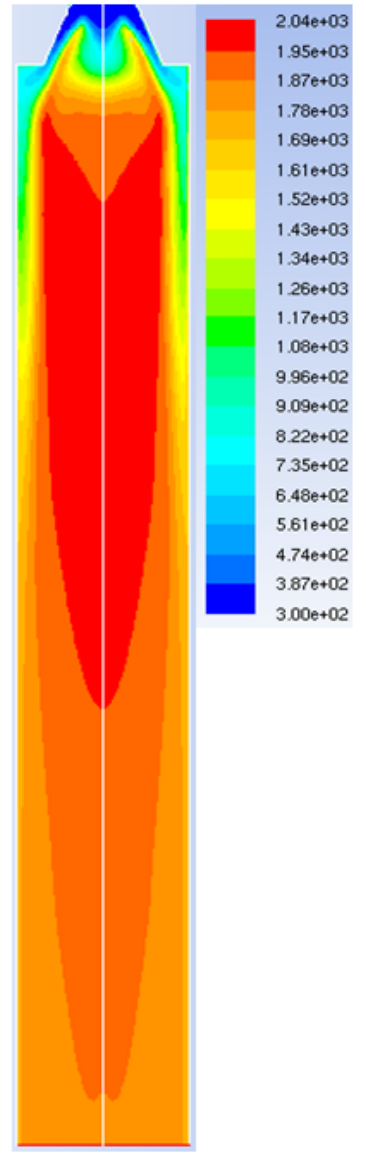

(a)

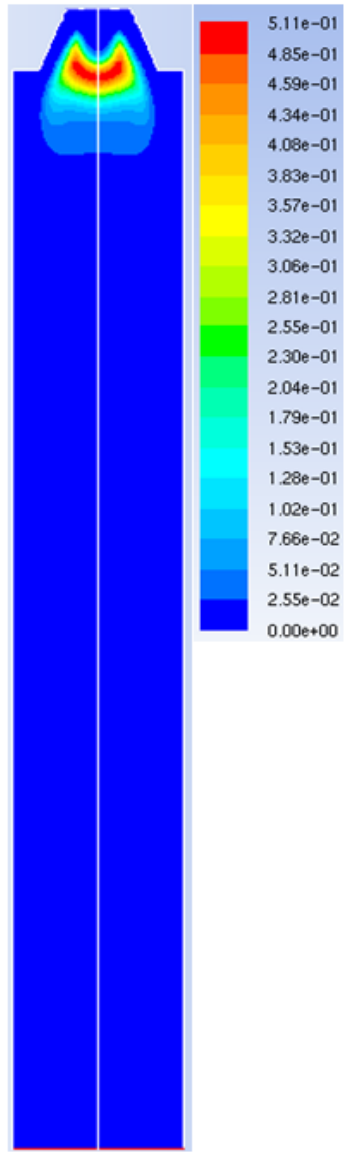

(b)

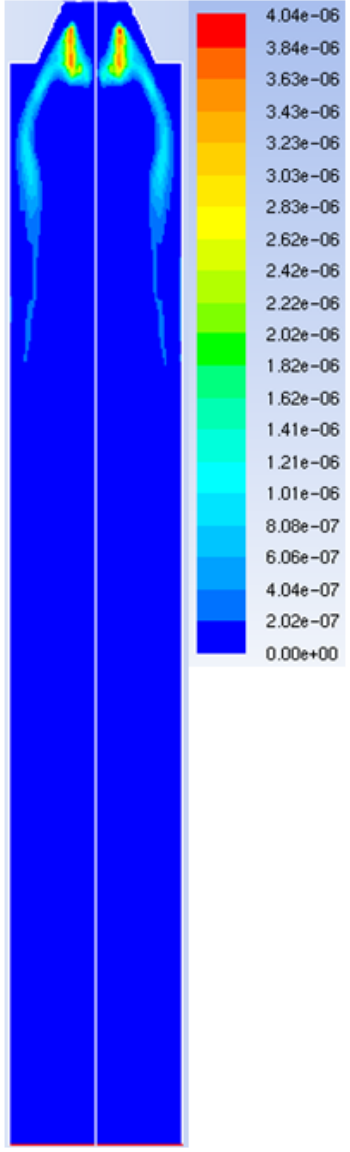

(c)

Figure 7-2. Contours of (a) Temperature (K), (b) Mass fraction of volatiles and (c) Char burnout $(\mathrm{kg} / \mathrm{s})$ for the OF25 case. 


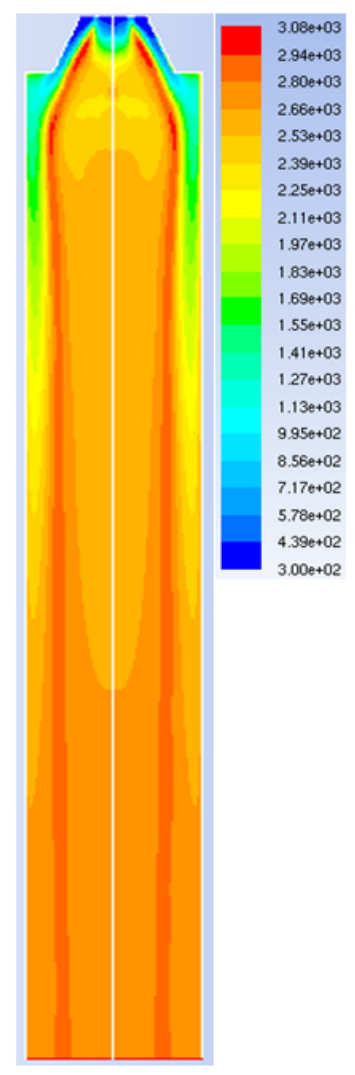

(a)

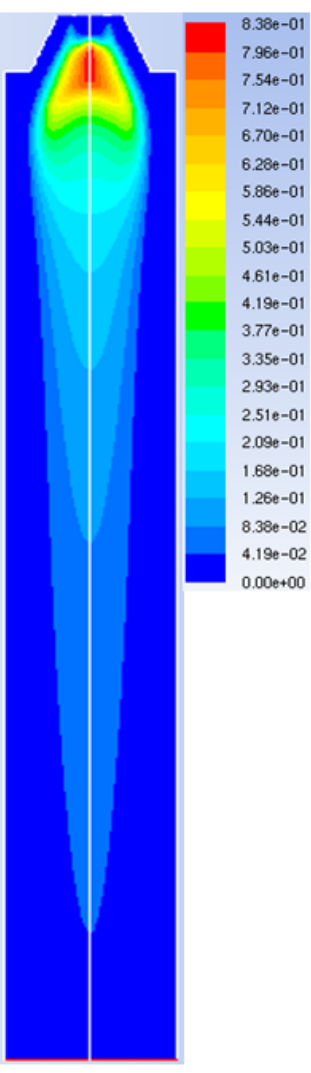

(b)

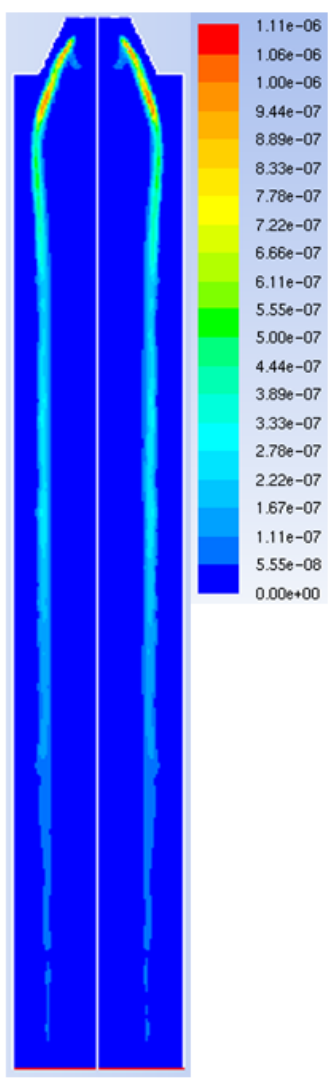

(c)

Figure 7-3. Contours of (a) Temperature (K), (b) Mass fraction of volatiles and (c) Char burnout $(\mathrm{kg} / \mathrm{s})$ for the OF50 case. 


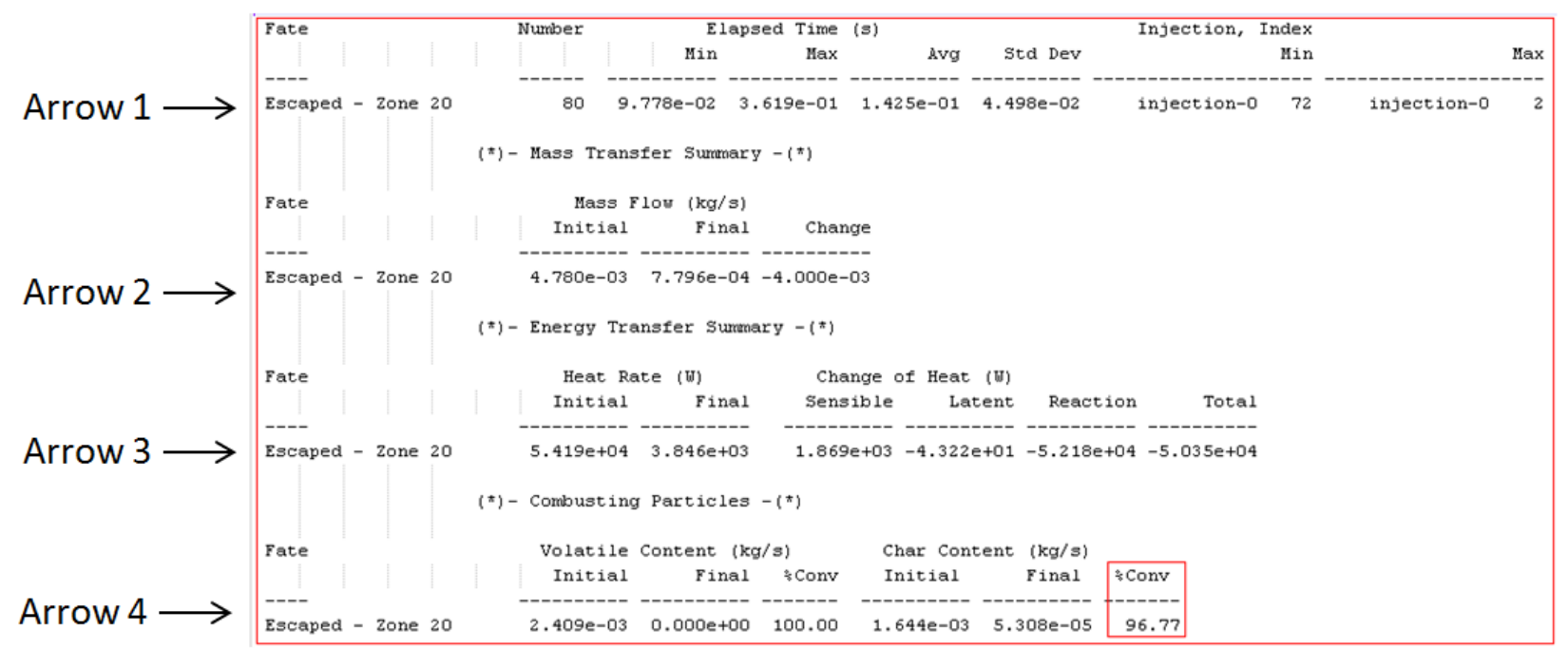

Figure 7-4. Discrete phase particle (DPM) report for OF50 case (Conversion of coal is 97 percent, approximately)

The aforementioned pilot study made it possible, saving computational costs, to envisage the combustion performance in terms of combustion stability and coal conversion. The study also allowed a first glance at the temperature levels aimed at providing the required operation conditions for $\mathrm{CaC}_{2}$ production.

The results showed that the desired conditions were obtained for oxidant mixtures with $\mathrm{O}_{2}$ molar fractions close to 0.50 . Therefore, the second stage of the exploratory study was conducted under these conditions. In this second stage, a more detailed computational model was built. This model is referred to as the OF50-E-02 case. In this model, further complexities, such as a length of $2 \mathrm{~m}$ for the combustion chamber, and the tangential injection of chemicals, were included. The heat losses through the wall were assumed to be $25 \mathrm{~kW}$, plus an additional loss of $9.8 \mathrm{~kW}$ to 
account for the energy consumed in the $\mathrm{CaC}_{2}$ reaction. In this stage of the project, the type of coal was known; particularly, it was Decker's coal mine. The properties of this coal are shown in Table 7-2, and mass flow rates are depicted in Table 7-3.

Table 7-2 Decker coal properties.

\begin{tabular}{|c|c|c|c|c|c|c|c|c|c|}
\hline \multicolumn{4}{|c|}{ Proximate analysis (wt.\% as received) } & \multicolumn{4}{c|}{ Ultimate analysis (wt.\% d.a.f.) } & LHV \\
\hline Moisture & Ash & Fixed carbon & Volatile Matter & C & H & N & S & O & $(\mathrm{MJ} / \mathrm{kg})$ \\
\hline 24.29 & 3.62 & 42.67 & 29.42 & 78.33 & 3.99 & 1.21 & 0.47 & 16.0 & 22.026 \\
\hline
\end{tabular}

Table 7-3 Inlet mass flow rates of every reactant in $\mathrm{kg} / \mathrm{s}$ through every injection port for the OF50-E-02 case.

\begin{tabular}{|l|c|c|c|}
\hline Reactant & Primary & Secondary & Tangential \\
\hline Oxidant & $1.4 \mathrm{e}-03$ & $1.62 \mathrm{e}-02$ & $8.76 \mathrm{e}-04$ \\
\hline Coal & $4.54 \mathrm{e}-03$ & 0 & $3.25 \mathrm{e}-03$ \\
\hline $\mathrm{CaO}$ & 0 & 0 & $2.16 \mathrm{e}-03$ \\
\hline
\end{tabular}

Figure 7-5 shows the temperature profiles for the OF50-E-02 case along with the radial distance in different axial locations and centerline. It can be noted that temperature is higher towards the wall when compared with the simplified model with no tangential flow of particle injection. This higher temperature near the wall is especially noticeable in the initial section of the combustion chamber and becomes nearly uniform after half of the combustion chamber length. Gas, particles, and wall temperature can be seen in Figure 7-6. It can be observed that all these values are within the range of temperature suggested by $\mathrm{Li}$ et al. [107] for $\mathrm{CaC}_{2}$ formation, i.e., 1733 and 1973K. 
Figures 7-6, 7-7 and 7-8 show the particle deposition and temperature in the wall location for each injection defined in the model, that is, coal for combustion, coal for the $\mathrm{CaC}_{2}$ reaction, and $\mathrm{CaO}$ particles. These values are inputs required in the slag model. Results show that the primary coal mass deposited on the wall of the down-fired reactor is $1.68 \mathrm{e}-03 \mathrm{~kg} / \mathrm{m}^{2} \mathrm{~s}$. This value is equivalent to 34.9 percent of the total primary coal mass injected. For the tangentially injected coal, the mass deposited on the wall is $1.60 \mathrm{e}-03 \mathrm{~kg} / \mathrm{m}^{2} \mathrm{~s}$. This value is equivalent to a 46.5 percent of the total primary coal mass injected. For the tangentially injected $\mathrm{CaO}$, the mass deposited on the wall is $4.27 \mathrm{e}-03 \mathrm{~kg} / \mathrm{m}^{2} \mathrm{~s}$. This value is equivalent to a 93.2 percent of the total primary $\mathrm{CaO}$ mass injected. Results for mass deposition are summarized in Table 7-4. 


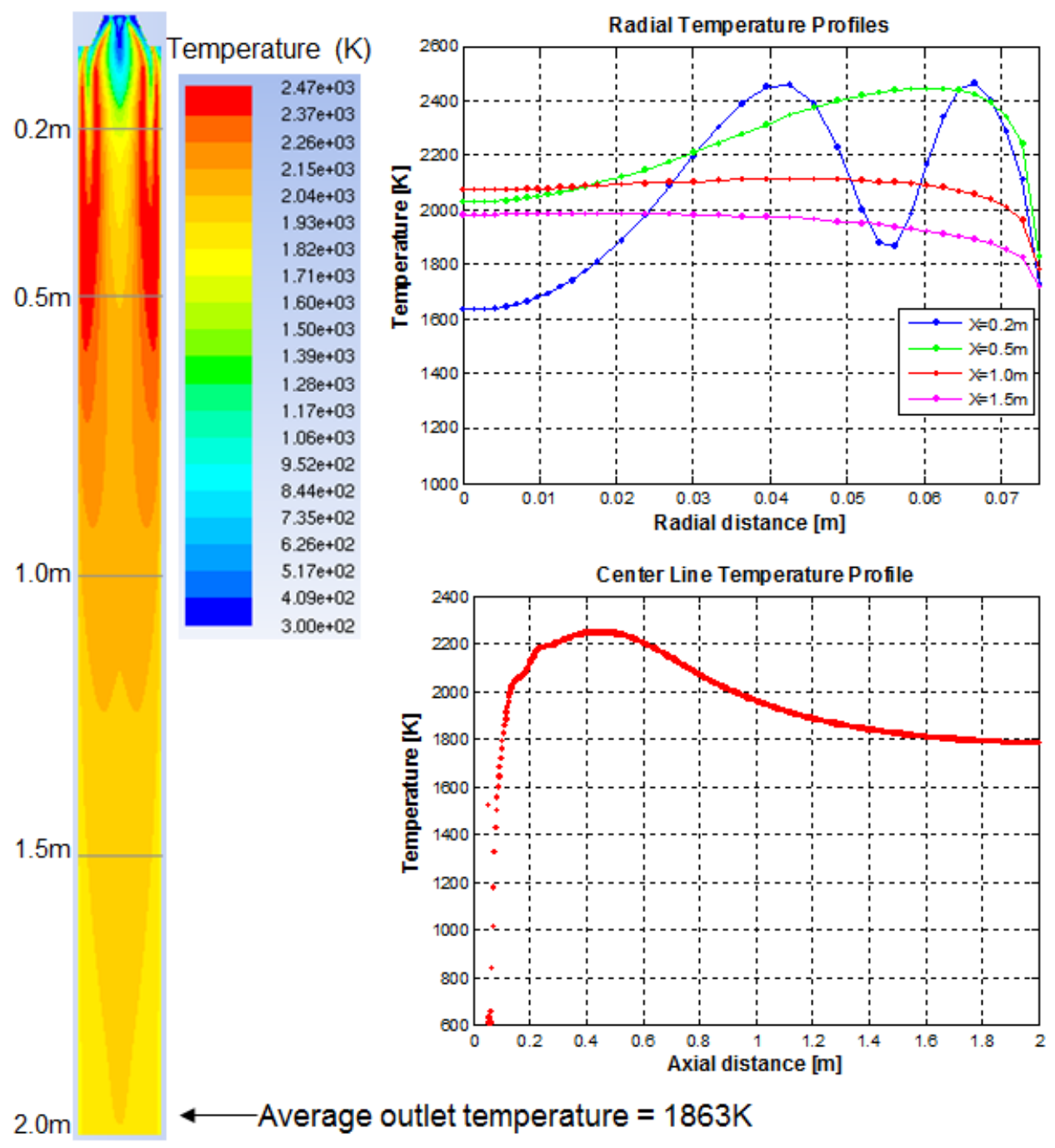

Figure 7-5.Temperature contours and profiles for the OF50E-02 case. 

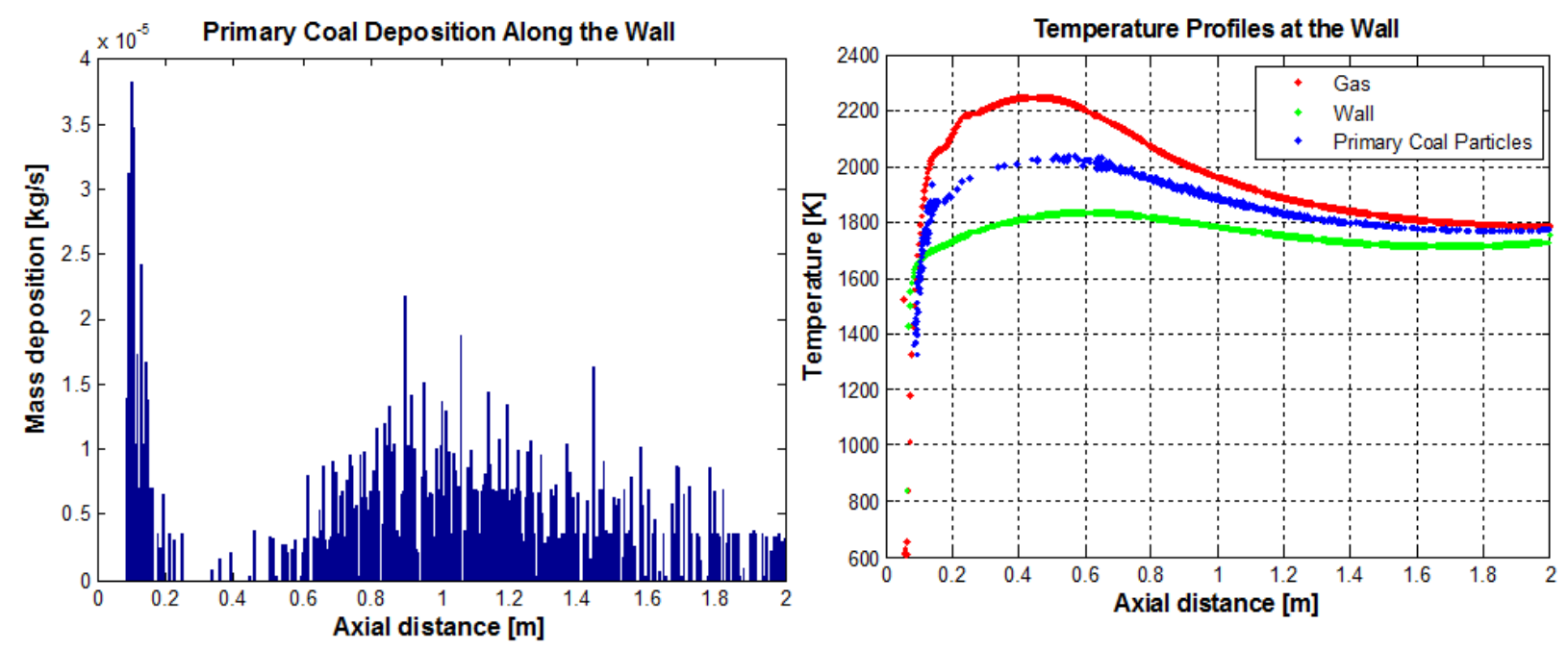

Figure 7-6. Particle deposition and temperature along the wall of coal injected through the primary port for the down-fired reactor (OF50-E-02 case).
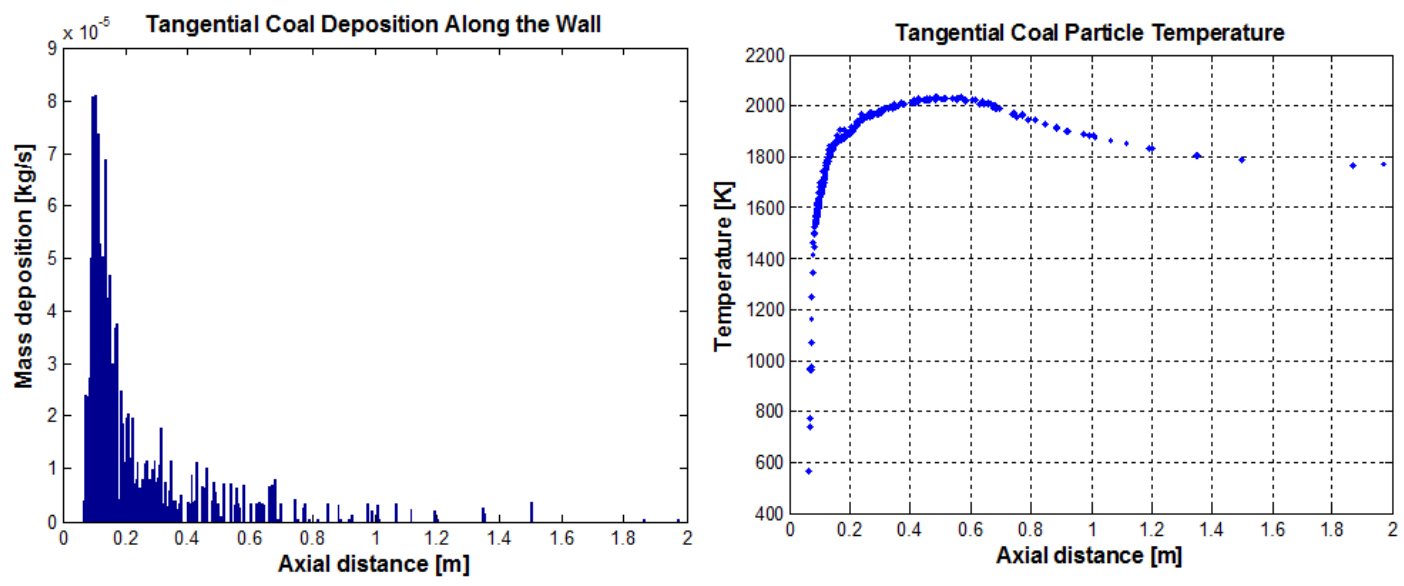

Figure 7-7. Particle deposition and temperature along the wall of tangentially injected coal for the down-fired reactor (OF50 case). 

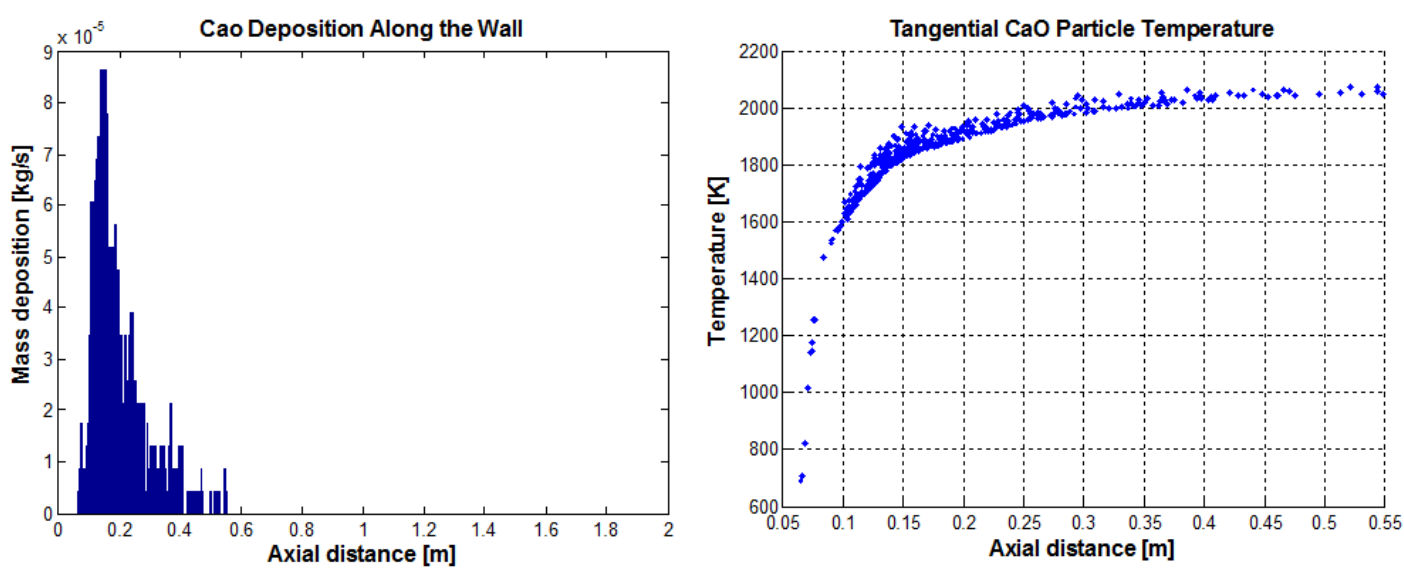

Figure 7-8. Particle deposition and particle temperature along the wall of down-fired reactor for tangentially injected $\mathrm{CaO}$ (OF50-E-02 case).

Table 7-4 Particle wall deposition for each of the injections for the OF50-E-02 case.

\begin{tabular}{|c|c|c|c|c|}
\hline Injection Type & $\begin{array}{c}\text { Injected } \\
\mathbf{( k g / s )}\end{array}$ & $\begin{array}{c}\text { Deposition } \\
\mathbf{( k g / s )}\end{array}$ & $\begin{array}{c}\text { Deposition } \\
\left(\mathbf{k g} / \mathbf{s ~ m}^{\mathbf{2}} \mathbf{)}\right.\end{array}$ & $\begin{array}{c}\text { \% of } \\
\text { total injected }\end{array}$ \\
\hline Primary coal & $4.54 \mathrm{e}-03$ & $1.58 \mathrm{e}-03$ & $1.68 \mathrm{e}-03$ & 34.9 \\
\hline Tangential coal & $3.25 \mathrm{e}-03$ & $1.51 \mathrm{e}-03$ & $1.60 \mathrm{e}-03$ & 46.5 \\
\hline Tangential $\mathrm{CaO}$ & $2.16 \mathrm{e}-03$ & $2.01 \mathrm{e}-03$ & $4.27 \mathrm{e}-03$ & 93.2 \\
\hline
\end{tabular}

Regarding the ash collector, a preliminary study was conducted considering the outlet results from the OF50-E-02 case as the boundary inlet conditions, i.e., an average gas temperature of $1863 \mathrm{~K}$ for the incoming gases, composed mainly of $75 \mathrm{vol} \% \mathrm{CO}_{2}, 21$ vol\% $\mathrm{O}_{2}$ and coal volatiles three percent by volume ${ }^{35}$. For the discrete phase, the percentages of the particles leaving the system were estimated considering the particle trajectory analysis. It was estimated that 28

\footnotetext{
${ }^{35}$ Remaining species were not considered.
} 
percent of the coal particles injected for combustion, i.e., through the primary port, and 11 percent of the coal particles injected for the reaction i.e., tangentially injected, were leaving the system. Particles were considered fly ash, with a total flow of $3.5 \mathrm{e}-05 \mathrm{~kg} / \mathrm{s}$.; for $\mathrm{CaO}, 6.8$ percent were leaving the system with a total flow of $3.09 \mathrm{e}-04 \mathrm{~kg} / \mathrm{s}$. Boundary conditions for heat transfer in the walls were specified as constant temperature in the side and bottom walls, and adiabatic in the top wall, with a value of $500{ }^{\circ} \mathrm{C}$.

Results for wall deposition showed that a 91 percent of the particles were trapped in ash collection system, and the outlet average gas temperature was 1206 K. Figure 7-9a shows the gas temperature contours for the outlet gases of the combustion chamber cooled down as the gases flow through the ash collector. Figure 7-9b depicts the particles traces of fly ash. Figure 7-9c shows the temperature contours of water in the middle of the annular region of the cooling jacket. The arrows show the water flow direction in inlet and outlets. Water is considered to be entering into the system with standard conditions, with a volumetric flow rate of 2.5 US gpm. Ports $\mathrm{A}$ and $\mathrm{B}$ are the tangential water injection and ports $\mathrm{C}$ and $\mathrm{D}$ show the water outlet. Results for the cooling jacket indicated that temperatures were far below the boiling temperature, which means that maximum temperatures are about $50{ }^{\circ} \mathrm{C}$. Nonetheless, it was noted that this occurs in some localized 'dead regions'. 


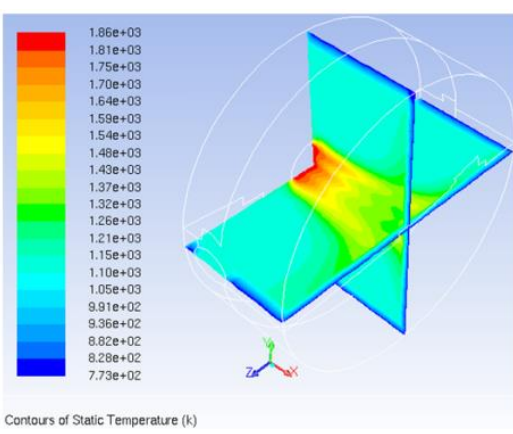

(a)

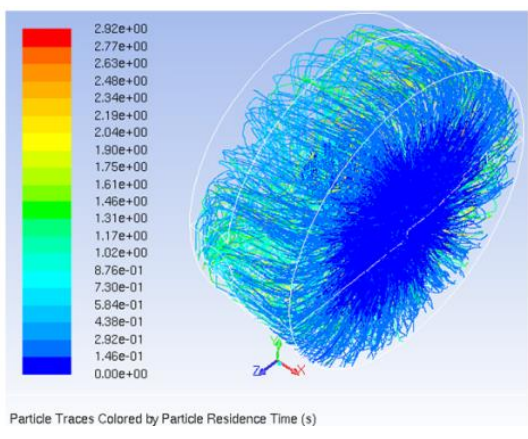

(b)

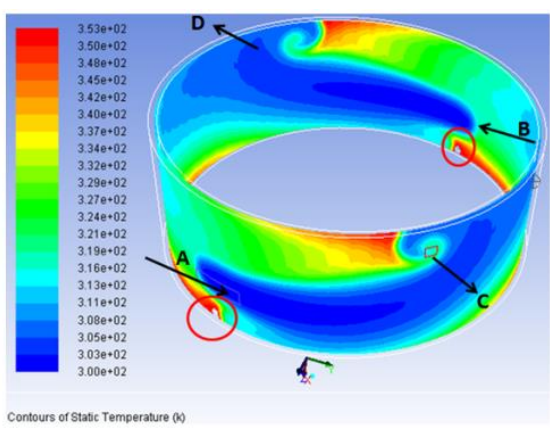

(c)

Figure 7-9. a) Ash collector temperature contours at planes xy and zx b) Particle flow pattern inside the ash collector c) Ash collector: temperature patter in the middle section of the cooling jacket.

\subsection{VHTER: Design for $\mathrm{CaC}_{2}$ Production}

In this section, the final results for the VHTER are included. The final set of simulations were aimed at obtaining stable combustion and estimating the required operating conditions for $\mathrm{CaC}_{2}$ production in a more precise manner than was done in the exploratory study.

Since the insulation materials and their dimensions were known at the final stage of this project, a modification to the boundary condition for the heat transfer through the wall was added. The modification entailed utilizing the thin shell model available in ANSYS Fluent. In this approach, a one-dimensional conduction equation is used to compute the thermal resistance offered by the wall; this means that the computation of the wall heat transfer was directly included in the combustion model. This was done by calculating an equivalent resistance and wall thickness considering the insulation material and their dimensions. The relevant information for the wall insulation materials is provided in appendix B. In addition to the thin shell model, the energy 
consumed by the heat of reaction Table 7-10 was included as a source term in the wall boundary condition. This required performing an iterative work between the combustion model and the SFM model.

A combustion stability study was conducted for all the simulations in order to establish the volumetric amount of oxidant injected through each port of the burner. An example of this study (for the OF50-01 case) is shown in Table 7-5. The results are tabulated based upon the volumetric gas percentage through the primary port. The volumetric flow rate through the tangential port was set to a value equal to four percent. This value provided an adequate particle deposition distribution in the initial portion of the combustion chamber.

In the combustion stability study, the swirl number was defined as recommended by Syred and Beer [137]:

$$
S=\frac{2 G_{\phi}}{G_{x} D_{e}}
$$

Where $G_{\phi}$ is the axial flux of angular momentum given by:

$$
G_{\phi}=\int_{0}^{R}(w r) \rho u 2 \pi r d r
$$

And $G_{x}$ is the axial flux of linear momentum calculated as:

$$
G_{x}=\int_{0}^{R}(u) \rho u 2 \pi r d r
$$

Costa et al. [138] suggest that, along with the swirl number, the ratio of the momentum of the secondary to the primary stream, $\mathrm{R}_{\mathrm{m}}$, also plays an important role in the assessment of 113 
combustion stability. The authors describe different regions of stability performance for different types of burners. The results are presented in a diagram depicting the secondary swirl vs. the ratio of the momentum of the secondary to the primary stream. Therefore, this ratio was also monitored and is included in Table 7-5.

The results for this example show that an optimum value for combustion stability, as well as for the maximum fuel conversion efficiency, is obtained for a volumetric percentage of oxidant through the primary port between eight and nine percent. For values higher than 12 percent, the momentum of the primary stream caused the coal particles to leave the flame region with insufficient time to attain a significant amount of devolatilization, thus resulting in flame extinction. Flame extinction was also observed for values below eight percent. In this case, the lack of axial momentum of the primary stream caused most of the particles to be forced towards the wall at the initial portion of the combustion chamber, without sufficient time to attain a stable flame. The results reported in Table 7-5 match the region of stability performance for this type of burner as shown by Costa et al. [138].

Two additional effects were analyzed and are also included in Table 7-5. The first one is the effect of increasing the amount of oxidant, i.e., a fuel-to-oxidant stoichiometric ratio of $0.85(\phi=$ 0.85). It can be observed that the char combustion increased from 93 to 99 percent at this level. This high burnout rate was already observed in the exploratory study, in which the same fuel to oxidant stoichiometric ratio was used. The second effect is a decrease in the swirl angle from 45 to $38^{\circ}$. It can be seen that this change caused the char burnout to decrease from 93 to 89 percent. 
Table 7-5. Example of the combustion stability study for the OF50 case.

\begin{tabular}{|c|c|c|c|c|c|c|c|c|}
\hline $\boldsymbol{\phi}$ & $\begin{array}{c}\text { Vol.\% } \\
\text { through } \\
\text { primary } \\
\text { port }\end{array}$ & $\begin{array}{c}\text { Swirl } \\
\text { vane } \\
\text { angle }\end{array}$ & $\begin{array}{c}\text { primary } \\
\text { stream } \\
\left(\mathbf{k g} / \mathbf{m s}^{\mathbf{2}}\right)\end{array}$ & $\begin{array}{c}\mathbf{G}_{\mathbf{x}} \\
\text { secondary } \\
\text { stream } \\
\left(\mathbf{k g} / \mathbf{m s}^{\mathbf{2}}\right)\end{array}$ & $\begin{array}{c}\mathbf{G}_{\mathbf{x}} \\
\text { secondary } \\
\text { stream } \\
\left(\mathbf{k g} / \mathbf{m}^{\mathbf{2}} \mathbf{s}^{\mathbf{2}}\right)\end{array}$ & $\mathbf{R}_{\mathbf{m}}$ & $\mathbf{S}_{\mathbf{s}}$ & $\begin{array}{c}\text { Char } \\
\text { burnout } \\
\mathbf{\%}\end{array}$ \\
\hline 1 & 8 & 45 & 8.43 & 73.26 & 1.72 & 0.12 & 0.84 & 93 \\
\hline 1 & 9 & 45 & 10.68 & 71.70 & 1.68 & 0.15 & 0.84 & 94 \\
\hline 1 & 10 & 45 & 13.22 & 70.12 & 1.64 & 0.19 & 0.84 & 92 \\
\hline 1 & 12 & 45 & 19.06 & 67.04 & 1.57 & 0.28 & 0.84 & 91 \\
\hline 1 & 8 & 38 & 8.45 & 73.33 & 1.34 & 0.12 & 0.65 & 89 \\
\hline 0.85 & 8 & 45 & 11.69 & 101.93 & 2.39 & 0.11 & 0.84 & 99 \\
\hline
\end{tabular}

Once the optimum volumetric gas distribution was established in every case, different strategies were followed to compare the performance of the VHTER. The first strategy involved estimating the performance of the VHTER under different oxidant atmospheres with oxidant mixtures containing $\mathrm{O}_{2}$ molar fractions; the $\mathrm{O}_{2}$ molar fractions ranged from 0.25 to 0.50 , i.e., $\mathrm{OF} 25$ to OF50, with $\mathrm{CO}_{2}$ as the balance gas.

The initial set of calculations was based on a fuel to oxidant stoichiometric ratio equal to one $(\phi$ $=1$ ) and all the gases were injected at ambient temperature. Furthermore, this set of simulations was tagged by adding the 01 identifier at the end of the case name, e.g., OF25-01. In this set of simulations, the performance of the VHTER was measured in terms of the gas temperature near 
the wall, since this quantity provides a direct estimation of the conditions to activate the $\mathrm{CaC}_{2}$ reaction. The inlet conditions utilized in this set of simulations are shown in Table $7-6^{36}$.

The gas temperature near the wall was monitored for every condition in order to establish if the resulting temperature profile was above the recommended range suggested by Li et al. [107] for $\mathrm{CaC}_{2}$ production, i.e., above $1973 \mathrm{~K}$. Initially, the amount of coal and $\mathrm{CaO}$ injected through the tangential port was set to the same value, since the amounts of char and $\mathrm{CaO}$ deposited on the wall are not known beforehand.

Table 7-6. Inlet conditions for the VHTER simulations

\begin{tabular}{|c|c|c|c|c|c|c|c|c|c|c|}
\hline \multirow{3}{*}{ Case ID } & \multirow{3}{*}{$\phi$} & \multicolumn{3}{|c|}{ Primary port } & \multirow{2}{*}{\multicolumn{2}{|c|}{$\frac{\text { Secondary port }}{\text { Gas }}$}} & \multicolumn{4}{|c|}{ Tangential port } \\
\hline & & \multicolumn{2}{|c|}{ Gas } & \multirow{2}{*}{$\begin{array}{l}\text { Coal } \\
\mathrm{kg} / \mathrm{h}\end{array}$} & & & \multicolumn{2}{|c|}{ Gas } & \multirow{2}{*}{$\begin{array}{l}\text { Coal } \\
\mathrm{kg} / \mathrm{h}\end{array}$} & \multirow{2}{*}{$\begin{array}{l}\mathrm{CaO} \\
\mathrm{kg} / \mathrm{h}\end{array}$} \\
\hline & & $\mathrm{kg} / \mathrm{h}$ & $\mathbf{T}, \mathbf{K}$ & & $\mathrm{kg} / \mathrm{h}$ & $\mathbf{T}, \mathbf{K}$ & $\mathrm{kg} / \mathrm{h}$ & $\mathbf{T}, \mathbf{K}$ & & \\
\hline OF25-01 & 1.0 & 19.04 & 300 & 16.34 & 116.99 & 300 & 5.44 & 300 & 11.70 & 11.70 \\
\hline OF30-01 & 1.0 & 17.20 & 300 & 16.34 & 94.50 & 300 & 4.47 & 300 & 11.70 & 11.70 \\
\hline OF35-01 & 1.0 & 12.83 & 300 & 16.34 & 81.49 & 300 & 3.77 & 300 & 11.70 & 11.70 \\
\hline OF40-01 & 1.0 & 9.75 & 300 & 16.34 & 71.53 & 300 & 3.25 & 300 & 11.70 & 11.70 \\
\hline OF45-01 & 1.0 & 7.47 & 300 & 16.34 & 63.67 & 300 & 2.85 & 300 & 11.70 & 11.70 \\
\hline OF50-01 & 1.0 & 5.67 & 300 & 16.34 & 57.37 & 300 & 2.52 & 300 & 11.70 & 11.70 \\
\hline
\end{tabular}

Figure 7-10 shows the profiles of the gas temperature near the wall for the cases included in Table 7-6. The results indicated that just oxidant mixtures with $\mathrm{O}_{2}$ molar fractions above 0.35

\footnotetext{
${ }^{36}$ In the final study, the values of mass flow rate are presented in $\mathrm{kg} / \mathrm{h}$, since this unit is more useful for the assessment of the calcium carbide production rate.
} 
meet the minimum temperature required for $\mathrm{CaC}_{2}$ production. These results allowed narrowing the range in the oxygen concentration for the next set of conditions explored.

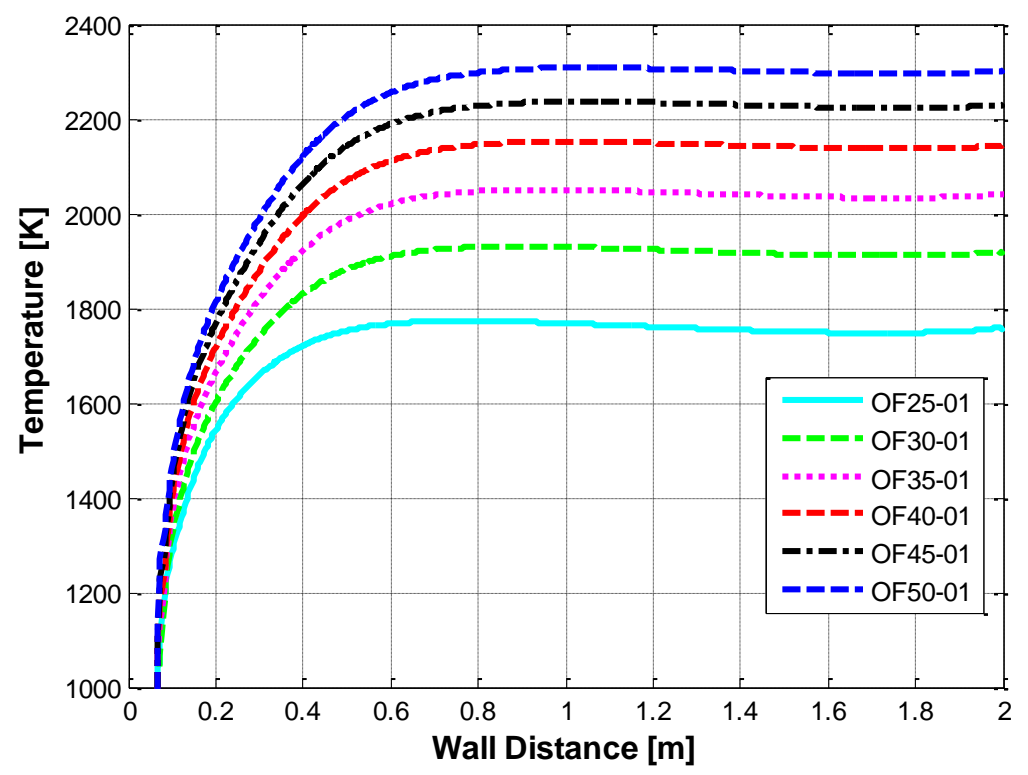

Figure 7-10. Gas temperature profiles near the wall for the VHTER cases in Table 7-6

Table 7-7 shows the mass deposition along the wall for the oxy-coal combustion cases in Table 7-6. The values for carbon and ash contained in the char are shown in the third and fourth columns. There, the level is depicted at which the mass deposition of char along the wall decreases as a result of the higher char consumption brought about by a higher oxygen concentration in the oxidant mixture. On the other hand, the amount of deposited lime was virtually unaffected. The last column of Table 7-7 shows the molar ratio of carbon to $\mathrm{CaO}$. 
Table 7-7. Deposition of mass on the wall in $\mathrm{kg} / \mathrm{h}$ for the VHTER cases in Table 7-6 suitable for $\mathrm{CaC}_{2}$ production.

\begin{tabular}{|c|c|c|c|c|c|}
\hline Case id & $\begin{array}{c}\text { Char } \\
\mathbf{k g} / \mathbf{h}\end{array}$ & $\begin{array}{c}\text { Carbon } \\
\mathbf{k g} / \mathbf{h}\end{array}$ & $\begin{array}{c}\text { Ash } \\
\mathbf{k g} / \mathbf{h}\end{array}$ & $\begin{array}{c}\mathbf{C a O} \\
\mathbf{k g} / \mathbf{h}\end{array}$ & $\begin{array}{c}\mathbf{C} / \mathrm{CaO} \\
\mathbf{m o l a r} \\
\text { ratio }\end{array}$ \\
\hline OF35-01 & 6.29 & 5.88 & 0.41 & 11.59 & 2.37 \\
\hline OF40-01 & 5.51 & 5.10 & 0.41 & 11.49 & 2.07 \\
\hline OF45-01 & 5.12 & 4.73 & 0.39 & 11.40 & 1.94 \\
\hline OF50-01 & 4.75 & 4.37 & 0.38 & 11.33 & 1.80 \\
\hline
\end{tabular}

In order to balance the amount of chemical reactants, the amount of particles injected through the tangential port was modified aimed towards obtaining a value close to the stoichiometric ratio of carbon to $\mathrm{CaO}$ of three. To accomplish this, the amount of coal injected through the tangential port was initially increased. Nonetheless, the increased amount of particles caused the gas temperature near the wall to decrease significantly. Therefore, a reduction in the amount of $\mathrm{CaO}$ was preferred. The effect of the amounts of injected reactants on the gas temperature near the wall is shown in Figure 7-11 for the OF50-01 cases. In these cases, the identifier $-\mathrm{A}$ indicates an increase in the amount of coal and $-\mathrm{B}$ a decrease in the amount of $\mathrm{CaO}$. 


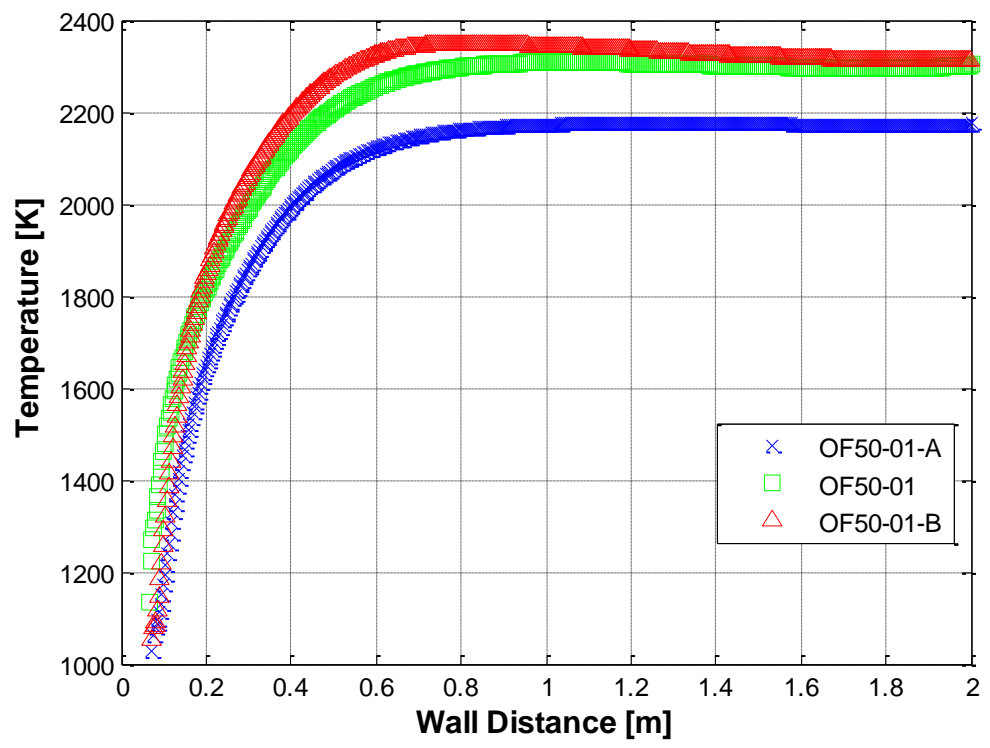

Figure 7-11. Effect of particle injection on the gas temperature near the wall for the OF50-01 cases.

It should also be noted, by observing Figures 7-10 and 7-11, that the low temperature region at the initial part of the combustion chamber is not beneficial to promote the early activation of the $\mathrm{CaC}_{2}$ reaction ${ }^{37}$ because of the higher deposition of chemicals attained in this region. This fact motivated the idea of preheating the gas injected through the secondary and tangential streams. The preheating value was set to $600 \mathrm{~K}$. This set of simulations was tagged by adding the 02 identifier at the end of the case. The letter B was kept as a remainder of the balanced condition for the chemical reactants. The conditions are provided in Table 7-8.

Figure 7-12 shows the comparison of the gas temperature profiles near the wall, with and without preheating, for the cases with the lower and higher oxygen concentrations, i.e., OF35 and OF50.

\footnotetext{
${ }^{37}$ This was already pointed out in the preliminary study.
} 
It can be observed that the temperature increase brought about by preheating is more evident in the initial length of the combustion chamber. Particularly, the average temperature increase in the region of the combustion chamber between 0 and $0.6 \mathrm{~m}$ is $247 \mathrm{~K}$ for the OF35 case. The corresponding value for the OF50 case is $268 \mathrm{~K}$. Nonetheless, the resulting temperature increase is not particularly high for the rest of the length; on the contrary, the average temperature increase for the rest of the length is $62 \mathrm{~K}$ for the OF35 case and decreases to $29.3 \mathrm{~K}$ for the OF50 case.

The results also suggest that the strategy of preheating the secondary gas stream promotes the activation of the $\mathrm{CaC}_{2}$ formation in the initial portion of the combustion chamber. That is due to the fact that the point at which the gas temperature near the wall surpass the value recommended by $\mathrm{Li}$ et al. [107] is reached sooner. For instance, in the OF35 case this point is reached at a distance of $0.15 \mathrm{~m}$ for the preheating condition as opposed to $0.37 \mathrm{~m}$ for the condition without preheating. For the OF50 case, this point is reached at $0.12 \mathrm{~m}$ for the preheating condition as opposed to $0.25 \mathrm{~m}$ for the condition without preheating. 


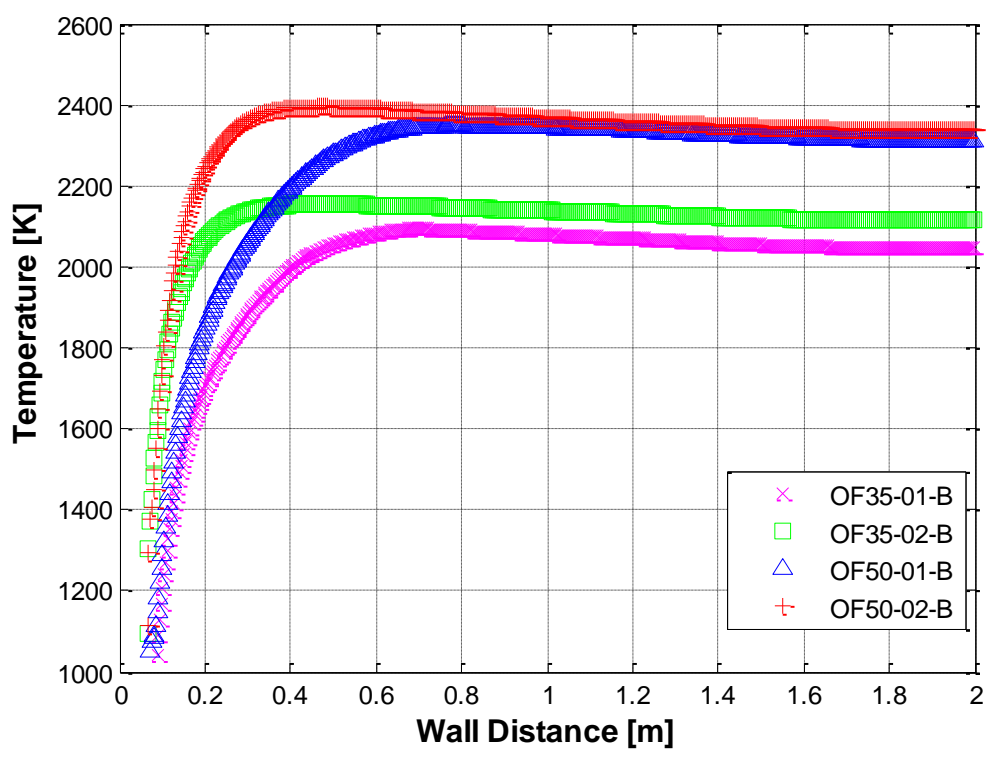

Figure 7-12. Effect of preheating on the temperature profiles near the wall for the VHTER.

This set of conditions, which is shown in Table 7-8, was selected for the study of the performance of the reactor. Figure 7-13 includes the temperature contours and the recirculation pattern in the burner region for this set of conditions.

Table 7-8. Inlet conditions for the VHTER cases with preheating and balanced amount of chemical reactants.

\begin{tabular}{|c|c|c|c|c|c|c|c|c|c|c|c|}
\hline \multirow{3}{*}{ Case ID } & \multirow{3}{*}{$\phi$} & \multicolumn{3}{|c|}{ Primary port } & \multirow{2}{*}{\multicolumn{2}{|c|}{$\begin{array}{c}\begin{array}{c}\text { Secondary } \\
\text { port }\end{array} \\
\text { Gas }\end{array}$}} & \multicolumn{4}{|c|}{ Tangential port } & \multirow{3}{*}{$\begin{array}{c}\text { Residence } \\
\text { time (s) }\end{array}$} \\
\hline & & \multicolumn{2}{|c|}{ Gas } & \multirow{2}{*}{$\begin{array}{c}\text { Coal } \\
\mathrm{kg} / \mathrm{h}\end{array}$} & & & \multicolumn{2}{|c|}{ Gas } & \multirow{2}{*}{$\begin{array}{l}\text { Coal } \\
\mathrm{kg} / \mathrm{h}\end{array}$} & \multirow{2}{*}{\begin{tabular}{|l}
$\mathrm{CaO}$ \\
$\mathrm{kg} / \mathrm{h}$
\end{tabular}} & \\
\hline & & $\mathrm{kg} / \mathrm{h}$ & $\mathbf{T}, \mathbf{K}$ & & $\mathrm{kg} / \mathrm{h}$ & $\mathbf{T}, \mathbf{K}$ & $\mathrm{kg} / \mathrm{h}$ & $\mathbf{T}, \mathbf{K}$ & & & \\
\hline OF35-02-B & 1.0 & 12.83 & 300 & 16.34 & 81.49 & 300 & 3.77 & 600 & 11.70 & 10.49 & 2.17 \\
\hline OF40-02-B & 1.0 & 9.75 & 300 & 16.34 & 71.53 & 30 & 3.25 & 600 & 11.70 & 10.39 & 2.48 \\
\hline OF45-02-B & 1.0 & 7.47 & 300 & 16.34 & 63.67 & 30 & 2.85 & 600 & 11.70 & 11.06 & 2.79 \\
\hline OF50-02-B & 1.0 & 5.67 & 300 & 16.34 & 57.37 & 300 & 2.52 & 600 & 11.70 & 10.36 & 3.10 \\
\hline
\end{tabular}



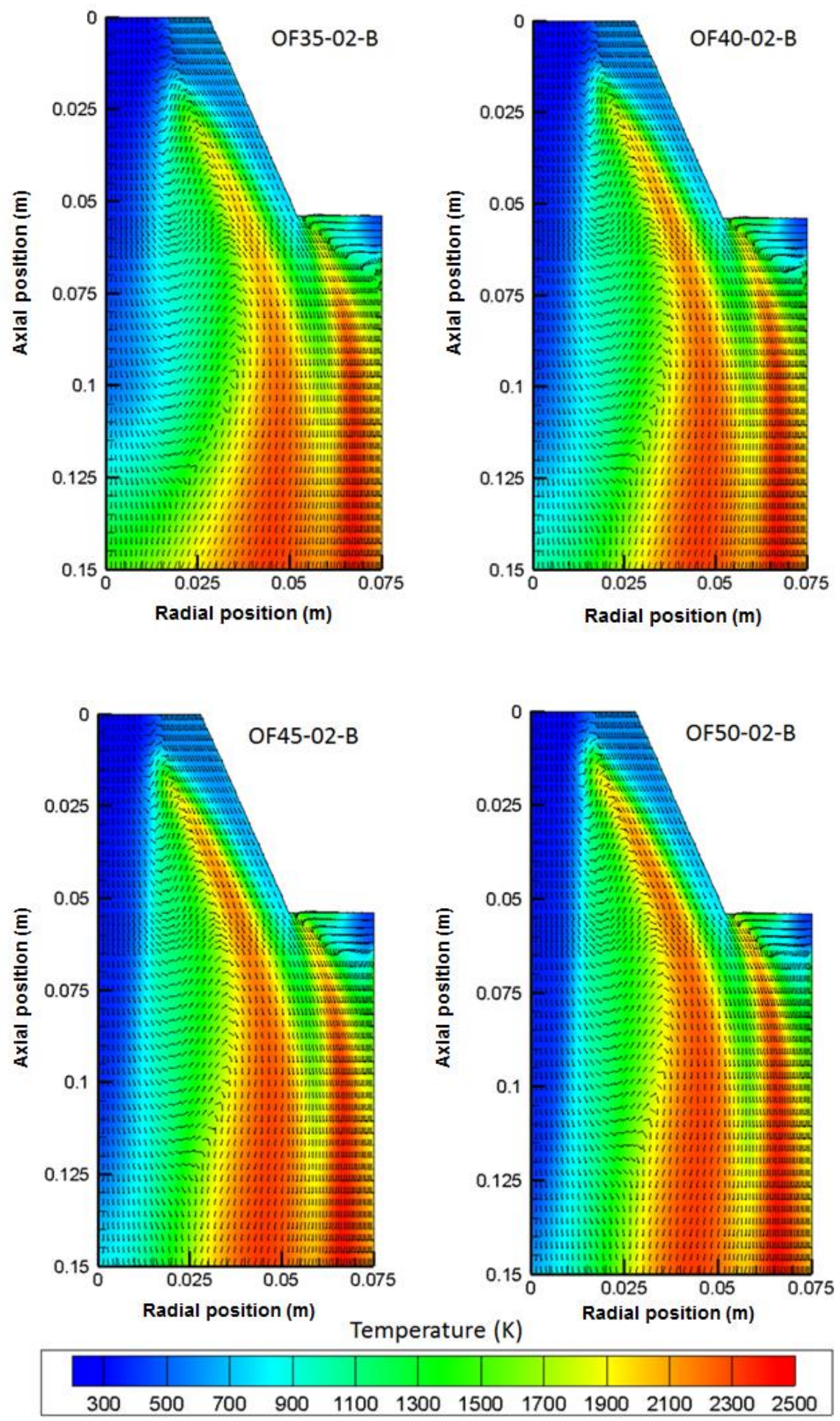

Figure 7-13. Velocity recirculation pattern and temperature contours in the BRZ for the cases in Table 7-8. 
Examples of the char and $\mathrm{CaO}$ particle distributions and temperatures are shown in Figure 7-14 and Figure 7-15 for the OF50-02-B case. The results for particle deposition are reported in Table $7-9$.

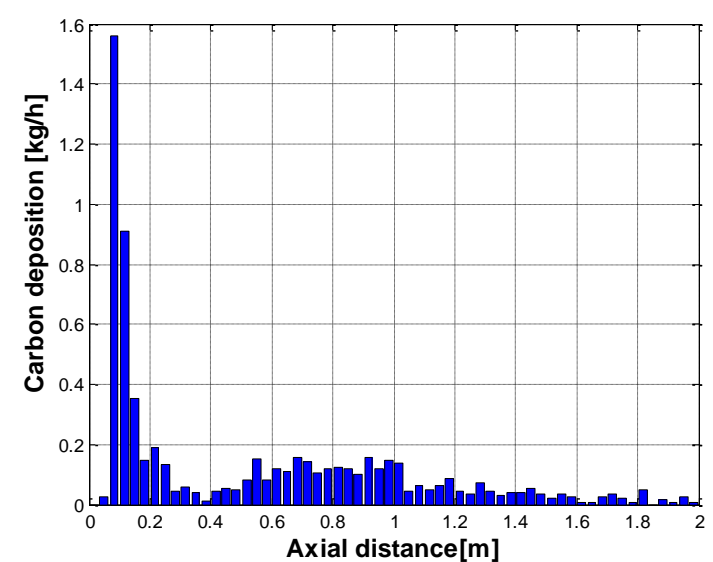

(a)

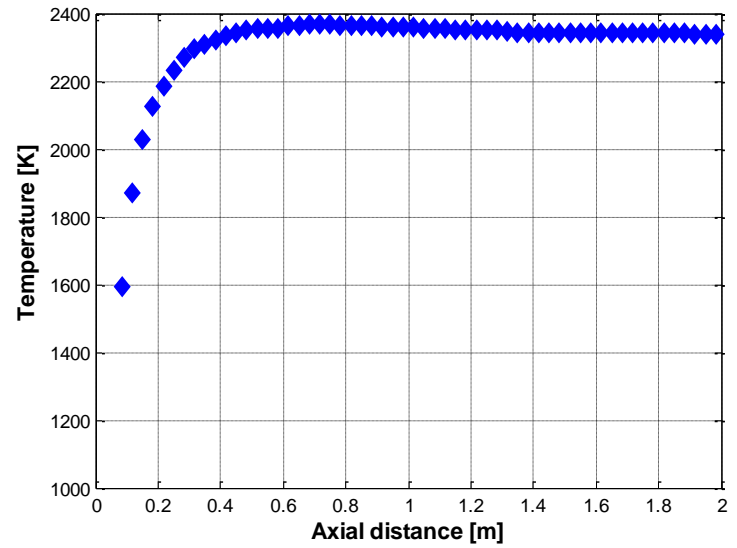

(b)

Figure 7-14. a) Deposition distribution and b) Temperature for char particles (OF50-02-B case)

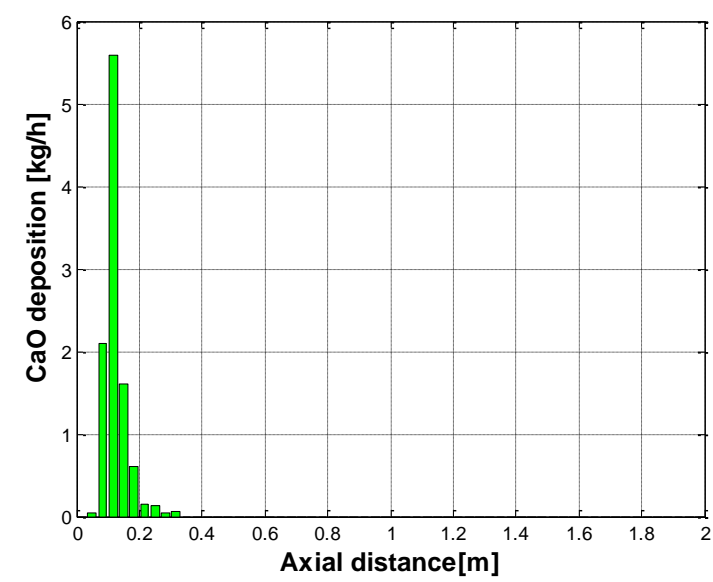

(a)

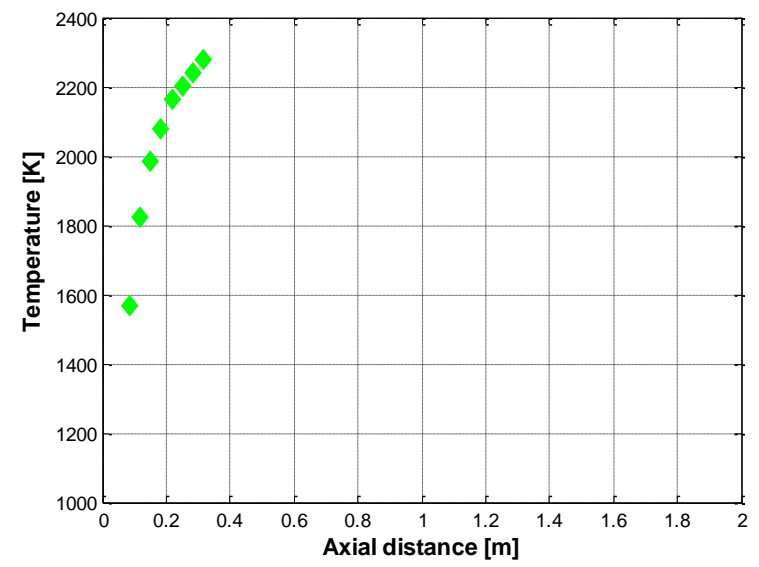

(b)

Figure 7-15. a) Deposition distribution and b) Temperature for $\mathrm{CaO}$ particles (OF50-02-B case). 
Table 7-9. Particle deposition on the wall on the wall the cases in Table 7-8.

\begin{tabular}{|c|c|c|c|c|c|}
\hline Case id & $\begin{array}{c}\text { Char } \\
\mathbf{k g} / \mathbf{h}\end{array}$ & $\begin{array}{c}\text { Carbon } \\
\mathbf{k g} / \mathbf{h}\end{array}$ & $\begin{array}{c}\text { Ash } \\
\mathbf{k g} / \mathbf{h}\end{array}$ & $\begin{array}{c}\mathbf{C a O} \\
\mathbf{k g} / \mathbf{h}\end{array}$ & $\begin{array}{c}\mathbf{C} / \mathrm{CaO} \\
\mathbf{m o l a r} \\
\text { ratio }\end{array}$ \\
\hline OF35-02-B & 6.92 & 6.50 & 0.42 & 12.04 & 3.08 \\
\hline OF40-02-B & 7.19 & 6.77 & 0.42 & 10.33 & 3.06 \\
\hline OF45-02-B & 7.33 & 6.92 & 0.42 & 10.98 & 2.94 \\
\hline OF50-02-B & 6.99 & 6.58 & 0.41 & 10.30 & 2.98 \\
\hline
\end{tabular}

\subsection{VHTER: Slag Model Results}

Figure 7-16 through Figure 7-22 show the results provided by the SFM for the selected cases in Table 7-8. Figure 7-16 shows the thickness of the liquid slag layer. The profiles are initially at their highest value due to most of the particle deposition occurs at the initial length of the combustion chamber. The sharp decrease is due to a significant reduction in viscosity which causes the slag to flow considerably faster. The viscosity of the slag is depicted in Figure 7-22. 


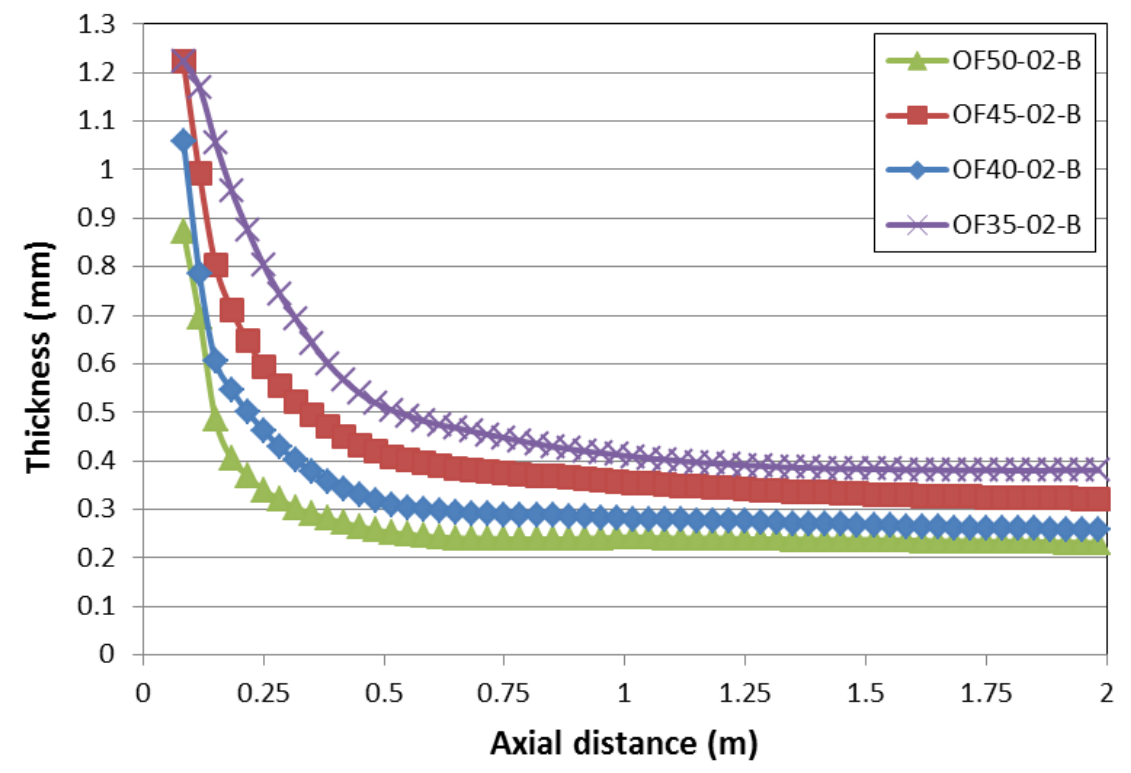

Figure 7-16. Liquid slag thickness for the conditions in Table 7-8.

Figure 7-17 shows the thickness of the solidified slag layer. It can be observed that the value is higher for cases with smaller oxygen concentrations. This behavior is consistent with the gas temperature profiles near the wall, so that smaller oxygen concentrations make the gas temperature near the wall smaller, which increases the amount of solidified slag. Similar to what happens with the liquid slag layer, the maximum thickness of the solidified slag occurs at the initial length of the wall. That is due to the fact that the temperature is smaller and the residence time of the slag is higher in this region due to a higher viscosity. 


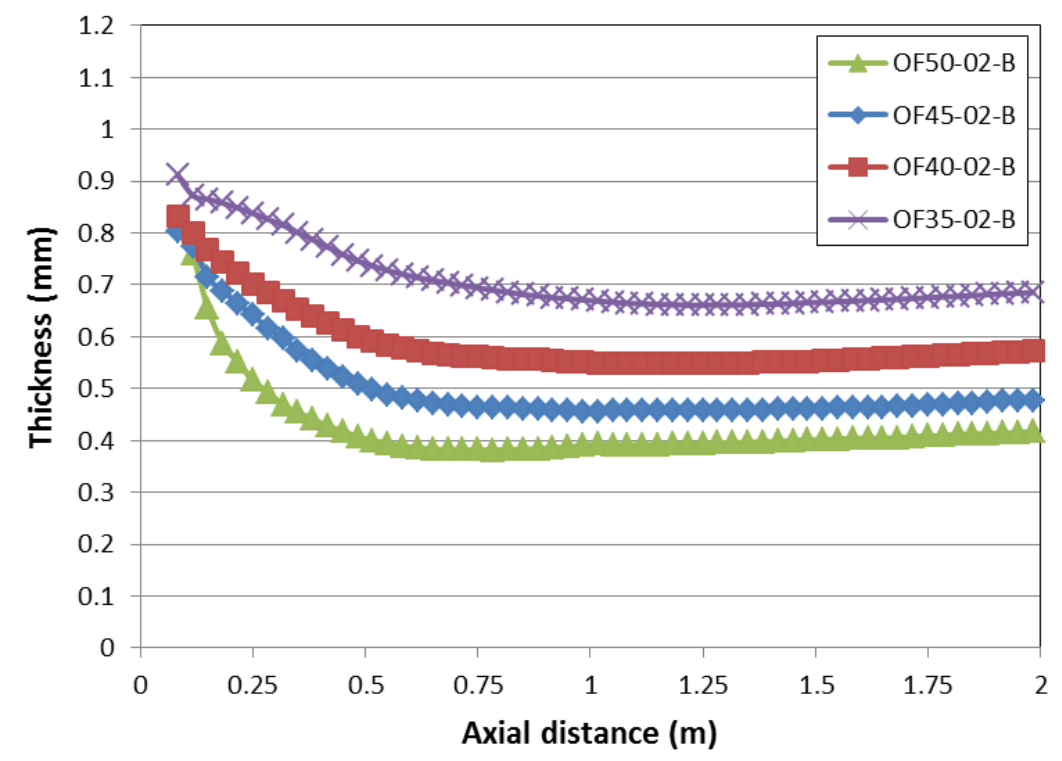

Figure 7-17. Thickness of the solidified slag layer for the conditions in Table 7-8.

Figure 7-18 shows the velocity profiles for the selected cases. The profiles behave in accordance with the viscosity behavior. The significant difference in the OF35-02-B case with respect to other cases is due to the corresponding difference between the viscosity profiles shown in Figure $7-22$. 


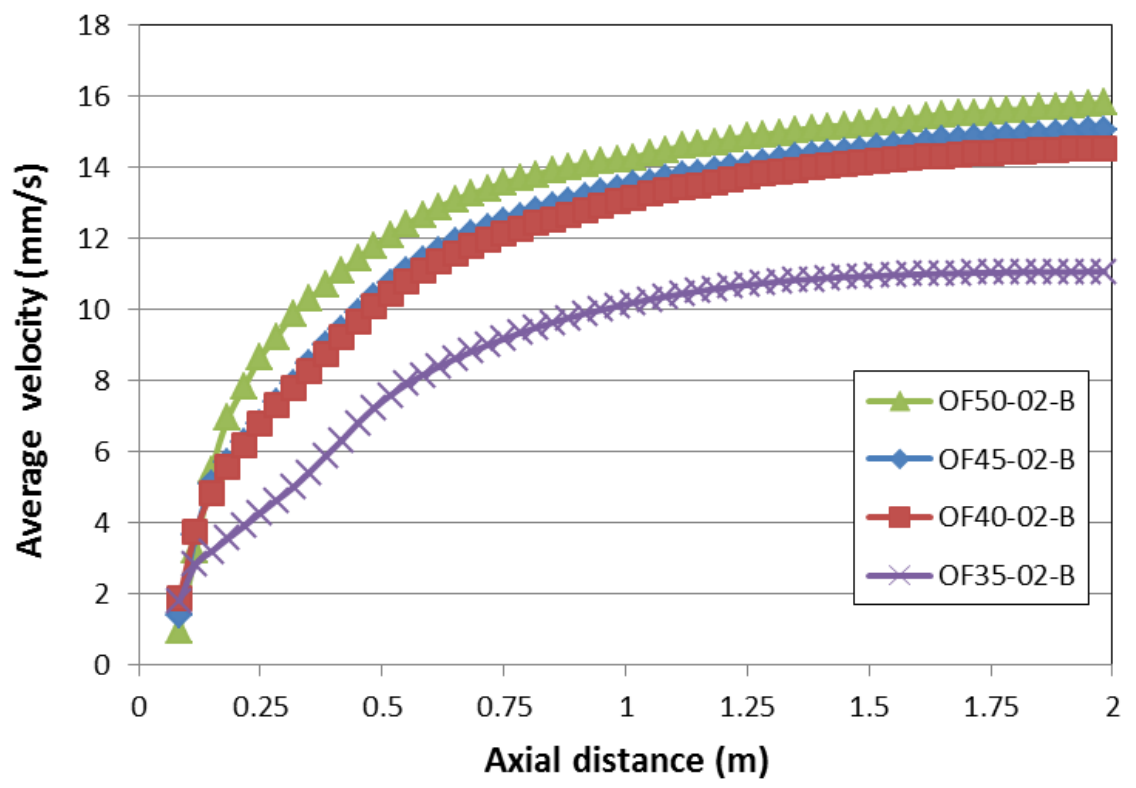

Figure 7-18. Average velocity of the liquid slag for the conditions in Table 7-8.

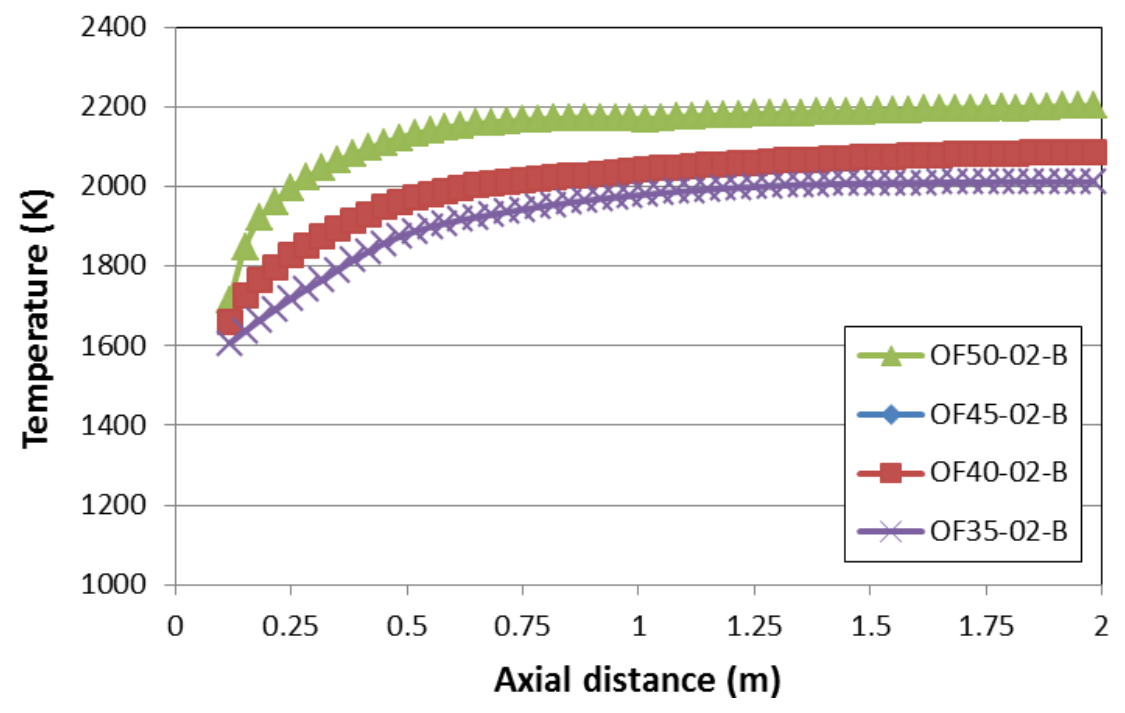

Figure 7-19. Bulk slag temperature for the conditions in Table 7-8. 
Figure 7-20 shows the formation of $\mathrm{CaC}_{2}$. The results are plotted in terms of the mass fraction of $\mathrm{CaC}_{2}$ in the slag layer. The figure depicts the point at which the formation of $\mathrm{CaC}_{2}$ starts to take place.

It can be observed that the formation of $\mathrm{CaC}_{2}$ is small in all the cases. That is most likely due to the fact that the residence time is too small to achieve a significant amount of $\mathrm{CaC}_{2}$. The residence time for these conditions is in the order of two minutes, and the values are shown in

Table 7-10. Nonetheless, there is a significant difference in the level of $\mathrm{CaC}_{2}$ formed in the slag. In fact, it can be observed that the amount of $\mathrm{CaC}_{2}$ in the slag is almost three times higher for the case OF50-02-B when compared to the case OF35-02-B.

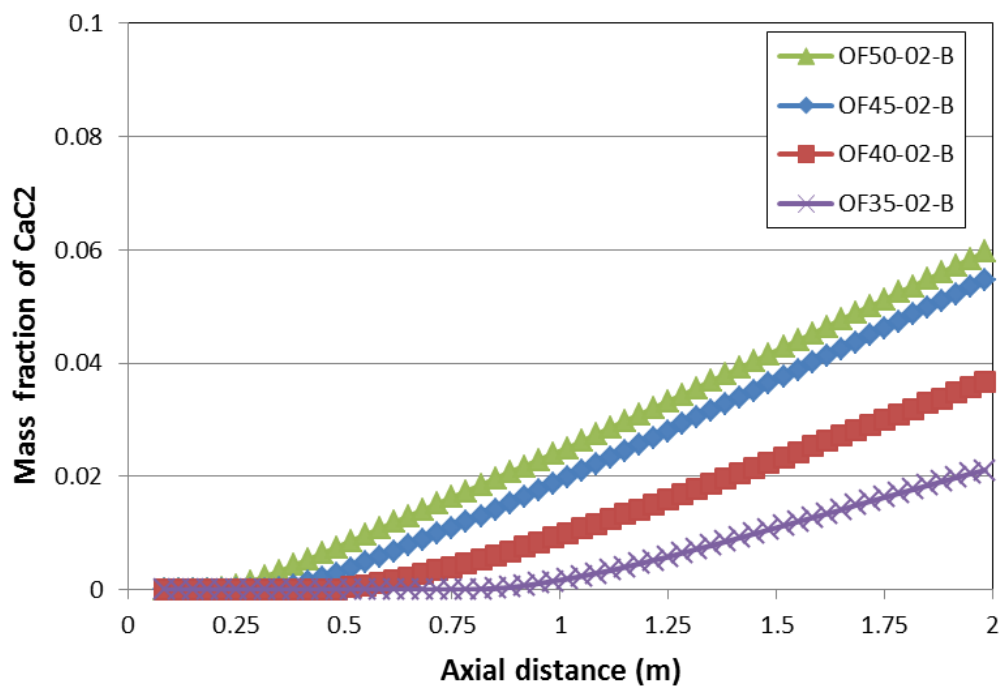

Figure 7-20. Mass fraction of $\mathrm{CaC}_{2}$ in the slag for the conditions in Table 7-8. 
Figure 7-21 shows the energy consumed by the $\mathrm{CaC}_{2}$ reaction along the slag. The values are shown in $\mathrm{kW}$. The total energy consumed in the reactor by the $\mathrm{CaC}_{2}$ reaction as well as the total energy consumed by kilogram of $\mathrm{CaC}_{2}$ produced is reported in Table 7-10.

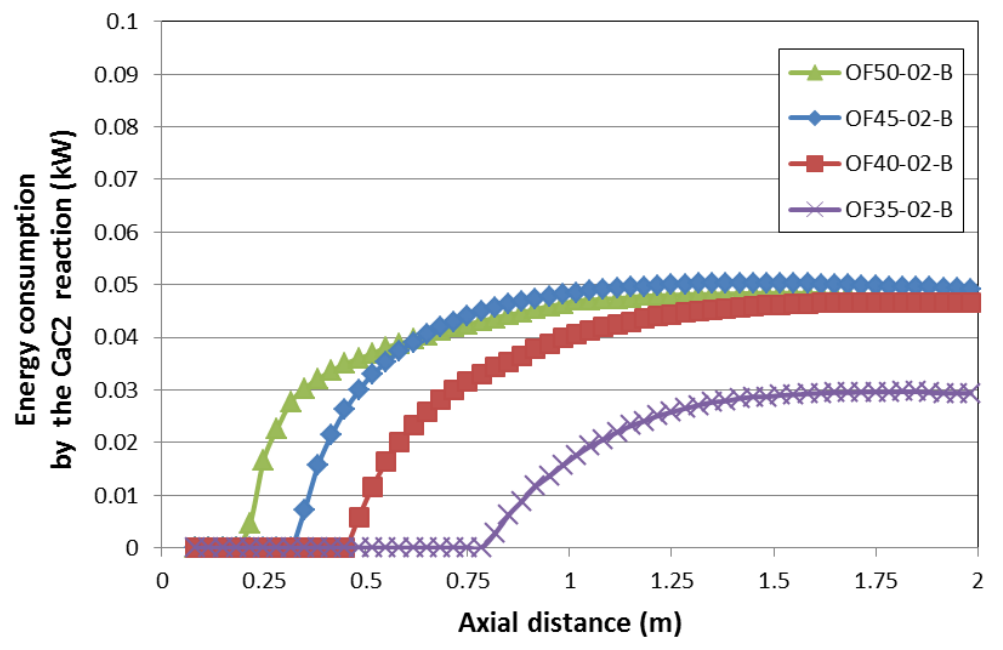

Figure 7-21. Energy consumed by the $\mathrm{CaC}_{2}$ reaction for the conditions in Table 7-8.

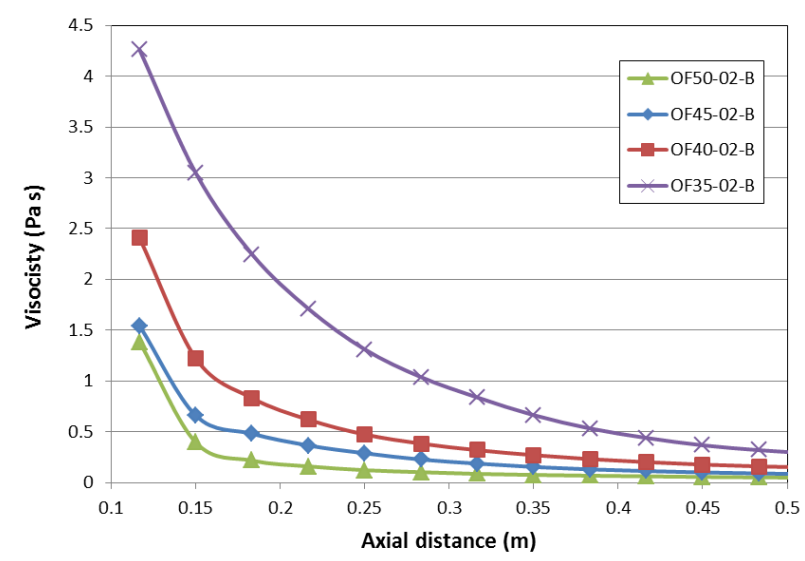

(a)

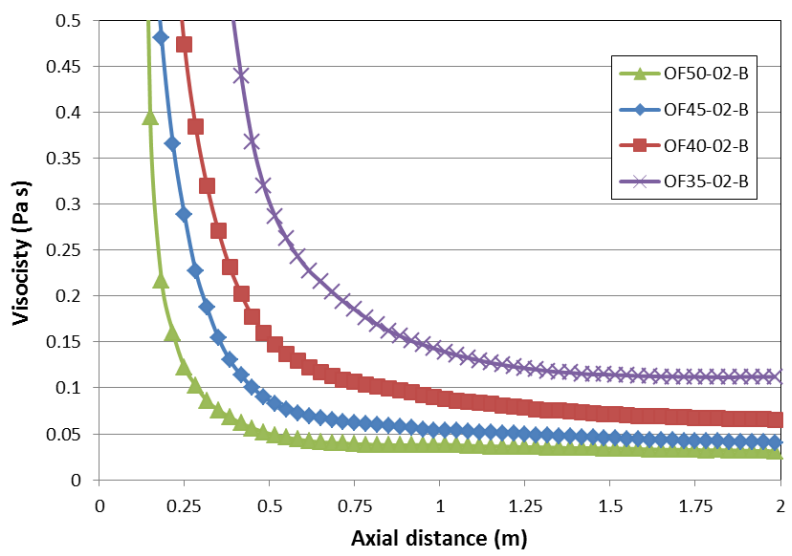

(b)

Figure 7-22. Slag viscosity profiles along the wall of the VHTER for the conditions in Table 7-8. a) between 0 and $0.5 \mathrm{~m}$ and $\mathrm{b}$ ) for viscosities smaller than $0.5 \mathrm{~Pa} \cdot \mathrm{s}$. 
Table 7-10. Relevant information to $\mathrm{CaC}_{2}$ production in the VHTER.

\begin{tabular}{|l|c|c|c|c|}
\hline \multicolumn{1}{|c|}{ Case id $\rightarrow$} & OF35-02-B & OF40-02-B & OF45-02-B & OF50-02-B \\
\hline $\mathrm{kg} / \mathrm{h}$ of slag leaving the reactor & 19.85 & 22.08 & 18.28 & 17.27 \\
\hline $\begin{array}{l}\mathrm{m} . f . \text { of } \mathrm{CaC}_{2} \text { in the slag leaving } \\
\text { the reactor }\end{array}$ & 0.02 & 0.04 & 0.05 & 0.06 \\
\hline $\mathrm{kg} / \mathrm{h}$ of $\mathrm{CaC}_{2}$ leaving the reactor & 0.42 & 0.81 & 1.00 & 1.03 \\
\hline Residence time of the slag $(\mathrm{min})$ & 2.79 & 2.06 & 2.00 & 1.86 \\
\hline $\begin{array}{l}\text { Energy consumed by the } \mathrm{CaC}_{2} \\
\text { reaction }(\mathrm{kW})\end{array}$ & 0.87 & 1.8 & 2.23 & 2.31 \\
\hline $\begin{array}{l}\text { Energy consumed by the } \mathrm{CaC}_{2} \\
\text { reaction per } \mathrm{kg} \text { of } \mathrm{CaC}_{2}(\mathrm{~kW} / \mathrm{kg})\end{array}$ & 2.07 & 2.22 & 2.23 & 2.24 \\
\hline
\end{tabular}




\section{Chapter 8 - Horizontal Reactor: Results and Discussion}

\subsection{CTC Reactor: Combustion Results for the Experimental Conditions at WRI}

Several series of simulations were conducted to support the research and development efforts of LP Amina. The results were included in the technical report developed and prepared by WRI, WVU and LP Amina this year. The results for the final set of simulations will be shown in this dissertation and will be compared with the experiments conducted at WRI. These results are shown with permission of LP Amina.

The operation conditions for these cases are shown in Table 8-1. These cases are identified by adding the month, day and year to the WRI identifier. In these simulations, the coal utilized was Decker coal, but with a moisture content decreased to $6 \%$. In all these tests, the TA port was closed.

Table 8-1. CTC Reactor Operation conditions: WRI tests, 2015's tests. Mass flow rates in kg/h, temperatures in $\mathrm{K}$.

\begin{tabular}{|c|c|c|c|c|c|c|c|c|}
\hline Case id & $\begin{array}{c}\text { Air } \\
(\mathbf{P A})\end{array}$ & $\begin{array}{c}\text { Coal } \\
(\mathbf{P A})\end{array}$ & $\begin{array}{c}\text { CaO } \\
(\mathbf{P A})\end{array}$ & $\begin{array}{c}\text { Air } \\
(\mathbf{S A})\end{array}$ & $\begin{array}{c}\text { O2 } \\
(\mathbf{S A})\end{array}$ & $\begin{array}{c}\text { NG } \\
(\mathbf{S A})\end{array}$ & $\begin{array}{c}\text { T(K) } \\
(\mathbf{P A})\end{array}$ & $\begin{array}{c}\text { T(K) } \\
(\text { SA })\end{array}$ \\
\hline WRI-01-23-15 & 20.13 & 18.91 & 0 & 119.37 & 0 & 3.34 & 298 & 802 \\
\hline WRI-02-03-15 & 20.13 & 18.91 & 0 & 119.37 & 5.56 & 2.23 & 298 & 816 \\
\hline WRI-03-31-15 & 24.16 & 17.3 & 0.82 & 119.57 & 8.89 & 2.23 & 298 & 784 \\
\hline
\end{tabular}

Figure 8-1 shows an example of the conditions registered by the instrumentation in the experiments. Those conditions correspond to the WRI-01-23-15 case. Figure 8-1 (a) shows the volumetric flow rate of primary air, secondary air, and natural gas in CFM. Conditions shown in 
Figure 8-1a are registered by the meters DL_LPA.FT1, DL_LPA.FT2 and DL_LPA.FT3, respectively. Figure $8-1 \mathrm{~b}$ shows the temperature of the thermocouple DL_LPA.TC1F, which measures the temperature of the air injected through the SA port. Figure 8-1c shows the reading of the weight gauge DL_LPA.WT1, where the coal feeder sits on. The mass flow rate of coal injected in $\mathrm{lb} / \mathrm{min}$ is estimated from this reading by linear regression. Figure 8 -1d shows the reading of the weight gauge DL_LPA.WT2 where the $\mathrm{CaO}$ feeder sits on.

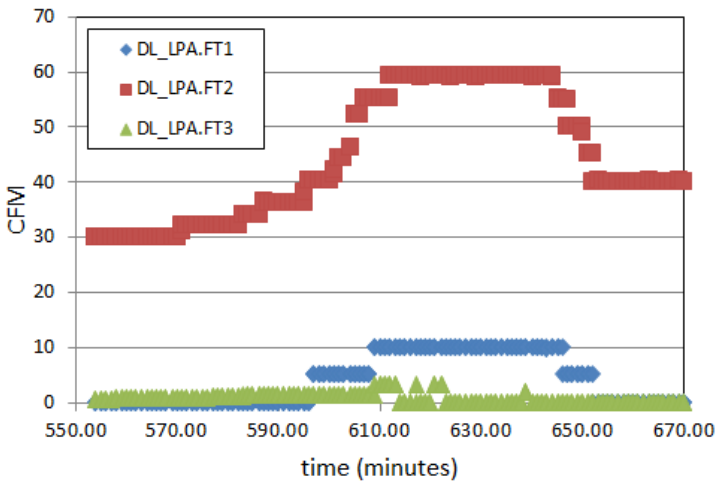

(a)

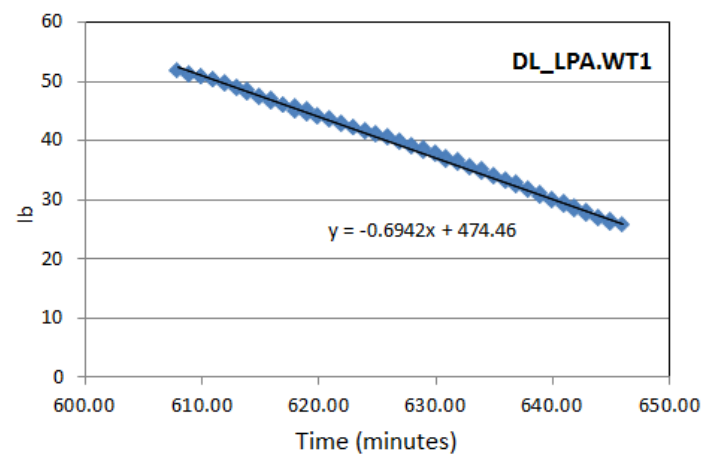

(c)

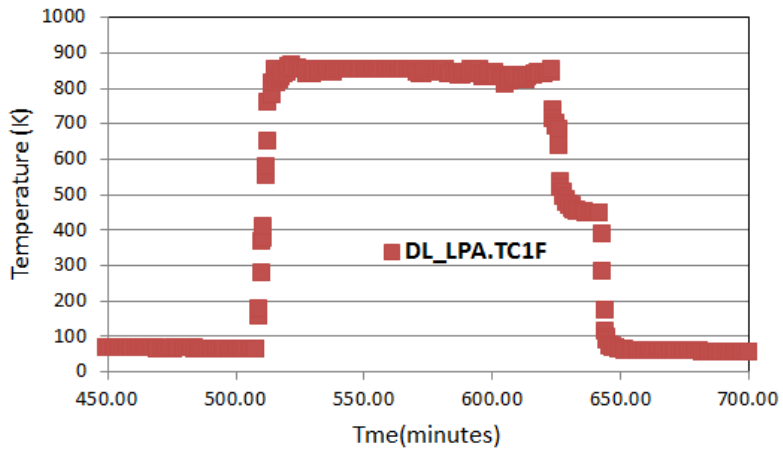

(b)

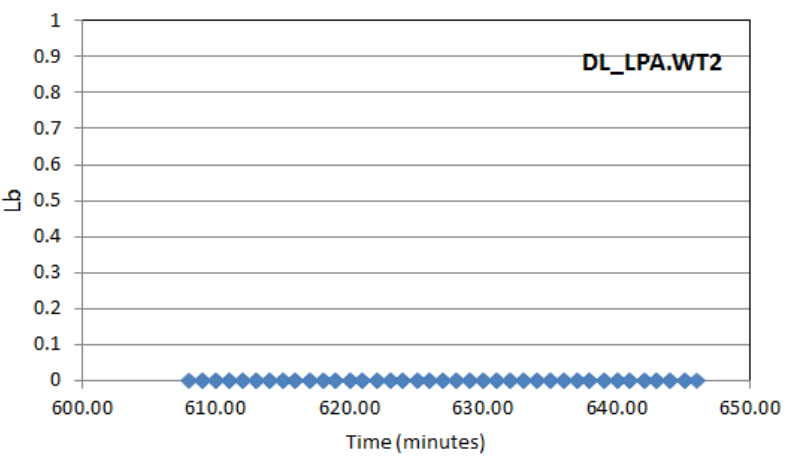

(d)

Figure 8-1. Example of the registered inlet conditions for the CTC reactor

Two instruments registered the temperature inside the CTC reactor. The first one is an infrared (IR) pyrometer, identified as DL_LPA_IRT1, and is located in the third SA port. The second one is a thermocouple, identified as DL_LPA_TCR18; this thermocouple was located at the top of 
the reactor, above the slag drain. The readings of these two instruments were compared to the appropriate wall and average gas temperatures from the CFD simulations. The CFD results and experimental measurements for these cases showed good agreement.

Figure 8-2 shows the comparison of simulation and experimental results for the WRI-01-23-15 case. The plot in Figure 8-2b shows the thermocouple reading, as well as it points out the location of the thermocouple in Figure 8-2a. Figure 8-2c shows the IR pyrometer reading, as well as it points out the location of the plane where the IR pyrometer is located. Figures $8-3$ and $8-4$ show this same comparison for the WRI-02-03-15 and WRI-03-31-15 cases, respectively.

WRI-01-23-15

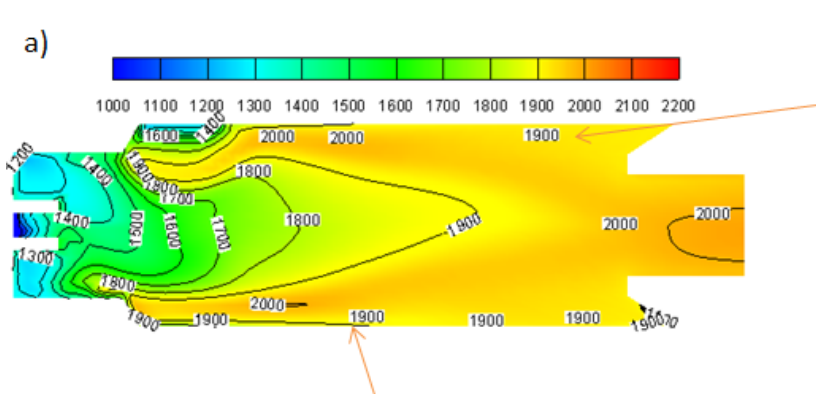

c)

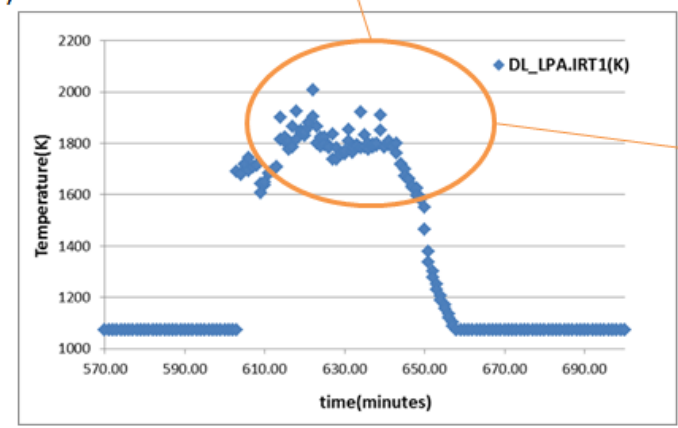

b)

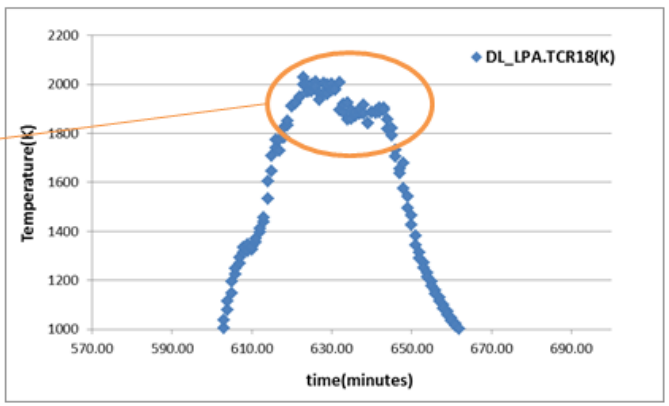

d)

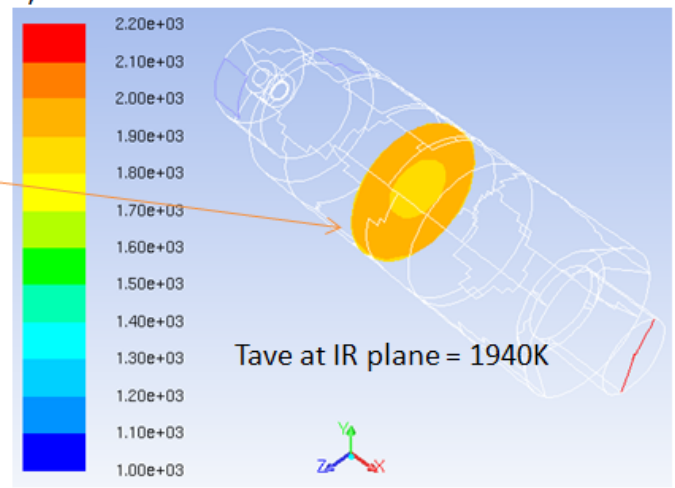

Figure 8-2. Comparison of simulation results and experimental results for WRI-01-23-15 case. 


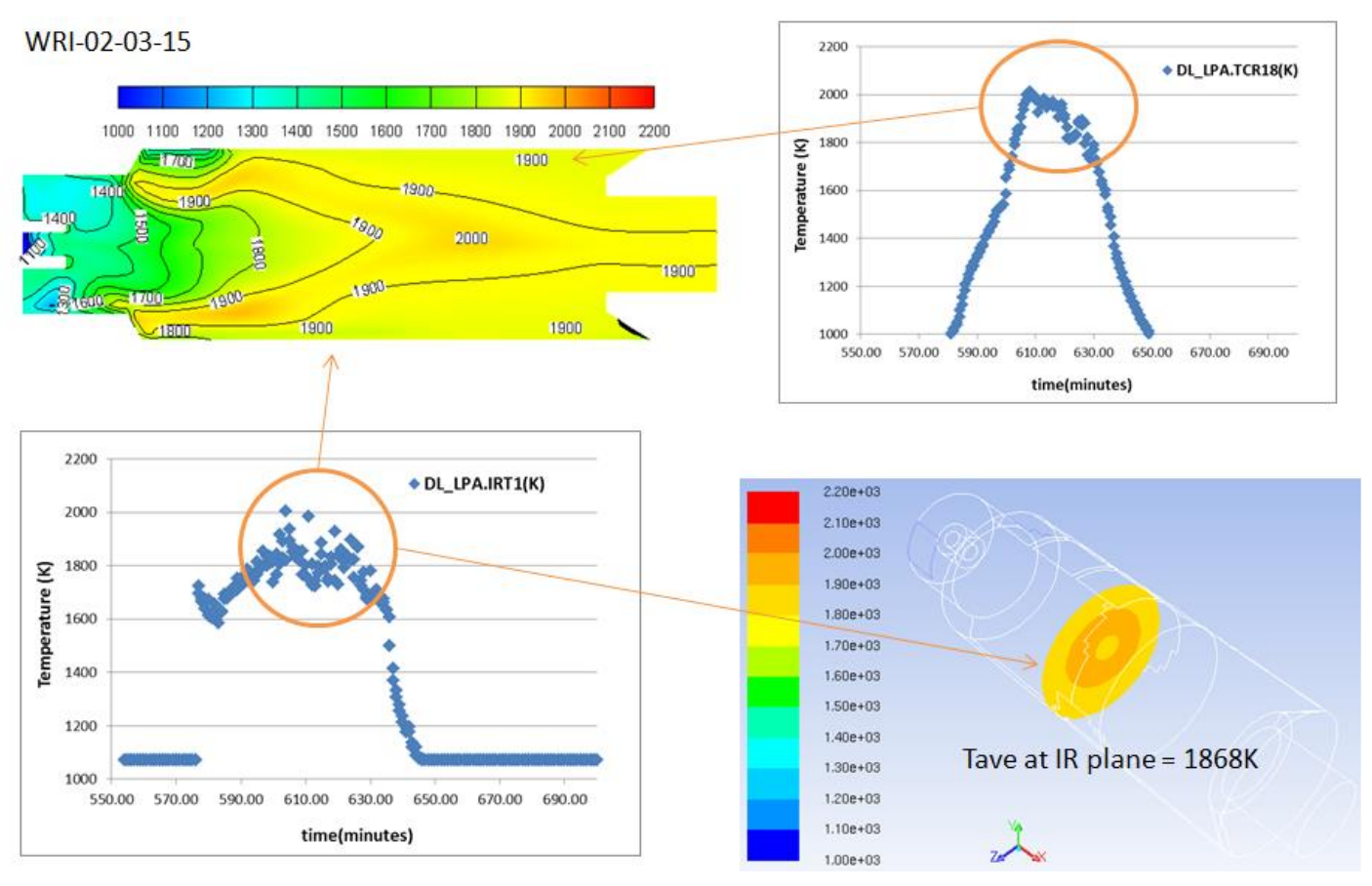

Figure 8-3. Comparison of simulation results and experimental results for WRI-02-03-15 case.

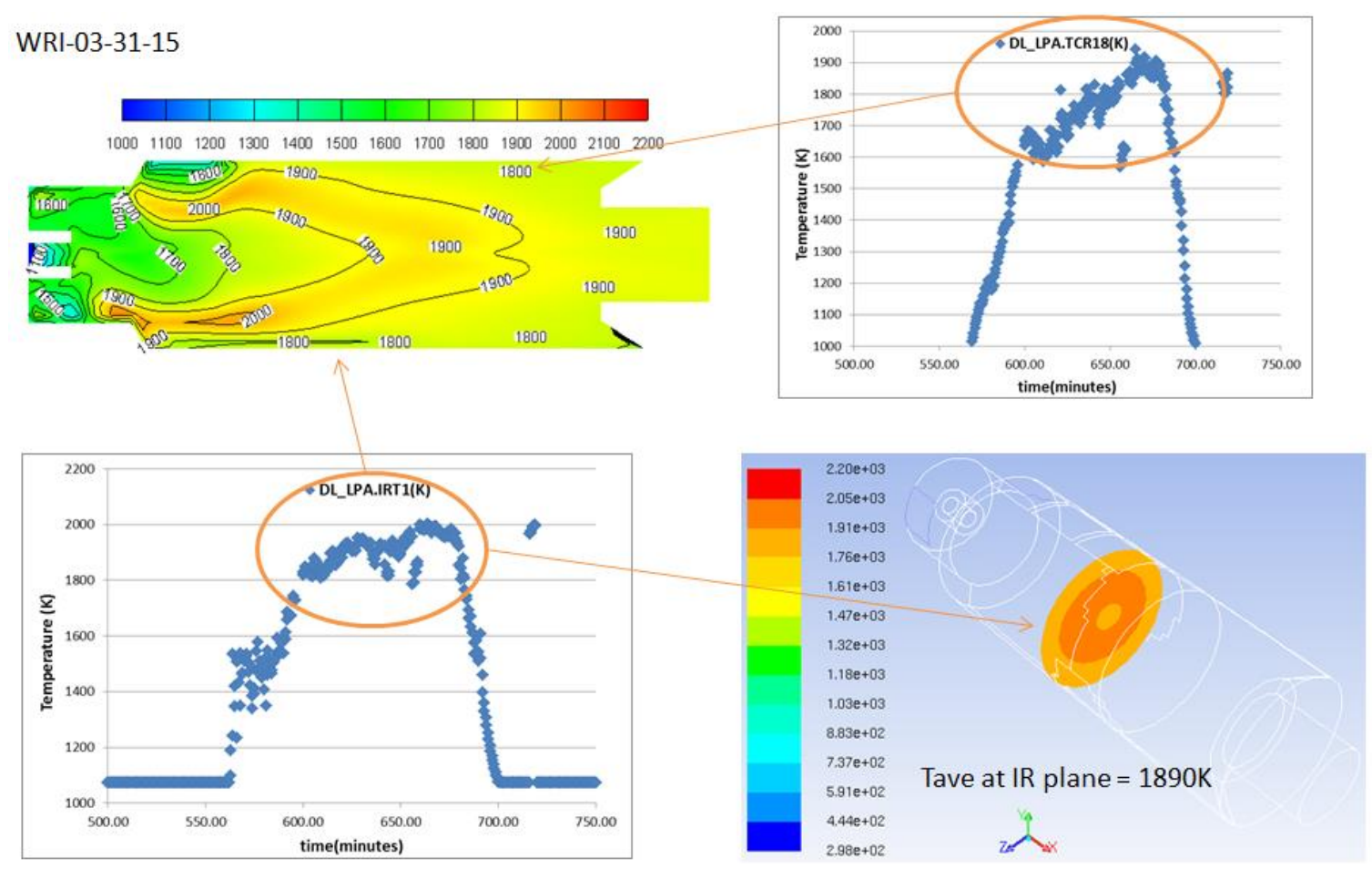

Figure 8-4. Comparison of simulation results and experimental results for WRI-03-31-15 case. 
These results showed that the CFD simulations were consistent with the measured temperatures. Nonetheless, these results also indicated that the temperatures achieved under the conditions tested at WRI were not sufficiently high for activation of the $\mathrm{CaC}_{2}$ reaction. The temperature profiles for these conditions are shown in Figure 8-5.

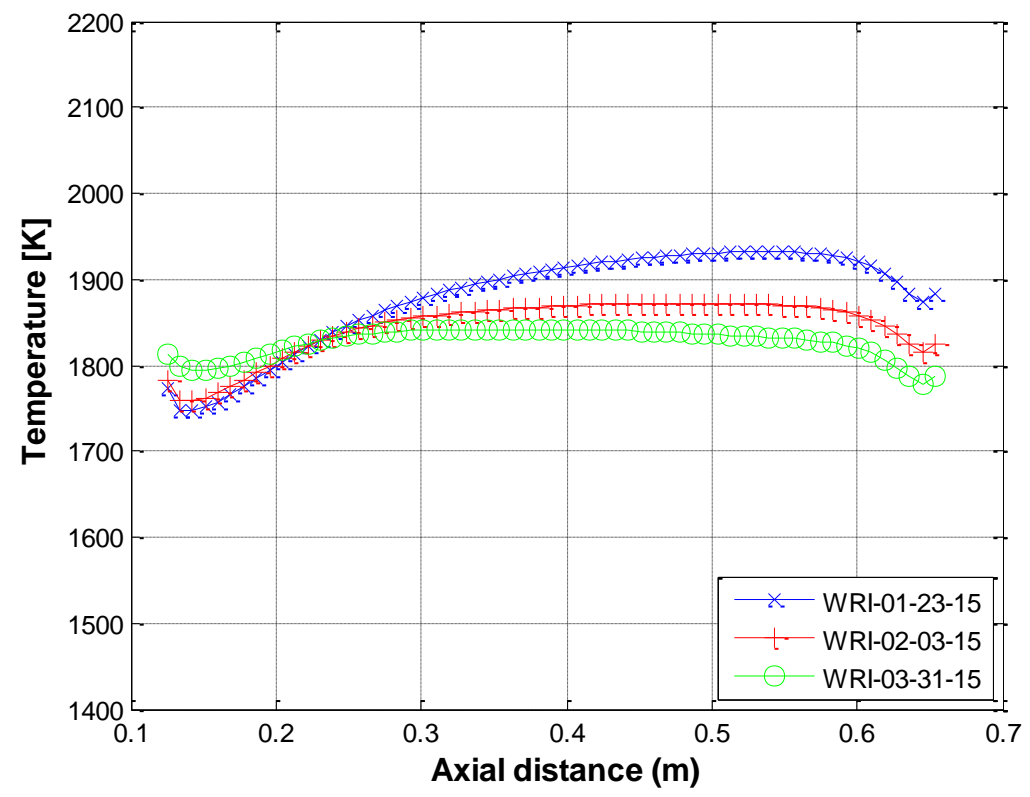

Figure 8-5. CTC Reactor bottom wall temperature profiles (cases in Table 8-1).

It can also be observed that the amount of $\mathrm{CaO}$ injected in these tests was considerably small. This fact, along with insufficiently high temperatures, is consistent with the lack of $\mathrm{CaC}_{2}$ formation evidenced in the tests performed at WRI. 


\subsection{CTC Reactor: Design for $\mathrm{CaC}_{2}$ Production}

In order to establish suitable conditions for the activation of $\mathrm{CaC}_{2}$, additional series of simulations were performed to obtain higher wall temperatures. In these simulations, the operating conditions utilized in the WRI-03-31-15 tests were used as a reference point.

The calculated temperatures shown in Figure 8-6 illustrate that the temperature near the bottom wall of the CTC reactor can indeed be increased substantially by increasing the amount of natural gas, as well as by replacing a portion of the air entering the reactor with pure $\mathrm{O}_{2}$. Additionally, the amount of $\mathrm{CaO}$ injected into the reactor was increased by approximately a factor of 10 .

The operation conditions for selected cases showing significant temperature improvements are provided in Table 8-2, where the value of the varied conditions is shown in bold format. The temperatures profiles for these cases are shown in Figure 8-6. The best results were seen with the case CTC-Reactor-52, which resulted in an increase in nearly $500 \mathrm{~K}$ over the reference case.

Table 8-2. Reactor operating conditions for simulations to enhance $\mathrm{CaC}_{2}$ production

\begin{tabular}{|c|c|c|c|c|c|c|c|c|}
\hline Case id & $\begin{array}{c}\text { Air } \\
\text { (PA) }\end{array}$ & $\begin{array}{c}\text { Coal } \\
(\mathbf{P A})\end{array}$ & $\begin{array}{c}\text { CaO } \\
(\mathbf{P A})\end{array}$ & $\begin{array}{c}\text { Air } \\
\text { (SA) }\end{array}$ & $\begin{array}{c}\text { O2 } \\
(\text { SA })\end{array}$ & $\begin{array}{c}\text { NG } \\
\text { (SA) }\end{array}$ & $\begin{array}{c}\text { T(K) } \\
(\mathbf{P A})\end{array}$ & $\begin{array}{c}\text { T(K) } \\
\text { (SA) }\end{array}$ \\
\hline WRI-03-31-15 & 24.16 & 17.3 & 0.82 & 119.57 & 8.89 & 2.23 & 298 & 784 \\
\hline CTC-Reactor-48 & 24.16 & 17.3 & 0.82 & 119.57 & $\mathbf{1 5 . 5 6}$ & $\mathbf{3 . 9}$ & 298 & 784 \\
\hline CTC-Reactor-49 & 24.16 & 17.3 & 0.82 & 119.57 & $\mathbf{1 5 . 5 6}$ & $\mathbf{3 . 9}$ & 298 & $\mathbf{9 0 0}$ \\
\hline CTC-Reactor-52 & 24.16 & 17.3 & $\mathbf{7 . 4 8}$ & 104.67 & $\mathbf{2 2 . 2 3}$ & $\mathbf{6 . 6 9}$ & 298 & $\mathbf{9 0 0}$ \\
\hline
\end{tabular}




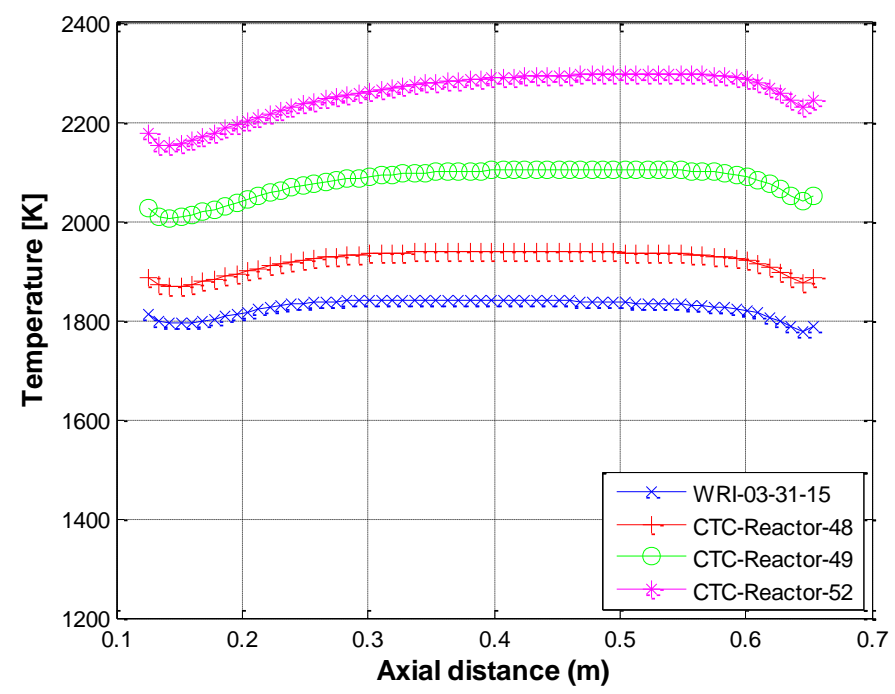

Figure 8-6. Bottom wall temperature profiles for simulations detailed in Table 8-2.

\subsection{CTC Reactor: Slag Model Results}

The results of the CFD model for the CTC-Reactor-52 case were utilized in the SFM to analyze the rate of $\mathrm{CaC}_{2}$ production. The deposition of chemicals is shown in Figure 8-7. These figures provide the deposition information both along the longitudinal axis of the reactor, and along the angular position with respect to the circumference of the reactor; Figure 8-8 provides a reference for how the angular positions are defined. The molar ratio of carbon to $\mathrm{CaO}$ in this case was balanced to a value close to 3.1 . 


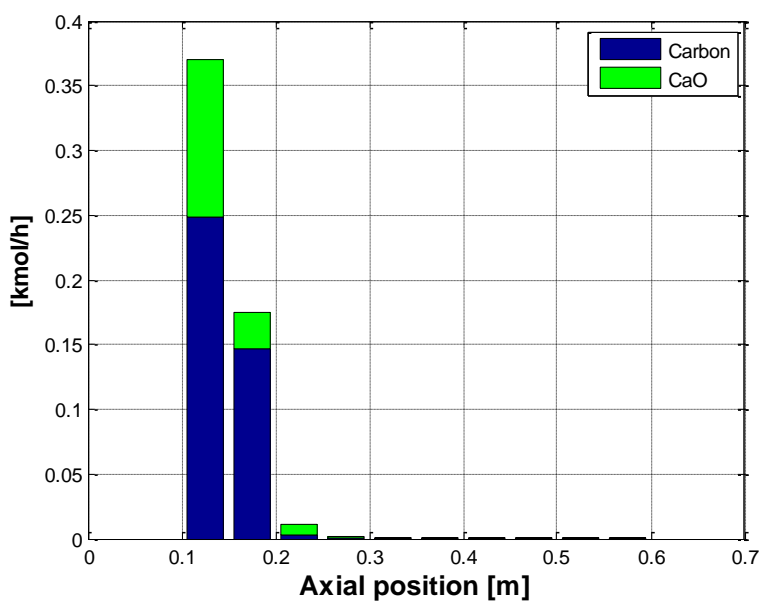

(a)

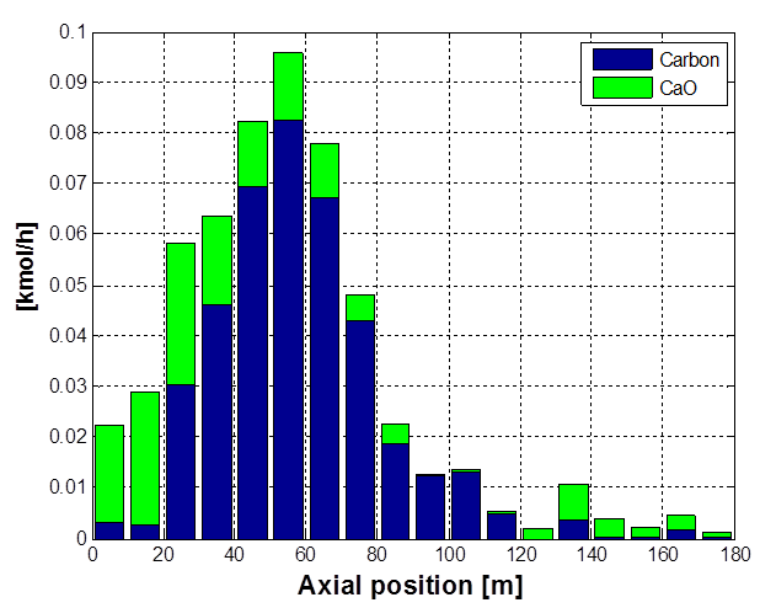

(b)

Figure 8-7. Particle deposition of carbon and $\mathrm{CaO}$ as a function of (a) distance along the longitudinal axis, and (b) reactor circumference angle for the CTC-Reactor-52 case.

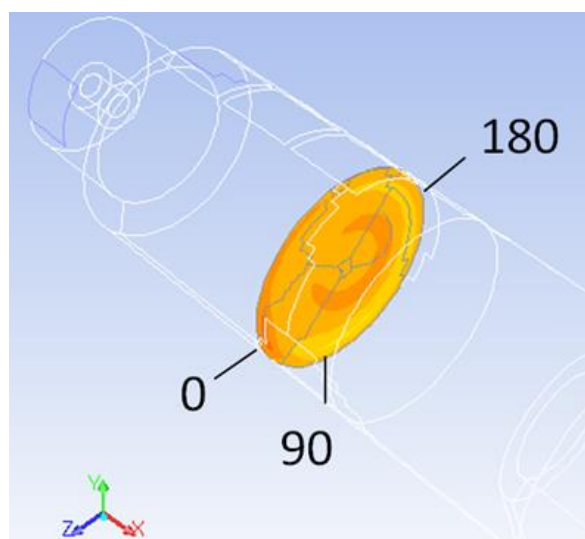

Figure 8-8. Reference for definition of angular deposition coordinates. 
The results at steady state provided by the SFM for the CTC-Reactor-52 case are shown in Figure 8-9. In these results, the mass fraction of $\mathrm{CaC}_{2}$ at the final portion of the reactor was close to 0.4 , which is a significant increase from 0.0 for case WRI-03-31-15. This corresponds to a change in $\mathrm{CaC}_{2}$ production of $0 \mathrm{~kg} / \mathrm{hr}$ for case WRI-03-31-15 to $4.37 \mathrm{~kg} / \mathrm{hr}$ for case CTCReactor-52.
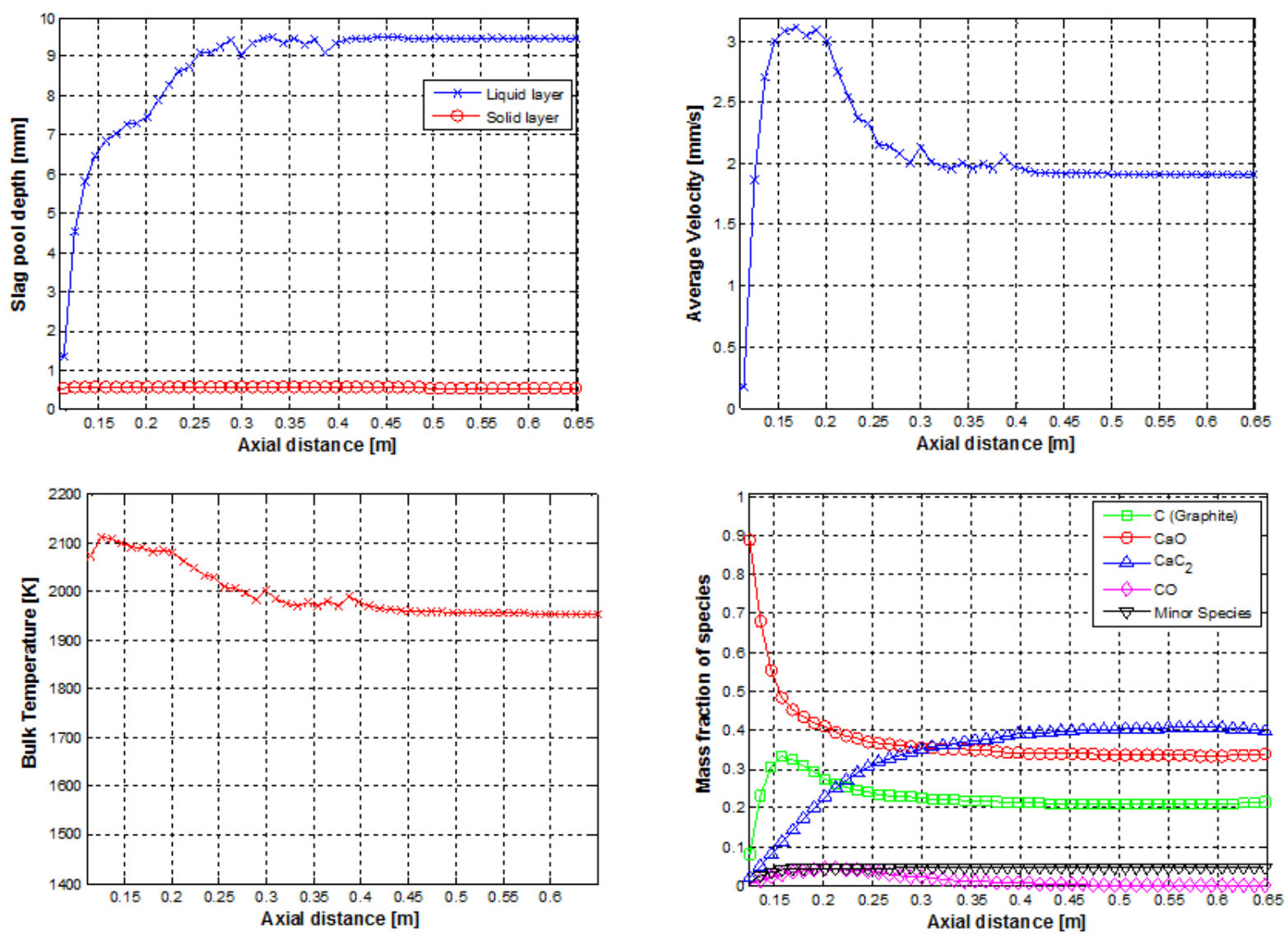

Figure 8-9. Slag model results at steady state for the CTC-Reactor-52 case. (top left) slag pool depth (top right) average slag velocity (bottom left) bulk temperature of slag (bottom right) species mass fractions. 
It is important to mention that for the case of the horizontal reactor, it was necessary to assume a small slope in order to promote the flow of slag. It was assumed that the slope was equal to $0.001^{\circ}$. If the slope is equal to zero, the slag flow model predicts a no flow condition in which the mass flow rate of molten ash will cause the accumulation of molten slag. In the reactors evaluated in this work, the accumulation will occur in the initial region of the combustion chamber, since this is the region where the mass is deposited. This condition is shown in Figure 8-10 for the OF50-02-B case.

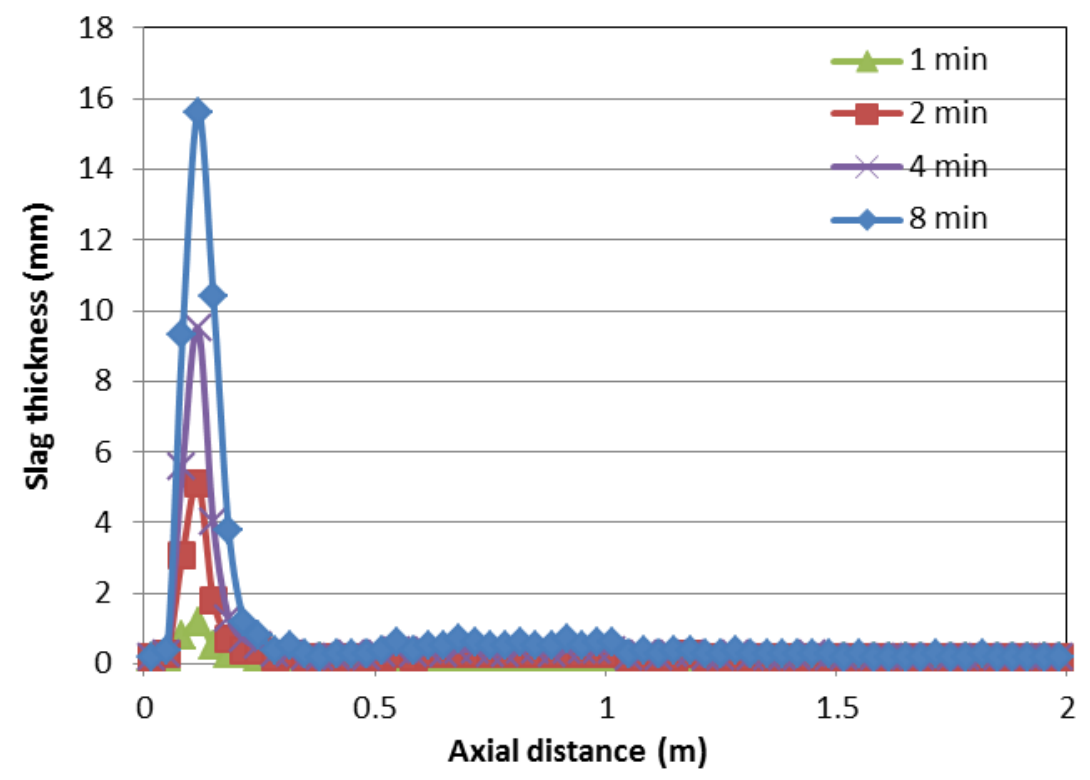

Figure 8-10. Accumulation of mass predicted by the SFM for the OF50-02-B case. 


\section{Chapter 9 - Conclusions and Future Work}

\subsection{Conclusions}

A numerical model was developed to study the process of $\mathrm{CaC}_{2}$ production in the molten slag of oxy-coal reactors. The model was developed in a computational framework that included a CFD model for oxy-coal combustion coupled with a one dimensional CFD model for the slag flow. The model was applied to the design of pilot scale reactors.

The results for oxy-coal combustion in the VHTER showed that is possible to obtain high gas temperatures near the wall. These temperatures provided the minimum temperature requirements for $\mathrm{CaC}_{2}$ production. Different $\mathrm{O}_{2} / \mathrm{CO}_{2}$ oxidant mixtures with molar oxygen concentrations ranging from 0.25 to 0.50 were evaluated. It was concluded that the minimum temperatures required to activate the $\mathrm{CaC}_{2}$ formation were obtained for oxy-coal combustion cases with molar oxygen concentrations close to 0.35 being $\mathrm{CO}_{2}$ the balance gas.

Regarding the design of the VHTER, it was found that the burner design of the VHTER allowed attaining a stable combustion with a well-defined burner recirculation zone. It was also found that the swirling flow pattern provided by the tangential flow promotes the collection of particles in the initial section of the combustion chamber. This tangential flow pattern was provided by the injection of particles by carrier gas. Additionally, it was found that the tangential injection of particles by carrier gas increases the temperature in the initial portion of the combustion chamber. 
The study conducted to balance the chemical reactants showed that the particle heat absorption has a significant impact on the gas temperature near the wall of the oxy-coal reactor. It was also shown that gas preheating can be used to promote the earlier formation of $\mathrm{CaC}_{2}$.

The slag flow model developed in this work included different features not available in previous formulations available in the literature. The model features considered in the present work included: i) an unsteady state formulation; ii) the species transport equation; iii) the kinetic model for calcium carbide production developed by Rowen et al. [108]; iv) a new approach based on the Stefan's condition [129] for the estimation of the solidified slag thickness and, v) a model based on the $\mathrm{CaO}-\mathrm{CaC} 2$ eutectic phase diagram to estimate the amount of solids transported in the slag.

The results for the slag flow model showed that although the VHTER reactor is able to attain the high temperatures required for the production of $\mathrm{CaC}_{2}$, such temperatures have a downside effect on viscosity. That means that, if the typical viscosity models available in the literature are extrapolated, the viscosities obtained can be so small that the residence time of the slag is insufficient to attain a considerable formation of $\mathrm{CaC}_{2}$ in the slag. This situation is more dramatic for the VHTER when compared to the CTC reactor.

The simulation results for the CTC reactor indicated that the operation conditions evaluated in the tests performed at WRI are not suitable for $\mathrm{CaC}_{2}$ production. Nonetheless, is possible to obtain suitable temperatures for production of $\mathrm{CaC}_{2}$ in the $\mathrm{CTC}$ reactor by modifying the operation conditions. The modifications include increasing the amount of natural gas, as well as replacing a portion of the air entering the reactor with pure $\mathrm{O}_{2}$. 


\subsection{Future Work}

The main obstacle found during the development of the present work was the lack of information related to the slag properties. This was mainly due to the more narrow focus of the production of $\mathrm{CaC}_{2}$ in the molten slag and also to the high temperatures involved. A detailed review of the slag flow properties was considered in this work in order to select the best possible values and models available in literature. Nonetheless, is highly recommended that experimental work support the further development of the slag flow model. Due to its relevance to the control and design of the process, viscosity is perhaps the property that should be investigated with priority from all the fluid and thermal properties.

Currently, the Computational Fluid Dynamics and Applied Multi-Physics (CFD \& AMP) center of West Virginia University is conducting research on the field of the reaction mechanism of $\mathrm{CaC}_{2}$ in the slag. Once this work is concluded, such mechanism should be implemented in the slag flow model. 


\section{REFERENCES}

[1] Koopal, S. , "Preparation of calcium carbide," U.S. Patent 2,749,219, June 51956.

[2] Koopal, S., "Preparation of calcium carbide," U.S. Patent 2,794,706, June 41957.

[3] Van, L. W., Koopal, S., "Process and apparatus for the production of calcium carbide," US Patent 2,858,197, Oct. 28, 1958.

[4] Van, L. W., Koopal, S., "Preparation of Calcium Carbide," U.S. Patent 2,738,256, Mar. 13, 1956.

[5] Koopal, S. , "Manufacture of calcium carbide in shaft furnace," U.S. Patent 2,880,069, Mar. 31, 1959.

[6] Badishe, A., Soda, F. , "Improvements in the production of calcium carbide," Patent GB700123, Nov. 25, 1951.

[7] Johnson, G. W, "Improvements in the operation of shaft furnaces," Patent GB724565, 1953.

[8] Badishe, A., Soda, F., "An improved delivery apparatus for lumpy material," Patent GB 829534, July 31, 1958.

[9] Friedrich W., Pietzarka, P., Meurer, W., Portz, F. W., Kampmann, "Process and plant for the production of synthesis gas," Patent EP 0107131, Apr 17, 1985. 
[10] Kersting, H., Erhard W., Willi P., Georg S. , "Production of calcium carbide," U.S. Patent 4,391,786, July 5, 1983.

[11] Hans, J. K., Erhard, W., Willi, P., Georg, S., "Process for the manufacture of calcium carbide," Patent EP 0068303, May 20, 1987.

[12] Morhenn, H., Mleczko, L., Felix-Karl, S. O., Haverkamp, V., Liu F., "Coal gasification with additional production of useful materials," Patent WO 2010105385, Sep 23, 2010.

[13] Bellinghausen, R., Latta, W., Michele, V., Mleczko L., Morhenn H.,Schlueter O., Targett, M., Vierstra S., , "Cyclone reactor and method for producing usuable by-products using cyclone reactor," Patent WO 2012115909, Aug 302012 .

[14] Seggiani, M., "Modelling and simulation of time varying slag flow in a Prenflo entrainedflow gasifier," Fuel, vol. 77, no. 14, pp. 1611-1621, 1998.

[15] Wang, X., Zhao D., He L. B., Jiang L.Q., He Q., Chen Y., "Modeling of a coal-fired slagging combustor: Development of a slag submodel," Combustion and Flame, vol. 149, no. 3, pp. 249-260, 2007.

[16] Yong S.Z. , Gazzino M. , Ghoniem A. F., "Modeling the slag layer in solid fuel gasification and combustion - Formulation and sensitivity analysis," Fuel, vol. 92, no. 1, pp. 162-170, 2012.

[17] Rowan, S., Celik, I., Gutierrez, A., "A Reduced Order Model for the Design of Oxy-Coal Combustion Systems," in International Pittsburgh Coal Conference, Pittsburgh, PA., 
2014.

[18] Grant, D. M.; Pugmire, R. J.; Fletcher, T. H.; Kerstein, A. R., "Chemical Model of Coal Devolatilization Using Percolation Lattice Statistics," Energy Fuels, vol. 3, no. 2, pp. 175$186,1989$.

[19] Fletcher, T. H.; Kerstein, A. R.; Pugmire, R. J.; Grant, D. M., "Chemical Percolation Model for Devolatilization. 2. Temperature and Heating Rate Effects on Product Yields," Energy \& Fuels, vol. 4, pp. 54-60, 1990.

[20] Fletcher, T. H.; Kerstein, A. R.; Pugmire, R. J.; Solum, M. S.; Grant, D. M., "Chemical Percolation Model for Devolatilization. 3. Direct Use of C NMR Data to Predict Effects of Coal Type," Energy \& Fuels, vol. 6, pp. 414-431, 1992.

[21] U.S. Energy Information Administration, "International Energy Outlook 2013," Washington, DC, 2013.

[22] Department of Energy of the United States of America, "Cooperation on a Clean Energy Research Center," (Join Publication With the Ministery of Science and Technology and the National Energy Administration of the People's Republic of China), Beijin, 2009.

[23] The Government of the United States of America, "Cooperation Agreement in Science and Technology," (In Agreement with the Governmnet of the People's Republic of China), Washington, 1979.

[24] Alstom. (2014, July) Alstom Group Website. [Online]. http://www.alstom.com/products- 
services/product-catalogue/power-generation/coal-and-oil-power/co2-capture-systemsccs/co2-capture-oxy-combustion-technology/

[25] Scheffknecht, G.,Al-Harahsheh, M., Schnell, U., Maier, J., "Oxy-fuel coal combustion-A review of the current state-of-the-art," International Journal of Greenhouse Gas Control, vol. 5, pp. S16-S35, 2011.

[26] Sean, D., Schlag, S., Funada, C., "Calcium Carbide," IHS Chemical, Chemical Economics Handbook, 2011.

[27] Li, G., Liu, Q.,Liu, Z, "Kinetic Behaviors of $\mathrm{CaC} 2$ Production from Coke and $\mathrm{CaO}$," Industrial \& Engineering Chemistry Research, vol. 52, no. 16, pp. 5587-5592, 2013.

[28] Morehead, J. T., De Chalmot, G., "The Manufacture of Calcium Carbide," The Journal of the American Chemical Society, vol. 18, no. 4, p. 311-331, 1896.

[29] Bingham, C., The Manufacture of Carbide of Calcium. London, U.K.: Ragget \& CO, 1916.

[30] U.S. Environmental Protection Agency, "Calcium Carbide Manufacturing," in Emission Factor Documentation for AP-42. U.S., 1995, ch. 11.4.

[31] Carbide Industries LLC. (2015, May) About Carbide Purity. [Online]. http://www.carbidellc.com/About/aboutpuritytest.html

[32] SMS Group. (2015, May) SAF-Submerged Arc Furnaces. [Online]. https://www.smssiemag.com/en/1510.html 
[33] El-Naas, M. H., Munz, R. J., Ajersch, F., "Solid-state synthesis of calcium carbide in a plasma reactor," Plasma Chemistry and Plasma Processing, vol. 18, no. 3, pp. 409-427, 1998.

[34] Mu, J. J., Hard, R. A., "A Rotary Kiln Process for Making Calcium Carbide," Ind. Eng. Chem. Res., pp. 2063-2069, 1987.

[35] Yue, S., "A method and a device for production of calcium carbide in a vertical oxy-fired furnace," Patent CN200510063216.3, 2005.

[36] Li, G., Liu, Q.,Liu, Z., Zhang, C., Li, C. Wu, W., "Production of Calcium Carbide from Fine Biochars," Angewandte Chemie International Edition, vol. 49, no. 45, pp. 8480-8483, 2010.

[37] Ranade, V., Computational Flow Modeling for Chemical Reactor Engineering. London, UK: Elsevier Academic Press, 2001, vol. 5.

[38] Xia, B., Sun, D.-W., "Applications of computational fluid dynamics (CFD) in the food industry: a review," Computers and Electronics in Agriculture, vol. 34, no. 1-3, pp. 5-24, 2002.

[39] Chen, L.,Ghoniem, A. F., "Simulation of Oxy-Coal Combustion in a $100 \mathrm{kWth}$ Test Facility Using RANS and LES: A Validation Study," Energy \& Fuels, vol. 26, p. 4783-4798, 2012.

[40] Fox, R.O., Computational Models for Turbulent Reacting Flows. New York, USA: 
Cambridge University Press, 2003.

[41] Versteeg, H.K.,Malalasekera, W., An introduction to computational fluid dynamics, The finite Volume method, 2nd ed. England: Pearson Education Limited, 2007.

[42] Chen, L. , Yong S.Z. , Ghoniem A.F., "Oxy-fuel combustion of pulverized coal: Characterization, fundamentals,stabilization and CFD modeling," Progress in Energy and Combustion Science, vol. 38, no. 2, pp. 156-214, 2012.

[43] Howell, J., Siegel, R., Menguck, M., Thermal Radiation Heat Transfer, 5th ed. Boca Raton, FL., U.S.: CRC press, 2011.

[44] Edwards, D. K., Radiation Heat Tansfer Notes. Washington D.C.: Hemisphere, 1981.

[45] Khare, S.P., Wall, T.F., Farida, A.Z., Liu, Y., Moghtaderi, B., Gupta, R.P., "Factors Influencing the Ignition of Flames from Air-fired Swirl PF Burners Retrofitted to Oxyfuel," Fuel, vol. 87, no. 7, pp. 1042-1049, 2008.

[46] Toporov D., Bocian P., Heil P., Kellermann A., Stadler H., Förster M., Kneer R., "Detailed investigation of a pulverized fuel swirl flame in $\mathrm{CO} 2 / \mathrm{O} 2$ atmosphere," Combustion and Flame, vol. 155, no. 4, pp. 605-618, 2008.

[47] Chen, L., Gazzino, M., Ghoniem, A. F., "Characteristics of Pressurized Oxy-Coal Combustion Under Increasing Swirl Number," in The 35th International Technical Conference on Clean Coal \& Fuel Systems, Clearwater, FL., 2010. 
[48] Nikolopoulos, N., Nikolopoulos, A., Karampinis, E., Grammelis, P., Kakaras, E., "Numerical Investigation of the Oxy-fuel Combustion in Large Scale Boilers," Fuel, vol. 90, no. 1, pp. 198-214, 2011.

[49] Andersson, K., Johnsson, F., "Flame and Radiation Characteristics of Gas-Fired O2/CO2 Combustion," Fuel, vol. 86, no. 5, pp. 656-668, 2007.

[50] Andersson, K., Johansson, R., Hjartstam, S., Johnsson, F., Leckner, B., "Radiation Intensity of Lignite-fired Oxy-fuel Flames," Experimental Thermal and Fluid Science, vol. 33, no. 1, pp. 67-76, 2008.

[51] Andersson, K., Johansson, R., Johnsson, F., Leckner, B., "Radiation Intensity of Propanefired Oxy-fuel Flames: Implications for Soot Formation.," Energy \& Fuels, vol. 22, pp. $1535-1541,2008$.

[52] Rathnam, R.K., Elliott, L.K., Wall, T.F., Liu, Y., Moghtaderi, B., "Differences in Reactivity of Pulverised Coal in Air (O2/N2) and Oxy-fuel (O2/CO2) Conditions," Fuel Processing Technology, vol. 90, no. 6, pp. 797-802, 2009.

[53] Bejarano, P.A., Levendis, Y.A., "Single-coal-particle combustion in O2/N2 and O2/CO2 environments," Combustion and Flame, vol. 153, no. 1-2, pp. 270-287, 2008.

[54] Shaddix, C.R., Molina, A., "Effect of O2 and High CO2 Concentrations on PC Char Burning Rates During Oxy-fuel Combustion," in The 33rd International Technical Conference on Coal Utilization and Fuel Systems, Clearwater, FL, 2008. 
[55] Shaddix, C.R., Hecht, E.S., Geier, M., Molina, A., Haynes, B.S., "Effect of Gasificaiton Reactions on Oxy-fuel Combustion of Pulverized Coal Char," in The 33rd international technical conference on coal utilization and fuel systems, Clearwater, FL, USA., 2010.

[56] Smith, I.W., "The combustion rates of coal chars: a review," Symposium (International) on Combustion, vol. 19, pp. 1045-1065, 1982.

[57] Kajitani, S., Hara, S., Matsuda, H., "Gasification Rate Analysis of Coal Char with a Pressurized Drop Tube Furnace," Fuel, vol. 81, no. 5, pp. 539-546, 2002.

[58] Singer, S., Chen, L., Ghoniem, A., "The influence of gasification reactions on char consumption under oxy-combustion conditions: Effects of particle trajectory and conversion," Proceedings of the Combustion Institute, vol. 34, no. 2, 2012.

[59] Brix, J., Jensen P.A., Jensen A.D., "Coal devolatilization and char conversion under suspension fired conditions in $\mathrm{O} 2 / \mathrm{N} 2$ and $\mathrm{O} 2 / \mathrm{CO} 2$ atmospheres," Fuel, vol. 89, no. 11, pp. 3373-3380, 2010.

[60] Naredi, P., Pisupati, S., "Effect of CO2 during Coal Pyrolysis and Char Burnout in OxyCoal Combustion," Energy Fuels, vol. 25, no. 6, pp. 2452-2459, 2011.

[61] Chui, E.H., Majeski, A.J., Douglas, M.A., Tan Y., Thambimuthu K., "Numerical investigation of oxy-coal combustion to evaluate burner and combustor design concepts," Energy, vol. 29, no. 9-10, pp. 1285-1296, 2004.

[62] Al-Abbas, A.H., Naser, J., Dodds, D., "CFD modelling of air-fired and oxy-fuel 
combustion of lignite in a $100 \mathrm{KW}$ furnace," Fuel, vol. 90, no. 5, pp. 1778-1795, 2011.

[63] Hjärtstam, S., Andersson, K. , Johnsson, F., Leckner B., "Combustion characteristics of lignite-fired oxy-fuel flames," Fuel, vol. 88, no. 11, pp. 2216-2224, 2009.

[64] Álvarez, L., Gharebaghi, M., Pourkashanian, M., Williams, A., Riaza, J., Pevida, C., Pis, J.J., Rubiera, F., "CFD modelling of oxy-coal combustion in an entrained flow reactor," Fuel Processing Technology, vol. 92, no. 8, pp. 1489-1497, 2011.

[65] Hurt, R.H., Sun,J.K., Lunden, M., "A Kinetic Model of Carbon Burnout in Pulverized Coal Combustion," Combustion and Flame, vol. 113, no. 1-2, pp. 181-197, 1998.

[66] Niksa, S., Liu, G.S., Hurt, R.H., "Coal conversion submodels for design applications at elevated pressures. Part I. devolatilization and char oxidation," Progress in Energy and Combustion Science, vol. 29, no. 6, pp. 425-477, 2003.

[67] Liu, G.S., Niksa, S., "Coal conversion submodels for design applications at elevated pressures. Part II. Char gasification," Progress in Energy and Combustion Science, vol. 30, no. 6, pp. 679-717, 2004.

[68] Senneca, O., Salatino, P., "A semi-detailed kinetic model of char combustion with consideration of thermal annealing," Proceedings of the Combustion Institute 33, vol. 33, no. 2, pp. 1763-1770, 2011.

[69] Yong, S. Z., Ghoniem, A., "Modeling the Slag Layer in Solid Fuel Gasification and Combustion - Two-way Coupling with CFD," Fuel, vol. 97, pp. 457-466, July 2012. 
[70] Ai, W., Kuhlman, J., "Simulation of Coal Ash Particle Deposition Experiments," Energy \& Fuels, vol. 25, no. 2, pp. 708-718, 2011.

[71] Ichikawa, K.; Oki, Y.; Inumaru, J. , "Study on the mechanism of the coal ash deposit and the growth in the gasifier - Analysis of ash particles," in Proceedings of the Effects of Coal Quality on Power Plant Performance: Ash Problems, Management and Solutions, Park City, UT, 2001, pp. Paper 2000-4.

[72] Johnson, K. L., Kendall, K., and Roberts, A. D., "Surface energy and the contact of elastic solids," in Proc. Royal Soc., London, 1971, pp. 324, 301-313.

[73] Brach, R.; Dunn, P. A, "Mathematical model of the impact and adhesion of microspheres," Aerosol Sci. Technol. , vol. 16, pp. 51-64, 1992.

[74] Soltani, M. and Ahmadi, G., "On particle adhesion and removal mechanisms in turbulent flows," Adhesion Science Technology, vol. 8, no. 7, pp. 763-785, 1994.

[75] Kuhlman, J., Ai, W., "Particle Deposition Predictions by Critical Viscosity and Mechanistic Particle Deposition Models," in 28th International Pittsburgh Coal Conference, Pittsburgh, 2011.

[76] Walsh, P.M., Sayre, A.N., Loehden, D.O., Monroe, L., "Deposition of bituminous coal ash on an isolated heat exchanger tube: effects of coal properties on deposit growth," Progress in Energy Combustion Science, vol. 16, no. 4, pp. 327-346, 1990.

[77] Browning, G.J., Bryant, G.W., Hurst, H.J., Lucas, J.A., "An Empirical Method for the 
Prediction of Coal Ash Slag Viscosity," Energy \& Fuels, vol. 17, no. 3, pp. 731-737, 2003.

[78] Baum, M. M., Street. P. J. , "Predicting the Combustion Behavior of Coal Particles," Combustion Science \& Technology, vol. 3, no. 5, pp. 231-243, 1971.

[79] Krishnaswamy, R., Kaneko, T. K., Mazumdar, B. M., "Infiltration Velociy and Thickness of Flowing Slag Film on Porous Refractory of Slagging Gasifiers," Journal of Energy Resources Technology, vol. 136, no. 3, 2014.

[80] Mills, K., "The Estimation of Slag Properties," in Southern African Pyrometallurgy, 2011.

[81] Streeter, R. C., Diehl, E. K. and Schobert, H. H., "Measurement Prediction of low-rank coal slag viscosity," American Chemical Society, Division of Fuel Chemistry, vol. 28, no. 4, p. 174, 1983.

[82] Vargas, S., Frandsen, F. J., Dam-Johansen, K., "Rheological Properties of HighTemperature Melts of Coal Ashes and Other Silicates," Progress in Energy and Combustion Science, vol. 27, no. 3, pp. 237-429, 2001.

[83] Mills, K. C., "Estimation of Physicochemical Properties of Coal Slags and Ashes," in Mineral Matter and Ash in Coal. Washington, D. C., U.S.: American Chemical Society, 1986, ch. 15, pp. 195-214.

[84] Urbain, G., Cambier, F., Delette, M., Anseau, M.R., "Viscosity of Silicate Melts," British Ceramic Society, vol. 80, pp. 139-141, 1981. 
[85] Schobert, H. H., Lignites of North America. New York: Elsevier, 1995, pp. 327-331.

[86] Kalmanovitch, D.P., Frank, M., "An Effective Model of Viscosity for Ash Deposition Phenomena," in In Engineering Foundation Conference of Mineral Matter and Ash Deposition from Coal, Santa Barbara, CA, USA, 1988.

[87] Nicholls, P., Reid, W. T., "Viscosity of Coal Ash Slags," Trans. ASME, pp. 141-153, 1940.

[88] Hoy, H. R., Roberts, A. G., Wilkins, D. M., "Behavior of Mineral Matter in Slagging Gasification Processes," Instn. Gas Engrs., vol. 672, p. 24, Nov. 1964.

[89] Watt, J. D., Fereday, F., "The Flow Porperties of Slags Formed from the Ashes of British Coals: Part 1. Viscosity of Homogeneous Liquid Slags in Relation to Slag Composition," J. Inst. Fuel, vol. 42, pp. 99-103, 1969.

[90] Laumb, J. D., Predicting Slag Viscosity from Coal Ash Composiiton. Grand Forks, U.S.: University of North Dakota, 2000.

[91] Fernandes, T. d., Gibson, L., Monazam, E. R., Spenik, J., Kuhlman, J., Shadle, L., "Evaluation of Viscosity Models for Slagging Entrained Gasifiers Using Bituminous Coals," in 2011 International Pittsburgh Coal Conference, Pittsburgh, PA., USA, 2011.

[92] Mills, K. C., Keene, B. J., "Physical Properties of BOS Slags," International Materials Reviews, vol. 32, no. 1, pp. 1-120, 1987.

[93] Mills, K. C., Rhine, J. M., "The Measurement and Estimation of the Porperties of Slags 
Formed During Coal Gasification. 1. Properties Relevant to Fluid Flow," Fuel, vol. 68, no. 2, pp. 193-200, 1989.

[94] Bottinga, Y. Weill, D. E., "Densities of Lliquid Silicates Systems Calcualted from Partial Molar Volumes of Oxide Components," American Journal of Science, vol. 269, no. 2, pp. 169-182, 1970.

[95] Nelson, S. A. Carmichael, I. S. E., "Partial molar volumes of oxide components in silicate liquids," Contributions to Mineralogy and Petrology, vol. 71, no. 2, pp. 117-124, 1979.

[96] Mo, X., Carmichael, I.S.E., Rivers, M., Stebbins, J., "The Partial Molar Volume of Fe2O3 in Multicomponent Silicate Liquids and the Pressure Dependence of Oxygen Fugacity in Magmas," Mineralogical Magazine, vol. 45, no. 337, pp. 237-45, 1982.

[97] Bottinga, Y., Weill, D., Richet, P., "Density calculations for silicate liquids. I. Revised method for aluminosilicate composition," Geochimica er Comochimico Acta , vol. 46, no. 6, pp. 909-919, 1982.

[98] Mills, K. C., Rhine, M. J., "The Measurement and Estimation of the Physical Properties of Slags Formed During Coal Gasification. 2. Properties Relevant to Heat Transfer," Fuel, vol. 68, no. 7, pp. 904-910, 1989.

[99] Nishioka, K., Maeda, T., Shimizu, M., "Application of Square-wave Pulse Heat Method to Thermal Properties Measurement of $\mathrm{CaO}-\mathrm{SiO} 2-\mathrm{Al} 2 \mathrm{O} 3$ System Fluxes," ISIJ International, vol. 46, no. 3, pp. 427-433, 2006. 
[100] Hayashi, M., Ishii, H., Susa, M., Fukuyama, H., Nagata, K., "Effect of Ionicity of Nonbridging Oxygen Ions on Thermal Conductivity of Molten Alkali Silicates," Physics and Chemistry of Glasses, vol. 42, no. 1, pp. 6-11(6), 2001.

[101] Tagawa, H., Sugawara, H., "The Kinetics of the Formation of Calcium Carbide in a SolidSolid Reaction," Bulletin of the Chemical Society of Japan, vol. 35, no. 8, pp. 1276-1279, 1962.

[102] Brookes, C., Gall, C. E., Hudgins, R. R., "A Model for the formation of Calcium Carbide in Solid Pellets," The Canadian Journal of Chemical Engineering, vol. 53, pp. 527-535, 1975.

[103] M. B. Müller, "Structure, properties and reactions of $\mathrm{CaO}$ in burnt Lime," Scandinavian Journal of Metallurgy, vol. 19, pp. 64-71, 1990.

[104] M.B. Müller, "Structure, properties and reactions of $\mathrm{CaO}$ in burnt lime: Part 2. Diffusion of carbon into solid lime," Scandinavian Journal of Metallurgy, vol. 19, pp. 191-200, 1990.

[105] M. B. Müller, "Structure, properties and reactions of $\mathrm{CaO}$ in burnt lime: Part 3. Composite reactions of $\mathrm{CaO}$ and $\mathrm{C}$ in solid and liquid state," Scandinavian Journal of Metallurgy, vol. 19, pp. 210-217, 1990.

[106] El-Naas, M. H., Munz, R. J., Ajersch, F., "Modelling of a plasma reactor for the synthesis of calcium carbide," Canadian Metallurgical Quarterly, vol. 37, no. 1, pp. 67-74, 1998.

[107] Li, G., Liu, Q.,Liu, Z, "CaC2 Production from Pulverized Coke and $\mathrm{CaO}$ at Low 
Temperatures-Reaction Mechanisms," Industrial \& Engineering Chemistry Research, vol. 51, no. 33, p. 10742-10747, 2012.

[108] Rowan, L., Celik, I., Escobar, J., Pakalapati, S.Target, M., "Reaction Kinetics Modeling of $\mathrm{CaC} 2$ Formation From Coal and Lime," Ind. Eng. Chem. Res., vol. 53, no. 8, p. 2963-2975, 2014.

[109] House, J. E., Principles of Chemical Kinetics , 2nd ed. Saint Louis, MO: Academic Press, 2007.

[110] Baumeister, T., Standard Handbook for Mechanical Engineers, 8th ed.: McGraw-Hill, 1978.

[111] Gutierrez, A., Posada, A., Celik, I., "CFD Study of Oxy Coal Combustion in a 100kW Down-Fired Furnace," in International Pittsburgh Coal Conference, Pittsburgh, PA, 2012.

[112] Launder, B. E., Spalding D. B., Lectures in Mathematical Models of Turbulence. London, England: Academic Press, 1972.

[113] Launder, B. E., Spalding, D. B., "The numerical computation of turbulent flows," Computer Methods in Applied Mechanics and Engineering, vol. 3, no. 2, pp. 269-289, 1974.

[114] J., U. Maas, R. W. Dibble Warnatz, Combustion, Physical and Chemical Fundamentals, Modeling and Simulation, Experiments, Pollutant Formation., 4th ed., Springer, Ed. Heidelberg, Karlruhe, Berkeley, US/Germany, 2006. 
[115] National Institute of Standards and Technology, NIST. (2013, August) NIST-JANAF Thermochemical Tables. [Online]. http://kinetics.nist.gov/janaf/

[116] Magnussen, B. F., Hjertaer, B.H., "On the mathematical models of turbulent combustion with special emphasis on soot formation and combustion," in 16th international symposium of The Combustion Institute, 1976.

[117] Badzioch, S., Hawksley, P. G. W., "Kinetics of Thermal Decomposition of Pulverized Coal Particles," Industrial \& Engineering Chmestry Process Design and Development, vol. 9, no. 4, pp. 521-530, 1970.

[118] G. A., Morris, R. M. Desai, M. J. Matthesius, "Prediction of the Volatile Matter in Coal from Ultimate and Proximate Analysis," J. S. Afr. Inst. Min. Metall., vol. 87, no. 6, pp. 157-161, Jun 1987.

[119] E. M. Peters, W. A. Howard J. B. Suuberg, "Product Composition and Kinetics of Lignite Pyrolysis," Ind. Eng. Chem. Process Des. Dev., vol. 17, no. 1, pp. 37-46, Jan 1978.

[120] Levenspiel, O., Chemical Reaction Engineering. An introduction to the Design of Chemical Reactors. New York, U.S.: John Wiley and Sons, 1962.

[121] Field, M. A., "Rate of Combustion Of Size-Graded Fractions of Char from a Low Rank Coal between 1200 K-2000 K," Combustion and Flame, vol. 13, no. 3, pp. 237-252, 1969.

[122] Boyd, R. K., Kent, J. H., "Three-dimensional Furnace Computer Modeling," in Symp. (Intl'l.) on Combustion. The Combustion Institute., 1986, pp. 265-274. 
[123] S. A., Alexander, A. J. Morsi, "An Investigation of Particle Trajectories in Two-Phase Flow Systems," Journal of Fluid Mechanics, vol. 55, no. 2, pp. 193-208, September 1972.

[124] Ansys, Inc., "Turbulent Dispersion of Particles," in ANSYS FLUENT 12.0, Theory Guide., 2009, ch. 15 , pp. 15-6,15-11.

[125] P., Rammler, E. Rosin, "The Laws Governing the Fineness of Powdered Coal," Journal of the Institute of Fuel, vol. 7, pp. 29-36, 1933.

[126] S. V. Patankar, Numerical Heat Transfer and Fluid Flow. Washington, DC, U.S.: Hemisphere, 1980.

[127] Ansys, Inc., Ansys Fluent 12.0 Theory Guide., 2009.

[128] Andersson, K., Characterization of Oxy-Fuel Flames - Their Composition, Temperature and Radiation (Doctoral Dissertation).: Chalmers Unversity of Technology, 2007.

[129] J. Stefan, "Uber einige Probleme der Theorie der Wärmeleitung," S B Wien Akad. Mat. Natur, vol. 98, pp. 473-84, 1889.

[130] Ji, L., Liu, Q., Liu, Z., "Thermodynamic Analysis of Calcium Carbide Production," Ind. Eng. Chem. Res., vol. 53, pp. 2537-2543, 2014.

[131] Solar, Y. M., Guthrie, R. I. L., "Kinetics of the Carbon-Oxygen Reaction in Molten Iron," Metallurgical Transactions, vol. 3, no. 3, pp. 713-722, 1972.

[132] Seggiani M., "Modelling and simulation of time varying slag flow in a Prenflo entrained- 
flow gasifier," Fuel, vol. 77, no. 14, pp. 1611-1621, 1998.

[133] Bejan, A., "External Natural Convection," in Convection Heat Transfer, 3rd ed. New Jersey: John Wiley \& Sons, 2004, ch. 4, pp. 234-235.

[134] L. C. Burmeister, "Laminar Natural Convection - Integral Approximate Solution," in Convective Heat Transfer. New York: John Wiley \& Sons, 1982, ch. 12, pp. 524-530.

[135] Ukrainczyk, N., Kurajica, S., Sipusic, J., "Thermophysical Comparison of Five Commercial Paraffin Waxes as Latent Heat Storage Materials," Chem. Biochem. Eng. Q., vol. 24, no. 2, pp. 129-137, 2010.

[136] Nikzat, H., Pak, H., Fuse, T., Hu, Y., Ogyu, K., Kobayashi, N., Hasatani, M. , "Characteristics of Pulverized Coal Burner Using a High-Oxygen Partial Pressure," Chemical Engineering Research and Design, vol. 82, no. 1, pp. 99-104, 2004.

[137] Syred, N., Beer, M. J., "Combustion in Swirling Flows: A review," Combustion and Flame, vol. 23, pp. 143-201, 1974.

[138] Costa, M., Costen, P., Clockwood, F., "Pulverized-coal and heavy fuel oil flames large scale experimental studies at Imperial College London," Journal of the Institute of Energy, vol. 64, no. 459, pp. 64-76, 1991.

[139] Senior, C. L., Srinivasachar, S., "Viscosity of Ash Particles in Combustion Systems for Prediction of Particle Sticking," Energy \& Fuels, vol. 9, no. 2, pp. 277-283, 1995. 
[140] Ozisik, M. N., Heat Conduction, 2nd ed. New York: Wiley-Interscience, 1993.

[141] Liang, Y., Richter, F. M., Davis, A. M., Watson, B. E., "Diffusion in silicate melts: I. Self diffusion in $\mathrm{CaO}-\mathrm{AI} 203-\mathrm{SiO} 2$ at $1500^{\circ} \mathrm{C}$ and $1 \mathrm{GPa}, "$ Geochimica et Cosmochimica Acta, vol. 60, no. 22, pp. 4353-4367, 1996.

[142] L., Yong, S., Ghoniem, A. Chen, "Modeling the slag behavior in three dimensional CFD: simulation of a vertically-oriented oxy-coal combustor," in The 37th International Technical Conference on Clean Coal \& Fuel Systems, Clearwater FL, 2012. 


\section{APPENDIX A}

\section{Stoichiometry calculations for the combustion process}

The calculations are based in the following global reaction for coal and methane:

$$
\mathrm{C}_{n} \mathrm{H}_{m} \mathrm{~S}_{p} \mathrm{~N}_{q} \mathrm{O}_{r}+\gamma \cdot \mathrm{CH}_{4}+a\left(\mathrm{O}_{2}+b \mathrm{CO}_{2}\right) \rightarrow x \mathrm{CO}_{2}+y \mathrm{H}_{2} \mathrm{O}+z \mathrm{SO}_{2}+w \mathrm{~N}_{2}
$$

This equation includes the possibility of using methane to provide additional heat.

For the case when no methane is used:

$$
\mathrm{C}_{n} \mathrm{H}_{m} \mathrm{~S}_{p} \mathrm{~N}_{q} \mathrm{O}_{r}+a\left(\mathrm{O}_{2}+b \mathrm{CO}_{2}\right) \rightarrow x \mathrm{CO}_{2}+y \mathrm{H}_{2} \mathrm{O}+z \mathrm{SO}_{2}+w \mathrm{~N}_{2}
$$

The mass balance is estimated using the following algebraic expressions:

$$
\begin{aligned}
& H: m=2 y \\
& S: p=z \\
& C: n+a b=x \\
& O: r+2 a+2 a b=2 x+y+2 z \\
& 2 a=2 n+\frac{m}{2}+2 p-r \\
& a=n+\frac{m}{4}+p-\frac{r}{2}
\end{aligned}
$$


An example of the stoichiometric calculations is shown below, considering as example, the German lignite utilized in the exploratory study of the VHTER. The properties of German lignite are shown in Table A.1.

Table A.1. German lignite properties.

\begin{tabular}{|c|c|c|c|c|c|c|c|c|c|}
\hline \multicolumn{3}{|c|}{$\begin{array}{l}\text { Proximate analysis } \\
\text { (wt\% as received) }\end{array}$} & $\begin{array}{c}\text { VM } \\
\text { (\%d.a.f) }\end{array}$ & \multicolumn{5}{|c|}{ Ultimate analysis (wt\% d.a.f.) } & \multirow{2}{*}{$\begin{array}{c}\text { LHV } \\
(\mathrm{MJ} / \mathrm{kg})\end{array}$} \\
\hline Moisture & Ash & Combustibles & \multirow{2}{*}{59.4} & $\mathrm{C}$ & $\mathrm{H}$ & $\mathrm{N}$ & $\mathrm{S}$ & $\mathrm{O}$ & \\
\hline 10.2 & 5.0 & 84.8 & & 69.9 & 5.4 & 0.6 & 1.0 & 23.1 & 20.9 \\
\hline
\end{tabular}

The combustibles percentage is calculated from the proximate analysis: $100-5-10.2=84.8 \%$.

Taking $100 \mathrm{~kg}$ of coal as reference, the amount of each coal component is determined by multiplying its mass fraction by the percentage of combustibles, e.g., for carbon:

$\mathrm{kg} \mathrm{C} / 100 \mathrm{~kg}$ coal $=69.9 *$ Combustibles $\% / 100 \mathrm{~kg}$ coal $=59.28 \mathrm{~kg} \mathrm{C} / 100 \mathrm{~kg}$ coal

The number of kmol/100kg is obtained by dividing the amount of each element by its molecular weight, e.g., for carbon:

$(59.28 \mathrm{~kg} \mathrm{C} / 100 \mathrm{~kg}$ coal $) /(12 \mathrm{kmol} / \mathrm{kg})=4.94 \mathrm{kmol} \mathrm{C} / 100 \mathrm{~kg}$ coal

The results for the other elements are shown in Table A.2. 
Table A.2.

\begin{tabular}{|c|c|c|c|}
\hline Element & $\mathbf{k g} / \mathbf{1 0 0 k g}$ coal & $\mathbf{W}(\mathbf{k g} / \mathbf{k m o l})$ & $\mathbf{K m o l} / \mathbf{( 1 0 0 k g}$ coal $)$ \\
\hline $\mathrm{C}$ & 59.28 & 12 & $4.94 \mathrm{E}+00$ \\
\hline $\mathrm{H}$ & 4.58 & 1 & $4.58 \mathrm{E}+00$ \\
\hline O & 19.59 & 16 & $1.22 \mathrm{E}+00$ \\
\hline N & 0.51 & 14 & $3.63 \mathrm{E}-02$ \\
\hline S & 0.85 & 32 & $2.65 \mathrm{E}-02$ \\
\hline Total & 84.80 & \multicolumn{3}{|l}{} \\
\cline { 1 - 4 }
\end{tabular}

Stoichiometric calculations for the oxidant per $100 \mathrm{~kg}$ of coal:

From the relation:

$$
a=n+\frac{m}{4}+p-\frac{r}{2}
$$

The value of the stoichiometric coefficient for the oxidant is calculated:

$$
a=4.94+\frac{4.58}{4}+0.0265-\frac{1.22}{2}=5.5
$$

The value of the coefficient $\mathrm{b}$ is modified according to the oxygen mass fraction in the oxidant, e.g., for OF25 the value of $b$ is equal to three $(b=3)$ :

$$
\mathrm{C}_{n} \mathrm{H}_{m} \mathrm{~S}_{p} \mathrm{~N}_{q} \mathrm{O}_{r}+a\left(\mathrm{O}_{2}+3 \mathrm{CO}_{2}\right) \rightarrow x \mathrm{CO}_{2}+y \mathrm{H}_{2} \mathrm{O}+z \mathrm{SO}_{2}+w \mathrm{~N}_{2}
$$

Based on the values of the stoichiometric coefficients, the stoichiometric amount of oxidant in kmol per $100 \mathrm{~kg}$ coal is calculated:

$5.5 * 1 \mathrm{kmol} \mathrm{O} / 2 / 100 \mathrm{~kg}$ coal $=5.5 \mathrm{kmol} \mathrm{O} 2 / 100 \mathrm{~kg}$ coal 


\section{$5.5 * 3 \mathrm{kmol} \mathrm{CO} / 100 \mathrm{~kg}$ coal $=16.5 \mathrm{kmol} \mathrm{CO} / 100 \mathrm{~kg}$ coal}

The stoichiometric amount of oxidant in $\mathrm{kg}$ per $100 \mathrm{~kg}$ coal is calculated as:

$5.5 \mathrm{kmol} \mathrm{O} 2 / 100 \mathrm{~kg}$ coal $*(32 \mathrm{~kg} / \mathrm{kmol})=176 \mathrm{~kg} \mathrm{O}_{2} / 100 \mathrm{~kg}$ coal

$16.5 \mathrm{kmol} \mathrm{CO} 2 / 100 \mathrm{~kg}$ coal $*(44 \mathrm{~kg} / \mathrm{kmol})=726 \mathrm{~kg} \mathrm{CO}_{2} / 100 \mathrm{~kg}$ coal

The amount of fuel and oxidant per $100 \mathrm{~kg} / \mathrm{coal}$ is summarized in the Table A.3.

Table A.3.

\begin{tabular}{|c|c|}
\hline Fuel & Kmol/100kg s \\
\hline $\mathrm{C}$ & $4.94 \mathrm{E}+00$ \\
\hline $\mathrm{H}$ & $4.58 \mathrm{E}+00$ \\
\hline $\mathrm{O}$ & $1.22 \mathrm{E}+00$ \\
\hline $\mathrm{N}$ & $3.63 \mathrm{E}-02$ \\
\hline $\mathrm{S}$ & $2.65 \mathrm{E}-02$ \\
\hline Oxidant & Kmol/100kg s \\
\hline $\mathrm{O} 2$ & 5.5 \\
\hline $\mathrm{CO} 2$ & 16.5 \\
\hline
\end{tabular}

The mass flow rate of coal is calculated from the power of the oxy-coal reactor $(100 \mathrm{~kW})$ :

$$
\dot{m}_{\text {coal }}=\frac{\text { power }}{L H V}=\frac{100 \mathrm{~kJ} / 2}{20900(\mathrm{~kJ} / \mathrm{kg})}=4.78 e-03 \mathrm{kgcoal} / \mathrm{s}
$$

The molar flow rates for fuel and oxidant are calculated as:

\section{Fuel}

$(4.94 \mathrm{kmol} \mathrm{C} / 100 \mathrm{~kg}$ coal $) *(4.78 \mathrm{e}-03 \mathrm{kgcoal} / \mathrm{s})=2.36 \mathrm{e}-04 \mathrm{kmol} / \mathrm{s}$ 
$(4.58 \mathrm{kmol} \mathrm{H} / 100 \mathrm{~kg} \mathrm{coal}) *(4.78 \mathrm{e}-03 \mathrm{kgcoal} / \mathrm{s})=2.19 \mathrm{e}-04 \mathrm{kmol} / \mathrm{s}$

$(1.22 \mathrm{kmol} \mathrm{O} / 100 \mathrm{~kg} \mathrm{coal}) *(4.78 \mathrm{e}-03 \mathrm{kgcoal} / \mathrm{s})=5.85 \mathrm{e}-05 \mathrm{kmol} / \mathrm{s}$

$(3.63 \mathrm{e}-02 \mathrm{kmol} \mathrm{N} / 100 \mathrm{~kg} \mathrm{coal}) *(4.78 \mathrm{e}-03 \mathrm{kgcoal} / \mathrm{s})=1.74 \mathrm{e}-06 \mathrm{kmol} / \mathrm{s}$

$(2.65 \mathrm{E}-02 \mathrm{kmol} \mathrm{S} / 100 \mathrm{~kg}$ coal $) *(4.78 \mathrm{e}-03 \mathrm{kgcoal} / \mathrm{s})=1.27 \mathrm{e}-06 \mathrm{kmol} / \mathrm{s}$

Results in kmol/s are summarized in the Table A.4.

Table A.4.

\begin{tabular}{|c|c|}
\hline Element & $\mathbf{K m o l} / \mathbf{s}$ \\
\hline $\mathrm{C}$ & $2.36 \mathrm{E}-04$ \\
\hline $\mathrm{H}$ & $2.19 \mathrm{E}-04$ \\
\hline $\mathrm{O}$ & $5.85 \mathrm{E}-05$ \\
\hline $\mathrm{N}$ & $1.74 \mathrm{E}-06$ \\
\hline $\mathrm{S}$ & $1.27 \mathrm{E}-06$ \\
\hline
\end{tabular}

\section{Oxidant}

For OF $25 \mathrm{~b}=0.5$ :

$$
\mathrm{C}_{n} \mathrm{H}_{m} \mathrm{~S}_{p} \mathrm{~N}_{q} \mathrm{O}_{r}+a\left(\mathrm{O}_{2}+0.5 \mathrm{CO}_{2}\right) \rightarrow x \mathrm{CO}_{2}+y \mathrm{H}_{2} \mathrm{O}+z \mathrm{SO}_{2}+w \mathrm{~N}_{2}
$$

The amount of stoichiometric $\mathrm{O}_{2}$ in $\mathrm{kg} / \mathrm{s}$ is in this case:

$(5.5 \mathrm{kmol} \mathrm{O} 2 / 100 \mathrm{~kg} \mathrm{coal}) *(4.78 \mathrm{e}-03 \mathrm{kgcoal} / \mathrm{s})=2.63 \mathrm{e}-04 \mathrm{kmol} / \mathrm{s}$

The total amount of stoichiometric $\mathrm{CO}_{2}$ is:

$(16.5 \mathrm{kmol} \mathrm{CO} 2 / 100 \mathrm{~kg} \mathrm{coal}) *(4.78 \mathrm{e}-03 \mathrm{kgcoal} / \mathrm{s})=7.89 \mathrm{e}-04 \mathrm{kmol} / \mathrm{s}$ 
For other $\mathrm{O}_{2} / \mathrm{CO}_{2}$ mixtures all the values but the amount of $\mathrm{CO}_{2}$ remains the same. i.e., the amount of $\mathrm{CO}_{2}$ is reduced in order to increase the oxygen concentration. For example, For OF50 $(b=1)$, the stoichiometric equation for the combustion reaction is written as:

$$
\mathrm{C}_{n} \mathrm{H}_{m} \mathrm{~S}_{p} \mathrm{~N}_{q} \mathrm{O}_{r}+a\left(\mathrm{O}_{2}+1 \mathrm{CO}_{2}\right) \rightarrow x \mathrm{CO}_{2}+y \mathrm{H}_{2} \mathrm{O}+z \mathrm{SO}_{2}+w \mathrm{~N}_{2}
$$

The stoichiometric amount of $\mathrm{CO}_{2}$ per $100 \mathrm{~kg}$ coal for this case is:

$$
5.5 * 1 \mathrm{kmol} \mathrm{CO} 2 / 100 \mathrm{~kg} \text { coal }=5.5 \mathrm{kmol} \mathrm{CO}_{2} / 100 \mathrm{~kg} \text { coal }
$$

The total amount of stoichiometric $\mathrm{CO}_{2}$ is:

$$
\left(5.5 \mathrm{CO}_{2} / 100 \mathrm{~kg} \mathrm{coal}\right) *(4.78 \mathrm{e}-03 \mathrm{kgcoal} / \mathrm{s})=2.63 \mathrm{e}-04 \mathrm{kmol} / \mathrm{s}
$$

Results in kmol/s are summarized in the Table A.5.

Table A.5.

\begin{tabular}{|l|l|l|}
\hline Element & $\begin{array}{c}\text { Kmol/s } \\
(\mathrm{OF} 25)\end{array}$ & \multicolumn{1}{|c|}{$\begin{array}{c}\mathbf{K m o l} / \mathbf{s} \\
(\mathrm{OF} 50)\end{array}$} \\
\hline $\mathrm{O} 2$ & $2.63 \mathrm{E}-04$ & $2.63 \mathrm{E}-04$ \\
\hline $\mathrm{CO} 2$ & $7.89 \mathrm{E}-04$ & $2.63 \mathrm{e}-04$ \\
\hline
\end{tabular}




\section{APPENDIX B}

\section{Property values utilized in the SFM}

Table B1.

\begin{tabular}{|c|c|}
\hline Property & Value \\
\hline $\begin{array}{l}\text { Convection heat transfer coefficient from the reactor } \\
\text { surroundings }\left(\mathrm{kW} / \mathrm{m}^{2} \mathrm{~K}\right)\end{array}$ & $5.57 \mathrm{e}-03$ \\
\hline Thermal conductivity of the slag $(\mathrm{kW} / \mathrm{mK})$ & $1.76 \mathrm{e}-03$ \\
\hline Total insulation resistance of the VHTER $(\mathrm{mK} / \mathrm{kW})$ & 723.6 \\
\hline Silica ratio of the coal slag & 0.517 \\
\hline Acid to basic ratio of the coal slag & 1.35 \\
\hline \multicolumn{2}{|c|}{ Molecular weights of the species considered in the slag $(\mathrm{kg} / \mathrm{kmol})$} \\
\hline $\mathrm{C}$ & 12.01 \\
\hline $\mathrm{CaO}$ & 56.08 \\
\hline $\mathrm{CaC}_{2}$ & 64.10 \\
\hline $\mathrm{CO}$ & 28.01 \\
\hline $\mathrm{SiO}_{2}$ & 60.08 \\
\hline $\mathrm{Al}_{2} \mathrm{O}_{3}$ & 101.96 \\
\hline $\mathrm{Fe}_{2} \mathrm{O}_{3}$ & 159.69 \\
\hline \multicolumn{2}{|c|}{ Enthalpy of formation of the reacting species considered in the slag $(\mathrm{kJ} / \mathrm{kg})$} \\
\hline $\mathrm{C}$ & 0 \\
\hline $\mathrm{CaO}$ & -11340.88 \\
\hline $\mathrm{CaC}_{2}$ & -934.38 \\
\hline $\mathrm{CO}$ & -3947.39 \\
\hline \multicolumn{2}{|c|}{ Specific heat of the species considered in the slag $(\mathrm{kJ} / \mathrm{kmol} \mathrm{K})$} \\
\hline $\mathrm{C}$ & 8.34 \\
\hline $\mathrm{CaO}$ & 58.25 \\
\hline $\mathrm{CaC}_{2}$ & 74.9 \\
\hline $\mathrm{CO}$ & 36.07 \\
\hline $\mathrm{SiO}_{2}$ & 44.57 \\
\hline $\mathrm{Al}_{2} \mathrm{O}_{3}$ & 192.5 \\
\hline
\end{tabular}




\begin{tabular}{|l|c|}
\hline \multicolumn{1}{|c|}{$\mathrm{Fe}_{2} \mathrm{O}_{3}$} & 146.8 \\
\hline \multicolumn{2}{|c|}{ Parameters associated with solidification/melting } \\
\hline Latent heat of fusion of the slag $(\mathrm{kJ} / \mathrm{kg})$ & 1200 \\
\hline Latent heat of fusion of the $\mathrm{CaO}(\mathrm{kJ} / \mathrm{kg})$ & 913 \\
\hline Latent heat of fusion of the $\mathrm{CaC} 2(\mathrm{~kJ} / \mathrm{kg})$ & 948 \\
\hline Relaxation parameter for solids transported in the slag $\left(a_{l s}\right)$ & 0.02 \\
\hline Parameter to modify the forward kinetic rate $\left(\lambda_{k-f}\right)$ & 1.5 \\
\hline Parameter to modify the backward kinetic rate $\left(\lambda_{k-B}\right)$ & 1.5 \\
\hline
\end{tabular}

Table B2. Insulation materials and dimensions for the VHTER.

\begin{tabular}{|c|c|c|c|}
\hline Material & $\begin{array}{c}\text { Thermal } \\
\text { conductivity } \\
\left(\mathbf{k W} / \mathbf{m}^{\mathbf{2}} \mathbf{K}\right)\end{array}$ & $\begin{array}{c}\text { Inner radius } \\
(\mathbf{m})\end{array}$ & $\begin{array}{c}\text { Outer radius } \\
(\mathbf{m})\end{array}$ \\
\hline $\mathrm{ZrO}_{2}$ & $1.80 \mathrm{E}-03$ & $7.50 \mathrm{E}-02$ & $2.00 \mathrm{E}-01$ \\
\hline Inswool & $6.00 \mathrm{E}-05$ & $2.00 \mathrm{E}-01$ & $2.10 \mathrm{E}-01$ \\
\hline Kol-30 & $6.30 \mathrm{E}-04$ & $2.10 \mathrm{E}-01$ & $3.46 \mathrm{E}-01$ \\
\hline Insblock & $7.00 \mathrm{E}-05$ & $3.46 \mathrm{E}-01$ & $3.97 \mathrm{E}-01$ \\
\hline Steel & $2.50 \mathrm{E}-02$ & $3.97 \mathrm{E}-01$ & $4.06 \mathrm{E}-01$ \\
\hline
\end{tabular}

Table B3. Ash composition of the Decker's coal

\begin{tabular}{|c|c|c|}
\hline Component & $\begin{array}{c}\text { Mass fraction } \\
\text { \% }\end{array}$ & $\begin{array}{c}\text { Mole fraction } \\
\text { \% }\end{array}$ \\
\hline $\mathrm{SiO}_{2}$ & 26.26 & 31.01 \\
\hline $\mathrm{Al}_{2} \mathrm{O}_{3}$ & 17.26 & 12.01 \\
\hline $\mathrm{MgO}$ & 3.19 & 5.62 \\
\hline $\mathrm{P}_{2} \mathrm{O}_{5}$ & 0.95 & 0.24 \\
\hline $\mathrm{SO}_{3}$ & 21.22 & 18.80 \\
\hline $\mathrm{TiO}_{2}$ & 1.16 & 1.03 \\
\hline $\mathrm{CaO}$ & 14.78 & 18.70 \\
\hline $\mathrm{Na}_{2} \mathrm{O}$ & 8.14 & 9.32 \\
\hline $\mathrm{K} 2 \mathrm{O}$ & 0.48 & 0.36 \\
\hline
\end{tabular}




\begin{tabular}{|c|c|c|}
\hline $\mathrm{Mn}_{3} \mathrm{O}_{4}$ & 0.00 & 0.00 \\
\hline $\mathrm{Fe}_{2} \mathrm{O}_{3}$ & 6.54 & 2.90 \\
\hline
\end{tabular}




\section{APPENDIX C}

This appendix considers an alternative procedure to the OMA performed over the energy equation. This OMA is intended to show that the thermal diffusion term along the slag flow direction ( $\mathrm{x}$ direction) and the viscous dissipation term can be neglected.

Considering the energy equation in terms of temperature:

$$
\frac{\partial}{\partial t}\left(\rho c_{p} T\right)=-\left[\frac{\partial}{\partial x}\left(\rho c_{p} u T\right)+\frac{\partial}{\partial y}\left(\rho c_{p} v T\right)\right]+\left[\frac{\partial}{\partial x}\left(k \frac{\partial T}{\partial x}\right)+\frac{\partial}{\partial y}\left(k \frac{\partial T}{\partial y}\right)\right]+\mu\left[\frac{\partial u}{\partial y}\right]^{2} \quad \text { C. } 1
$$

Dividing this expression by $\rho c_{p}$ and assuming the scales relevant to the process, this expression can be written as:

$$
\frac{\Delta T}{\tau}=-U_{r e f} \frac{\Delta T}{L}-V_{r e f} \frac{\Delta T}{\delta}+\alpha \frac{\Delta T}{L^{2}}+\alpha \frac{\Delta T}{\delta^{2}}+\frac{\mu}{\rho c_{p}} \frac{U_{r e f}^{2}}{\delta^{2}}
$$

Where $V_{\text {ref }}$ has been related to $U_{\text {ref }}$ from the continuity equation:

$$
V_{r e f}=\frac{\delta}{L} U_{r e f}
$$

The maximum temperature difference, $\Delta T$, is assumed to be given by the difference between the temperature at the interface of the liquid slag and the and the critical viscosity temperature:

$$
\Delta T=\left(T_{g}-T_{c v}\right)
$$

If the unsteady term is neglected for comparison purposes, C. 2 can be written as: 


$$
U_{r e f} \frac{\Delta T}{L}+V_{r e f} \frac{\Delta T}{\delta}=\alpha \frac{\Delta T}{L^{2}}+\alpha \frac{\Delta T}{\delta^{2}}+\frac{\mu}{\rho c_{p}} \frac{k}{k} \frac{U_{r e f}^{2}}{\delta^{2}}
$$

This expression can be modified as:

$$
\frac{U_{r e f}}{L}+\frac{U_{r e f}}{L}=\frac{\alpha}{L^{2}}+\frac{\alpha}{\delta^{2}}+\frac{\alpha}{\delta^{2}} \frac{\mu U_{r e f}^{2}}{k \Delta T}
$$

$$
1=\frac{\alpha}{L U_{r e f}}+\frac{L \alpha}{U_{r e f} \delta^{2}}+\frac{\alpha L}{U_{r e f}} \frac{L^{2}}{L^{2}} \frac{1}{\delta^{2}} B r
$$

$$
1=\frac{1}{P e_{t h}}\left[1+\frac{L^{2}}{\delta^{2}}+\frac{L^{2}}{\delta^{2}} B r\right]
$$

Where the Brinkman $(\mathrm{Br})$ and the thermal Peclet $\left(P e_{t h}\right)$ numbers are defined as:

$$
B r=\frac{\mu U^{2}}{k\left(T_{g}-T_{c v}\right)}
$$




$$
P e_{t h}=\frac{L U}{\alpha}
$$

It can be recognized that the three terms inside brackets of C.7 relate to the terms of equation C. 1 in the following way:
1) $1 \rightarrow$ Relates to: $\frac{\partial}{\partial x}\left(k \frac{\partial T}{\partial x}\right)$
2) $\frac{L^{2}}{\delta^{2}} \rightarrow$ Relates to: $\frac{\partial}{\partial y}\left(k \frac{\partial T}{\partial y}\right)$
3) $\frac{L^{2}}{\delta^{2}} B r \rightarrow$ Relates to: $\mu\left[\frac{\partial u}{\partial y}\right]^{2}$

Clearly, the second term dominates over the first one and the third term compares to the second one depending on the value of the Brinkman number. In order to illustrate the order of magnitude of the Brinkman and Peclet numbers, their value is estimated based on the properties given in Table 6-1, the reactor dimensions and the typical slag velocity values:

$$
\begin{aligned}
& B r=\frac{\mu U^{2}}{k\left(T_{g}-T_{c v}\right)}=\frac{(6.2 P a \cdot s)(0.002 \mathrm{~m} / \mathrm{s})}{(1.73 e-03 \mathrm{~kW} / \mathrm{mK})(2200-1500 \mathrm{~K})}=1.02 e-02 \\
& P e_{t h}=\frac{L U}{\alpha}=\frac{[2 \mathrm{~m}][0.002 \mathrm{~m} / \mathrm{s}]}{4.51 e-07 \mathrm{~m}^{2} / \mathrm{s}}=8.86 e+03
\end{aligned}
$$


From the value of the Brinkman number, it can be seen that the third term is smaller than the second. Therefore, the thermal diffusion term along the slag flow direction (x direction) and the viscous dissipation term can be neglected in the energy equation. 